\title{
Real-Time Water Quality Monitoring and Habitat Assessment in the San Luis National Wildlife Refuge
}

\author{
Nigel W.T. Quinn PhD, P.E. \\ Jeremy S. Hanlon \\ Josephine R. Burns \\ HydroEcological Engineering Advanced Decision Support \\ Lawrence Berkeley National Laboratory \\ 1 Cyclotron Road, 70A-3317H \\ Berkeley, CA 94720 \\ Karl A.K. Stromayer, PhD \\ Brandon M. Jordan \\ Mike J. Ennis \\ Dennis W. Woolington
}

San Luis National Wildlife Refuge Complex

P.O. Box 2176

Los Banos, CA 93635

August 28, 2005 


\section{ACKNOWLEDGEMENTS}

This project was supported by the CALFED Drinking Water Program and administered by California State University, Fresno through US Department of Energy Contract No. DEAC03-76SF00098. The first author would like to thank Lisa Holm and Sam Harader of the CALFED Drinking Water Program for their financial support. The project wouldn't have been possible without the cooperation of our partners at the San Luis National Wildlife Refuge Complex. Kim Forrest, Refuge Manager, Bob Parris and Dennis Woolington provided welcome in-kind support to help achieve the project goals. Chris Shoeneman, while working at the Refuge, was instrumental in helping to site the monitoring stations. Brandon Jordan and Mike Ennis provided much appreciated assistance to Jos Burns and Sara Feldmann, sharing their knowledge of the wetland ecosystem and assisting in the design of the vegetation mapping experiments. Brandon also helped Florence Cassel with access to the same sites where we measured and mapped soil salinity. Thanks also to Tryg Lundquist, Kate Hucklebridge, Will Stringfellow, Rebecca Leonardson and Christophe Taylor of the Earth Sciences Division at LBNL who all made contributions to the project. Will Stringfellow has received CALFED support to investigate seasonal wetland carbon dynamics at the same sites monitored in this study. I am additionally grateful to Will Stringfellow for reviewing the report and providing helpful comments. 


\begin{abstract}
The purpose of the research project was to advance the concept of real-time water quality management in the San Joaquin Basin by developing an application to drainage of seasonal wetlands in the San Luis National Wildlife Refuge. This project follows a successful CALFED sponsored pilot demonstration of the potential for real-time wetland drawdown management in the Grassland Water District. The Grassland Water District demonstration project ended on September 30, 2004.
\end{abstract}

Real-time water quality management is defined as the coordination of reservoir releases, wetland and agricultural return flows and river diversions to improve water quality conditions in the San Joaquin River and ensure compliance with State water quality objectives. Real-time water quality management is achieved through information exchange and cooperation between shakeholders who contribute or withdraw flow and salt load to or from the San Joaquin River. This project complements a larger scale project that was undertaken by members of the Water Quality Subcommittee of the San Joaquin River Management Program (SJRMP) which produced forecasts of flow, salt load and San Joaquin River assimilative capacity between 1999 and 2003. These forecasts have potential to help those entities exporting salt load to the River to develop salt load targets as a mechanism for improving compliance with salinity objectives.

A second important outcome of this project was the development and application of a methodology for assessing potential impacts of real-time wetland salinity management. Drawdown schedules are typically tied to weather conditions and are optimized in traditional practices to maximize food sources for over-wintering wildfowl as well as providing a biological control (through germination temperature) of undesirable weeds that compete with protein-rich moist soil plants such as swamp timothy, watergrass and smartweed. This methodology combines high resolution remote sensing, ground-truthing vegetation surveys using established survey protocols and soil salinity mapping using rapid, automated electromagnetic sensor technology. This survey methodology could be complemented with 
biological surveys of bird use and invertebrates to produce a robust long-term monitoring strategy for habitat health and sustainability. 


\section{TABLE OF CONTENTS}

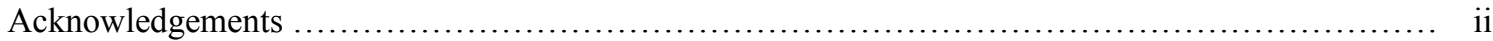

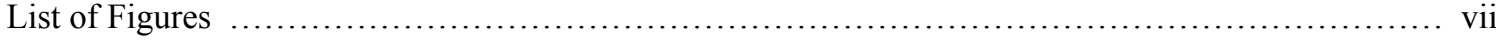

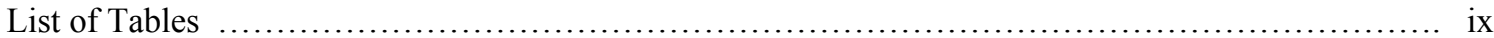

\section{CHAPTER 1 INTRODUCTION}

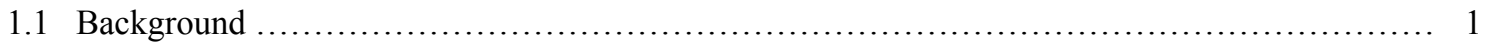

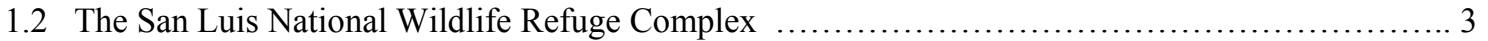

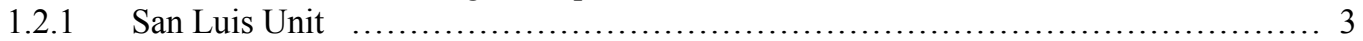

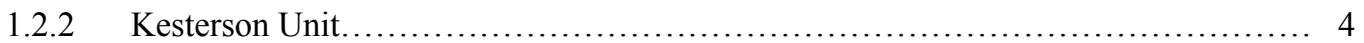

1.2.3 East Bear Creek Unit ........................................................... 5

1.2.4 West Bear Creek Unit ....................................................... 5

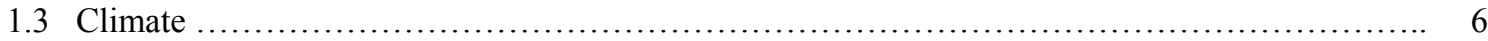

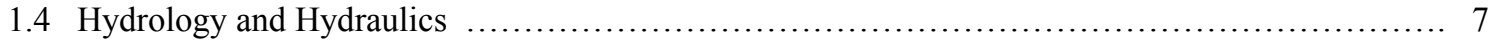

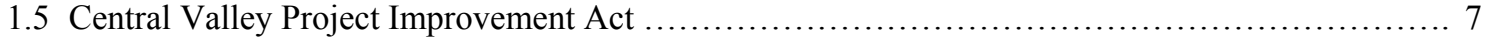

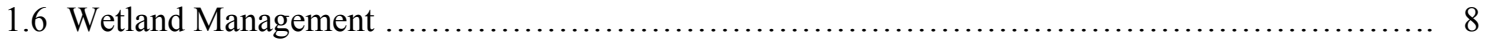

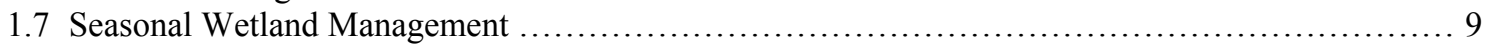

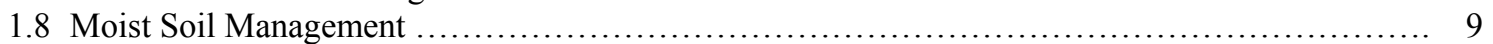

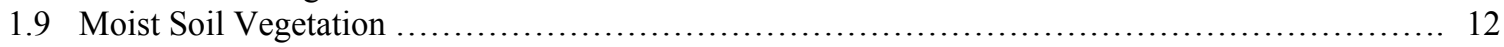

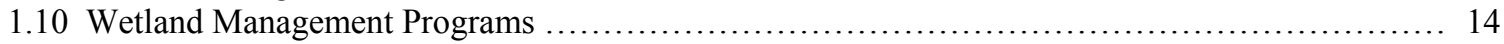

1.11 Impacts of Wetland Management on the San Joaquin River ................................... 14

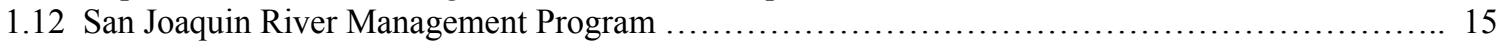

1.13 Coordination between Wetland Management and the San Joaquin River ........................ 16

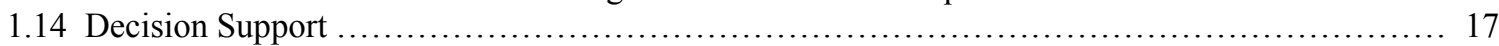

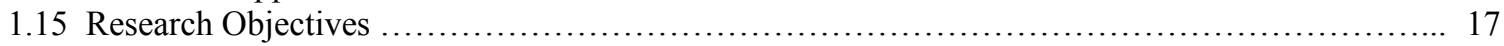

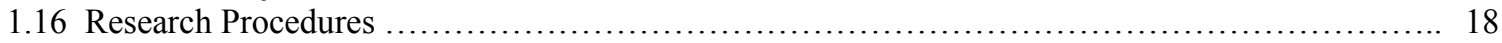

\section{CHAPTER 2 REAL TIME WETLAND WATER QUALITY MONITORING}

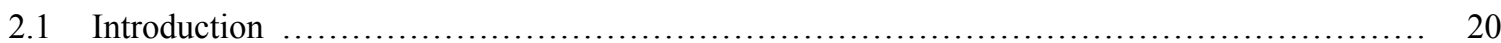

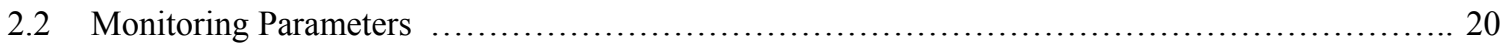

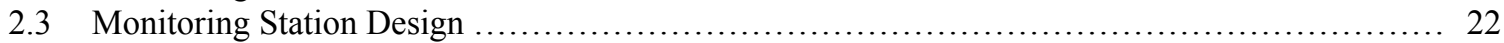

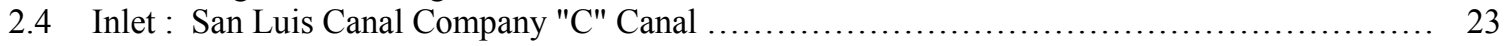

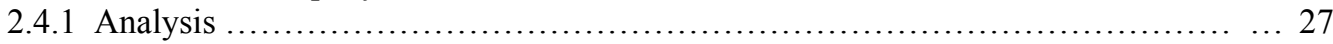

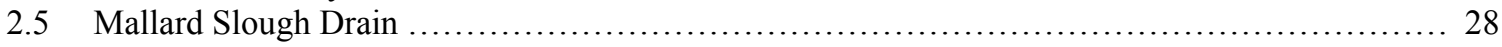

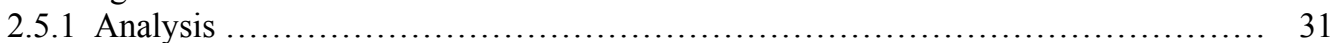

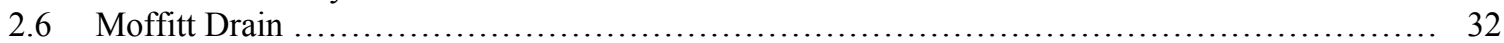

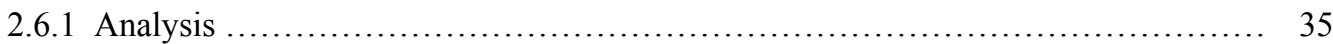

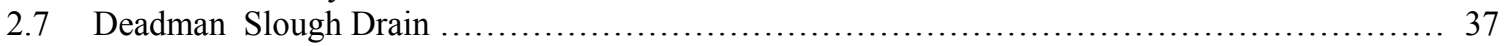

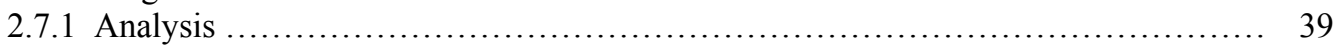

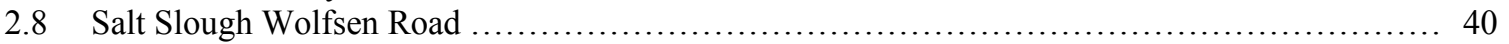

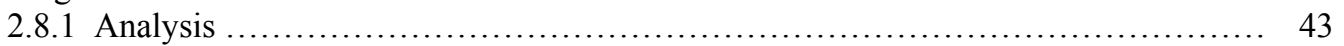

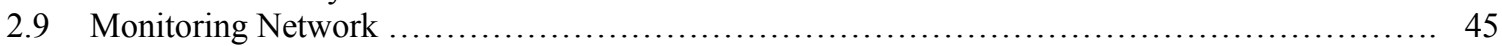

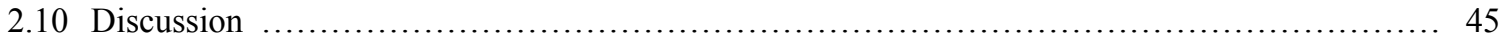

\section{CHAPTER 3 DEVELOPMENT AND APPLICATION OF A REAL-TIME WETLAND WATER QUALITY MODEL}

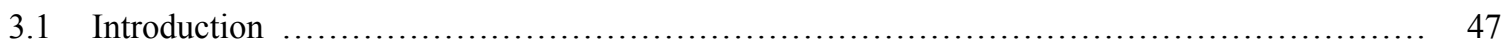

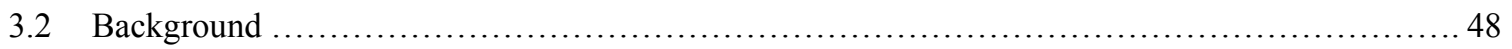

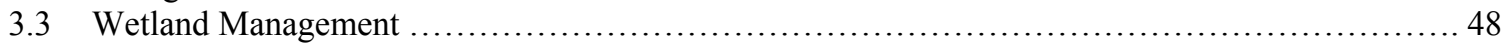

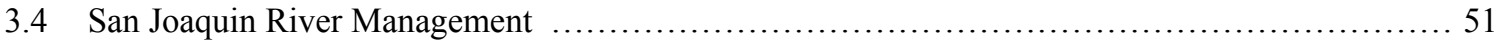




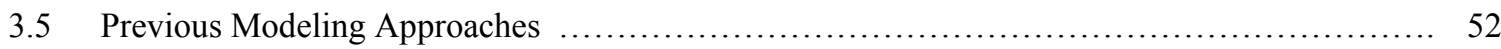

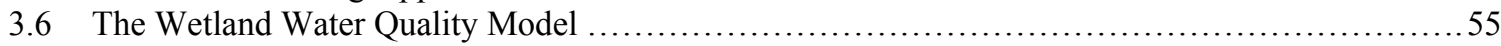

3.6.1 Model development ..................................................... 56

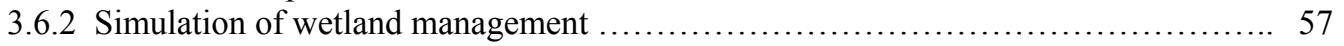

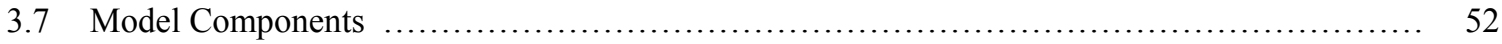

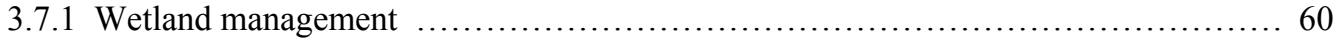

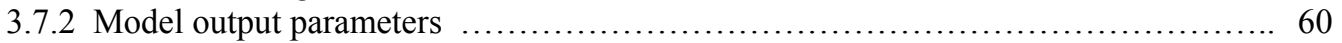

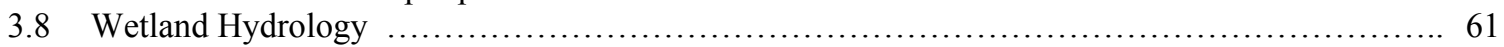

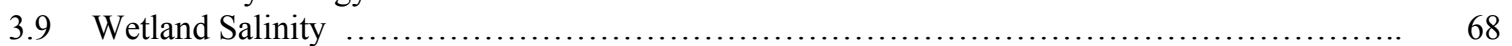

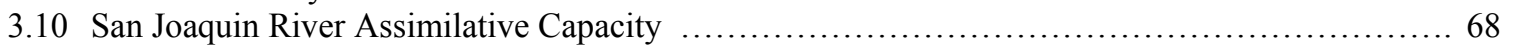

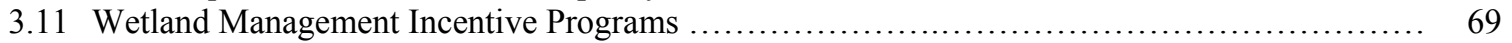

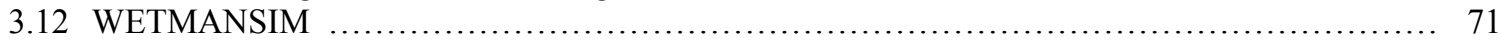

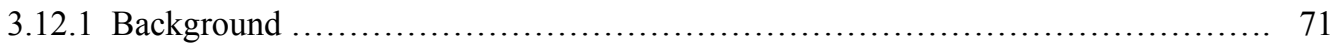

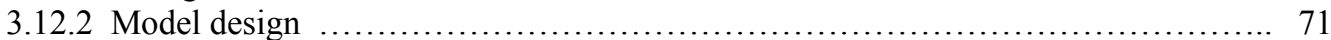

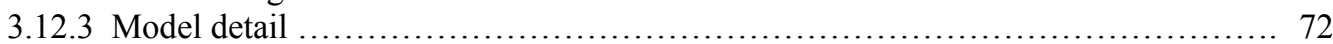

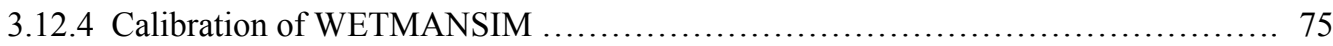

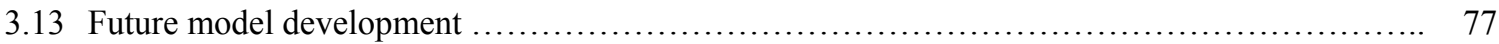

\section{CHAPTER 4 REMOTE SENSING HABITAT ASSESSMENT METHODOLOGY}

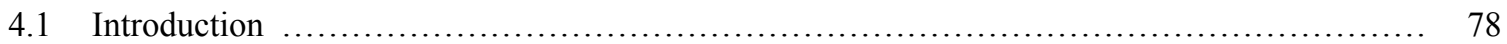

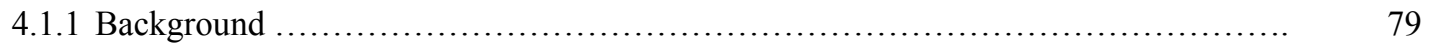

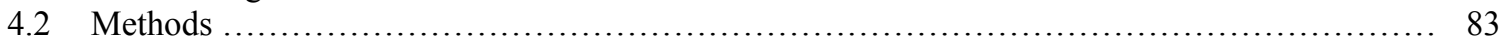

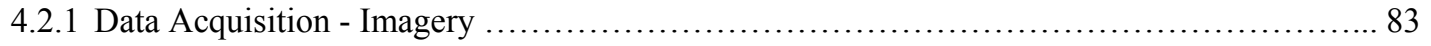

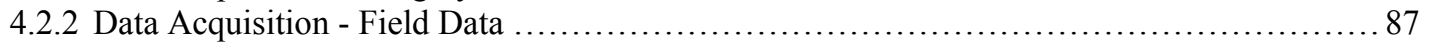

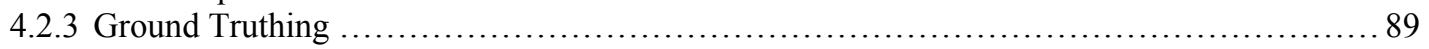

4.2.4 Image Processing ......................................................................... 96

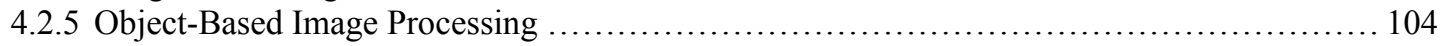

4.2.6 Image processing Accuracy Assessment ................................................ 107

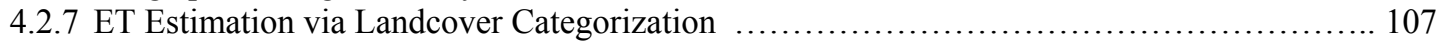

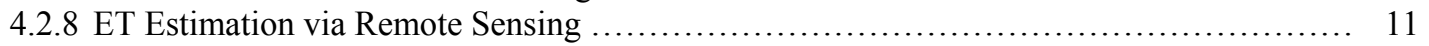

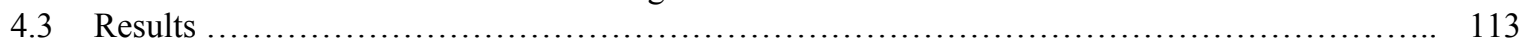

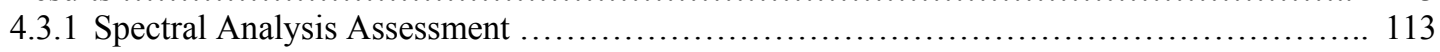

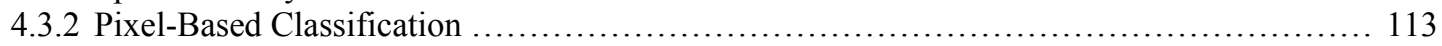

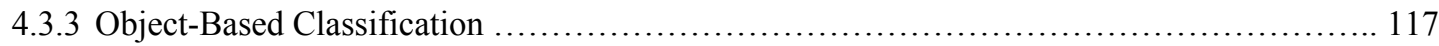

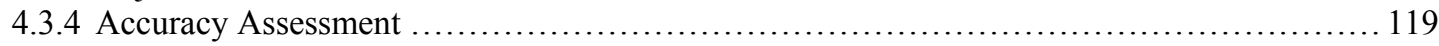

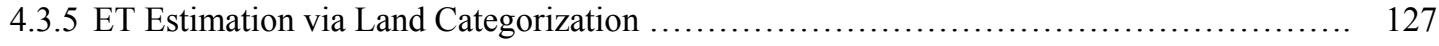

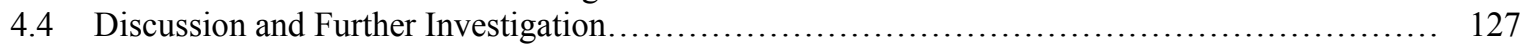

\section{CHAPTER 5 ESTIMATING SOIL SALINITY IN WETLANDS}

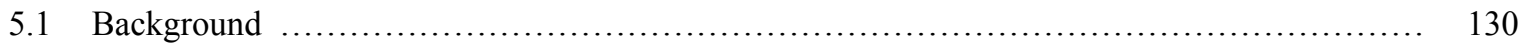

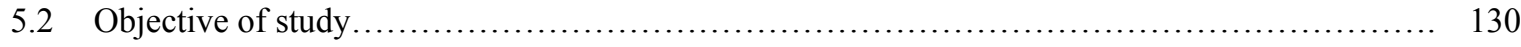

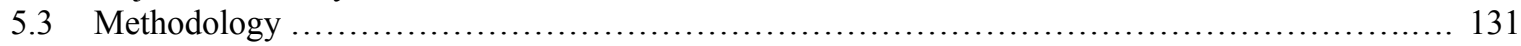

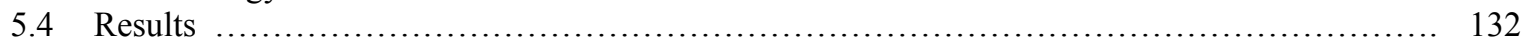

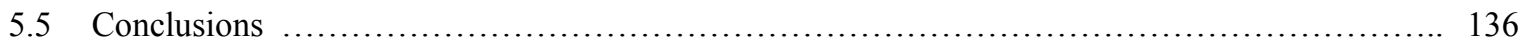

\section{CHAPTER 6 CONCLUSIONS}

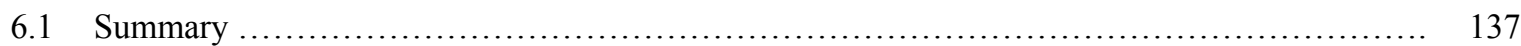

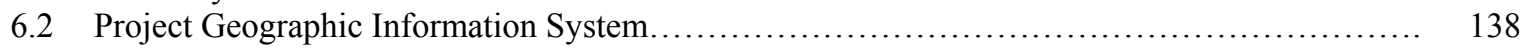

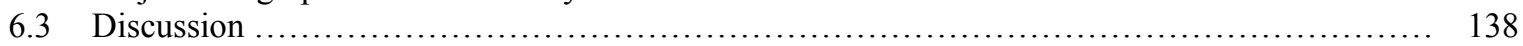




\section{APPENDICES}

Appendix 1 - Quinn, N. W. T., and W. M. Hanna, 2003. A decision support system for adaptive real-time management of seasonal wetlands in California. Environmental Modeling and Software (18) 2003, 503-511....

Appendix 2 - Quinn N.W.T. Sensor Quality Assurance Workshop. San Luis National Wildlife Refuge Complex Office, Los Banos, CA. April 8, 2005.

Appendix 3 - Cassels F. Soil Salinity Assessment: Theory and Practice.Soil Salinity Assessment and MappingWorkshop. San Luis National Wildlife Refuge Complex Office,

Los Banos, CA. April 22, 2005

Appendix 4 - Cassels F. Soil Salinity Assessment: Theory and Practice. Presentation for: Soil Salinity Assessment and Mapping Workshop. San Luis National Wildlife Refuge Complex Office, Los Banos, CA. April 22, 2005.

Appendix 4 - Cassels F. Soil Salinity Assessment Manual: Handout presented at: Soil Salinity Assessment and Mapping Workshop. San Luis National Wildlife Refuge Complex Office, Los Banos, CA. April 22, 2005. 


\section{LIST OF FIGURES}

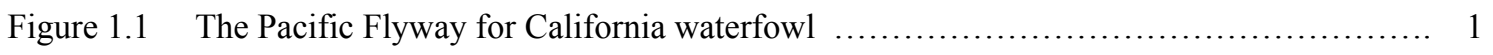

Figure 1.2 The Grassland Ecological Area within the San Joaquin River Basin. .................... 2

Figure 1.3 San Luis National Wildlife Refuge Complex showing component wetland units......... 4

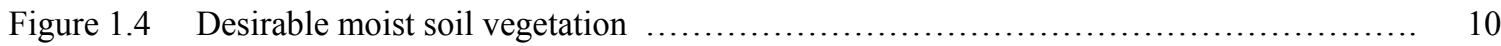

Figure 1.5 Recommended irrigation schedules for certain desirable moist soil plants ............... 11

Figure 1.6 Seasonal wetland drawdown practice in the San Luis National Wildlife Refuge.......... 12

Figure 2.1 Inlet monitoring site - San Luis Canal Company "C" Canal in the SLNWR ............... 24

Figure 2.2 Electrical conductivity data at the "C" Canal inlet in the SLNWR .................. 25

Figure 2.3 Estimated flow (cfs) at the "C" Canal inlet in the SLNWR ....................... 26

Figure 2.4 Estimated salt load (tons) at the "C" Canal inlet in the SLNWR ...................... 26

Figure 2.5 Mallard Slough drainage monitoring site in the San Luis Unit of the SLNWR.......... 28

Figure 2.6 Electrical conductivity ( $\mathrm{uS} / \mathrm{cm})$ at Mallard Slough drain in the SLNWR ................... 29

Figure 2.7 Bubbler stage (ft) at Mallard Slough drain in the SLNWR ........................ 30

Figure 2.8 Estimated flow (cfs) at Mallard Slough drain in the SLNWR .............. 30

Figure 2.9 Estimated salt load (tons/day) at the Mallard Slough drain in the SLNWR ......

Figure 2.10 Moffit Drain monitoring site in the SLNWR ........................................ 32

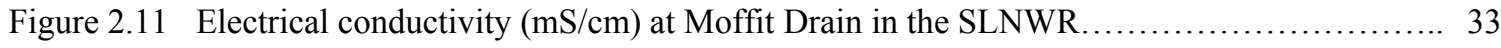

Figure 2.12 Bubbler stage (ft) at Moffit Drain in the SLNWR ............................. 34

Figure 2.13 Estimated flow (cfs) at Moffit Drain in the SLNWR ................................. 34

Figure 2.14 Estimated salt load (tons/day) at Moffit Drain in the SLNWR ........................ 35

Figure 2.15 Deadman Slough drainage monitoring site in the SLNWR .......................... 37

Figure 2.16 Electrical conductivity $(\mathrm{mS} / \mathrm{cm})$ at Deadman Slough drainage monitoring station

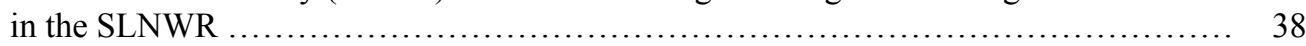

Figure 2.17 Stage reading ( $\mathrm{ft}$ ) at Deadman Slough drainage monitoring station in the SLNWR ...... 39

Figure 2.18 Salt Slough at Wolfsen Road monitoring station in the SLNWR ....................... 40

Figure 2.19 Electrical conductivity $(\mathrm{mS} / \mathrm{cm})$ at Salt Slough Wolfsen Road monitoring station ......... 41

Figure 2.20 Measured stage (ft) at Salt Slough Wolfsen Road monitoring station .................... 42

Figure 2.21 Estimated flow (cfs) at Salt Slough Wolfsen Road monitoring station ................... 42

Figure 2.22 Estimated salt load at Salt Slough Wolfsen Road monitoring station ...................... 43

Figure 3.1 Scheduling of San Joaquin River salinity, assimilative capacity versus NGWD loading ... 50

Figure 3.2 Flow and electrical conductivity in the SJR between Jan 15 and Mar 1, $1996 \ldots \ldots \ldots \ldots . . .53$

Figure 3.3 Wetland water quality model data schematic ....................................... 56

Figure 3.4 Flow and assimilative capacity forecasts for the San Joaquin River, June 2001_.......... 57

Figure 3.5 The Salinas Land and Cattle Club - an example of a mid-depth seasonal wetland unit ..... 58

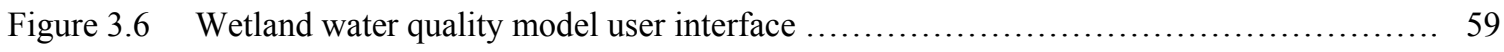

Figure 3.7 Hydrologic inputs and outputs for seasonal wetlands ................................. 62 
Figure 3.8 The crop coefficient Kc for emergent wetland vegetation in the San Joaquin Valley ........ 67

Figure 3.9 Seasonal wetland management practice with year types incorporated ......................6 69

Figure 4.1 Project imagery from April 2004 (Quickbird) Image in false color mapping ............... 81

Figure 4.2 Project imagery from June 2005 (Quickbird) . Interior delineation..................... 82

Figure 4.3 Project imagery from April 2004. Differences between two study areas.. ................ 85

Figure 4.4 Project imagery from May 2004. Differences between two study areas ................... 86

Figure 4.5 Project imagery from June 2004. Differences between two study areas ................. 87

Figure 4.6 Ground truth locations, 2004. San Luis Unit in SLNWR .............................. 93

Figure 4.7 Ground truth locations, 2004. Salinas Club, Merced Co. ............................. 94

Figure 4.8 Ground truth locations, 2005. San Luis Unit in SLNWR ............................. 95

Figure 4.9 Ground truth locations, 2005. Salinas Club, Merced Co. ............................. 96

Figure 4.10 Histograms for bands 1,2,3 and 4 in the May 14, 2004 multispectral imagery ............. 98

Figure 4.11 Mean values of the training signatures of three land cover classes ...................... 99

Figure 4.12 Example of training signature delineation, Salinas Club............................ 100

Figure 4.13 May 14, 2004. Spectral signature file ............................................ 101

Figure 4.14 Feature space analysis of separability of three land cover classes in bands 2 and $4 \ldots \ldots \ldots . .103$

Figure 4.15 Separability matrix showing transformed divergence values for first ten land over classes .. 104

Figure 4.16 Close-up image showing eCognition's automated segmentation of the landscape........... 105

Figure 4.17 Preliminary fuzzy classification of May 2004 project imagery ......................... 106

Figure 4.18 LANDSAT 7 ETM+ imagery from June 2005 showing black strips of missing data $\ldots \ldots . .112$

Figure 4.19 May 14, 2004. Maximum likelihood classification of SLNWR ….................... 115

Figure 4.20 June 19, 2004. Maximum likelihood classification of SLNWR ....................... 116

Figure 4.21 May 14, 2004. Polygon-based maximum likelihood classification of SLNWR ........... 118

Figure 5.1 Location of sites surveyed at the SLNWR San Luis Unit .......................... 131

Figure 5.2 EM38 dual mode meter placed in a carrier sled that was attached to the rear of an ATV ... 132

Figure 5.3 Soil salinity estimated at 0-6 inches depth at two sites surveyed at the San Luis Refuge .... 134

Figure 5.4 Soil salinity estimated at 6-12 inches at two sites surveyed at the San Luis Refuge 2004 .. 135 


\section{LIST OF TABLES}

Table 2.1 San Luis Canal Company "C" Canal inlet monitoring station specifications ................ 25

Table 2.2 Mallard Slough monitoring station specifications..................................... 29

Table 2.3 Moffit Drain monitoring station specifications.......................................... 33

Table 2.4 Deadman Slough monitoring station specifications.................................... 38

Table 2.5 Salt Slough Wolfsen Road monitoring station specifications............................. 41

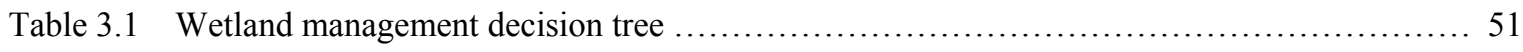

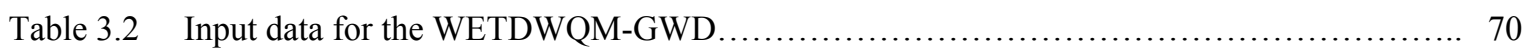

Table 3.3 WETMANSIM assumptions and sample values..................................... 72

Table 3.4 WETMANSIM model output for san Luis Unit within the SLNWR Complex............... 76

Table 3.5 Comparison of WETMANSIM model drainage salinity and WY 2004 field data.............. 77

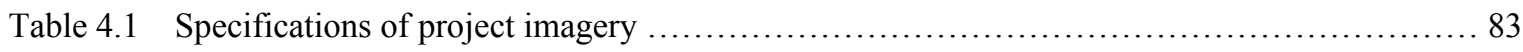

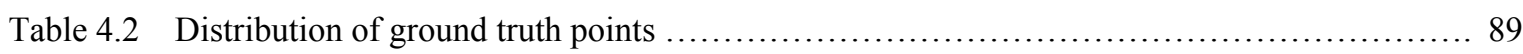

Table 4.3 Sample field data from modified CNPS Rapid Assessment Protocol ......................... 91

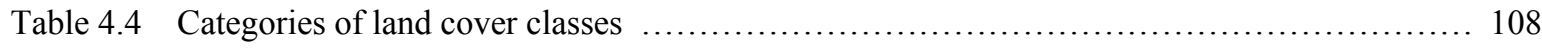

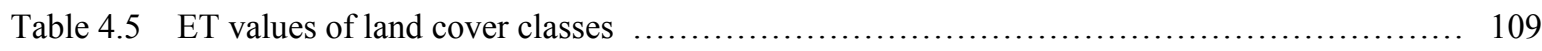

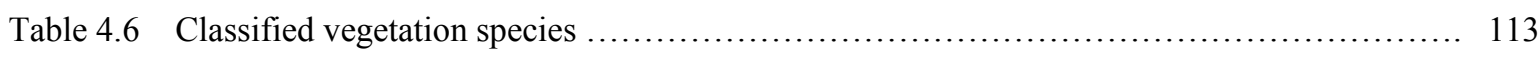

Table 4.7 Error matrix for pixel-based maximum likelihood classification of May 14, 2004 imagery.... 120

Table 4.8 Error matrix for pixel-based maximum likelihood classification of June 19, 2004 imagery.... 122

Table 4.9 Error matrix for polygon-based maximum likelihood classification of May 14, 2004 imagery 125

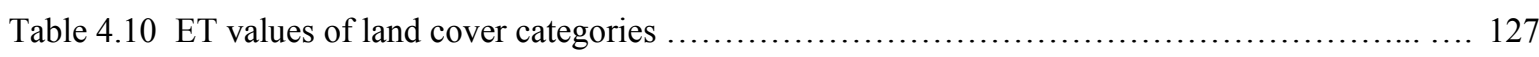

Table 5.1 Soil electrical conductivity $(\mathrm{ds} / \mathrm{cm})$ for samples collected at all survey sites................. 133

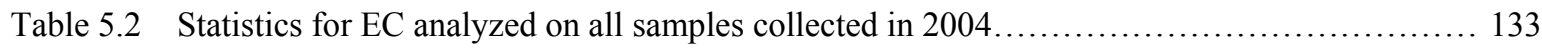

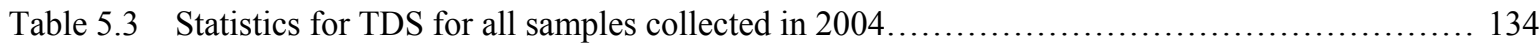




\section{CHAPTER 1 INTRODUCTION}

\subsection{Background}

California's Central Valley is the most important wintering area for migratory waterfowl within the Pacific Flyway (Figure 1). However, over 90\% of California's wetlands have been eliminated through agricultural expansion and urban development (Campbell, 1988; USFWS, 1999). Historically, much of California's Central Valley was an arid plain dominated by grasses and low shrubs. In the lower-lying areas adjacent to the San Joaquin River large wetland complexes existed. During the wet season, much of the area was transformed into marshes. These wetlands supported an abundance of native vegetation, migratory waterfowl, shorebirds, and other wildlife (Stoddard \& Associates, 1986; Campbell, 1988; Isola, 1998).

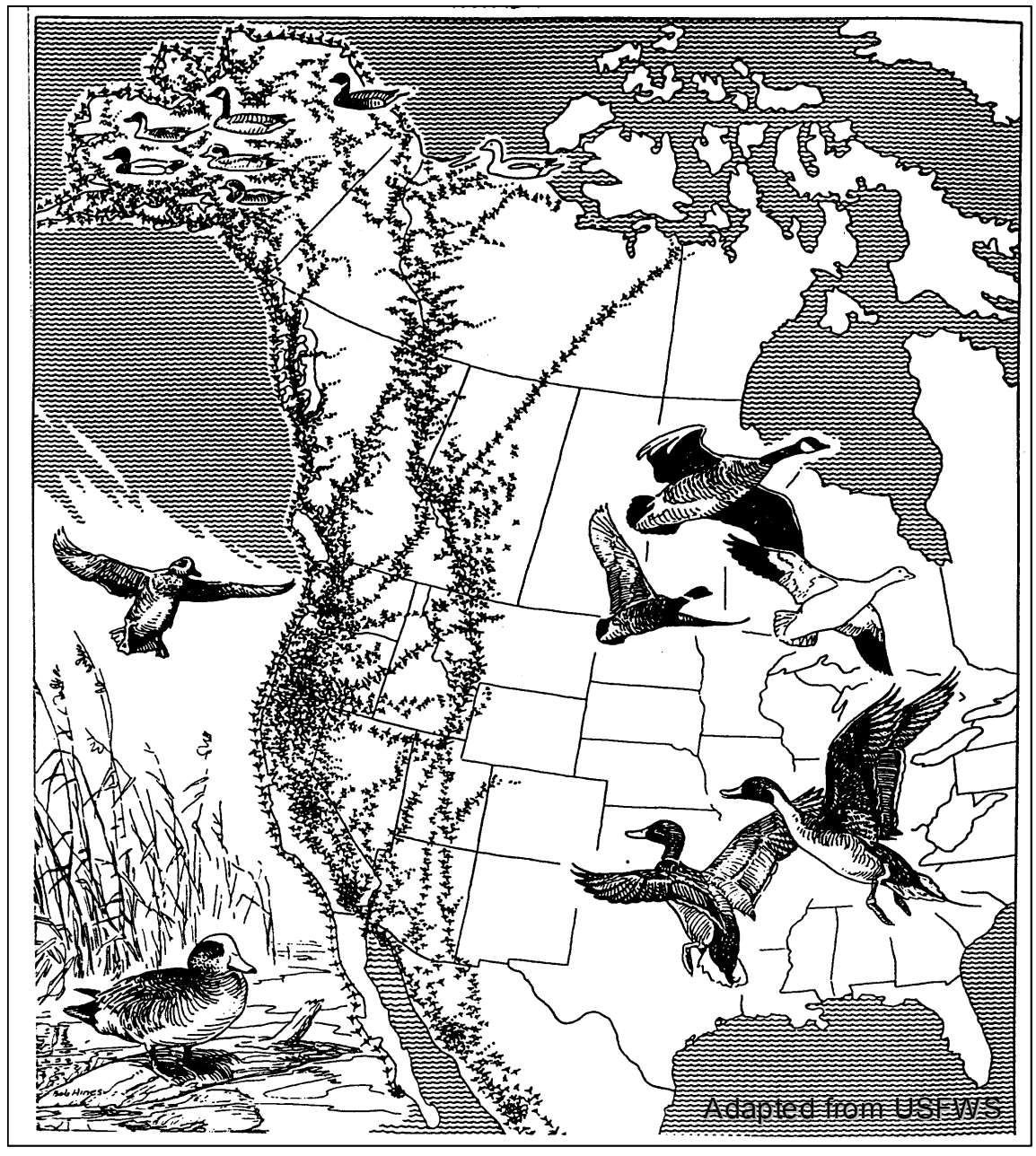

Figure 1.1 The Pacific Flyway for California waterfowl. 
Over time, as more people immigrated to California, land in California was rapidly acquired by settlers. One of California's largest land owners in the early 1900's was the Miller and Lux Cattle Corporation (Miller and Lux). The area encompassing the present day Grassland Basin was once a part of the Miller and Lux land holdings (Grassland Water District, 1986) When Miller and Lux began selling portions of its land holding to market hunters and

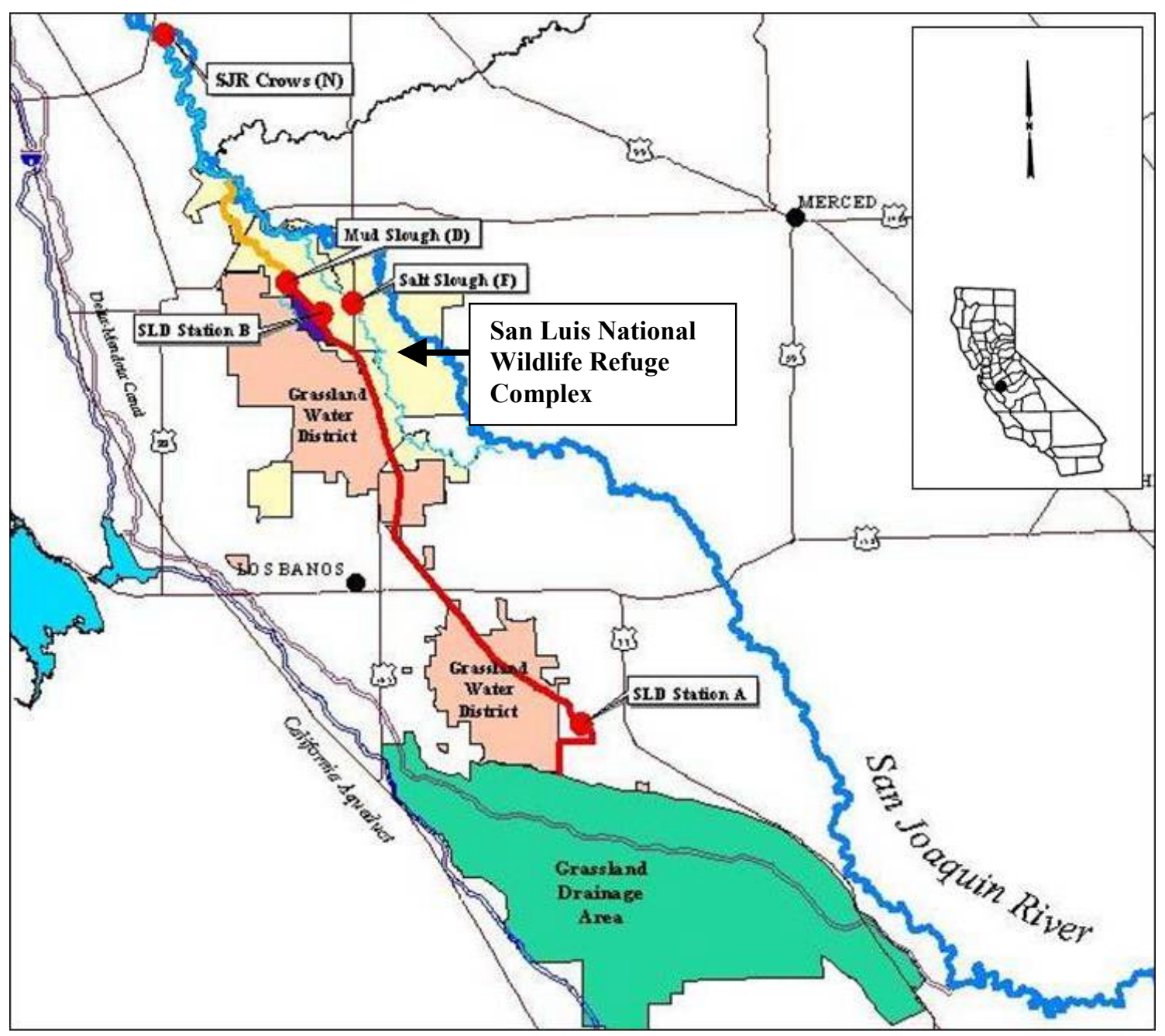

Figure 1.2. The Grassland Ecological Area within the San Joaquin River Basin.

recreational hunters in 1926, the corporation retained most water rights, thus centralizing this vast resource under one entity (Grassland Water District, 1986; Stoddard \& Assoc., 1998). In 1939, the U.S. Bureau of Reclamation acquired the water rights from the Miller and Lux Company to develop the Central Valley Project (CVP), which allowed Reclamation to 
expand irrigation service to the southern San Joaquin Valley by trading San Joaquin River water supply with surface water pumpage from the South Delta.

\subsection{The San Luis National Wildlife Refuge Complex}

Only five percent of the four million acres of historic wetlands still exist in the Central Valley of California (Forrest, personal communication, 2004). The 160,000-acre Grassland Ecological Area, which includes all of the refuges of the San Luis NWR Complex (except San Joaquin River NWR), is the largest contiguous wetland area remaining in California.

The Federal San Luis National Wildlife Refuge Complex comprises four wetland units including : San Luis, Kesterson, West Bear Creek. and East Bear Creek. Management goals for the Federal Refuge Complex includes: 1) managing and providing habitat for endangered or sensitive species (Aleutian Canada goose, bald eagle, San Joaquin kit fox, fairy/tadpole shrimp, California tiger salamander, tricolored blackbird, white-faced ibis and Swainson's hawk); 2) producing optimum habitat conditions for wintering waterfowl and other migratory birds; 3) Maintaining and enhancing the overall biodiversity associated with the existing mix of vegetative communities; and,4) Providing an area for compatible management oriented research and education/interpretation and recreational programs which include observation, photography and hunting : (http:/www.fws.gov/pacific/sanluis /refuges.htm )

The following descriptions of the various refuge units were obtained from the USFWS website (listed above).

\subsubsection{San Luis Unit}

The San Luis Unit is the oldest of the USFWS properties in the wetland complex. The original 7,340 acres were acquired in 1966 with Duck Stamp funds and is the major sanctuary for mallards, green-winged teal, ring-necked ducks, and northern pintails with a large diversity of raptors. The San Luis Unit is a remnant of San Joaquin bottomland/floodplain habitat. The diverse mixture of habitats: riparian, wetland, native grassland, vernal pools, alkali sinks, etc., attract a wide diversity of species, including those of threatened and endangered status. State-of-the-art water delivery facilities (water control 
structures, lift pumps, deep wells, major canals and feeder ditches) are utilized within the San Luis Unit to distribute up to 30,000 acre-feet of water supply provided from Mendota Pool and the Delta Mendota Canal through a wheeling agreement with the San Luis Canal Company. The primary inlets of fresh water to the Refuge are the San Luis Canal Company "C" Canal and Salt Slough. A resident herd of indigenous tule elk is maintained under a FWS/CDFG cooperative agreement. This is a major visitor attraction for over 25,000 tourists each year.

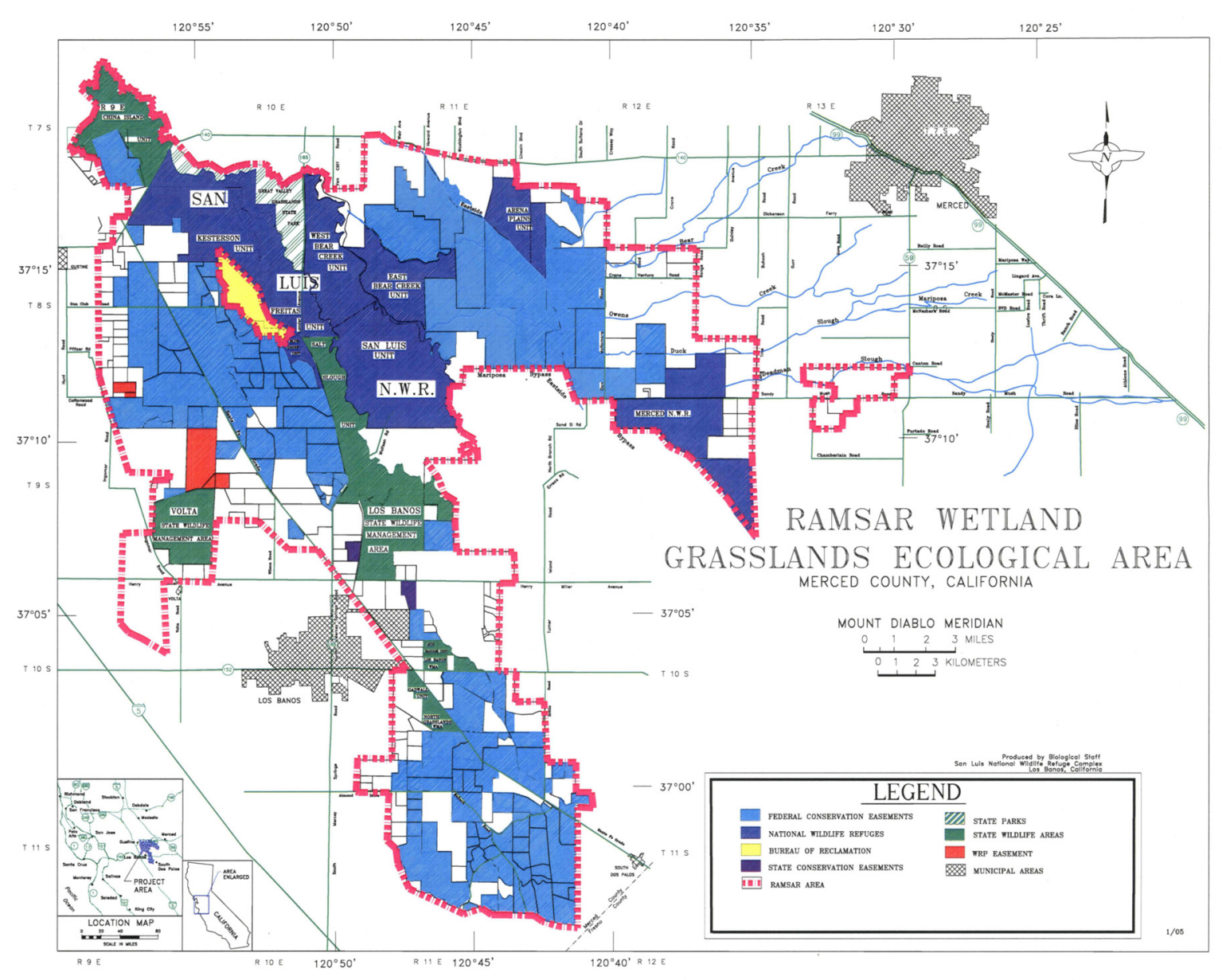

Figure 1.3 San Luis National Wildlife Refuge Complex showing individual component wetland units

\subsubsection{Kesterson Unit}

The Kesterson Unit of San Luis NWR consists of 10,621 acres and is located 4 miles east of Gustine and approximately 18 miles north of Los Banos in Merced County, California and 
lies within the historic floodplain of the San Joaquin River. The lands are primarily native grasslands (7,061 acres), wetlands (1,612 acres), 36 miles of riparian habitat (totaling 1,232 acres), and 700 acres of vernal pools and floodplain habitat and host a variety of endangered crustaceans and unique plants. The flat grasslands, typical of this area, are disrupted by narrow meandering channels of former streams and sloughs. The Kesterson Unit is bisected by Mud Slough, a tributary of the San Joaquin River. The elevation of the Refuge ranges from 60 to 75 feet above mean sea level.

The Kesterson Unit was originally established in July 1970 as Kesterson NWR. This unit consists of three areas: the original Kesterson Unit (4,466 acres/ excluding Kesterson Reservoir), the newly acquired adjacent Freitas Ranch (5,600 acres), and the Blue Goose property (555 acres). The U.S. Justice Department obtained the Freitas Ranch via a Grant Deed as a result of a litigative settlement on April 19, 1990. The USFWS obtained the property through fee title on July 17, 1991. The former Claus property was purchased in fee title on July 27, 1990. The property consists of 555 acres and will be identified hereafter as the Blue Goose Unit of San Luis NWR.

\subsubsection{East Bear Creek Unit}

The East Bear Creek Unit was acquired in 1993 under the San Joaquin Basic Action Plan. This 4,000-acre unit consists of floodplain habitat that has been cut off from flood flows, degraded riparian habitat within flood control levees, and irrigated pasture. A total of 1,883 acres of emergent and riparian wetlands were restored between 2000 and 2001 together with 1,773 acres of wetland associated uplands - these were restored by leveling old berms and levees, removing unnecessary fences, and disking up and planting native grasses on former irrigated pasture.

\subsubsection{West Bear Creek}

The 3,892-acre West Bear Creek Unit was purchased from Joseph Gallo by the Fish and Wildlife Service in 1993 by using Migratory Bird Conservation Act funds and the Land and Water Conservation Fund. This acquisition, formerly identified as West Gallo, was a major component of the San Joaquin Basin Plan/Kesterson Mitigation Plan, an interagency 
agreement involving the Bureau of Reclamation, U.S. Fish and Wildlife Service and the California Department of Fish and Game.

At time of acquisition, this area consisted mainly of native grasslands and leveled agricultural fields, bordered on the west by Salt Slough and on the east by the San Joaquin River. Past land use has primarily been cattle grazing on the native grasslands and sugar beet/silage production. The forested riparian zone associated with the San Joaquin River and Salt Slough provided habitat for a wide variety of wildlife, including neotropical migratory birds, but was heavily impacted by cattle grazing and levee maintenance operations. Major heron and egret rookeries are present along the San Joaquin River. The native grasslands support upland wildlife such as ground-nesting birds, coyotes, badgers, foraging raptors, and their prey base. In the winter, these uplands are subject to flooding and are heavily used by sandhill cranes, arctic-nesting geese, shorebirds, and dabbling ducks. A large number of vernal pools are distributed throughout the grasslands and host a wide array of vernal pool plants and wildlife. Endangered, threatened, or candidate species documented as present on the area include the Federally listed San Joaquin kit fox, vernal pool tadpole shrimp, fairy shrimp, and California tiger salamander and the State listed Swainson's hawk, greater sandhill crane, and delta button celery.

The natural channels and associated basins on the south end of the project area were floodedup with both delivered water and rainfall/groundwater during summer 1995 and during winter/spring 1995-96 to 1997-98. Waterfowl using those natural channels, basins, vernal pools, and associated uplands included white-fronted and cackling Canada geese, breeding duck pairs, and hens with broods (counts as high as 500-1200). In addition, up to 3,000 sandhill cranes use the area in winter.

\subsection{Climate}

Regional climate in the San Joaquin Valley resembles Mediterranean conditions - warm, dry summers and cool, damp winters (Rundel and Vankat, 1989). During the summer temperatures often exceed 100 degrees Fahrenheit and produce an evaporation potential of $90+$ inches per year, although average precipitation at the valley floor is only ten inches. 


\subsection{Hydrology and Hydraulics}

Wetland hydrology is dictated by the regional flooding regime. Within the GWD, this regime is managed artificially to maintain standing water from mid-September through midto late-April (Grober et al., 1995; Quinn et al., 1997; Quinn and Karkoski, 1998). Historically, floodplain inundation and wetland hydrology was more variable, caused by flood flows in the San Joaquin River resulting from from winter rains and spring snowmelt. Surface and groundwater regional flow in the Refuge Complex is from the south-west to the north-east, following the regional topography. The area includes three natural drainages. These drainages are Salt Slough, Mud Slough, Deadman Slough and Los Baños Creek In addition to these historic drainages, there are numerous constructed channels, ditches, drains, culverts, gates, and siphons throughout the Refuge Complex.

\subsection{Central Valley Project Improvement Act}

In October 1992, Congress passed a Western water bill that included, as a major provision, the CVPIA. The CVPIA mandated major changes in the operation of the Central Valley Project (CVP). The CVP was constructed by the U.S. Bureau of Reclamation in 1935 to permit surface water to be diverted from both the Sacramento and San Joaquin Rivers for farmland in the San Joaquin Valley. In addition to supplying agricultural irrigation water, other benefits such as flood control, navigation, power generation, and municipal and industrial water supply were realized by the CVP. Shasta and Keswick dams on the Sacramento River as well as Friant Dam on the San Joaquin River were among the first units built. Canals such as the Friant-Kern, the Madera, the Delta Cross Channel, and the DeltaMendota Canal were designed to transport and deliver surface water supplies throughout the San Joaquin Valley. With the CVP the origin of water supply for entities such as the Grassland Water District and the State and Federal refuges was transferred from the Sierra Nevada mountain range and the San Joaquin River to the Sacramento-San Joaquin River Delta and pumped south through the Delta Mendota Canal.

One of the key provisions of the 1992 CVPIA legislation was a recognition that the CVP water allocations to San Joaquin Basin wetlands were inadequate to provide sustainable 
wetland habitat. Hence the Act dedicated 800,000 acre-feet of water from the CVP primarily for fish and wildlife purposes. A goal of the legislation was to increase wetland supply water from a Level II maintenance allocation to a Level IV optimal allocation. The San Luis National Wildife Refuge has been the recipient of a portion of this reallocated water supply.

Increased water supply allocations under the CVPIA have improved wildlife habitat but have also resulted in increased seasonal wetland drainage, producing more flow and salt loading to the San Joaquin River. This has, in turn, created opportunities to coordinate the release of seasonal wetland drainage with the assimilative capacity of the San Joaquin River. Coordinated releases of west-side agricultural and wetland drainage with east-side reservoir releases can potentially help to achieve salinity objectives in the main stem of the San Joaquin River and and improve fish habitat in the Sacramento-San Joaquin Delta. Improved scheduling of west-side discharges can assist in avoiding water quality violations and remove an important stressor leading to improvements in the San Joaquin salmon fishery

\subsection{Wetland management}

Preservation and enhancement of wetlands in California's Central Valley is important to ensuring wildlife and habitat diversity. The regional wetlands are home to millions of waterfowl and shorebirds, a diverse community of moist-soil vegetation, and other common and endangered wildlife (Mason, 1969; Small, 1974; Cogswell, 1977; Stoddard and Associates, 1998; Shuford et al., 1998; Sibley, 2000). Because of the great importance of this wildlife, management practices (BMPs) for wetland management have been developed. Depending on the goals, these BMPs can include grading, discing, mowing, grazing, burning, herbicide application, dry season irrigations, and the timing of wetland flood-up and drawdown. By timing flood-up and drawdown in the San Joaquin Valley, managers mimic the wet/dry seasonal cycle that these historical wetlands once experienced. This seasonal cycle aids life's processes and can be adapted to promote desired species (Frederickson and Laubhan, 1995).

Under "natural" conditions, this diversity would be supported through seasonal flooding and natural disturbances (drought, fire) that historically followed the seasonal cycle. However, due to anthropogenic effects (water projects, agricultural and urban development, etc.), the 
hydrologic regime that once defined these annual cycles in the Central Valley no longer exists. To mimic these natural processes, research has been undertaken to understand the role of water manipulation, irrigation, waterfowl habitat requirements and both vegetation and waterbird responses to different management techniques. Altering wetland drainage schedules affects the timing and rate of drawdown of wetland ponds and hence the forage value of the wetlands for migrating and wintering shorebirds and waterfowl. Wetland salinity management measures also affect the productivity and diversity of vegetation that can be grown in the watershed (Rosenberg and Sillett, 1991; Mushet et al., 1992).

\subsection{Seasonal wetland management}

Wetland drawdowns are timed to make seed and invertebrate resources available during peak waterfowl and shorebird migrations and to correspond with optimal germination conditions (primarily soil moisture and temperature) for naturally occurring moist-soil plants (Smith et al., 1995). Spring drainage that is timed for optimal habitat conditions occurs at a sensitive time for agriculture in the South Delta in that these drainage releases occur during the time crops are being irrigated or the first time and are germinating - potentially affecting crop yields. Studies suggest that approximately $10 \%$ of the San Joaquin River's annual flow, and $30 \%$ of its annual salt load, passes through wetlands within the Grasslands Basin, which includes the San Luis National Wildife Refuge (Grober et al., 1995; Karkoski et al., 1995; Quinn et al., 1997; Quinn and Karkoski, 1998).

\subsection{Moist-Soil Management}

The wetland "best management practice" (BMP) specific to this research project focuses on water level manipulation and is most often called "moist-soil management". Moist-soil management refers to a process of water level manipulations to promote productive habitat conditions and beneficial vegetation such as smartweed (Polygonum punctatum), watergrass (Echinochloa crusgalli), and swamp timothy (Heleochloa schoenoides) for foraging 


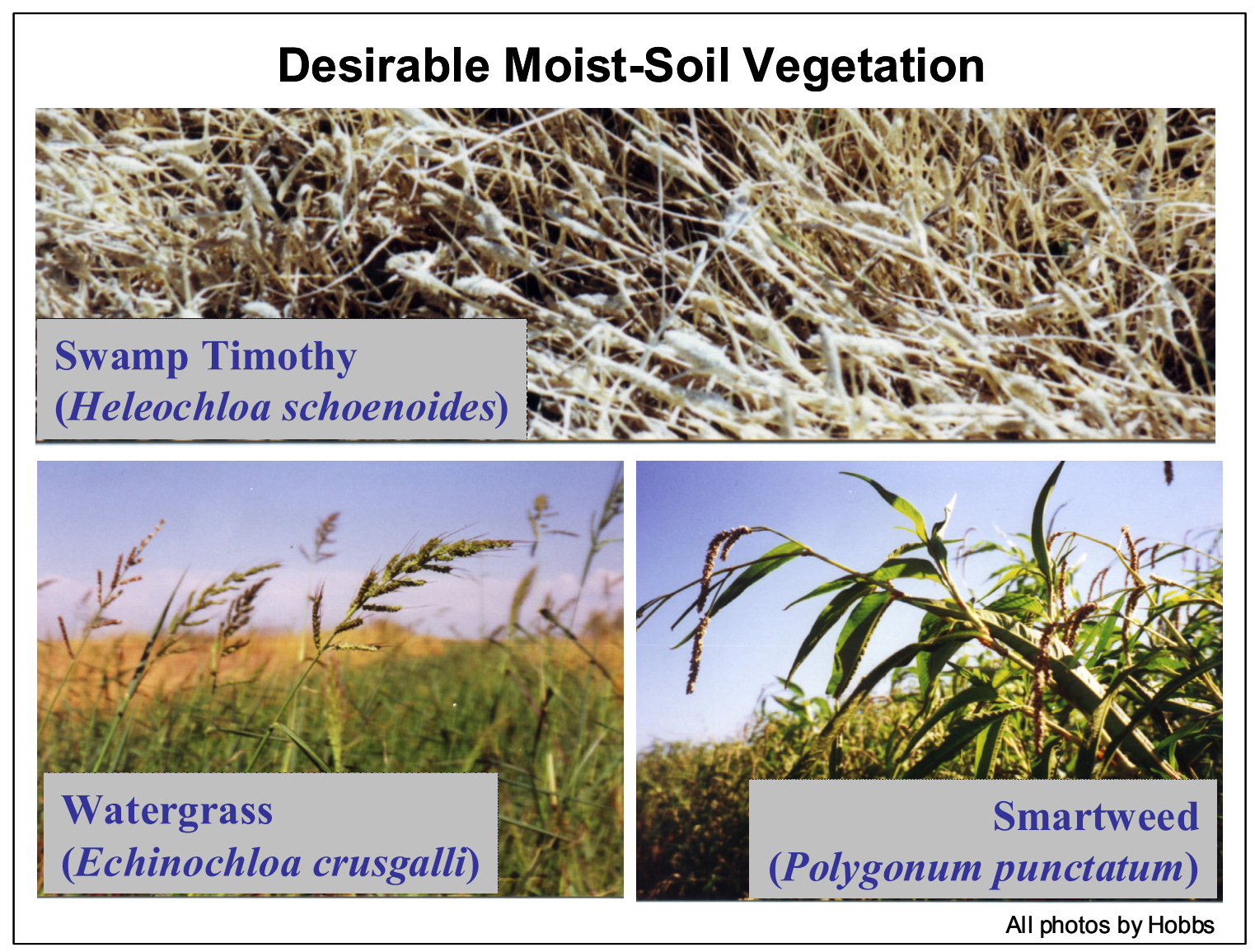

Figure 1.4 Desirable moist-soil plant vegetation.

waterfowl (Figure 1.5). Water-level manipulations include flood-up in the fall and wetland drawdown in the spring, and provide optimal conditions at each stage of vegetation development. In addition to flood-up and drawdown, several summer irrigations are conducted by wetland managers to sustain and improve growth characteristics of the desired vegetation (Figure 1.6). The seeds of moist-soil plants are recognized as a critical waterfowl food source, providing essential nutrients and energy for wintering and migrating birds (Fredrickson and Taylor 1982; Bundy, 1997; Shuford et al. 1998). Not only does the desirable vegetation provide direct nutritional value through consumption, but it also encourages healthy invertebrate populations, a high-protein food source at critical times of the year (Swanson, 1988; Mushet et al., 1992; Smith et al., 1995; Bundy, 1997; Stoddard and Associates, 1998). 


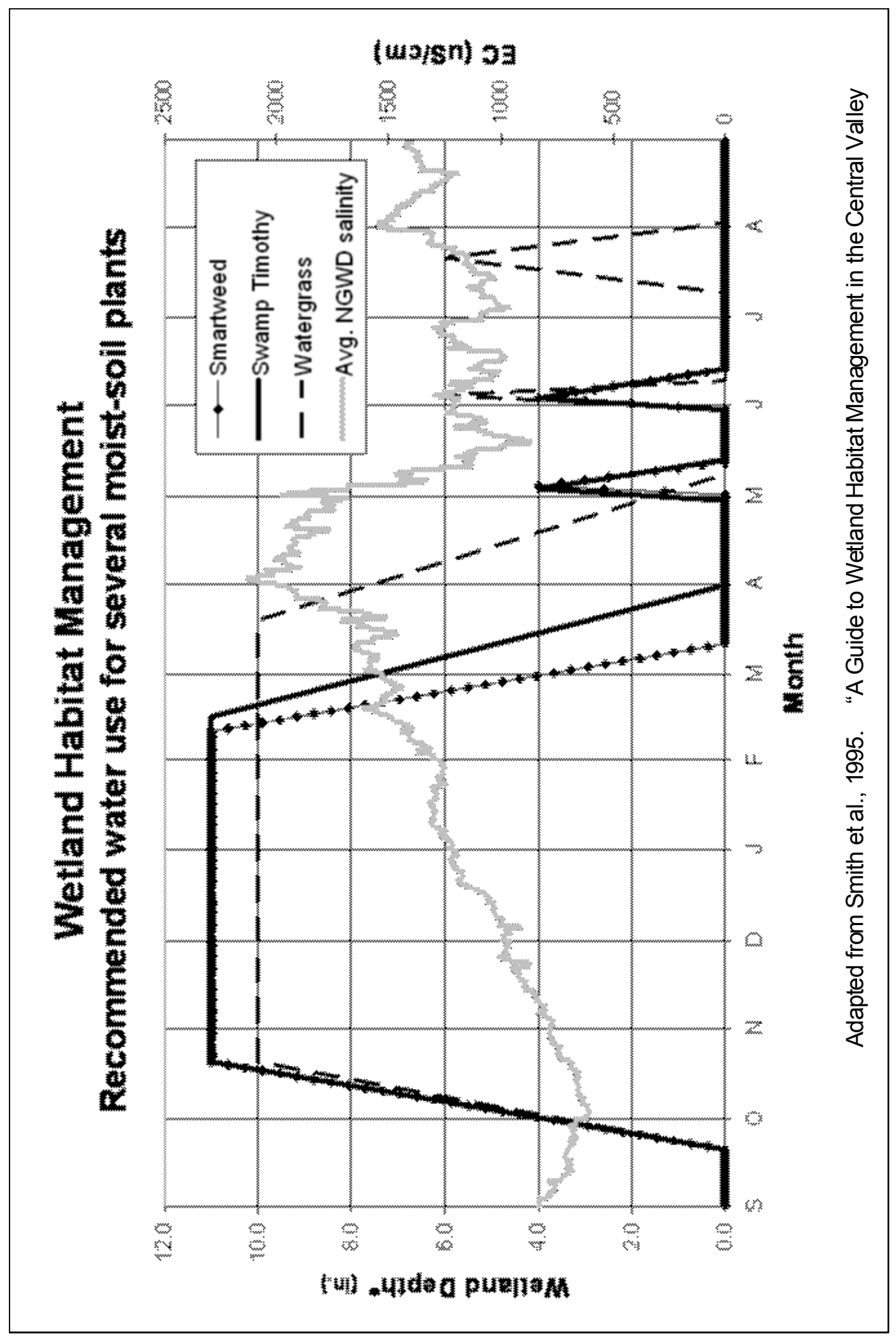

Figure 1.5. Recommended irrigation schedules for certain desirable moist soil plants. 


\section{Seasonal Wetland Management Drawdown Practice}

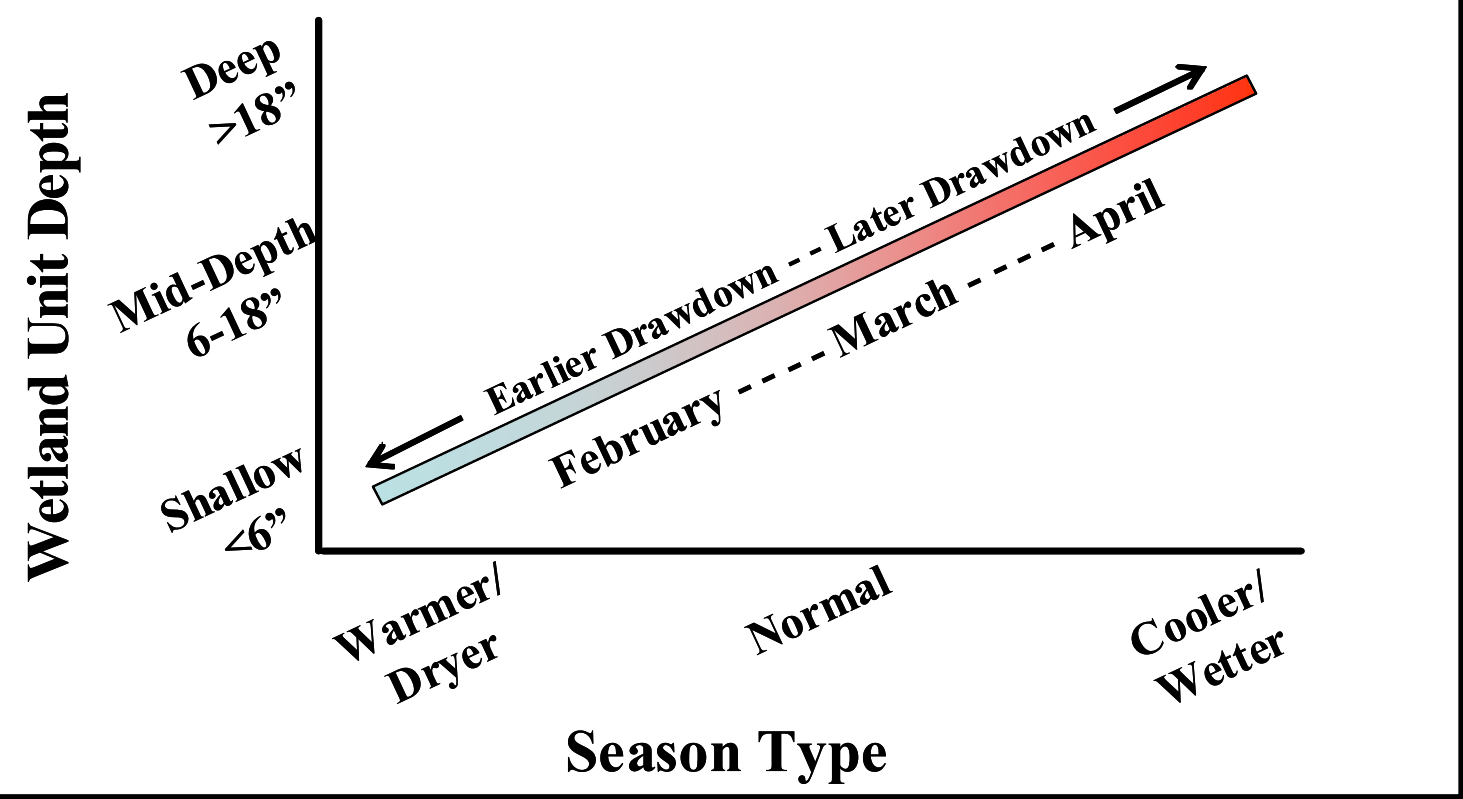

Figure 1.6 Seasonal wetland drawdown practice in the San Luis National Wildlife Refuge.

It is generally accepted by wetland managers that during cool wet years, and for wetlands of greater depth, it is better to drain them later because the optimal conditions of soil temperature and soil moisture tend to occur later. Conversely, during warm dry years, and for shallower type wetlands, it is better to drain them earlier because the optimal conditions of soil temperature and soil moisture tend to occur earlier. However, in intensively managed wetland complexes such as the San Luis National Wildlife Refuge, the heterogeneity of wetland soils, year to year variations in the weather and the complex dynamic ecology of the wetland resource require constant hydrologic manipulation and fine tuning of management decisions by wetland biologists.

\subsection{Moist-Soil Vegetation}

Many different species of vegetation grow within the San Luis National Wildlife Refuge. Together they form a mosaic of vegetation communities that provide the habitat required to 
sustain wildlife. Wetland managers often classify this vegetation, either native or naturalized, into two categories: desirable or non-desirable. Desirable plants include native species that form a healthy mixed marsh or that can provide shelter or food stores to migratory waterfowl and shorebirds. Non-desirable plants are often invasive/introduced species and may consume resources (such as light and soil) that otherwise would go to desirable species.

There are generally three major desirable moist-soil plant communities that are targeted for waterfowl forage potential. These targeted communities are found in a mixed marsh setting and are either dominated by smartweed, swamp timothy, or watergrass. A healthy mixed marsh for the San Joaquin Valley could include several other desirable species such as sprangletop (Leptochloa fascicularis), brass buttons (Cotula coronopifolia), and alkali heath (Frankenia grandifolia). While targeting one of the highly desirable plants in the mixed marsh such as swamp timothy, wetland mangers also promote the other listed species (Smith et al, 1995). Several other acceptable plants work well in a mixed marsh community and can include, but are not limited to, tule or hardstem bulrush (Scirpus acutus), cattail (Typha latifolia), spikerush (Haleocharis palustris), purple ammannia (Ammannia coccinea), alkali bulrush (Scirpus robustis), fat-hen (Atriplex patula), and beggar-ticks (Bidens spp.).

The three desirable plants above, swamp timothy, watergrass, and smartweed, have a tendency to grow in large stands, bordered by mixed marsh consisting of desirable plants along with other acceptable plants. As conditions change (drainage plans, for instance), so does the composition of the stands and border areas. Wetland mangers target species by means of water manipulation and other management practices (i.e. flood-up and drawdown plans, disturbance, dry season irrigation, alternative land use).

However, there are several non-desirable plants that tend to establish a stronghold when conditions are not ideal for the more desirable plants. These non-desirable plants include, but are not limited to, aster (Aster spp.), cocklebur (Xanthium strumarium), salt grass (Distichlis spp.), Bermuda grass (Cynodon dactylon), and dock (Rumex spp.). These species grow in 
dense stands and can dominate the more desirable wetland species if unchecked (Smith et al, 1995).

\subsection{Wetland Management Programs}

Two habitat management programs provide funding for wetlands in the Grassland Ecological Area The Pressley Program is sponsored by the California Department of Fish and Game and the Conservation Resource Program is managed by the US Department of Agriculture. Both the State and Federal programs promote managing wetlands for optimal habitat conditions while paying the wetland entity an annual allowance per acre included in the program. Historically, the Pressley Program tends to put slightly more emphasis on overwintering conditions and food supply for migratory waterfowl, whereas the Conservation Resource Program emphasizes brood water habitat to provide spring breeding water.

\subsection{Impacts of Wetland Management on the San Joaquin River}

The wetlands of the San Luis National Wildlife Refuge are flooded in the fall with water supplied by the Delta-Mendota Canal. These water supplies contain varying concentrations of salt, with a dissolved salt concentration (measured as electrical conductivity) in the range of 500 to 1,000 microSiemens per centimeter $[\mathrm{uS} / \mathrm{cm}$ ] (375 to $750 \mathrm{mg} / \mathrm{L})$. As the flooded season progresses, the ponded water increases in salinity as a result of the processes of direct evaporation and evapotranspiration from emergent wetland vegetation as well as through contact with the environment (soil residues, ground water inputs, bird usage, etc.). When the flooded season ends spring releases are discharged into tributaries of the Lower San Joaquin River. These releases, along with agricultural and municipal return flows, contain varying loads of total dissolved solids (TDS) and boron. These constituents have been identified as stressors that lead to frequent exceedance of water quality objectives established for the San Joaquin River by State and Federal agencies (Grober et al., 1995; Quinn et al., 1997).

This spring drawdown in the seasonal wetlands is timed for optimal germination conditions for the most desirable moist-soil vegetation. However, at times these spring releases coincide with higher salt concentrations in the SJR during lower flows and with downstream agricultural withdrawals from the SJR. Peak assimilative capacity typically occurs between 
the months of January and April. This period is often earlier than the traditional wetland drawdown period (February - April). The response of moist-soil plants and of migratory waterfowl and shorebirds to an altered drawdown regime that would coincide with the highest San Joaquin River assimilative capacity for salt is unknown. Experimentation necessary to determine these impacts will help to identify potential impacts on seed germination rates, waterbird foraging rates, habitat availability, and species diversity and abundance. It is possible that early, experimental drawdown may make food sources available to wildlife without negatively effecting wetland vegetation community and plant species diversity, hence benefiting both wildlife and the health of the San Joaquin River.

\subsection{San Joaquin River Management Program}

To improve flow and water quality conditions in the San Joaquin River system, the California Department of Water Resources formed the San Joaquin River Management Program (SJRMP), a stakeholder group representing many of the agencies, landowners and other parties interested in improving the San Joaquin River ecosystem. One of the SJRMP's mandates was to reconcile and coordinate the various uses and competing interests along the river. The SJRMP created a number of working subcommittees - one of which was the Water Quality Subcommittee. This subcommittee applied for grants, one of which supported early work on real-time water quality management in the SJR. One of the Water Quality Subcommittee's initial tasks was to develop solutions to address the occurrence of high salinity levels in the lower San Joaquin River at certain critical times of the year such as the onset of pre-irrigation in Delta agricultural lands.

Studies conducted initially under the SJRMP and subsequently by Berkeley National Laboratory, have suggested that wetland drainage from the GWD could be scheduled to coincide with peak assimilative capacity in the San Joaquin River to help improve downstream water quality (Grober et al., 1995; Quinn et al., 1997; Quinn and Karkoski, 1998). Increased surface water supply allocations under the Central Valley Project Improvement Act (CVPIA) have created greater opportunity than existed previously to coordinate the release of seasonal wetland drainage with the assimilative capacity of the San Joaquin River. Coordinated releases will help achieve salt and boron water quality objectives 
and improve both downstream agricultural draws and fish habitat in the main stem of the San Joaquin River and Sacramento-San Joaquin Delta. Improved scheduling of west-side discharges can assist in avoiding conflict with critical time periods for early season irrigation as well as fish rearing and remove an important stressor leading to improvements in the San Joaquin salmon fishery (Quinn and Delamore, 1994; Grober et al., 1995; Karkoski et al., 1995; Quinn et al., 1997; Quinn and Karkoski, 1998).

The research project conducted as part of the "Real-Time Adaptive Wetland Water Quality Management in the Grassland Water District", which concluded in September 2004 focused on developing techniques for better coordinating salt loading from the Grassland Water District with the assimilative capacity for salts in the SJR. To assess the feasibility of such a reconciliation, flow and water quality monitoring experiments were conducted within the 30,000 acres of seasonal wetlands in the Northern Division of the GWD (NGWD). The

project provided a systematic data collection program to evaluate the short and long-term consequences of real-time wetland drainage management.

\subsection{Coordination between Wetland Management and the San Joaquin River}

Management of wetland drainage, through scheduling of releases to coincide with periods of San Joaquin River assimilative capacity, can help improve San Joaquin River water quality and improve compliance with water quality objectives. These objectives were set by the California State Water Quality Control Board (SWQCB) as a result of a lawsuit between the South Delta Water Agency and the USBR that showed the need for salinity objectives to protect south delta agricultural interests. Hence, these objectives were set to protect downstream riparian irrigators who use the San Joaquin River as their sole water supply and to protect the salmon fishery (Grober et al., 1995; Quinn et al., 1997; Quinn and Karkoski, 1998). However, these actions may need to be considered relative to potential biological impacts of changes to traditional wetland management practices. Increased CVPIA water allocations, while increasing the flexibility of the operation of seasonal wetlands and improving the quality of seasonal wetland return flows, also increase the total salt load discharged to the San Joaquin River. 
Late season wetland releases (April) containing high salt loads can impact salinity levels in the lower San Joaquin River system. The negative impacts are twofold:

- High salinity releases that coincide with agricultural pre-season irrigation downstream can inhibit germination and reduce crop yields; and

- Salmon can become confused during their annual migration when high flows from sloughs carry high volumes of drainage water.

\subsection{Decision Support}

Depending on the water year type (wet, normal, dry, etc.), wetland drawdown from the San Luis national Wildlife Refuge can contribute significant salt load to the SJR. The real-time wetland water quality management project was conceived to complement the salinity assimilative capacity forecasting project led by the SJRMP Water Quality Subcommittee. Since there was no continuous monitoring of salt loads leaving the San Luis Unit of the San Luis National Wildlife Refuge at the onset of the project, the project required the installation of a series of wetland monitoring stations at major outlets from the San Luis Unit of the San Luis National Wildlife Refuge to Salt Slough. A decision support system (DSS) was developed to help manage this information and to help Refuge biologists and water managers to make drawdown scheduling decisions and to manage salt export to coincide with periods of significant San Joaquin River assimilative capacity.

\subsection{Research Objectives}

This CALFED sponsored study had the following objectives:

1. To develop, construct, and maintain a real-time flow and salinity data acquisition network to aid seasonal wetlands drainage management.

2. To develop a habitat assessment methodology for measuring the impacts of changes in seasonal wetland drawdown schedules on moist-soil plant production and habitat health. 


\subsection{Research Procedures}

These objectives are accomplished in this study as follows :

1. To develop, construct, and maintain a real-time flow and salinity data acquisition network to aid seasonal wetlands drainage management.

A real-time wetland water quality network was established to measure flow, salinity (in the form of electrical conductivity, or EC), and temperature at the major inlet and outlets of the San Luis Unit of the San Luis National Wildlife Refuge Complex. The main water supply conveyance is the San Luis Canal Company's "C" Canal which supplies water to more than $80 \%$ of the wetlands in the San Luis Unit Wetland drainage is discharged to the San Joaquin River via Salt Slough. Mallard Drain, Moffitt Drain and Deadman Slough Drain are the three most significant discharge points to Salt Slough. Dataloggers collected data continuously at each of these stations and transmitted the data through phone and satellite telemetry to Berkeley National Laboratory where it was processed, made available on the project website.

3. To develop a soil and habitat assessment methodology for measuring the potential impacts of changes in seasonal wetland drawdown schedules on long-term moist-soil plant production and habitat health.

Soil and habitat impact assessment, was accomplished through the development of a habitat assessment methodology. This set of measurements was used to monitor the wetland vegetation communities as a means of assessing long term impacts of salinity management to meet San Joaquin River water quality objectives . The methodology employs remote sensing and pattern recognition technologies. One of these technologies, high-resolution satellite imagery, utilizes multi-spectral digital images of the wetland areas and associated uplands in panchromatic (black and white), red, green, blue, and near-infrared bandwidths. The images are then processed using an image classifier, which separates the different signals and in turn clusters regions with similar attributes. The habitat-monitoring methodology was designed to answer questions directly related to seasonal wetland management in the San Luis National Wildife Refuge. Principally, how 
do the seasonal wetlands respond to timing of wetland drawdown that is different from traditional drainage schedules? More specifically, how would the wetlands of the San Luis Unit respond to an earlier, or later, than normal drawdown as salinity assimilative capacity in the San Joaquin River might suggest? 


\section{CHAPTER 2 REAL-TIME WETLAND WATER QUALITY MONITORING}

\subsection{Introduction}

The California Regional Water Quality Control Board (CRWQCB), in 2004, announced salinity and boron Total Maximum Daily Loads (TMDL's) for the San Joaquin River - a regulatory procedure to encourage compliance with river water quality objectives. The TMDL requires that all dischargers to the River monitor their drainage return flows as well as the salt loading contained in these return flows (CRWQCB, 2002). The SLNWR has been recording daily observational flow readings for water management purposes for more than a decade. However analysis of similar environmental data in the Grassland Water District (Quinn et al, 2004) has shown that continuous data provides a more accurate record of channel flow and salt export loading. To aid data collection and drainage salinity assessment a real-time wetland water quality network was developed for the Refuge. This real-time data network has been developed using state-of-the-art environmental sensors, dataloggers and both cellular and satellite telemetry. Data obtained by telemetry from the monitoring network is stored in a project database that is accessible through the world wide web. SLNWR staff can access the data to assess conditions without costly and time consuming trips into the field. In addition, the web database helps satisfy the Regional Board's data collection requirements, and can be used to develop and calibrate water quality models for meeting water needs, explore salinity trading possibilities, and aid in wetland drainage management.

\subsection{Monitoring Parameters}

The main objectives of the monitoring program are:

1. Measure the flow and the salinity of wetland water supply and drainage, and calculate the total salt load entering and leaving the SLNWR.

2. Report these data on a real-time basis, through the use of the Internet, to a database capable of advancing wetland modeling efforts and providing decision support to wetland biologists allowing them to make timely drainage management decisions. 
3. Develop and test a methodology for assessing habitat impacts that may result for realtime salinity management and altered drawdown schedules.

To accurately measure the flow rate at individual monitoring sites, several methods were employed. These methods depend upon site characteristics and commonly require the development of a relationship between stage and discharge using a flow rating curve or, where velocity is measured directly, between stage and cross-sectional area. In the latter case the cross sectional area of flow is multiplied by the mean velocity to obtain discharge. Direct measurement of velocity is valuable, especially in system subjected to seasonal backwater conditions. Under these conditions water backs up in the channel causing high stages that are unrelated to discharge.

Salinity is estimated by sampling the electrical conductivity of the water. Electrical conductivity (EC), measured in micro-Siemens per centimeter $[\mathrm{uS} / \mathrm{cm}]$, is a measure of the ions present in the water. The ions consist mainly of Calcium $\left(\mathrm{Ca}^{+}\right)$, Magnesium $\left(\mathrm{Mg}^{+}\right)$, Sodium $\left(\mathrm{Na}^{+}\right)$, and Potassium $\left(\mathrm{K}^{+}\right)$cations and Bicarbonate $\left(\mathrm{HCO}_{3}{ }^{-}\right)$, Sulfate $\left(\mathrm{SO}_{4}^{-}\right)$and Chloride $\left(\mathrm{Cl}^{-}\right)$anions. There is a direct relationship between EC in $\mathrm{uS} / \mathrm{cm}$ and TDS in mg/L. The flow and EC data can be used for the computation of the total salt loading to and from the GWD. The computation to convert the flow and EC readings in $\mathrm{cfs}$ and $\mathrm{uS} / \mathrm{cm}$ respectively, to total salt load in tons of salt per day [tpd] follows:

$$
\text { SaltLoad }=M \times Q \times E C
$$

where $\boldsymbol{Q}$ is in cubic feet per second [cfs], $E C$ is in microSiemens per centimeter $[\mathrm{uS} / \mathrm{cm}]$ and $\boldsymbol{M}$ is the ratio of $T D S[\mathrm{mg} / \mathrm{L}]$ to $E C[\mathrm{uS} / \mathrm{cm}] . M$ is determined experimentally and is typically 0.75 in the Grassland Basin (California Environmental Protection Agency, 2002). Converting salt load into tons per day [tpd] becomes:

$$
\text { SaltLoad }[\text { tpd }]=\frac{M\left[\frac{m g / L}{u S / c m}\right] \times Q\left[\frac{c u . f t .}{\mathrm{sec}}\right] \times E C\left[\frac{\mathrm{uS}}{\mathrm{cm}}\right] \times 28.32\left[\frac{\mathrm{L}}{\mathrm{cu} . f t .}\right] \times 2.2046\left[\frac{\mathrm{lb} .}{\mathrm{kg}}\right] \times 86,400\left[\frac{\mathrm{sec}}{d a y}\right]}{1,000,000\left[\frac{\mathrm{mg}}{\mathrm{kg}}\right] \times 2,000\left[\frac{\mathrm{lb}}{\mathrm{ton}}\right]}
$$


or, simplified, it becomes:

$$
\text { SaltLoad }[t p d]=Q[c f s] \times E C\left[\frac{u S}{c m}\right] \times 0.002023
$$

\subsection{Monitoring Station Design}

Three drainage outlets and one supply inlet were monitored. The major surface water supply to the Refuge, as described in Chapter 1, is the San Luis Canal Company "C" Canal, which delivers Delta Mendota Canal water from Mendota Pool to the Refuge boundary. Flow transducers and electrical conductivity (EC) sensors were installed at the inlet and three outlet stations within the SLNWR. The dataloggers attached to the environmental sensors take measurements every 15 minutes to provide an accurate measurement of salt loading into and out of the SLNWR boundary. Flow and EC data at each site recorded on the batterypowered datalogger are communicated through either cell phone modem (inlet) or satellite (outlets) allowing these data to be accessed 24 hours a day.

All of the drainage outlets sites have weir control structures allowing the development of a simple stage - discharge relationship. At these sites a Design Analysis H355 Smart Gas bubbler system were used. to obtain weir stage readings. The pressure reading measured by the bubbler transducer is proportional to the force necessary to push the air through the water column above the bubbler orifice. The pressure reading is converted to a depth measurement by the H250XL software. The direct stage measurement at the weir is used as the primary measurement. If weir boards are removed or changed in any way, the flow rating is no longer valid - hence having a secondary measurement to check on the accuracy of the weir flow rating helps to prevent loss of data and provides data quality assurance.

STARFLOW acoustic velocity transducers manufactured by UNIDATA Inc. were used at the Moffit and Mallard drain sites. A third STARFLOW unit, designated for Deadman Slough could not be installed owing to the difficult configuration and restricted culvert access at the site. Only EC was successfully monitored at the Deadman Slough drain. The STARFLOW transducers utilize the Doppler principle whereby each transducer produces short pulses of sound at a known frequency along two different axes. Sound from the outgoing pulses is 
reflected ("scattered") in all directions by particulate matter in the water. Some portion of the scattered energy travels back along the beam axes to the transducer. These return signals have a frequency shift proportional to the velocity of the scattering material. This frequency change (Doppler shift), as measured by the circuitry within the transducer, is proportional to the projection of the water velocity onto the axis of each acoustic beam. By combining data from both beams, and knowing the relative orientation of those beams, the device measures velocity in the two-dimensional plane defined by its two acoustic beams. Each STARFLOW unit has a built-in pressure transducer. Discharge is calculated by estimating the crosssectional area from a stage-area relationship for the culvert and multiplying this by the velocity obtained from the STARFLOW acoustic velocity sensor (AVM). The location of the monitoring stations in the SLNWR were determined by a global positioning system (GPS) survey and located on GIS maps of the study area.

Temperature-compensated EC sensors manufactured by Campbell Scientific, Inc. were used to obtain real-time salinity and temperature data at each site. Monthly data quality assurance assessment at each of these sites was performed in accordance with a Project Quality Assurance Plan, developed for the Grassland Bypass Project and adopted for this project, to ensure data accuracy and reliability.

\subsection{Inlet : San Luis Canal Company "C" Canal}

The San Luis Canal Company "C" canal provides the majority of the surface water supply used by the Refuge. Water supply can also pass into the Refuge along delivery canals west of "C" canal but these are rarely used. The Refuge has a historic water right to water in Salt Slough. Intakes are located on the south-west corner of the Refuge and at terminus of Deadman Slough which contains both a lift pump and drainage structure, allowing water to be diverted from and drain into Salt Slough.

The initial monitoring plan at the Inlet station called for the deployment of a SONTEK acoustic velocity meter mounted slightly downstream of the inlet structure to measure flow and a Campbell Scientific electrical conductivity/temperature sensor. However, the inherent problems that would have ensued reconciling the SLCC delivery records and those based on 
our own monitoring suggested a more cooperative strategy. Hence the late Jim Staker, District Manager of the San Luis Canal Company was approached and it was suggested that by upgrading the current flow monitoring system using propeller meters we could provide real-time telemetered data to both the Refuge and the Water District simultaneously at no cost to the Water District. This was agreed to and modules installed that allowed the output from each of the three propeller meters, mounted in the three inlet culverts, to be fed directly into a Campbell datalogger. The electrical conductivity/temperature sensor was deployed in front of the first culvert through the walkway grating and the cable from all sensors fed into the gauge house through buried PVC pipe. This site has yielded excellent data and has been very stable.

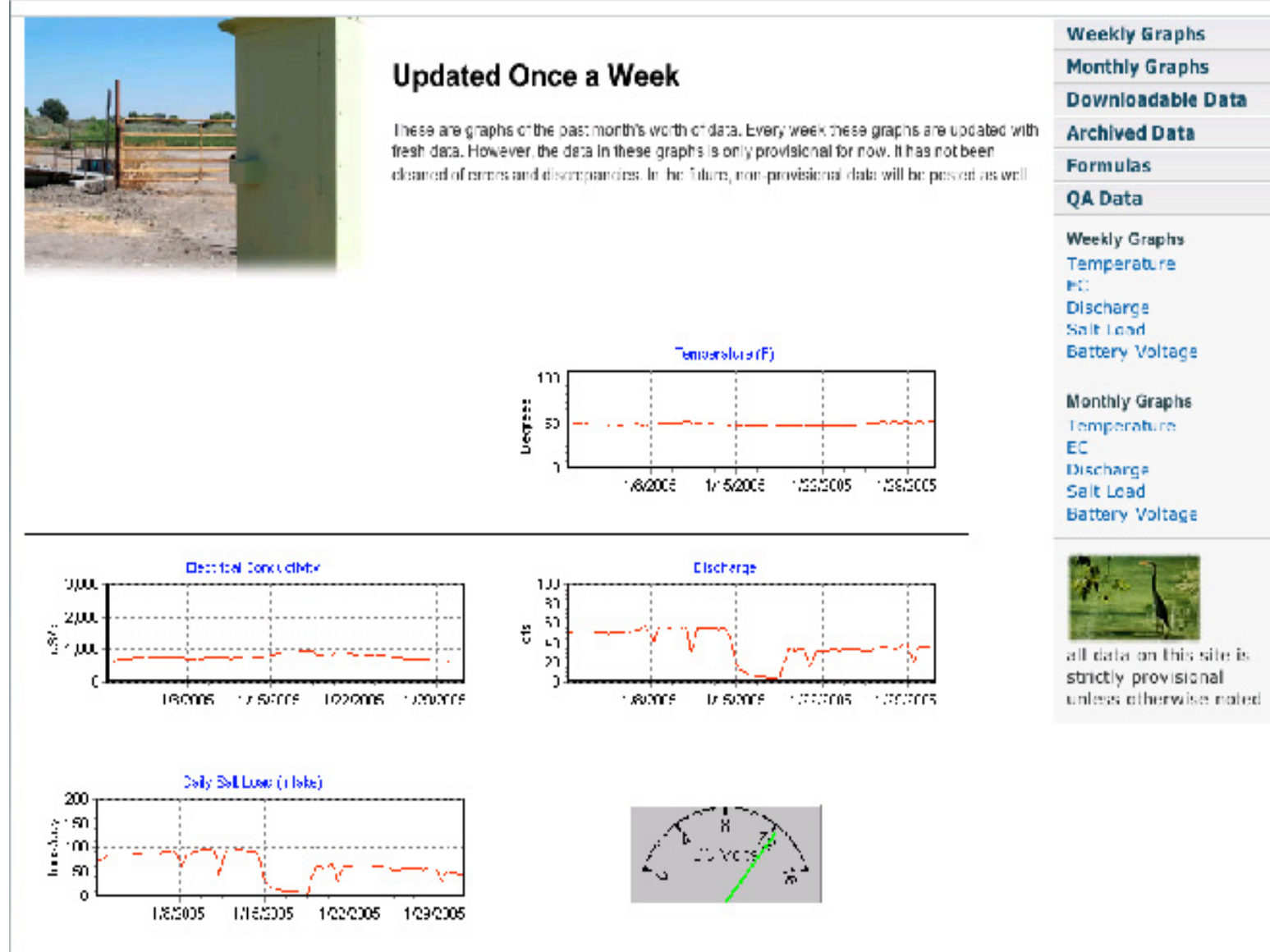

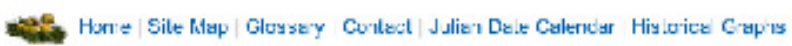

Figure 2.1 Inlet monitoring site - San Luis Canal Company 'C” Canal inlet. 
The site specifics for the SLCC Inlet monitoring station are shown below in Table 2.1.

Table 2.1 - San Luis Canal Company "C" Canal inlet monitoring station specifications

\begin{tabular}{|l|l|}
\hline Site Summary & $\begin{array}{l}\text { The SLCC Inlet station accounts for the majority of surface inflow } \\
\text { to the SLNWR }\end{array}$ \\
\hline Power & Solar Panel with 12-volt battery \\
\hline Datalogger & CSI 10X Datalogger \\
\hline EC Sensor & CSI temperature compensated EC probe \\
\hline Flow Measurement & $\begin{array}{l}\text { The pulse counter on the datalogger is used to count revolutions of } \\
\text { each propeller meter and convert this data into instantaneous } \\
\text { discharge (in cfs). The site has three culverts - two that contain } 36 \\
\text { inch gates and the middle culvert has a 24 inch gate. Total } \\
\text { discharge is the sum of the flow recorded at all three meters. }\end{array}$ \\
\hline$\bullet \quad$ Depth & Not measured \\
\hline \multicolumn{1}{|c|}{ Velocity } & Propeller meter rotation proportional to velocity \\
\hline Telecommunications & CDMA modem \\
\hline
\end{tabular}

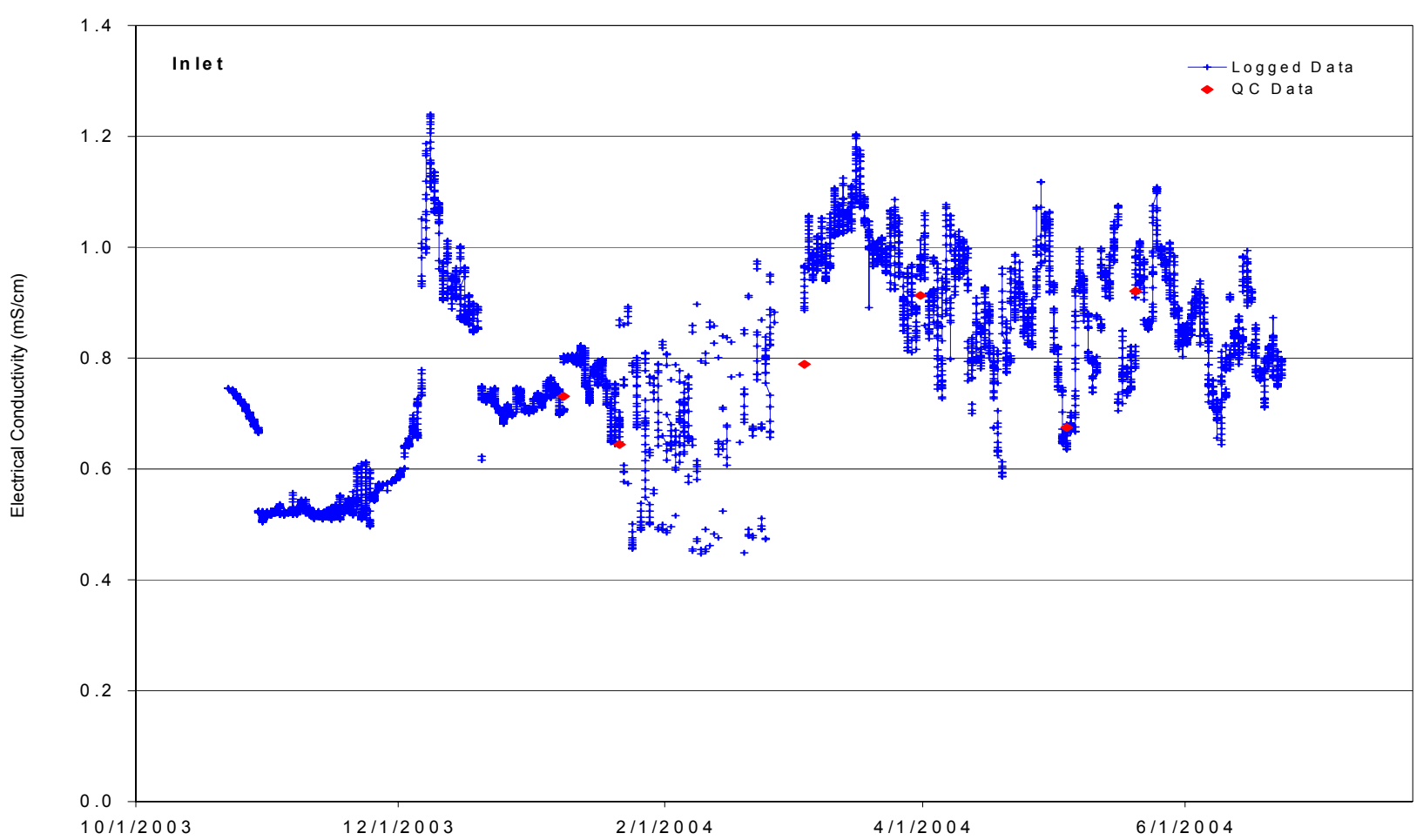

Figure 2.2 Electrical conductivity data at the "C" Canal inlet : 10/1/2003-6/1/2004. 


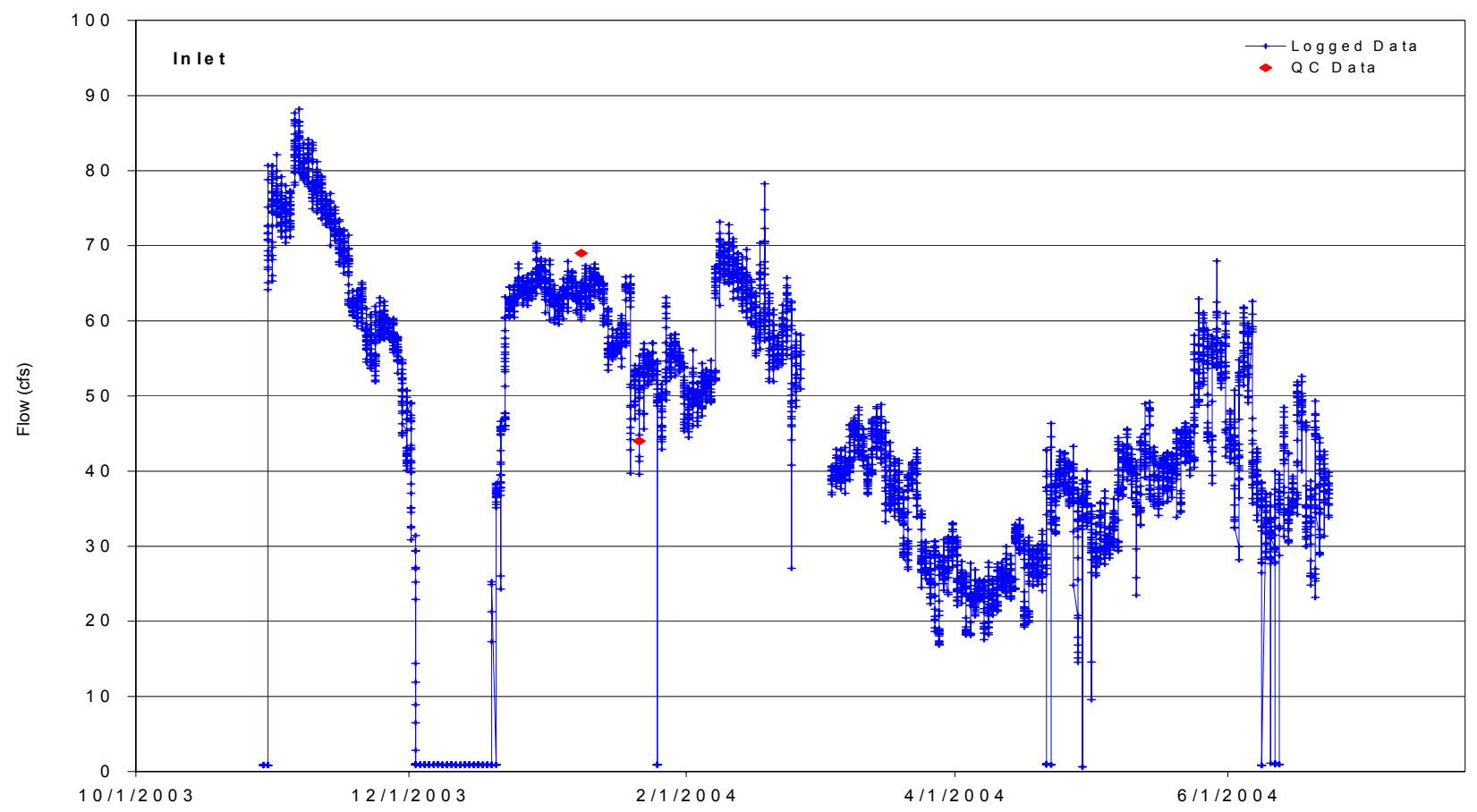

Figure 2.3 Estimated flow (cfs) at the "C" Canal inlet : 10/1/2003 - 6/1/2004.

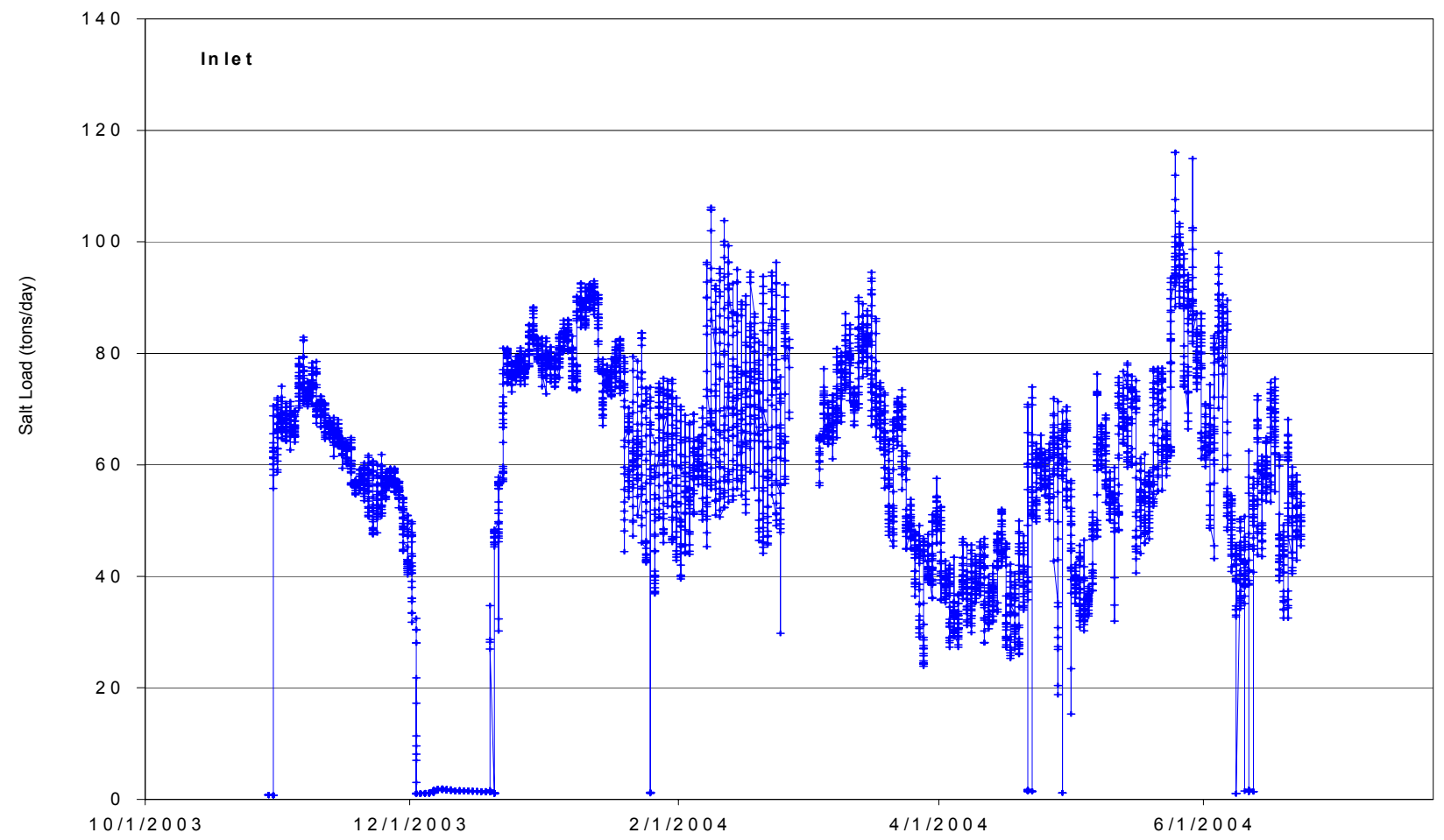

Figure 2.4 Estimated salt load (tons/day) at the "C" Canal inlet : 10/1/2003 - 6/1/2004 


\subsubsection{Analysis}

The flow record shows canal diversions ranging between 0 and $90 \mathrm{cfs}$, with inflow occurring during most months of the year, with highest inflow during the September flood-up period and lesser flow volumes during seasonal wetland irrigation between March and late May, depending on the water year type. Periods of zero flow occur during December after floodup - typically winter precipitation is sufficient to make up for evaporation losses during the rainy season. Influent salt loads mostly mirror the flow diversion from the "C" canal, however, as shown in Figure 2.1, water quality from Mendota pool can be variable in quality. The influent electrical conductivity ranged from a low of $500 \mathrm{uS} / \mathrm{cm}$ to $1200 \mathrm{uS} / \mathrm{cm}$. Surprisingly the highest EC was recorded in December, when Delta Mendota Canal inflows to the Mendota Pool are at their lowest. Heavy rainfall can induce pump-ins along the Delta Mendota Canal which occasionally causes elevated selenium levels. This may explain some of the high EC values during this period of time. During the spring when Delta pumpage draws in greater volumes of snowmelt runoff and rainfall runoff from the Sacramento and San Joaquin Rivers, water quality generally improves at the pumps. As summer progresses water quality tends to degrade. This trend is evident in Figure 2.1 which shows a mean electrical conductivity of about $650 \mathrm{uS} / \mathrm{cm}$ during the spring months and $850 \mathrm{uS} / \mathrm{cm}$ during the summer months. 


\subsection{Mallard Slough Drain}

Mallard Slough is located within the Elk Pasture close to Salt Slough, which runs along the western boundary of the Refuge. Mallard Slough Drain provides drainage to the Elk Pasture and seasonal wetlands located in the southern portion of the Refuge. The weir outlet is occasionally affected by high stage in Salt Slough which can drown the control structure. During these periods the acoustic Doppler sensor is used preferentially to provide a more accurate measurement of velocity and stage - stage is used to estimate cross-sectional area and area and velocity combined to estimate discharge.

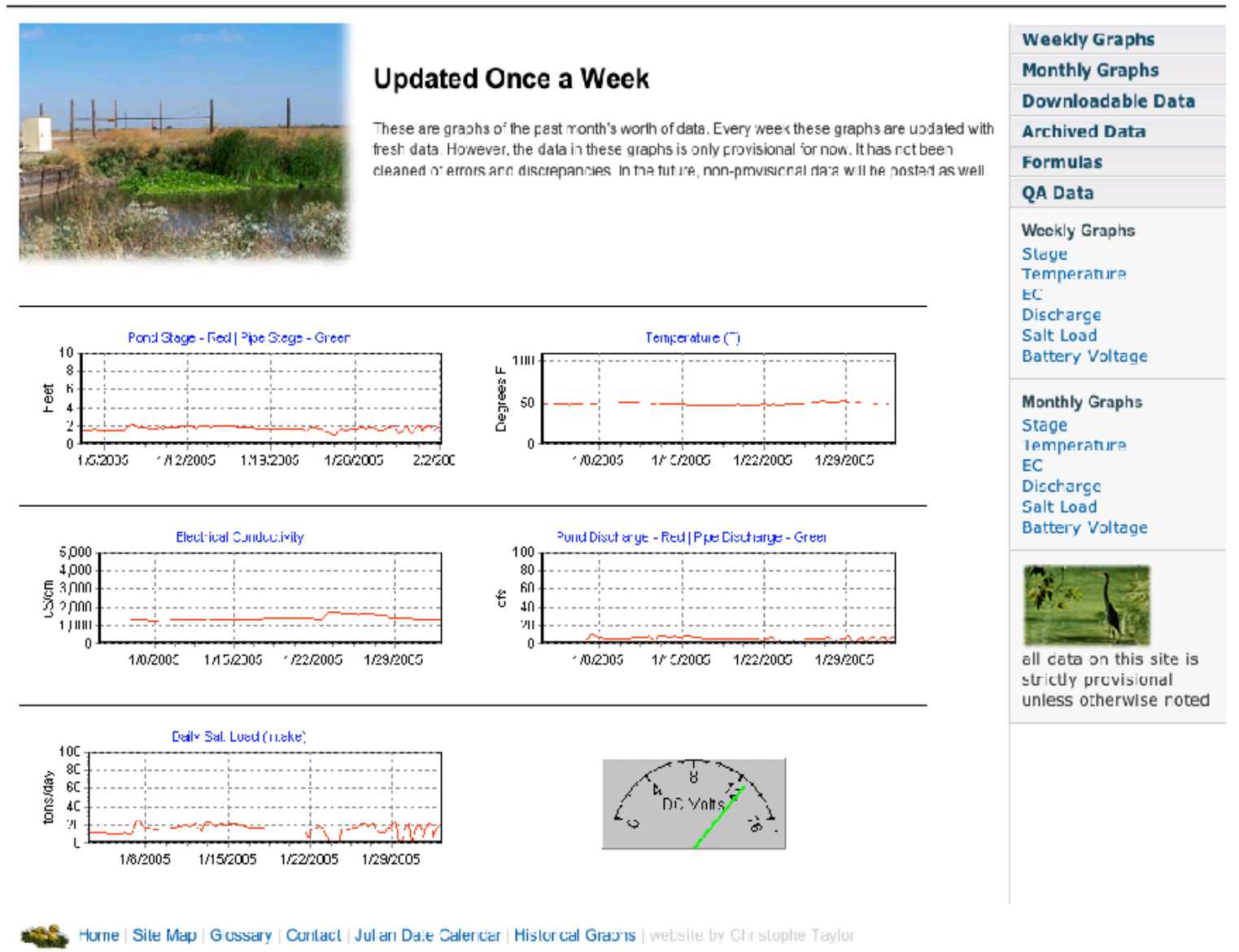

Figure 2.5. Mallard Slough drainage monitoring site in the SLNWR.

The measurement of stage at Mallard Slough drain is occasionally impacted by a build-up of water hyacinth in the reservoir above the weir structure, which can cause artificially high readings. Likewise a build-up of debris in the culvert, often caused by beaver activity, can drown the weir structure also producing erroneous elevated discharge measurements. 
The site specifics for the Mallard Slough monitoring station are shown below in Table 2.2.

Table 2.2 - Mallard Slough monitoring station specifications

\begin{tabular}{|c|c|}
\hline Site Summary & $\begin{array}{l}\text { Mallard Slough - located on the west boundary of the Elk } \\
\text { pasture, it is the most southerly drainage outlet draining to salt } \\
\text { Slough }\end{array}$ \\
\hline Power & Solar Panel with 12-volt battery \\
\hline Datalogger & CSI 10X Datalogger \\
\hline EC Sensor & $\begin{array}{l}\text { CSI temperature compensated EC probe Primary flow } \\
\text { measurement is a weir structure with a Design Analysis } \\
\text { H350XL smart gas bubbler system which measures stage over } \\
\text { the weir boards. Secondary system is a STARFLOW acoustic } \\
\text { Doppler sensor manufactured by Omnidata. Sensor estimates } \\
\text { velocity and stage above the sensor. }\end{array}$ \\
\hline \multicolumn{2}{|l|}{ Flow Measurement } \\
\hline - Depth & $\begin{array}{l}\text { Smartgas bubbler stage above orifice and STARFLOW } \\
\text { pressure above acoustic sensor }\end{array}$ \\
\hline - Velocity & STARFLOW acoustic sensor \\
\hline Telecommunications & GOES telemetry \\
\hline
\end{tabular}

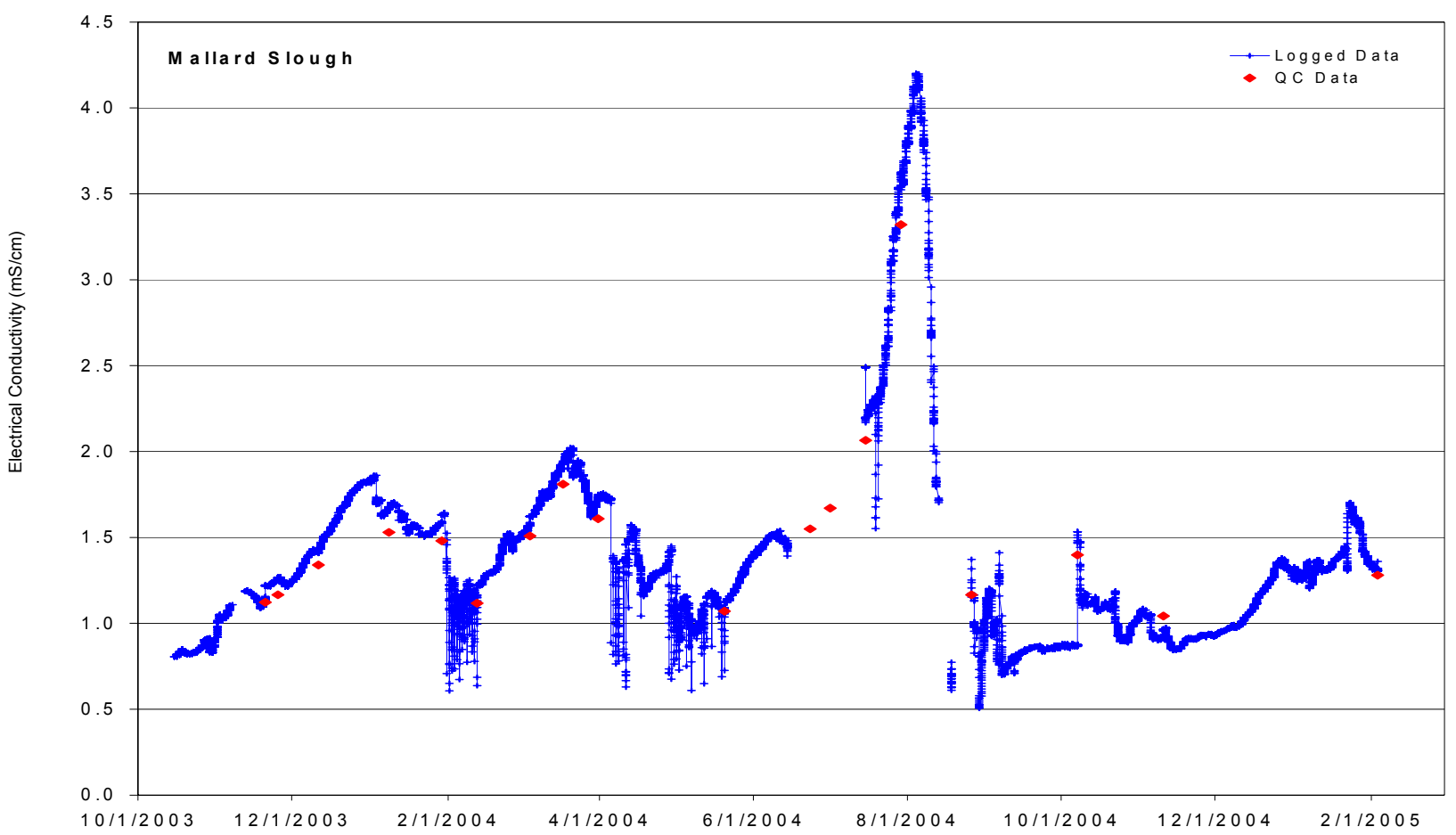

Figure 2.6 Electrical conductivity $(\mathrm{uS} / \mathrm{cm})$ at Mallard Slough drain in the SLNWR: $10 / 1 / 2003-2 / 1 / 2005$ 


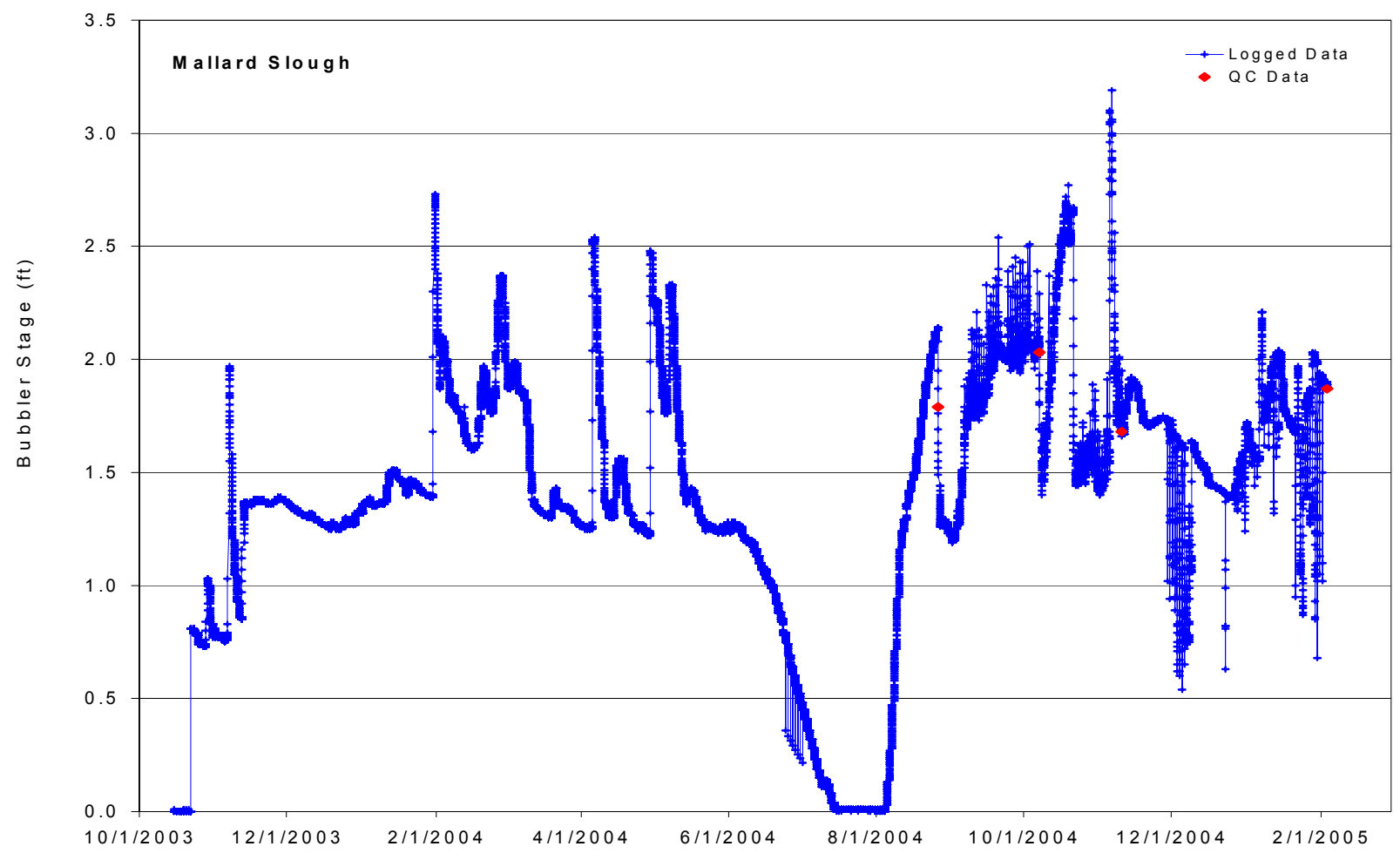

Figure 2.7 Bubbler stage (ft) at Mallard Slough drain in the SLNWR : 10/1/2003 - 2/1/2005

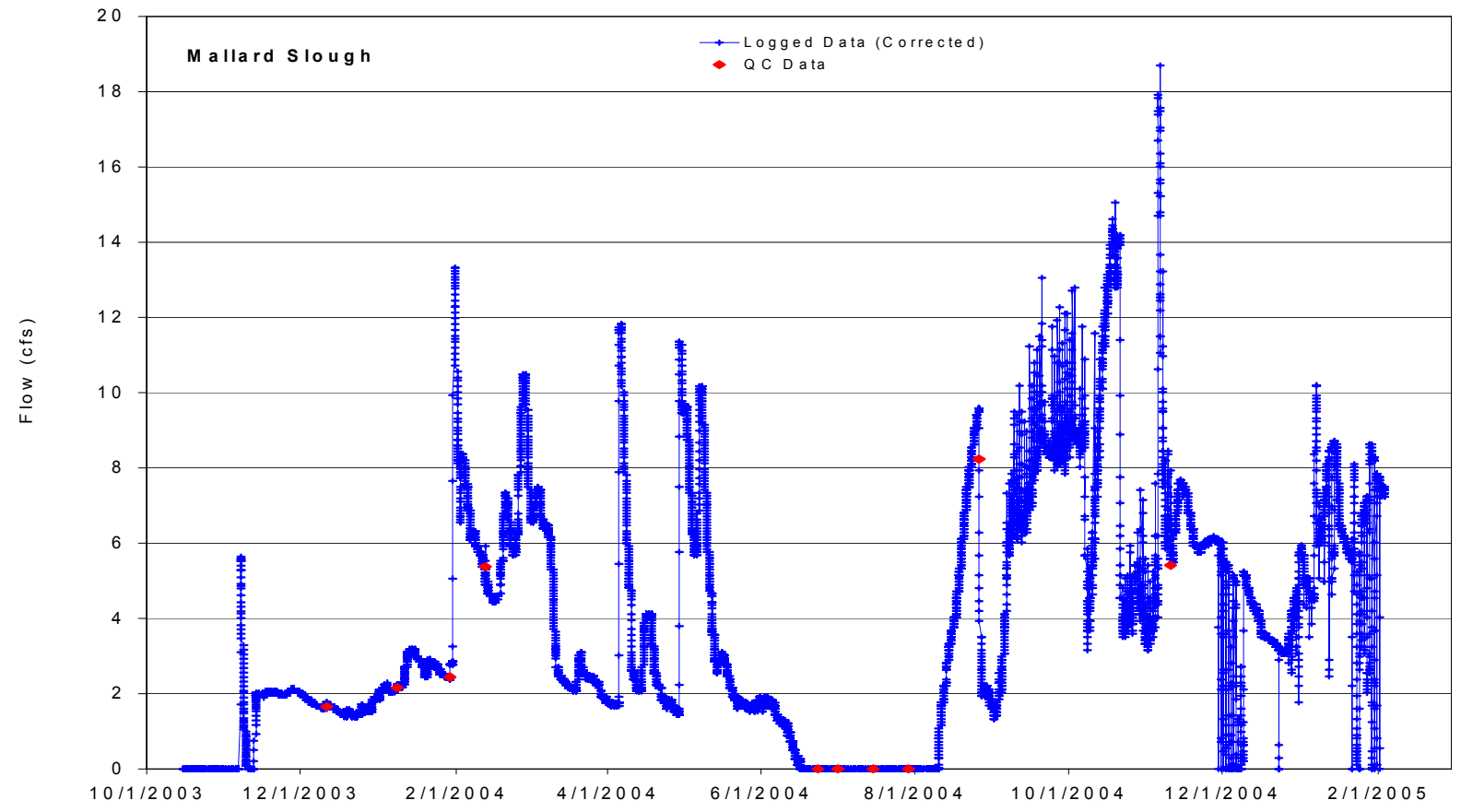

Figure 2.8 Estimated flow (cfs) at Mallard Slough drain in the SLNWR: 10/1/2003 $2 / 1 / 2005$ 


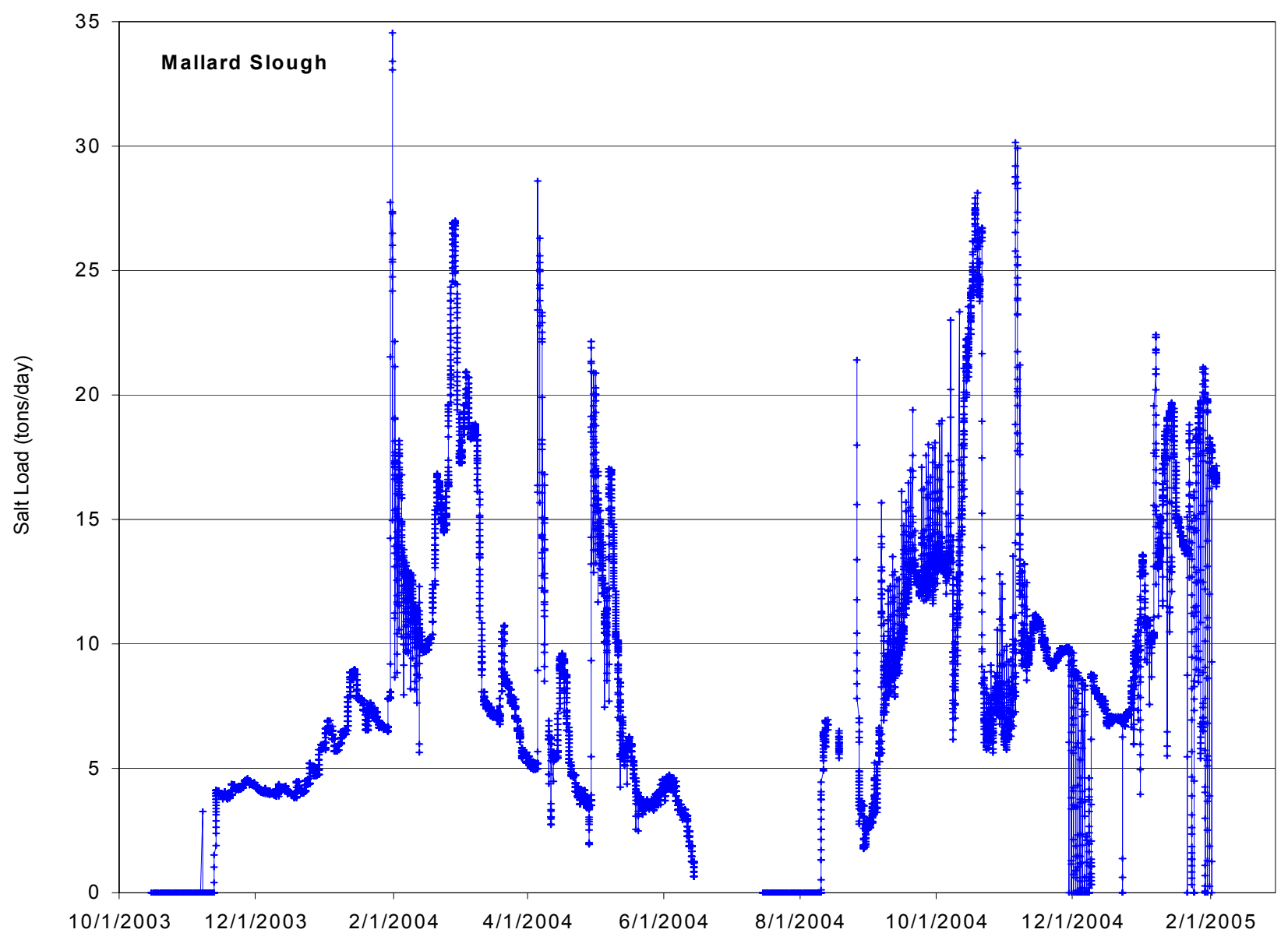

Figure 2.9 Estimated salt load (tons/day) at the Mallard Slough drain in the SLNWR : 10/1/2003 - 21/2005.

\subsubsection{Analysis}

The Mallard Slough sites reports outflow most of the year with the exception of the period between mid-June and mid-August when flows and salt loads decline to zero. Flow and corresponding salt loading from this monitoring site to Salt Slough shows sharp spikes most likely corresponding to weir board changes - which cause a rapid increase in velocity as water in the reservoir behind the weir boards equilibrates to the new control structure elevation. The salt loading to Salt Slough varies from 0 tons per day to a high of 35 tons per day during the early spring. Spikes in flow are typically of short duration. Mean flow from the site is the range of $10-15 \mathrm{cfs}$. 


\subsection{Moffit Drain}

Moffit Drain is located in the West Bear Creek Unit and drains areas of seasonal wetlands on the east side of the Refuge, located in both the San Luis and West Bear Creek Units. The monitoring site is upstream of a 36 inch culvert and is subjected to frequent debris accumulation from woody vegetation from draining seasonal wetlands and from small beaver dams constructed above the weir. This causes periodic elevated stage readings at the site. The STARFLOW acoustic velocity meter provided a useful secondary recorder to keep track of periods when the weir stage reading was compromised.

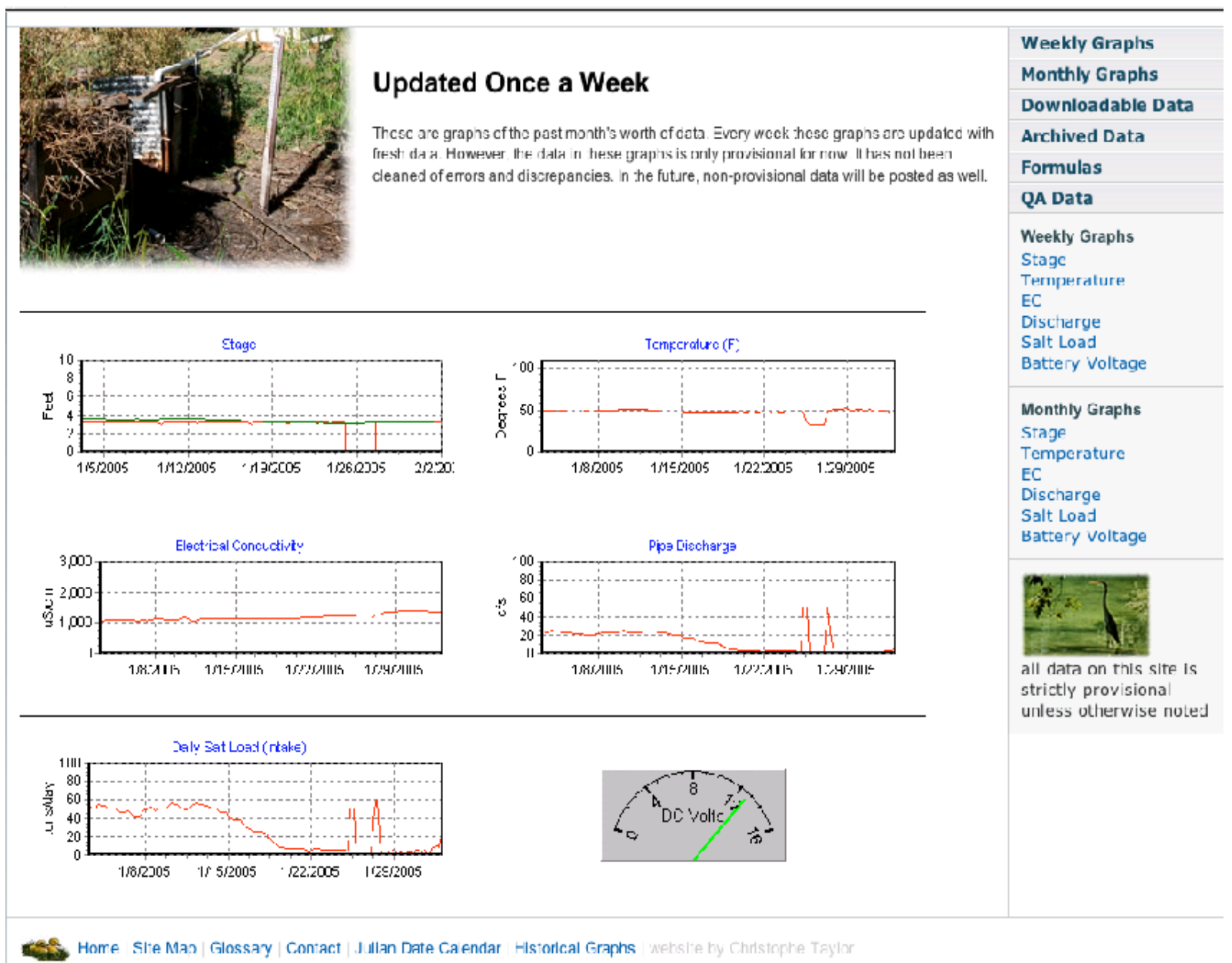

Figure 2.10. Moffit Drain monitoring site in the SLNWR. 
The site specifics for the Moffit Drain monitoring station are shown below in Table 2.3.

Table 2.3. Moffit Drain monitoring station specifications

\begin{tabular}{|l|l|}
\hline Site Summary & $\begin{array}{l}\text { Moffit is a minor drainage outlet draining seasonal wetlands } \\
\text { in both the san Luis and West Bear Creek units. }\end{array}$ \\
\hline Power & Solar Panel with 12-volt battery \\
\hline Datalogger & CSI 10X Datalogger \\
\hline EC Sensor & CSI temperature compensated EC probe \\
\hline Flow Measurement & $\begin{array}{l}\text { Primary flow measurement is a weir structure with a Design } \\
\text { Analysis H350XL smart gas bubbler system which measures } \\
\text { stage over the weir boards. Secondary system is a } \\
\text { STARFLOW acoustic Doppler sensor manufactured by } \\
\text { Omnidata. Sensor estimates velocity and stage which is used } \\
\text { to determine flow cross-sectional area in the culvert }\end{array}$ \\
\hline$\bullet \quad$ Depth & $\begin{array}{l}\text { Smartgas bubbler stage above orifice and STARFLOW } \\
\text { pressure sensor in body of AVM }\end{array}$ \\
\hline Telocity & STARFLOW acoustic sensor \\
\hline Telecommunications & GOES telemetry \\
\hline
\end{tabular}

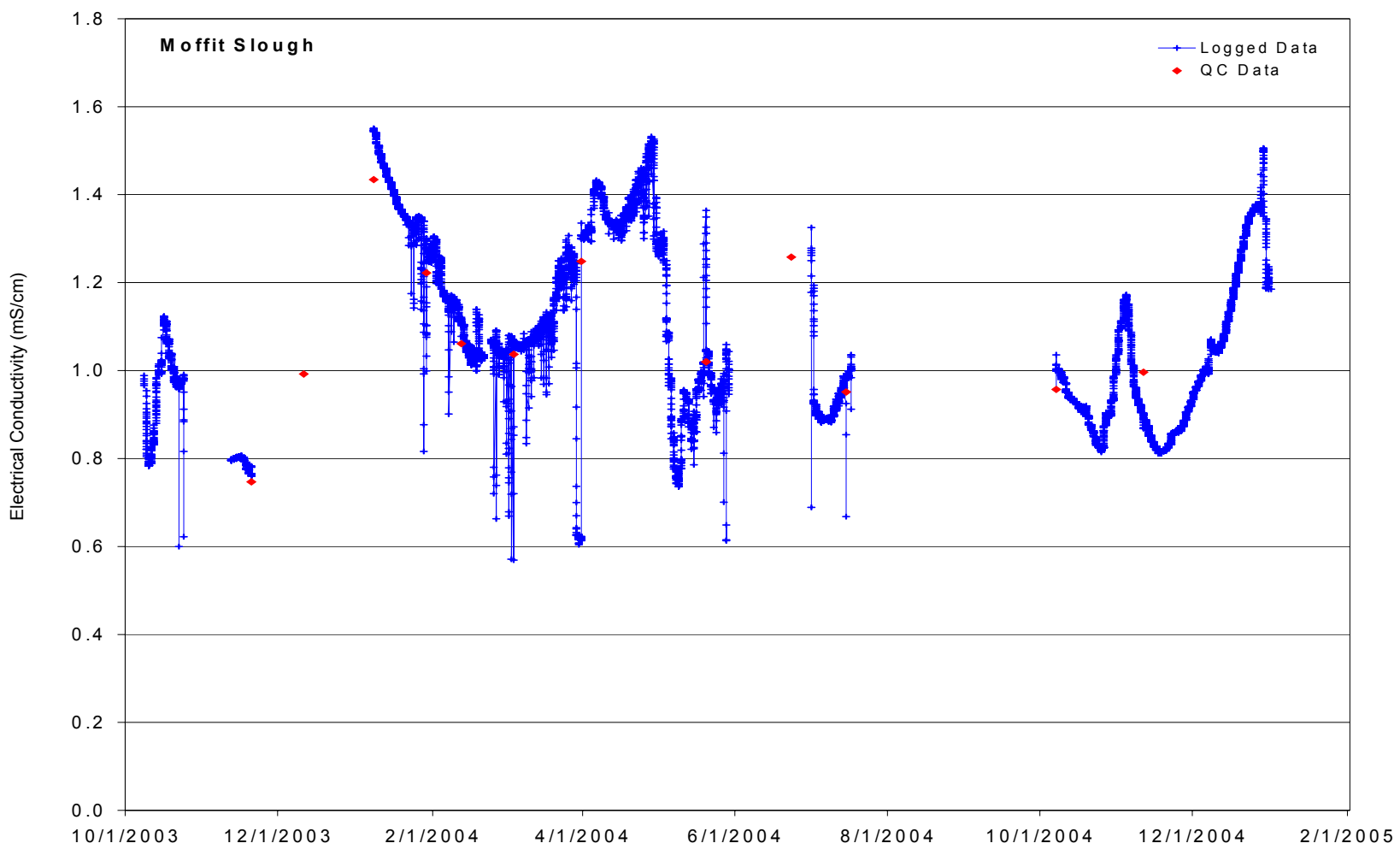

Figure 2.11 Electrical conductivity $(\mathrm{mS} / \mathrm{cm})$ at Moffit Drain in the SLNWR 


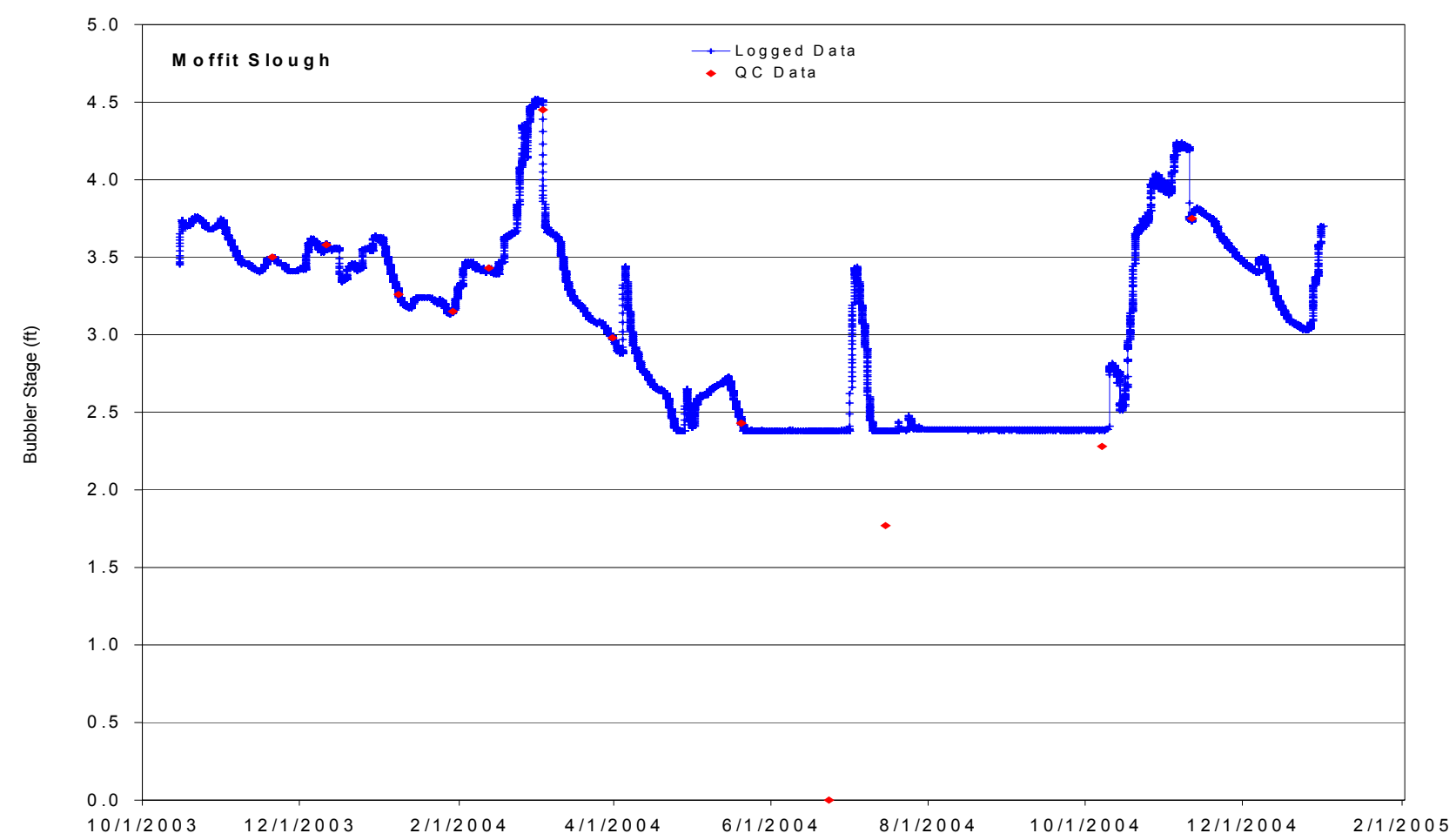

Figure 2.12. Bubbler stage (ft) at Moffit Drain in the SLNWR : 10/1/2003 - 2/1/2005

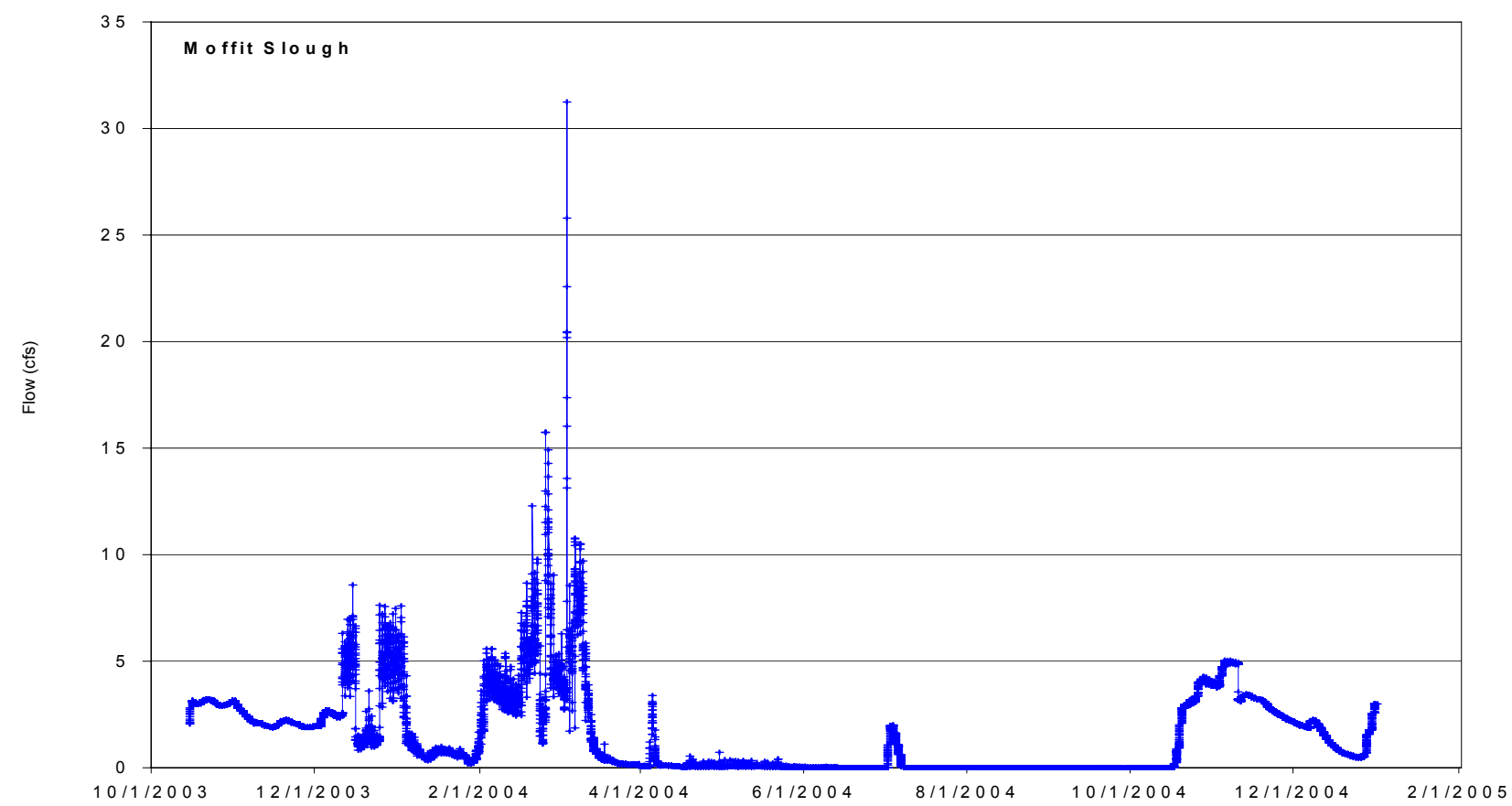

Figure 2.13 Estimated flow (cfs) at Moffit Drain in the SLNWR : 10/1/2003 - 2/1/2005 


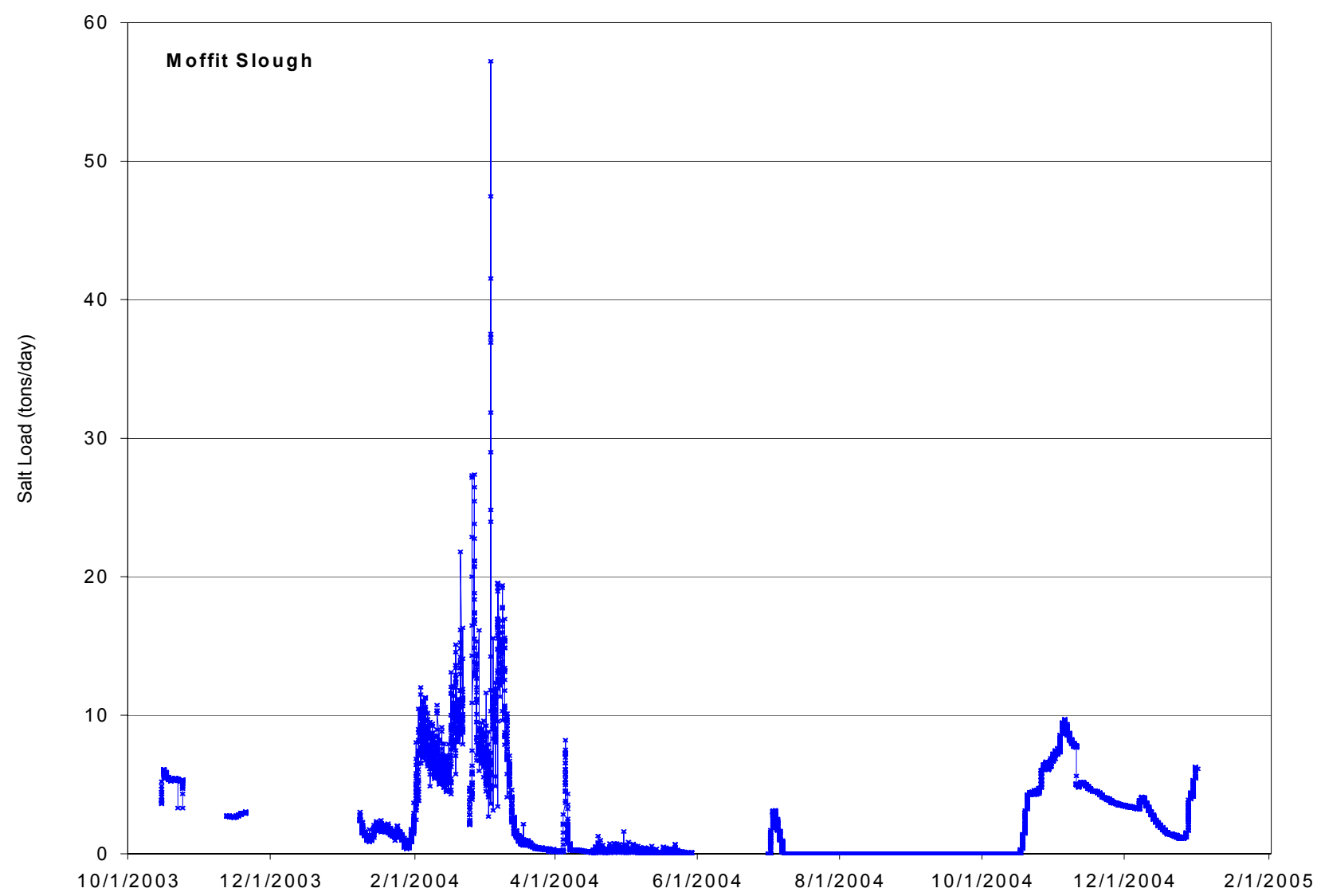

Figure 2.14 Estimated salt load (tons/day) at Moffit Drain in the SLNWR: 10/1/2003 $2 / 1 / 2005$

\subsubsection{Analysis}

The electrical conductivity at Moffit Drain shows a number of periods during the typical season when there is no drainage from the seasonal wetlands upslope and hence the electrical conductivity sensor is in contact with the atmosphere. During those periods when the electrical conductivity sensor is immersed the electrical conductivity shows much more variability than the other sites. Unlike the other sites, there is no drainage reservoir upstream of the control structure, which acts as a buffer to water quality - incoming water must mix with the ponded water before flowing through the drain outlet. Moffit Drain electrical conductivity is therefore more sensitive to the various upstream contributing sources. Since there are several wetland impoundments that feed into Moffit Drain, rainfall runoff, and 
operational spill during flood-up and irrigation can all cause short episodes of drainage with electrical conductivity similar to the water quality of the supply water. Electrical conductivity measured at Moffit Drain ranges in quality from $600 \mathrm{uS} / \mathrm{cm}$ (supply water quality) to almost 1,600 uS/cm. Even at 1,600 uS/cm this drainage water is of higher quality than the drainage at Deadman Slough or Mallard Slough.

Flow at Moffit Drain is episodic with the highest flow volumes during the spring drawdown period. The flow peaked at $30 \mathrm{cfs}$ in mid-March, which is more than the culvert is designed to handle. This may be an artifact of a beaver dam breaking or the clearing of accumulated debris at the control structure - which would have produced a short duration pulse of exceedingly high velocity. 


\subsection{Deadman Slough Drain}

Deadman Slough drain is located at the end of Deadman Slough along the fence line between the San Luis and West Bear Creek Units of the SLNWR and provides the majority of surface drainage for the San Luis Unit. The reservoir above the weir structure acts as both a drainage sump and a pool from which surface water diverted from Salt Slough can be stored before it is lifted into the West Bear Creek surface water distribution system. Water hyacinth and debris are a major problem at this monitoring station. The narrow width between the weir boards and the culvert wall, the ever present woody debris and the high stage in Salt Slough relative to the outlet, conspired to make installation of the STARFLOW acoustic sensor impossible. Although stage measurements made by the"Smart Gas" bubbler system were of good accuracy, occasional high flow events produced elevated stage which crested the second weir board, increasing the effective weir length of the control structure. This made accurate flow measurement using the weir alone, impossible. Interpretation of both the flow and EC readings could be compromised by diversion flows from Salt Slough which could mix with drainage. Weir board alteration was not well documented and only noted during site visits of the field data quality assurance further compromising measurement.

\section{Monthly Graphs}

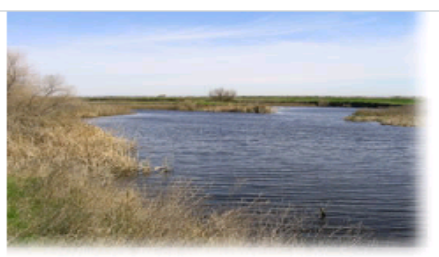

\section{Updated Once a Week}

These are graphs of the past morth's worth of data. Every 'week these graphs are updated with fresh data. Ho'vever, the cata in the se graohs is cnly provisional fo' now. l: has nct been cteanted of etrrors and discrepances. In the uture, nor-provisicnal data vill be posled as well
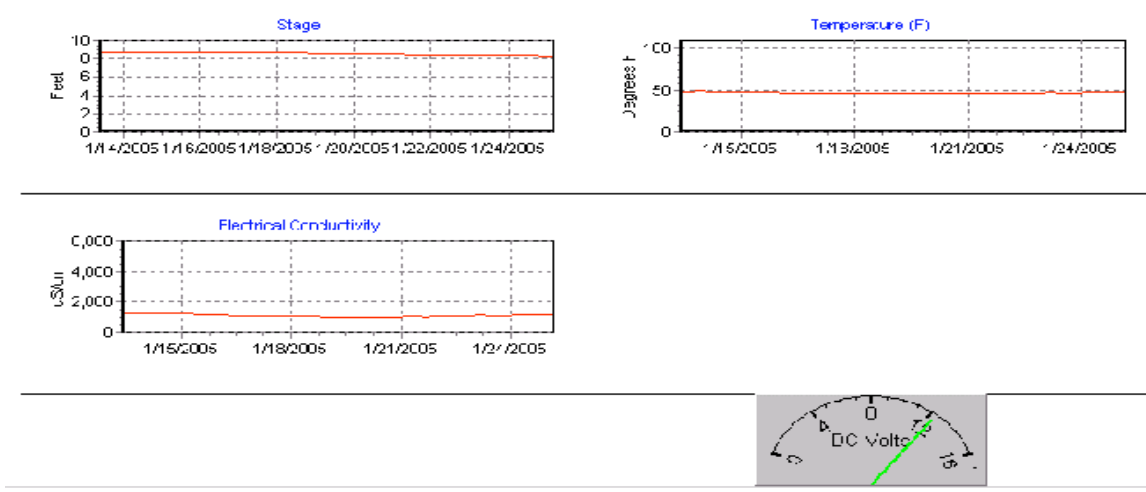

Home | Site Mar | Gilossary | Contact | .Julian Date Calenciar | Historical Girans

Weekly Graphs Monthly Graphs Formulas

QA Data Weekly Graphs Stage Temperature Battery voltage Monthly Graphs Stage EC Battery voltage

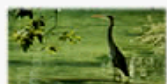
all data on this site is strictiy rimvisional unless otherwise noter

Figure 2.15 Deadman Slough drainage monitoring site in the SLNWR. 
The site specifics for the Deadman Slough monitoring station are shown below in Table 2.4.

Table 2.4 - Deadman Slough drainage monitoring station specifications

\begin{tabular}{|l|l|}
\hline Site Summary & $\begin{array}{l}\text { Deadman Slough is the major drainage conveyance of the San } \\
\text { Luis Unit of the SLNWR. The reservoir at the end of Deadman } \\
\text { Slough serves as both a drainage collector and a pool from } \\
\text { which water diverted from Salt Slough can be lifted into the } \\
\text { supply canals that serve West Bear Creek. }\end{array}$ \\
\hline Power & Solar Panel with 12-volt battery \\
\hline Datalogger & CSI 10X Datalogger \\
\hline EC Sensor & CSI temperature compensated EC probe \\
\hline Flow Measurement & $\begin{array}{l}\text { Primary flow measurement is a weir structure with a Design } \\
\text { Analysis H350XL smart gas bubbler system which measures } \\
\text { stage over the weir boards. Secondary system is a STARFLW } \\
\text { acoustic Doppler sensor manufactured by Omnidata. Sensor } \\
\text { estimates velocity and stage above the sensor. The } \\
\text { STARFLOW sensor could not be installed because of the } \\
\text { configuration of the weir structure and high stage in Salt Slough }\end{array}$ \\
\hline \multicolumn{1}{|c|}{ Depth } & Smartgas bubbler stage above orifice \\
\hline Velocity & \multicolumn{2}{|c|}{} \\
\hline Telecommunications & GOES telemetry \\
\hline
\end{tabular}

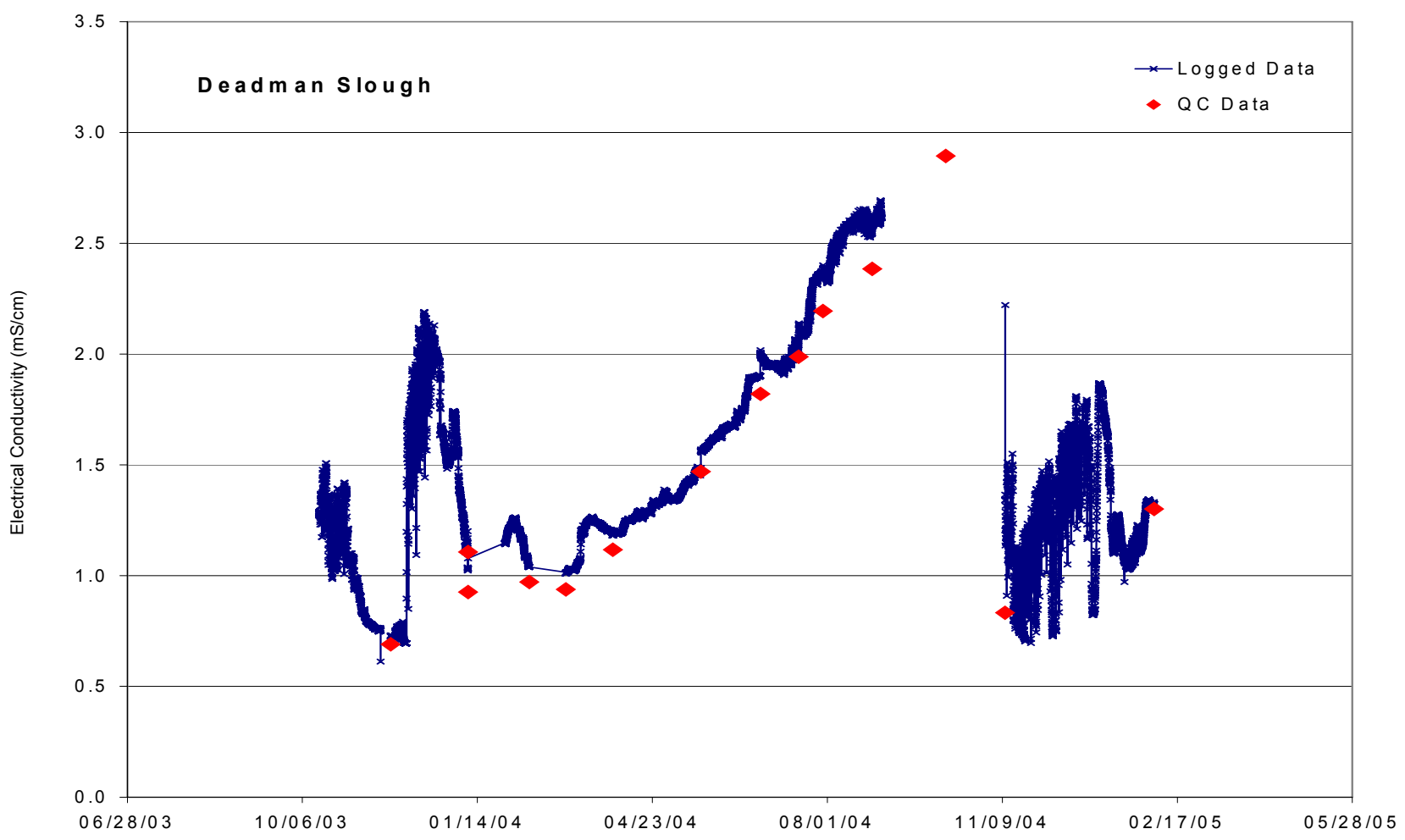

Figure 2.16 Electrical conductivity $(\mathrm{mS} / \mathrm{cm})$ at Deadman Slough drainage monitoring station in the SLNWR 


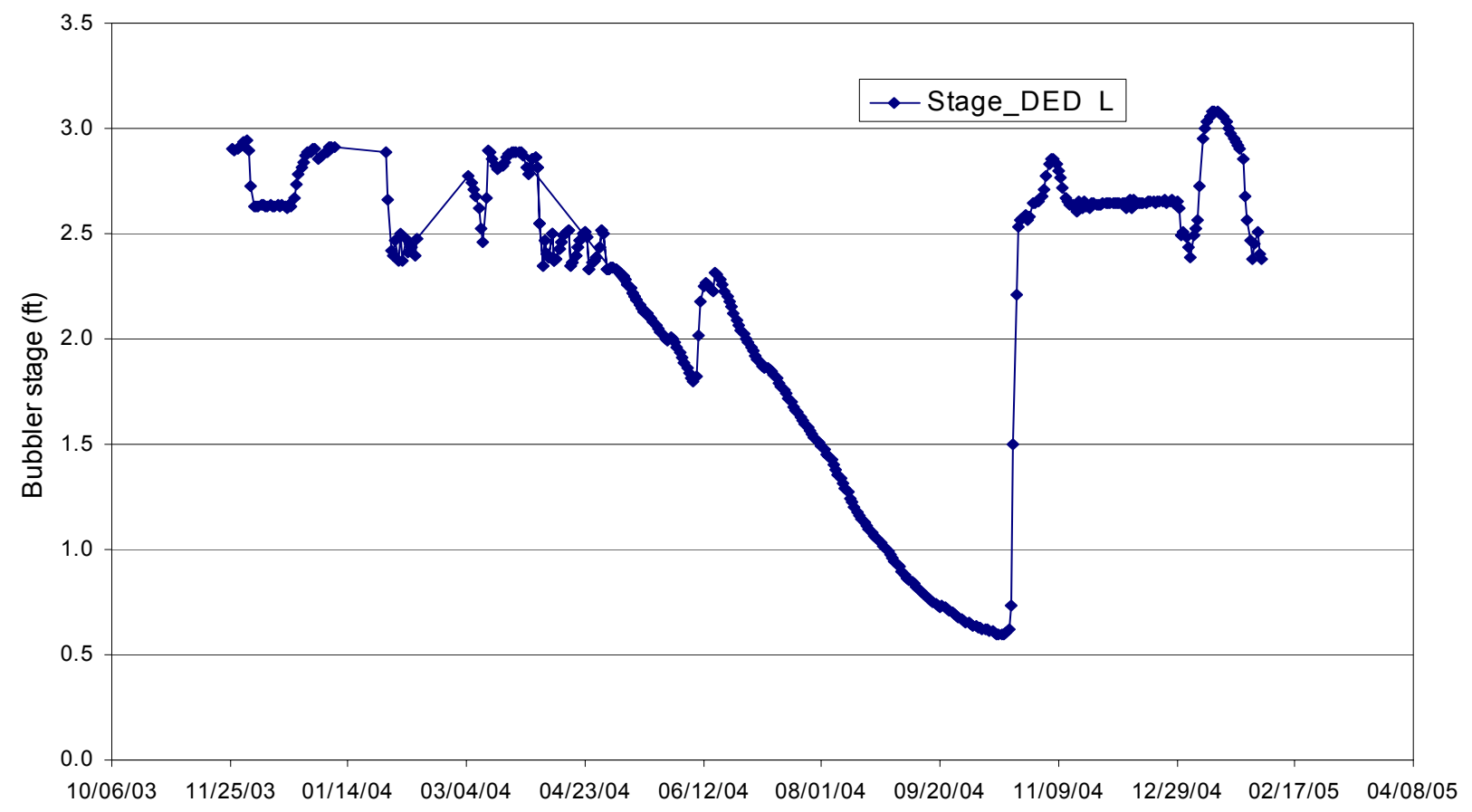

Figure 2.17. Stage reading (ft) at Deadman Slough drainage monitoring station in the SLNWR.

\subsubsection{Analysis}

Interpretation of the monitoring data collected at Deadman Slough is complemented by the fact that the site acts as both a staging reservoir for Salt Slough diversions that are pumped into the West Bear Creek conveyance system and holds drainage water that moves through the outlet weir to Salt Slough. Changes in weir board settings in either or both outlet structures can cause rapid fluctuations in drainage discharge. The electrical conductivity shows a fairly linear increase in concentration from early April through late September when fresh water inflow from during seasonal wetland flood-up dilutes drainage reservoir electrical conductivity from a high of $3,000 \mathrm{uS} / \mathrm{cm}$ to a low of $700 \mathrm{uS} / \mathrm{cm}$ (close to the concentration of Mendota Pool supply water. The 2005 data shows a lower overall drainage electrical conductivity - most likely due to the dilution effect of the higher than usual seasonal precipitation. Figure 2.17 shows a fairly dramatic lowering of the weir boards during the summer months allowing the reservoir behind the control structure to be drained. 


\subsection{Salt Slough at Wolfsen Road}

The Salt Slough at Wolfsen Road station is located to the east of the road bridge across Salt Slough approximately 1.5 miles from the Wolfsen Road turnoff from State Highway 165. The station was installed to provide the means of developing a salinity mass balance for the San Luis National Wildlife Refuge when combined with flow and electrical conductivity data from the USGS monitoring on Salt Slough at Lander Avenue. Subtracting the flow volume and salt load estimated from the Wolfsen Road station from the same estimates from Lander Avenue should be equivalent to the net outflow from the Refuge. The San Luis NWR has a water right in Salt Slough and has the ability to divert Salt Slough water through pumping stations located at the south-west corner of the District and at the Deadman Slough intake channel.

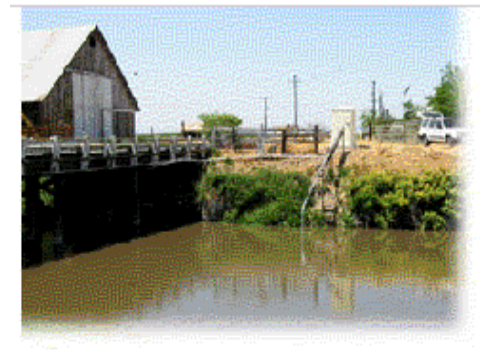

\section{Updated Once a Week}

These are graons cf the past mon-h's wrorth of data. Every week these graphs are ufdated with tresh da:a. Ho'vever the da:a in hese graphs is only orovis onal tor now. li: has rot been

cleaned of errors and ciscreparicies. In the Uture, ron-provisiond da.d sill be posited as viell.
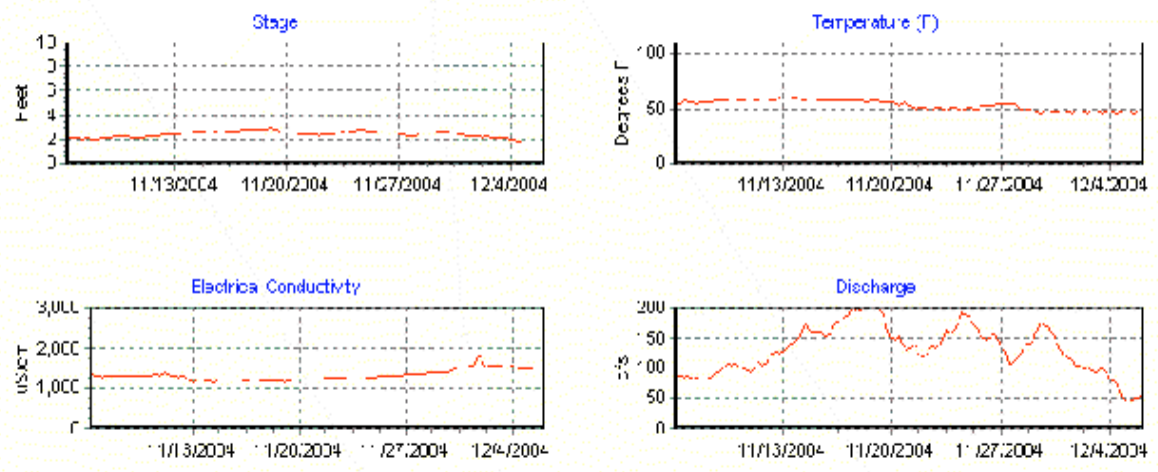

Weekly Graphs

Monthly Graphs

Downloadable Data

Archived Data

Formulas

QA Data

Weekly Graphs

Stage

lemperature

EC

Discharge

Salt Load

Battery Voltoge

Monthly Graphs

Stage

Temperature

FC.

Discharge

Salt Load

Battery voltage

\section{\%.}

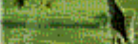

all data on this site is strictly provisional

unless otherwise noted
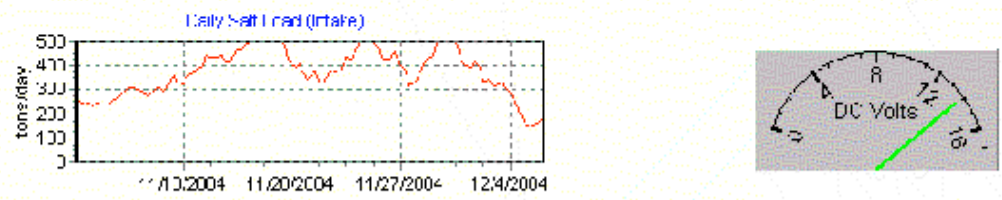

Hone | Site Map Glossary | Contact Julian Date Caendar Historical Grashs

Figure 2.18 Salt Slough at Wolfsen Road monitoring station in the SLNWR 
The site specifics for the Salt Slough at Wolfsen Road monitoring station are shown below in Table 2.5.

Table 2.5 Salt Slough at Wolfsen Road monitoring station specifications

\begin{tabular}{|l|l|}
\hline Site Summary & $\begin{array}{l}\text { S-Lake Drain accounts for roughly 10\% of the drainage flow } \\
\text { from the North Grasslands Water District. }\end{array}$ \\
\hline Power & Solar Panel with 12-volt battery \\
\hline Datalogger & CSI 10X Datalogger \\
\hline EC Sensor & CSI temperature compensated EC probe \\
\hline Flow Measurement & $\begin{array}{l}\text { Primary flow measurement is a weir structure with a Design } \\
\text { Analysis H350XL smart gas bubbler system which measures } \\
\text { stage over the weir boards. Secondary system is a } \\
\text { STARFLOW acoustic Doppler sensor manufactured by } \\
\text { Omnidata. Sensor estimates velocity and stage above the } \\
\text { sensor. }\end{array}$ \\
\hline$\bullet \quad$ Depth & $\begin{array}{l}\text { Smartgas bubbler stage above orifice and STARFLOW } \\
\text { pressure above acoustic sensor }\end{array}$ \\
\hline \multicolumn{1}{|c|}{ Velocity } & STARFLOW acoustic sensor \\
\hline Telecommunications & GOES telemetry \\
\hline
\end{tabular}

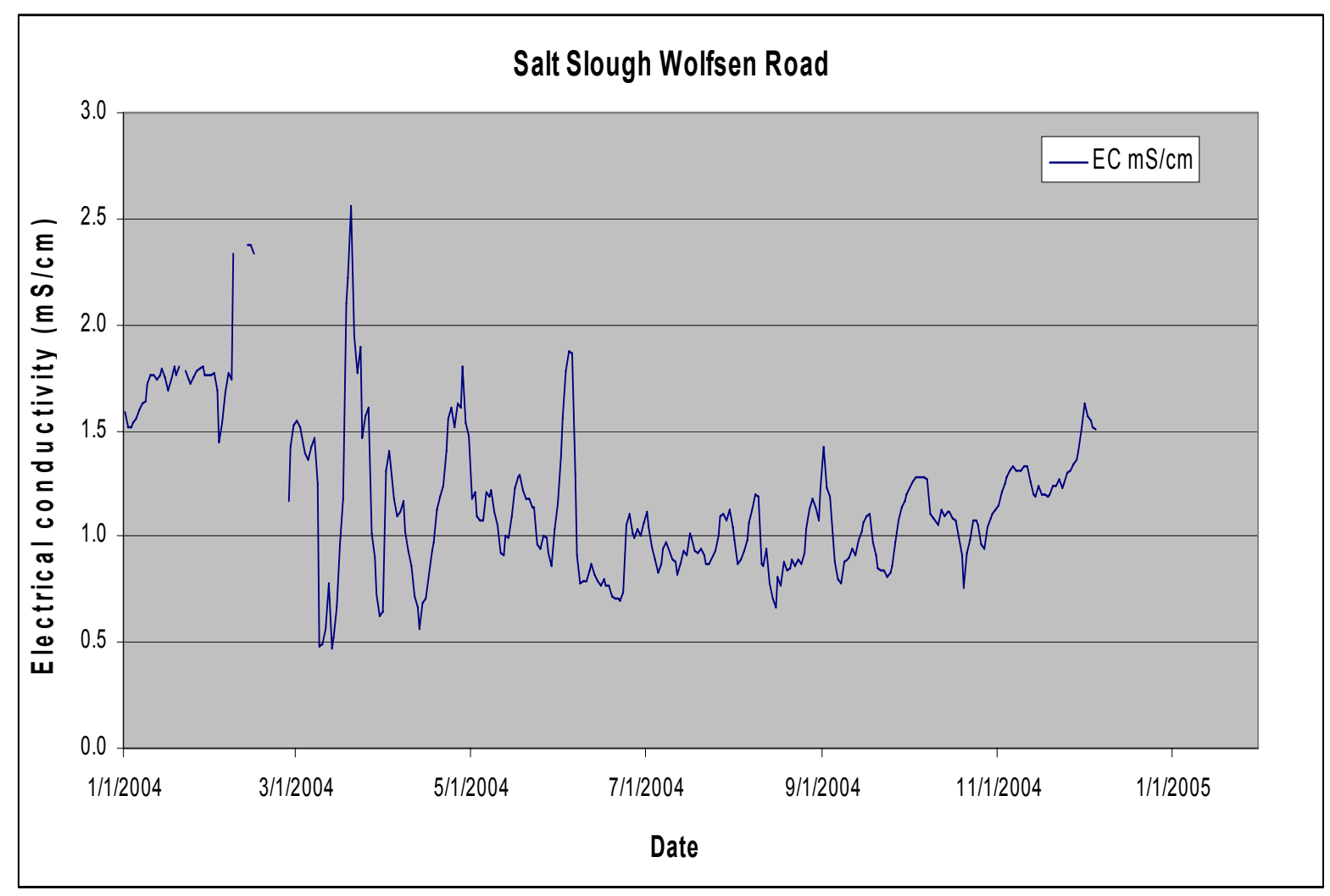

Figure 2.19 Electrical conductivity $(\mathrm{mS} / \mathrm{cm})$ at Salt Slough Wolfsen Road monitoring station 


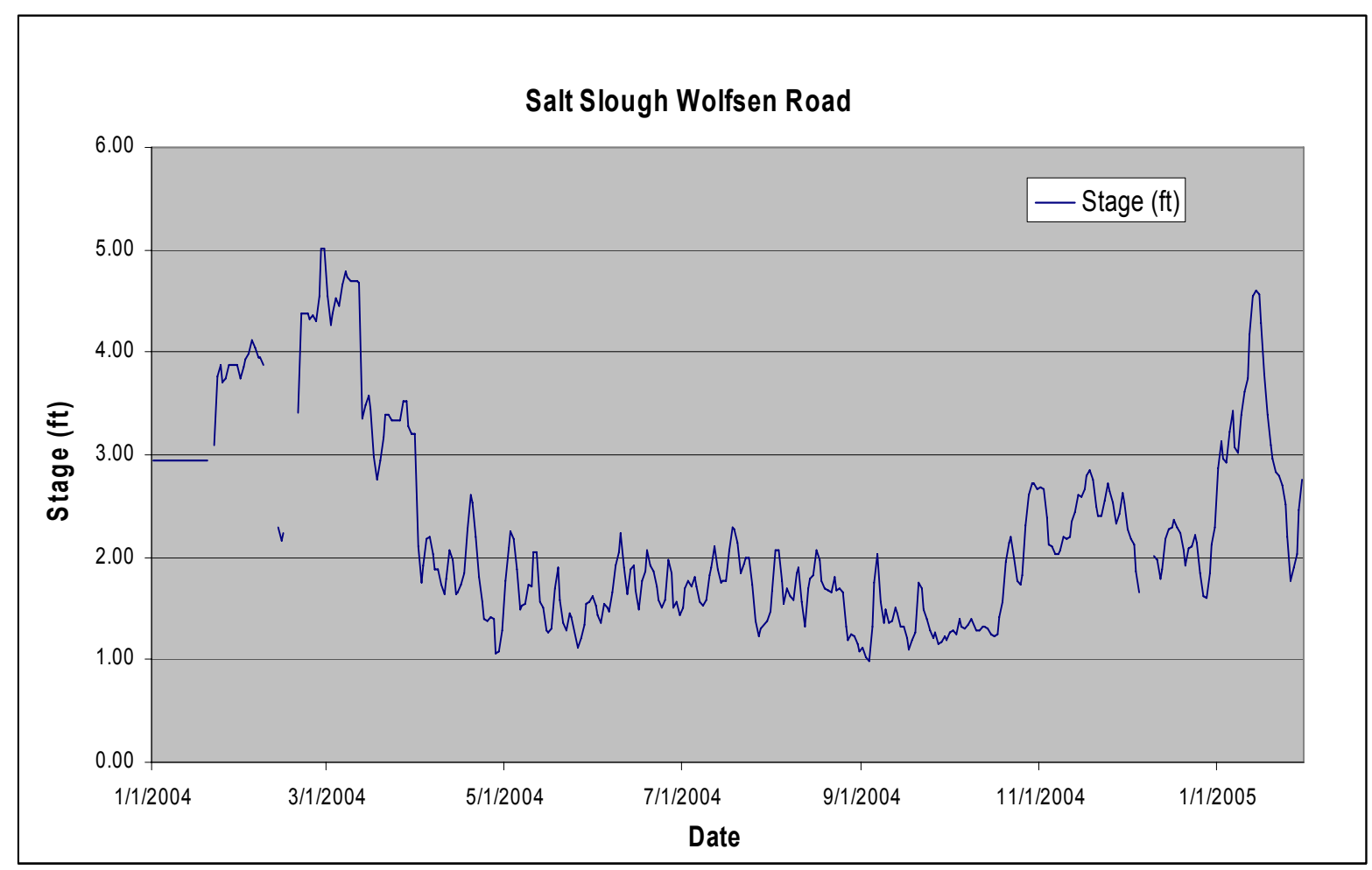

Figure 2.20 Measured stage (ft) at Salt Slough Wolfsen Road monitoring station

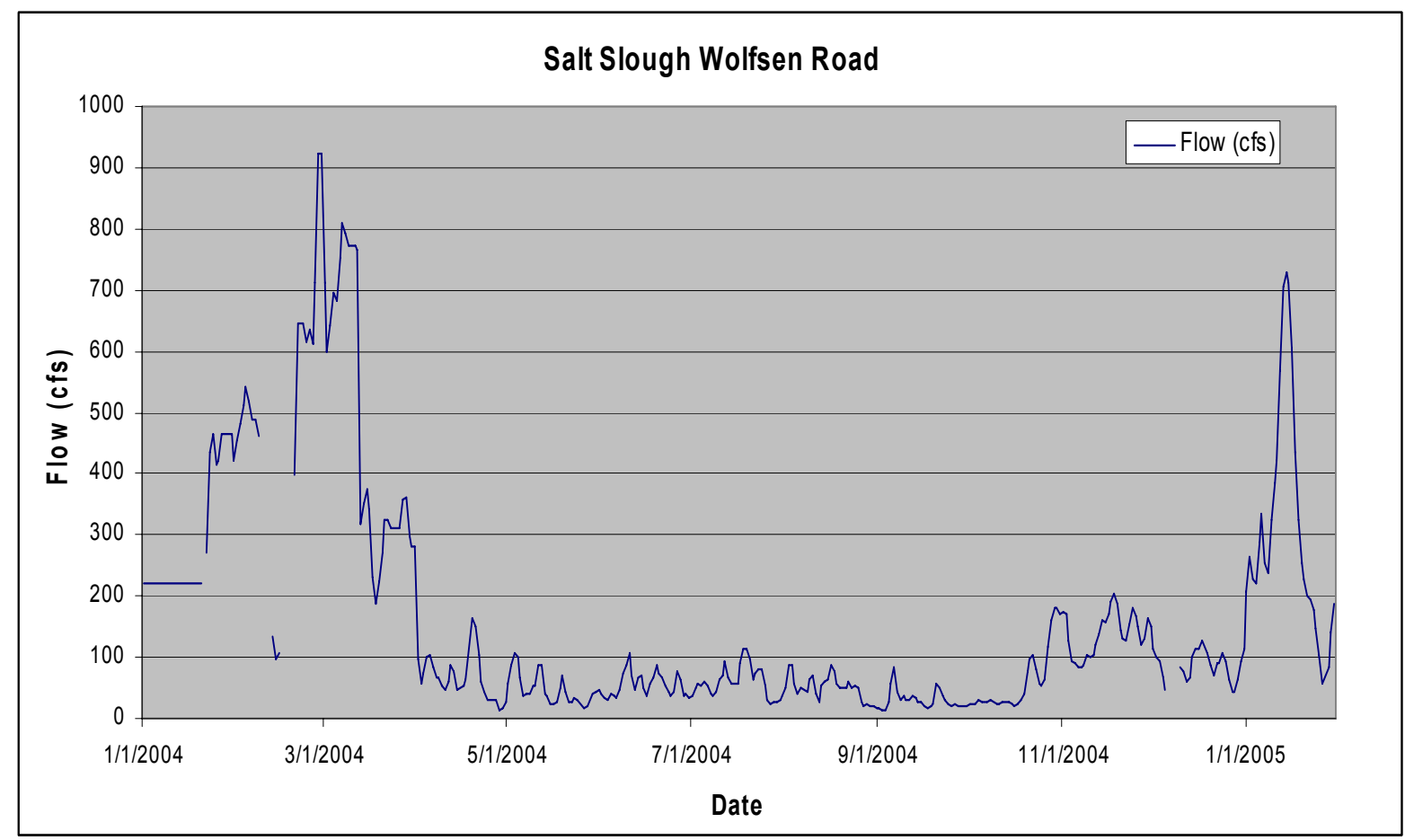

Figure 2.21 Estimated flow (cfs) at Salt Slough Wolfsen Road monitoring station 


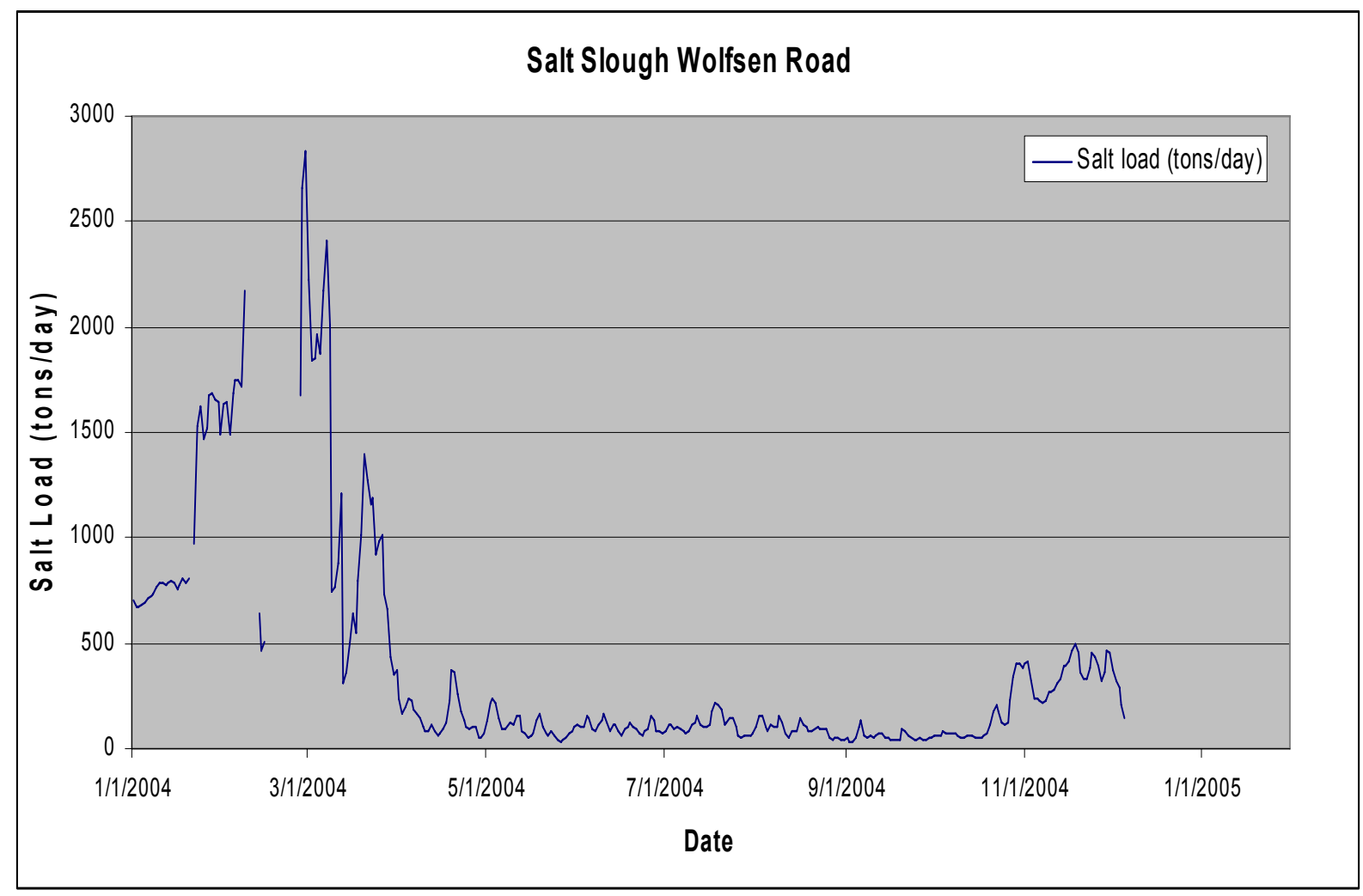

Figure 2.22 Estimated salt load (tons/day) at Salt Slough Wolfsen Road monitoring station

\subsubsection{Analysis}

Salt Slough water quality fluctuates about a mean of approximately $1000 \mathrm{uS} / \mathrm{cm}(1.0 \mathrm{mS} / \mathrm{cm})$ with a high of $2500 \mathrm{uS} / \mathrm{cm}$ and a low of $500 \mathrm{uS} / \mathrm{cm}$. Salt Slough drains a large area of that includes a large portion of the Exchange Contractor irrigation and water districts of San Luis Canal Water District (SLCWD) and the Central California Irrigation District (CCID) as well as the South Grassland Water District, the Los Banos Wildlife Management Area and the San Luis and West Bear Creek Units of the San Luis National Wildlife Refuge Complex. The variability of water quality at this site is largely due to the variety of land uses that are discharging to the Slough at any one time. Flow at the Salt Slough Wolfsen Road monitoring station peaked in late February, early March, 2004 when a combination of wetland return flows and rainfall runoff from agricultural land produced flow in excess of $900 \mathrm{cfs}$. Much of the salt load that is measured by this station is recorded between mid-February and the 
beginning of April. The highest salt load of 2837 tons/day was recorded on February 29, 2004.

The Salt Slough Wolfsen Road monitoring station was installed ostensibly to check on the salt balance of the San Luis Unit within the San Luis National Wildlife Refuge Complex. By subtracting daily salt load estimates at the USGS Salt Slough monitoring station along Highway 165 http://cdec.water.ca.gov/cgi-progs/staMeta?station_id=SSH from daily salt load estimates from the Salt Slough Wolfsen Road monitoring station we had hoped to be able to validate our monitoring site data at Mallard, Moffit and Deadman Slough drains. Several factors prevented this from occurring:

1. Although the three sites captured the majority of the drainage flows entering the San Joaquin River between Wolfsen Road and the USGS Salt Slough monitoring station - some minor drainage flows were not accounted for.

2. There is ungauged surface agricultural drainage which discharges into Salt Slough less than 100 yards downstream from the Wolfsen Road station and upstream of the southern boundary of the San Luis Unit of the SLNWR Complex. Salt load associated with this inflow would need to be subtracted from the salt load recorded at the USGS salt Slough monitoring station.

3. There was an incomplete record of flow at all stations - the most severe being at Deadman Slough where it proved impossible to obtain a good flow rating at the outlet structure. The Water Master at the San Luis Unit has suggested that this structure be redesigned and replaced with a more suitable structure for continuous flow and electrical conductivity measurement. 


\subsection{Monitoring Network}

The five wetland water quality monitoring stations described above are connected through a real-time network. The monitoring stations collect and store wetland drainage flow, EC and temperature data. These data are then distributed either via land line to a central database, or through Geostationary Operational Environmental Satellite (GOES) telemetry to the NESDIS data repository in Wallops, Washington. The downloaded information is compiled and errorchecked using proprietary data management software and parsed standard report formats. The data are presented on the Internet in graphical and tabular formats. The real-time data is updated weekly, and is accessible at the following website :

http://esd.lbl.gov/people/nwquinn/Grassland_website/grasslandwd/index.html.

These data are used in two ways. Their primary use is to help wetland managers monitor and manage salt loads present in seasonal drainage. The data is also useful for calibration of a real-time wetland water quality model developed for the SLNWR wetlands. The utility of the model is to develop a better understanding of salinity mass balance in these wetlands - once calibrated the model can assist future scheduling of wetland drainage.

\subsection{Discussion}

The real-time wetland water quality monitoring project has demonstrated the feasibility of operating and maintaining a network of telemetered flow and water quality stations in drainage canals discharging into the San Joaquin River. In addition to providing continuous real-time flow and water quality data for use in adaptive salinity management the data has also proved useful in the development of a wetland water quality model. This model provides tributary input to the San Joaquin River Input Output Daily Model (SJRIODAY) operated by the SJRMP Water Quality Subcommittee. The SJRMP Water Quality Subcommittee was funded until the year 2002 to enhance the existing network of real-time monitoring stations along the main-stem of the San Joaquin River and to improve the coordination of agricultural return flows and scheduled east-side fish flows (Quinn et al. 1997).

The real-time flow and water quality monitoring data from key locations in the NGWD helps provide decision support to wetland managers scheduling drawdowns and irrigations. Mean 
daily salinity loading from the NGWD is calculated from the monitoring data and is compared with the daily assimilative capacity determinations on the SJR. The GWD now can evaluate wetland discharge opportunities during the spring months (when the majority of saline discharges from seasonal wetlands occur) and make relevant decisions based upon the real-time data. In addition, this network can provide the backbone for further monitoring efforts to help alleviate other problems within the San Joaquin Basin such as elevated concentrations of nitrates, dissolved organic carbon, and dissolved oxygen. 


\section{CHAPTER 3 DEVELOPMENT AND APPLICATION OF WETLAND WATER QUALITY MODELS FOR OPERATIONS SIMULATION AND LONGER TERM PLANNING}

\subsection{Introduction}

A wetland water quality model WETMANSIM was developed for the seasonal wetlands in the San Joaquin River Basin (SJR). The model was applied to the wetlands of the Grassland Ecological Area (GEA) including the San Luis National Wildlife Refuge. The model is an extension of the WWQM model, herein called WETDWQM, developed by Hanna and Quinn (Quinn et al., 2004) as part of the Grassland Water District real-time adaptive wetland water quality management research project. This chapter provides a description of the daily WETDWQM model, how it was applied in the Grassland Water District study how features of this model were incorporated into the monthly WETMANSIM v1.0 model for the San Luis National Wildlife Refuge.

The WETDWQM, a salt and water balance box-type model, utilizes wetland management practices, daily climatic data, land use values, and daily surface water supply data to forecast wetland drainage salinity levels. These forecasts, when used in conjunction with assimilative capacity forecasts for salts in the SJR, can assist wetland managers to better coordinate salt loading from seasonal wetland areas to the SJR. The main objective of the WETDWQM is to simulate and forecast seasonal wetland salinity levels in the SJR Basin. The model also can be used to compare these wetland salt loads with assimilative capacity forecasts for salts in the SJR. This linkage allows the user to estimate the effects of salt loading to the SJR during spring wetland drawdown (February-April), and hence make better decisions regarding salt export. A description of the WETDWQM application to the Grassland Water District (WETDWQM-GWD) is included in this document as an example of how it might be applied to the San Luis National Wildlife Refuge.

The WETDWQM-GWD was successfully applied to the seasonal wetlands of the Northern Division of the GWD (NGWD) during the spring 2003 drawdown season. The NGWD contains the majority of the private seasonal duck, land and cattle clubs in the GWD - all these lands drain into Los Banos Creek and Mud Slough. The model was calibrated and 
validated continually using actual wetland drainage salinity data collected by the monitoring stations in the NGWD. This application assisted the GWD water master in choosing optimal drawdown dates and to improve coordination of salt export from the wetlands with individual duck club managers.

\subsection{Background}

The California Regional Water Quality Control Board (CRWQCB) is the policing arm of the U.S. Environmental Protection Agency. The Central Valley Regional Water Quality Control Board regulates water quality in the SJR. Among other constituents of concern, the CRWQCB regulates salinity discharges from point and non-point sources. Using a procedure known as the Total Maximum Daily Load (TMDL), the CRWQCB can allocate the assimilative capacity of a water body such as the SJR for salts and other pollutants among watershed sources in order to maintain water quality. However, if watershed sources develop the ability to better coordinate their pollutant exports through real-time management, more management flexibility is possible. The standard TMDL approach offers little flexibility and is restrictive since allowable loads are fixed and typically based on a $10 \%$ exceedence hydrology, a maximum specified frequency of violation and an arbitrary safety factor. Under real-time management much larger mass loading of salt could be exported during periods of high assimilative capacity, provided water quality objectives are not exceeded. Although, during periods of low assimilative capacity for salts in the SJR, exports would need to be curtailed, on aggregate annual allowable salt loading to the River would be higher. The management of sources of salt load through real-time control requires the development of flow and water quality monitoring systems, adaptive wetland management strategies and a higher level of coordination with other water and drainage districts in the Basin. For the realtime concept to work, drainage discharges from west-side agricultural sources and east-side reservoir releases must be coordinated.

\subsection{Wetland Management}

Wetlands in the SJR Basin seasonally contribute salinity to the SJR, are flooded in the fall and drawn down in the spring to mimic the natural wet-dry cycle these wetlands once experienced. As the flooded season progresses, the salinity in the wetlands increases. This 
salinity increase is due to many different factors, foremost among them the quality of the water supply and secondly the further concentration of the salts from evaporative and evapotranspirative losses. Other factors contributing to the salinity increase that are harder to quantify are groundwater infiltration, bird usage, and water management at the regional level.

Management of wetland drainage, through scheduling of releases to coincide with periods of SJR assimilative capacity, can help improve SJR water quality. However, these actions may need to be considered relative to potential biological wetland impacts of changes to traditional wetland management practices. Seasonal wetlands in the SJR Basin are intensively managed to provide optimal conditions for waterfowl habitat. One set of wetland "best-management practices" (BMPs) is presented in the publication A Guide to Wetland Habitat Management in the Central Valley (Smith et al., 1995). This guide was a cooperative effort between the California Department of Fish and Game and the California Waterfowl Association. In the guide water management plans for optimal productivity are presented for three desirable moist-soil plants - smartweed (Polygonum punctatum), swamp timothy (Heleochloa schoenoides), and watergrass (Echinochloa crusgalli). According to the guide, wetland managers should initiate wetland drawdown between the months of February and April. In practice, wetland mangers try to drain wetlands earlier when it is unseasonably warm or dry, and later in the season when it is unseasonably cool or wet (Table 3.1). In many instances boards are pulled on individual duck clubs to initiate drainage for a variety of reasons including tradition, a desire to move cattle on to the land and convenience.

Wetland salinity levels are highest during the wetland drawdown period. In addition, peak assimilative capacity for salts in the SJR typically occurs between the months of January and March (Figure 3.1). This time period is often earlier than the traditional wetland drawdown period (February-April). Hence, the response of wetland habitat conditions to an altered drawdown regime must be assessed. It is possible that earlier experimental drawdown may make food sources available to wildlife without negatively affecting the wetland vegetation community and plant species diversity, benefiting both wildlife and the water quality of the San Joaquin River. 


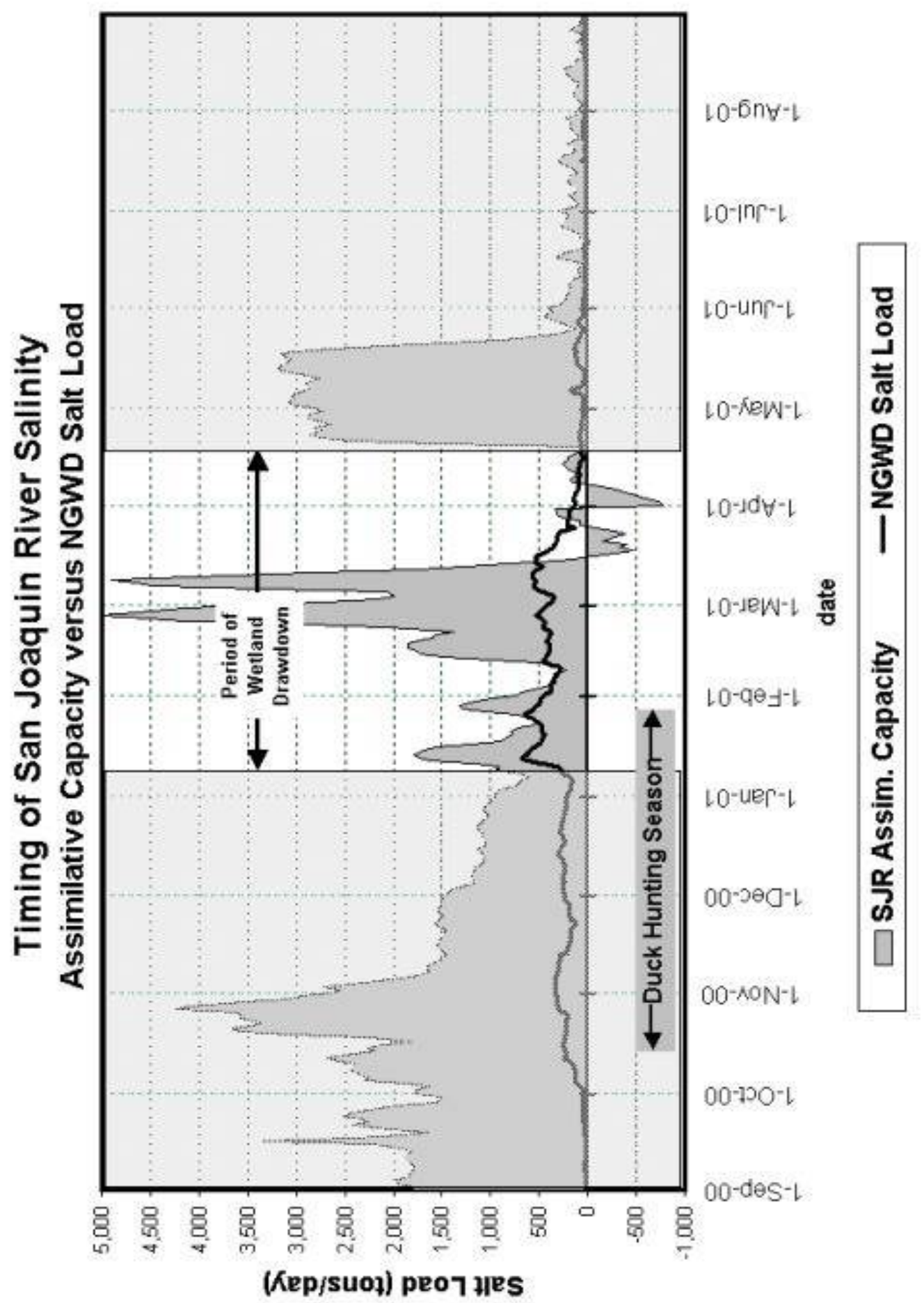

Figure 3.1. Scheduling of San Joaquin River salinity, assimilative capacity versus salt loading from private wetlands in North Grassland Water District (NGWD). The peak NGWD wetland drainage occurs between March and mid-April, a little earlier than drainage from the San Luis National Wildlife Refuge. 
Table 3.1. Wetland Management Decision Tree

\begin{tabular}{|lll|c|c|}
\hline \multicolumn{5}{c}{ Theoretical Decision Tree for Wetland Drainage } \\
Moisture Regime & Temp. Regime & Drawdown Type & SJR Assim. Cap. & Conflict \\
\hline Very Dry & Cold & Traditional & Early & $\mathbf{X}$ \\
Very Dry & Normal & Traditional & Early & $\mathbf{X}$ \\
Very Dry & Warm & Early & Early & \\
Dry & Cold & Traditional & Early & $\mathbf{X}$ \\
Dry & Normal & Traditional & Early & $\mathbf{X}$ \\
Dry & Warm & Early & Early & $\mathbf{X}$ \\
Normal & Cold & Late & Average & $\mathbf{X}$ \\
Normal & Normal & Traditional & Average & \\
Normal & Warm & Traditional & Early & \\
Wet & Cold & Late & Late & \\
Wet & Normal & Late & Late & \\
Wet & Warm & Traditional & Average & \\
\hline
\end{tabular}

Note: Conflict refers to the actions associated with wetland drawdown types not coinciding with SJR assimilative capacity.

\subsection{San Joaquin River Management}

Better coordination of agricultural and wetland drainage with reservoir releases of good quality snow-melt water on the east-side of the SJR Basin has been suggested as a means of improving SJR water quality for all beneficial uses (Quinn and Delamore, 1994; Karkoski, Quinn and Grober, 1995; Quinn et al., 1997; Quinn and Karkoski, 1998). Real-time monitoring and management of agricultural drainage and east-side reservoir releases combined with forecasts of assimilative capacity for salinity on the SJR has been successfully demonstrated (Quinn and Karkoski, 1998) Implementation of the strategies discussed in this project builds upon this previous work to help to coordinate seasonal wetland drainage with the assimilative capacity of the SJR.

In 1990, Assembly Bill AB 3603 authorized the creation of the SJRMP, along with an advisory council. The SJRMP covers a regional area along the SJR from Friant Dam downstream through the northern boundary of the South Delta Water Agency and all other tributaries of the SJR up to the first major dam. The major tributaries are the Merced, Tuolumne and Stanislaus Rivers. Minor tributaries include agricultural returns from the east 
and west sides, environmental areas such as the Grassland Wetland Area (primarily Mud and Salt Sloughs) as well as smaller creeks like Orestimba Creek The advisory council was required to identify problems facing the SJR system and prepare a plan that would identify solutions for improvement, restoration, and enhancement of the currently degraded conditions. AB 3603 initiated a consensus-based effort to solve water-use problems within the SJR system.

The SJRMP Water Quality Subcommittee installed and demonstrated a San Joaquin River Real-Time Water Quality Management Network on a pilot scale and used telemetered flow and salinity data and in combination with computer models to simulate and forecast water quality conditions along the lower SJR. The computer model, SJRIODAY, developed by Les Grober (CRWQCB), facilitates interpretation of the raw data collected by the flow and water quality monitoring network (Quinn, 1997). Results of the modeling enables participants to make informed water management decisions regarding the SJR Basin and to eliminate or reduce the frequency of water quality violations, thereby reducing the number and/or magnitude of high quality releases made specifically to meet SJR salinity objectives at the Vernalis compliance point (Quinn and Karkoski, 1998; Grober et al., 1995). Other potential benefits include a reduction in conflicts between reservoir operators, wetland managers, and agricultural drainers in meeting Vernalis salinity objectives; improved SJR and Bay-Delta water quality for agricultural, drinking water, industrial, and recreational beneficial uses; and increased understanding and management of activities that affect SJR water quality .

\subsection{Previous Modeling Approaches}

Watershed modeling is an important tool in integrated basin management. There are an abundance of qualified models developed for hydrologic purposes. However, many do not incorporate water quality (Arnold et al, 1998). If these watershed models are to be used for environmental applications, water quality along with hydrology must be considered. One of the first salt and water modeling projects utilized dynamic simulation of salinity and other water pollutants such as pesticide residues in the Klamath River Basin, California (Woods and Orlob, 1963). Other early modeling efforts included consumptive use equations for water quality parameters in the Sacramento River Basin, California (Woods, 1967); linear 
and multiple regression for salinity impacts on irrigated agriculture in the Lower San Joaquin Basin, California (California Department of Water Resources, 1969); and elemental analyses for salt balances in the Upper Santa Ana River Basin, California (Water Resources Engineers, 1969). Box models for salts and water include mass-balance calculations to estimate TDS and N waste loading from irrigated agriculture (Bay-Valley Consultants, 1974; Tanji, 1977; Aragues et al., 1985); a comprehensive macro-scale simulation/ mathematical model to estimate hydrology and salinity for large catchment basins (U.S. Bureau of Reclamation, 1977) and a dual-type salinity box model for the separate isoclines in the Black Sea (Karaka et al., 1999).

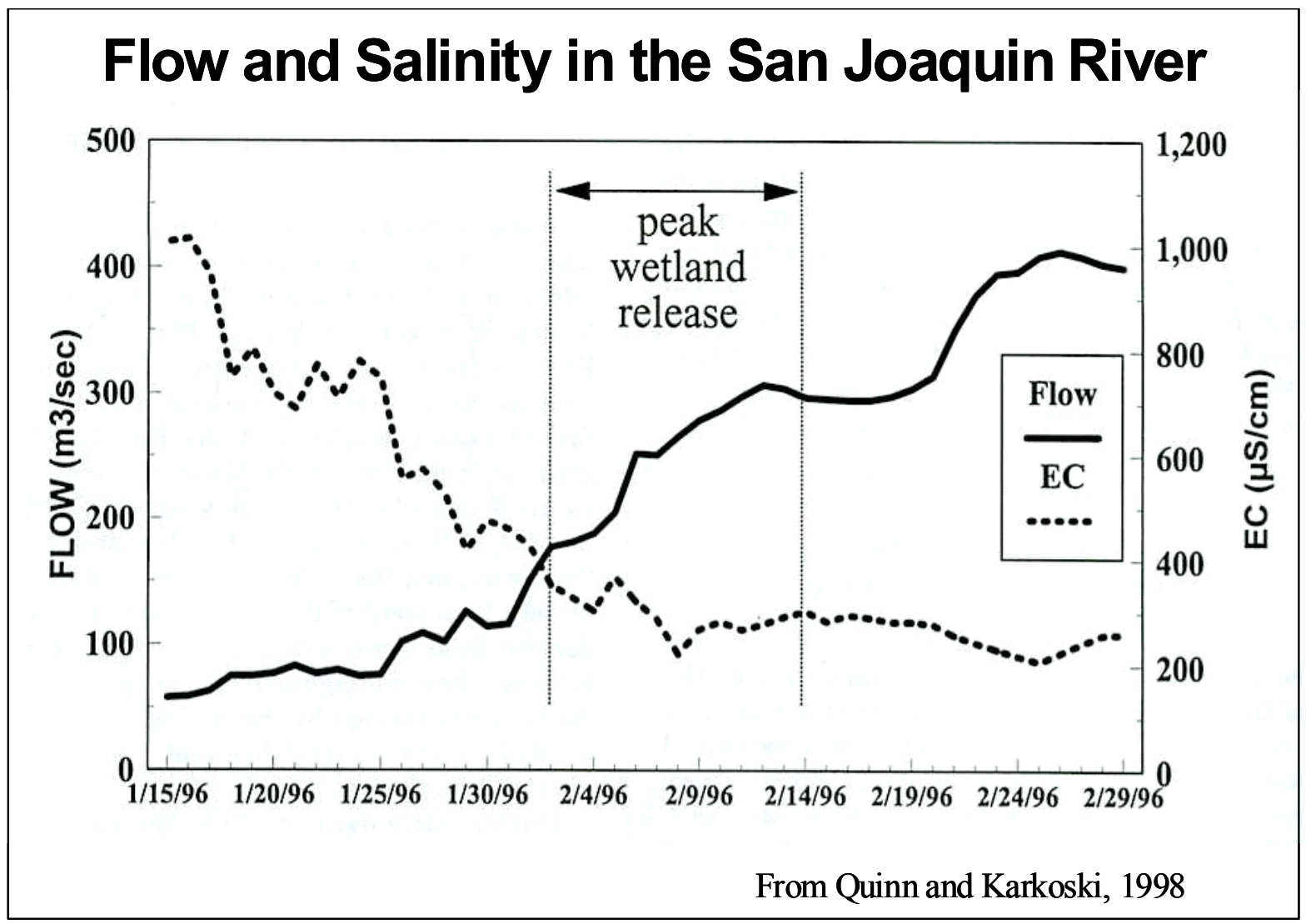

Figure 3.2 Flow and electrical conductivity in the San Joaquin River between January 15 and March 1, 1996.

More recently, modeling attempts have focused on entire systems. A basin-scale modeling is described as a water resource planning tool in New Zealand watershed Basins (Cooper and Bottcher, 1993). The model, BNZ (Basin-New Zealand), utilizes algorithms similar to those 
in CREAMS (Chemicals, Runoff, and Erosion from Agricultural Management Systems) developed by the U.S. Department of Agriculture (Knisel, 1980). Several research studies applied dual type box models to describe the layered salinity flux in the Black Sea (Karaka et al., 1999). Recent studies have compared several methods for training artificial neural networks for use in salinity forecasting and other aspects of water resources planning and management.

The literature contains several examples of applying real-time data acquisition to planning and operations modeling. Real-time control of power plant cooling water discharges utilizing optimization models that incorporate stochastic data along with climatic factors were simulated in order to ascertain compliance with temperature standards (Krajewski et al., 1993). A real-time modeling approach was applied to wastewater treatment operations and suggest adaptive management schemes so that facilities' management can better adapt and operate efficiently (Novotny et al., 1992).

In the San Joaquin River Basin, a mass balance model is currently in use to predict the assimilative capacity of the San Joaquin River. This model, the San Joaquin River InputOutput Daily Model (SJRIODAY), calculates daily flows and concentrations of TDS for a 60-mile $(96 \mathrm{~km})$ reach of the San Joaquin River from Lander Avenue to Vernalis. Using real-time flow and EC data from five major tributaries and several small tributaries, daily flow calculations are performed using hydrologic routing techniques. The data are used to establish initial conditions for model runs and to generate two-week forecasts of flow and EC (Quinn et al., 1997; Quinn and Karkoski, 1998). Coordination of west-side agricultural and wetland drainage with east-side reservoir releases is the goal of the decision support system and it relies on accurate and readily available data. The accuracy of the SJRIO forecasts is greatest when east side reservoir releases are pre-determined and forecasts of agricultural and wetland drainage can be made using the San Joaquin Real-Time monitoring network (Quinn and Karkoski, 1998).

The WETDWQM-GWD complements SJRIODAY and associated by providing a predictive tool for wetland drainage from the Northern Division of the Grassland Water District 
(NGWD). Wetland drainage from the NGWD enters the SJR through Mud Slough, an input location for flow and salt load in SJRIODAY. These values then can be compared to the SJR assimilative capacity, providing a quantitative impact assessment tool for adjusting wetland drainage schedules and managing the wetland component of salinity in the SJR. In reality, until SJR assimilative capacity can be dynamically allocated among those entities producing drainage discharge and there are significant incentives for these entities to adhere to State salinity objectives, it is unlikely that significant adjustment will be made to wetland drainage schedules or to traditional drainage practices.

\subsection{The Wetland Drainage Water Quality Model}

The WETDWQM is a generic salt and water balance box-type model designed to assist coordination of salt loading from wetlands within the Grasslands Ecological Area (which includes the San Luis National Wildlife Refuge Complex) with the assimilative capacity for salt in the San Joaquin River. This box model is similar to other salinity box models (for example, salinity models of the Black Sea) in that it calculates salinity through a weighted contribution from all inputs, outputs and changes in storage (Karaka et al., 1999). The WETDWQM is updated and calibrated on a daily basis and tracks continuously the weighted flow and salinity contributions into and out of each wetland unit (Figure 3.3 using the salt balance equation below :

$\mathrm{EC} \mathrm{Ct}_{\mathrm{Dt}}=$

$\left[\left(\mathrm{Dt}-1 \times \mathrm{ECDt}_{-1}\right)+(\mathrm{Pt} \times \mathrm{ECPt})+(\mathrm{It} \times \mathrm{ECIt})+(\mathrm{GIt} \times \mathrm{ECGIt})-(\mathrm{Et} \times \mathrm{ECEt})-(\mathrm{ETt} \times \mathrm{ECETt})-(\mathrm{GOt} \times \mathrm{ECGOt})-(\mathrm{Ot} \times \mathrm{ECOt})\right]$

$\left[\left(\mathrm{Dt}_{\mathrm{t}-1}+\mathrm{Pt}_{\mathrm{t}}+\mathrm{It}_{\mathrm{t}}+\mathrm{GIt}_{\mathrm{t}}-\mathrm{Et}_{\mathrm{t}}-\mathrm{ET}_{\mathrm{t}}-\mathrm{GOt}-\mathrm{Ot}\right)\right]$

Where $E C_{X t}$ is the salinity measured as electrical conductivity for parameter $X$ at time $t$ $[\mu \mathrm{S} / \mathrm{cm}] ; D$ is the end of day depth [in]; $P$ is precipitation [in]; $I$ is inflow [in]; $G I$ is the groundwater inflow seepage [in]; $E$ is the evaporation [in]; ET is the evaporation [in]; $G O$ is the groundwater outflow seepage [in]; and $O$ is the wetland outflow [in].

The WETDWQM requires time series data inputs of variables such as inflow volume and water quality, residence time, evapotranspiration, evaporation, precipitation, land use, vegetation types and management strategies. The model tracks salinity changes in each of the wetland basins over the flooded season including drawdown (September through April) 
and incorporates user-defined schedules for wetland drawdown in the spring months to determine salinity loading to the SJR (Figure 3.1).

\section{Wetland Drainage Water Quality Model Data Schematic}

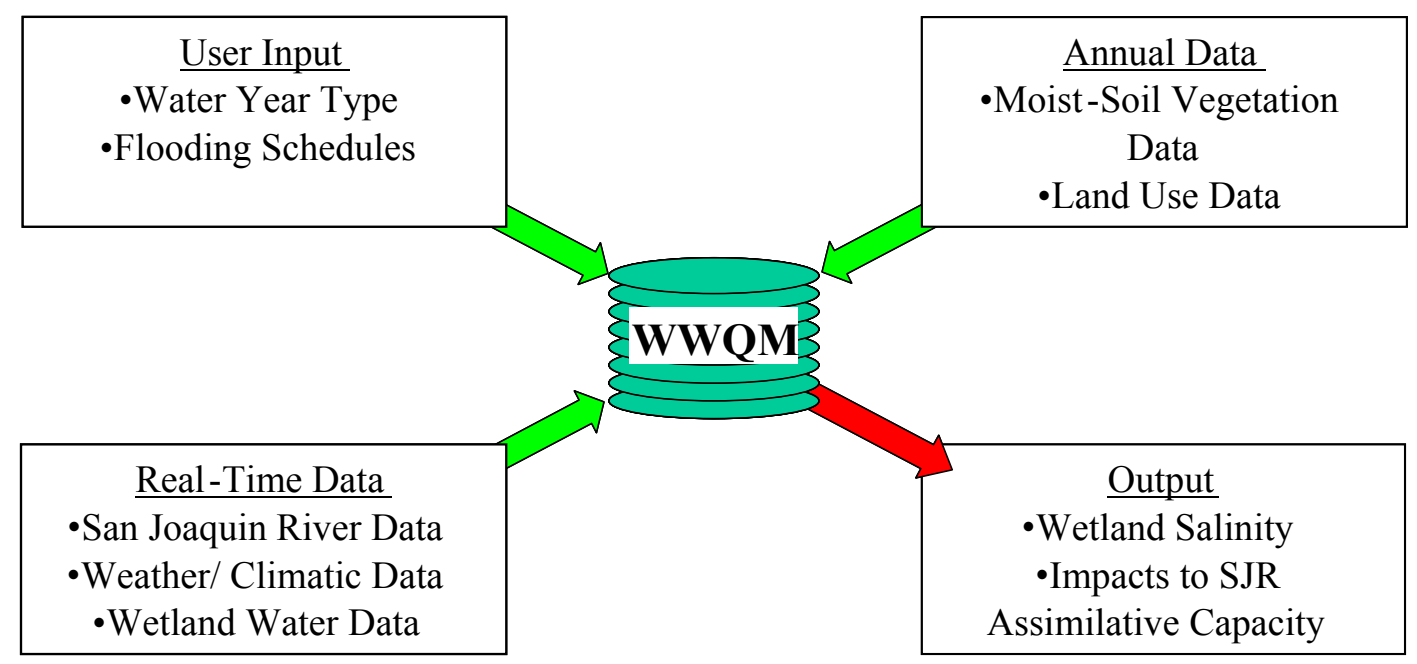

Figure 3.3 . Wetland Drainage Water Quality Model (WETDWQM) data schematic.

Real-time salinity monitoring data at each drainage outlet can be used to calibrate the model. Once calibrated, the model is used to simulate different management strategies to control salt loading to the SJR.

\subsubsection{Model Development}

The WETDWQM was developed within Microsoft's ${ }^{\mathrm{TM}}$ two database and file systems, Access $^{\mathrm{TM}}$ and Excel $^{\mathrm{TM}}$. This development scenario was ideal because the Excel ${ }^{\mathrm{TM}}$-based user interface is familiar to wetland managers. Moreover, Excel ${ }^{\mathrm{TM}}$ allows computation and insertion of logic and is supported by the Access ${ }^{\mathrm{TM}}$ database. Access ${ }^{\mathrm{TM}}$ has the ability to support Excel ${ }^{\mathrm{TM}}$ and the monitoring network constructed specifically for this project, and also readily communicates with ArcGISTM 8.X, Environmental Systems Research Institute's (ESRI) latest Geographical Information System (GIS) software package. The model's structure allows it to perform historic hydrology simulations as well as seasonal "gaming" alternatives. These gaming alternatives include different wetland drawdown protocols such 
as (a) early drawdown (critically dry to dry year), (b) traditional drawdown (dry to wet year), (c) late drawdown (wet year), and (d) a pre-flushing option to determine the effects of early salt exports while maintaining desired depths within the wetlands.

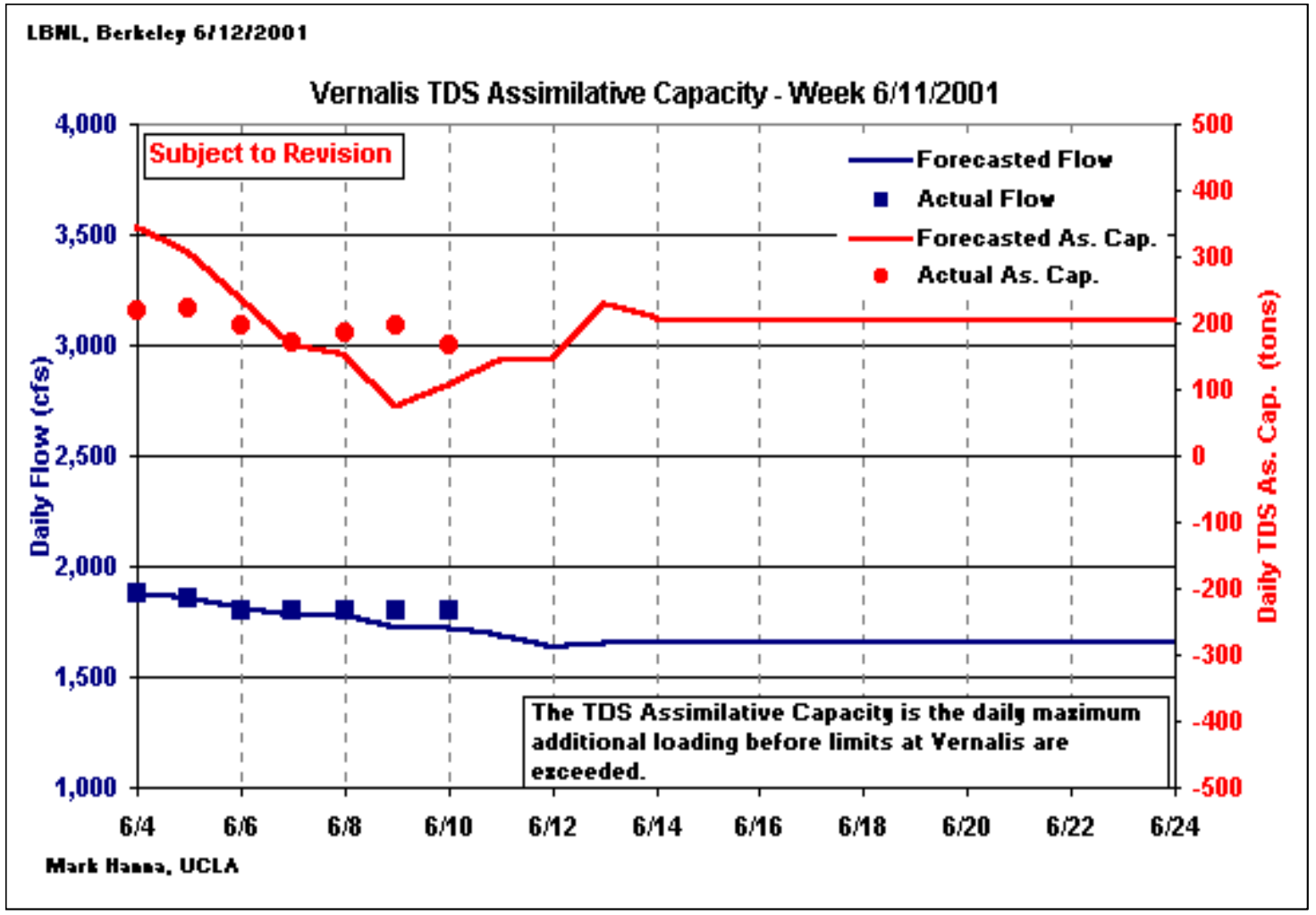

Figure 3.4 Flow and assimilative capacity forecasts on the San Joaquin River for June, 2001 produced by the SJRIODAY Model

The WETDWQM user interface also resides in the Microsoft Excel ${ }^{\mathrm{TM}}$ platform (Figure 3.6) because, as previously noted, there is widespread familiarity with this product among the wetland managers in the Grassland Ecological Area. In addition, the model has been designed to allow linkage to GIS software packages such as ARCGIS so results can be viewed and assessed.

\subsubsection{Simulation of wetland management}

Within the class of seasonal wetlands, there are three different subclasses of wetlands that should be considered in the Grasslands Ecological Area and San Luis National Wildlife Refuge. These are shallow seasonal wetlands, mid-depth seasonal wetlands, and deep 
seasonal wetlands. The primary reason mid-depth wetlands are the most popular type of wetland - estimated at greater than 70 percent of the total seasonal wetland area in the Grasslands Ecological Area - is that they are most productive and cater to the largest variety of waterfowl. Wetland managers try to keep the majority of the ponded area in these wetlands between 10 and 12 inches deep. This is the water depth most preferred by desired waterfowl such as mallards (Anas platyrhynchos), green-winged teats (A. crecca), northern pintail (A. acuta) and other dabbling ducks. Accordingly, waterfowl hunters most commonly want to hunt in these types of wetlands (Frederickson and Taylor, 1982, Grober et al 1995, and Smith et al, 1995).

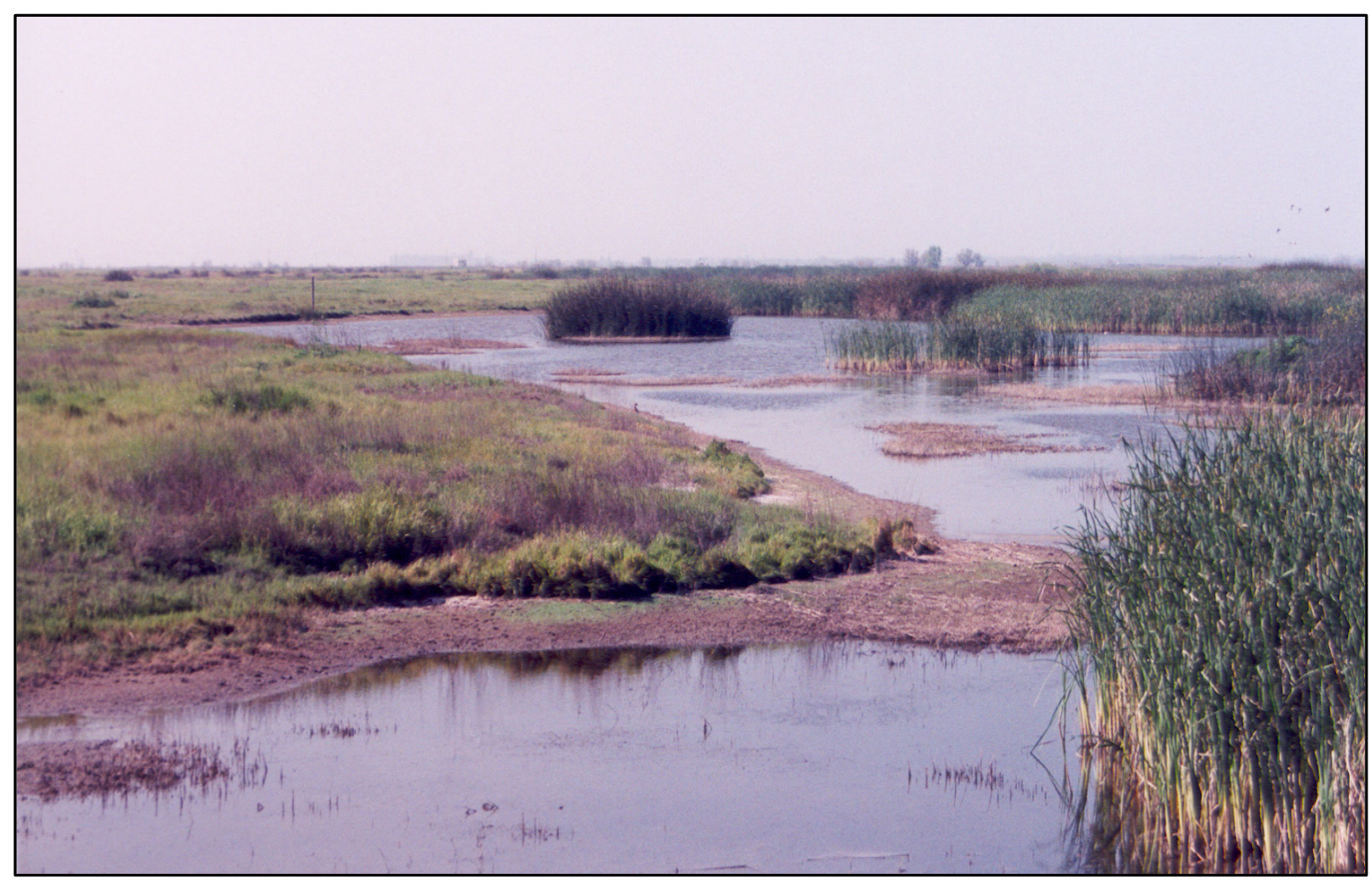

Figure 3.5. The Salinas Land \& Cattle Club is an example of a mid-depth seasonal wetland also common in the San Luis National Wildlife Refuge.

A secondary reason for the selection of mid-depth wetlands is that the hydrology of mid depth wetlands is much easier to understand. Such understanding leads to more accurate modeling. Shallow wetlands tend to have fluctuating aerial extent because they are more susceptible to daily variations in the weather and, as a result, usually have less well defined 
hydrology and salinity increases with evaporation and plant transpiration are harder to estimate.

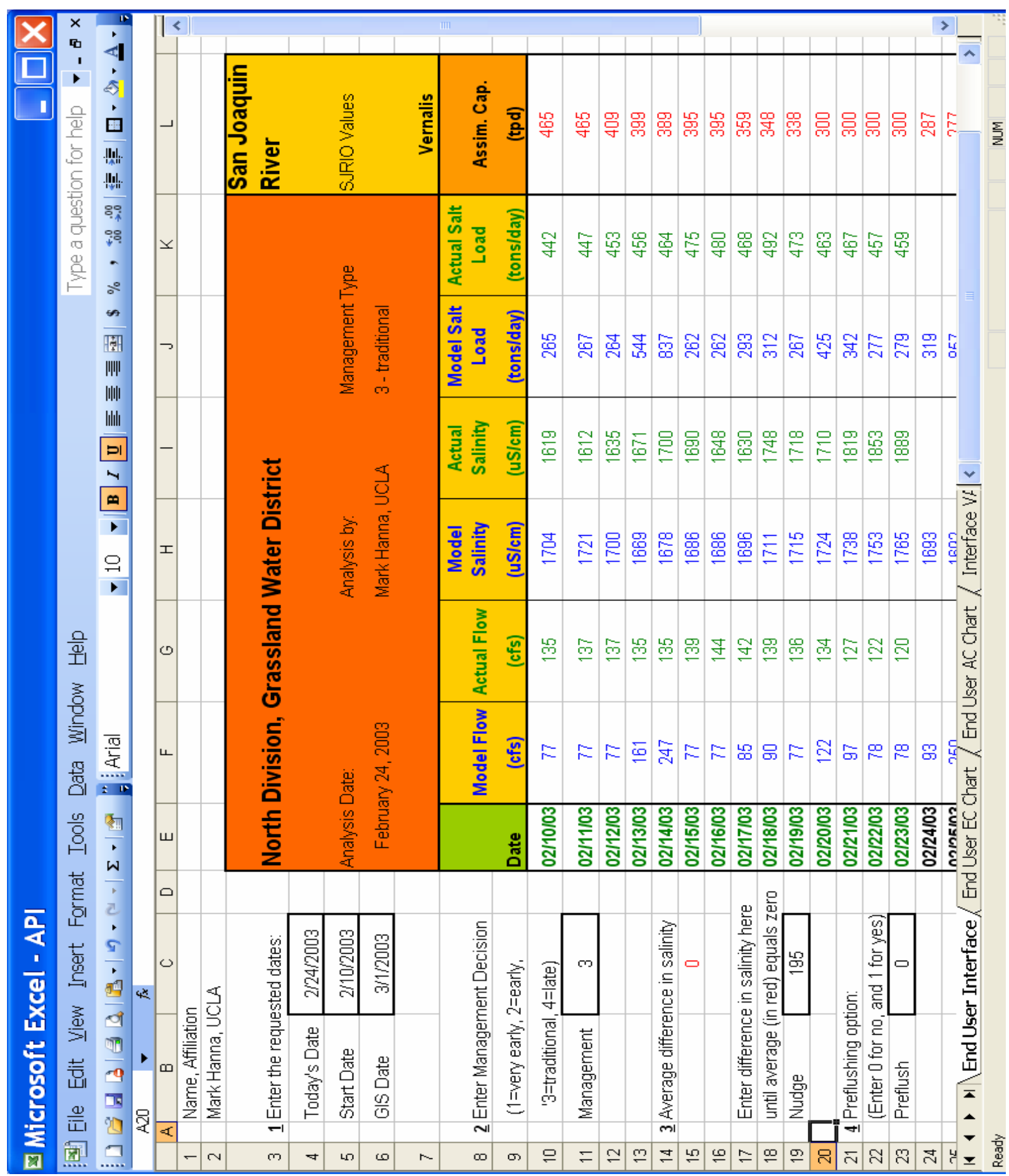

Figure 3.6. Wetland Drainage Water Quality Model user interface used in the Grassland Water District study and applicable to the San Luis National Wildlife Refuge 


\subsection{Model Components}

To track wetland conditions as they progress through the flooded season and monitor their impacts on the SJR, four different analytical worksheets were created within the WETDWQM-GWD. These four components -- wetland management, wetland hydrology, wetland salinity, and San Joaquin River assimilative capacity -- are discussed below.

\subsubsection{Wetland Management}

The WETDWQM assumes a combination of accepted wetland "best management practices" (BMPs) for seasonal wetlands. The specific BMP used for the seasonal wetland habitat management component is the recommended flooding regime published in "A Guide to Wetland Habitat Management in the Central Valley". This guide was developed, as noted earlier, through a cooperative effort of the California Department of Fish and Game and the California Waterfowl Association (Smith et al., 1995). For seasonal wetlands in California's Central Valley, this guide suggests flooding regimes for optimal wetland management of the most valuable moist-soil plants.

\subsubsection{Model output parameters}

\section{Ai-Target Depth, TD}

The model calculates the average depth, or "target depth", in a typical wetland unit. The target depth is dictated by date, water year type, and the combination of the wetland percentages delineated as "habitat units" (HC) and "cattle units" (CC). In the case of the Grassland Water District private wetlands can be designated as either "duck habitat clubs" or "cattle clubs" - these distinctions are not as clear in the case of the San Luis National Wildlife Refuge, although cattle grazing is a legitimate management practice. Habitat units are those that are managed for habitat throughout the year. Cattle units, on the other hand, are flooded during hunting season but drained shortly thereafter in order to graze cattle. The model treats the cattle units exactly like habitat units during fall floodup and throughout the flooded season. However, no matter the water year type, the WETDWQM initiates drawdown for cattle units on February $1^{\text {st }}$ each year. This target depth, which is a combination of the depth for the habitat units (HAB) and cattle units (CAT), along with their 
present percentage of the total land, is the controlling factor during the daily time step process within the WETDWQM :

$$
T D_{t}=\left(\% H C \times H A B_{t}\right)+\left(\% C C \times C A T_{t}\right)
$$

Using the "season type" decision variables within the user interface (Figure 3.5), the end user can shift the wetland management timing curve earlier or later, depending upon the user's interpretation of the current year type (extremely dry, dry, normal, and wet). This target depth, calculated for a specific wetland system (i.e. shallow, mid-depth, or deep) and water year type, is then compared to the modeled wetland storage depth, $D$, using the water balance formula in Equation 4). This comparison affects the following day's decisions by either suggesting a need for additional surface water input or that no water is required.

\subsection{Wetland Hydrology}

Bi-Wetland Storage Depth, $D$

WETDWQM-GWD considers the water cycle (Figure 3.7) and its associated water balance equation. The water balance equation has been arranged to calculate the wetland storage depth, $D_{t}$, using the following inputs:

$$
D_{t}=D_{t-1}+\sum_{t=1}^{t}\left(I_{t}+P_{t}+G I_{t}-E_{t}-E T_{t}-O_{t}-G O_{t}\right)
$$

where $\mathrm{t}$ is the time step; $D_{t}$ is the end of period storage depth in the wetland units; $I_{t}$ is the wetland inflow; $P_{t}$ is the precipitation that falls within the individual wetland units; $G I_{t}$ is the groundwater inflow to the individual wetland units; $E_{t}$ is the direct evaporation from the open water surfaces within each wetland unit; $E T_{t}$ is the evapotranspiration from the vegetated portions of the wetland units; $O_{t}$ is the combined wetland outflow and operational spill; and $G O_{t}$ is the groundwater inflow / outflow. The Wetland Storage Depth, $D_{t}$, is calculated by starting each iteration with the results from the previous time step's storage depth, $D_{t-1}$. The model then adds and subtracts the daily inputs and outputs for the present time, $t$. The inputs are precipitation $\left(P_{t}\right)$, operational inflow $\left(I_{t}\right)$, and groundwater input $\left(G I_{t}\right)$. The outputs are evaporation $\left(E_{t}\right)$, evapotranspiration $\left(E T_{t}\right)$, outflow $\left(O_{t}\right)$ and groundwater outflow $\left(G O_{t}\right)$. 


\section{Bii-Precipitation, $P$}

Precipitation data are measured values. The precipitation data come directly from the California Irrigation Management Information System (CIMIS) website, www.cimis.water.ca.gov, operated by the California Department of Water Resources (DWR). CIMIS publishes daily climatic data recorded at many weather monitoring stations throughout California. The total volume of rainfall, therefore, is the value of precipitation, measured in inches, multiplied over the land area. The closest CIMIS station is located within the former Kesterson Reservoir north of Los Banos.

\section{Biii-Groundwater Inflow, GI}

Lateral groundwater inflow and salinity can be accounted for in the WETDWQM. The WETDWQM accepts groundwater data through update files similar to those used for the climate and land use data. Although there is a general groundwater flow gradient in a north easterly direction towards the San Joaquin River there are no models of groundwater flow for the region - lateral groundwater flows are therefore ignored in the model simulation.

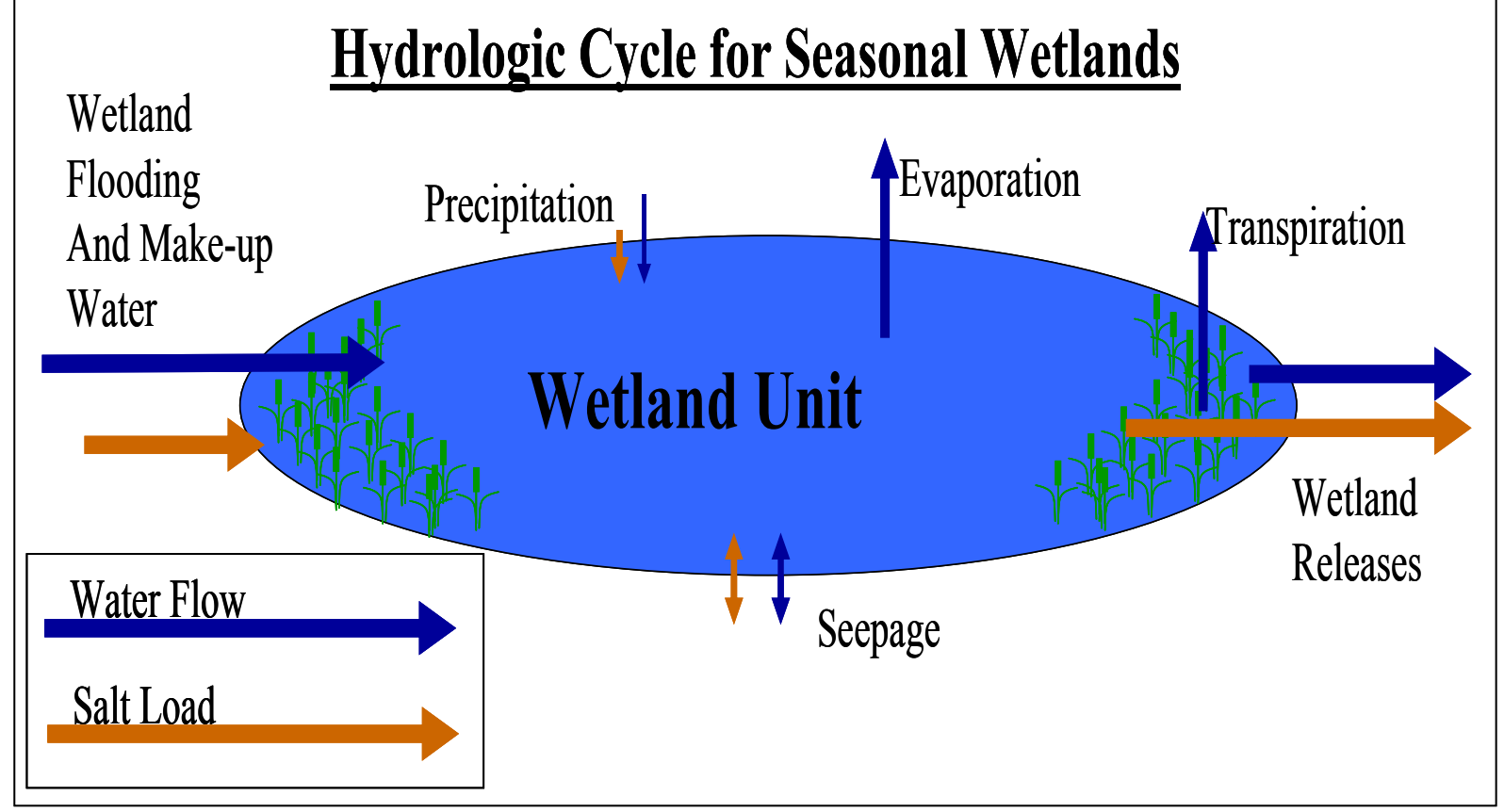

Figure 3.7 - Hydrologic inputs and outputs for seasonal wetlands. 


\section{Biv - Surface Water Inflow, I}

Surface water inflow is a model calculated value. It represents all water diverted to the wetlands during flood-up, plus make-up and irrigation water. It is the water added seasonal wetlands to maintain their depth at or near management targets, or to provide summer irrigation water. The net inflow is set equal to the difference between the desired depth and the simulated depth, expressed as a volume. The WETDWQM assumes zero make-up water when simulated depth is greater the management target. Inflow is accounted for in the model in the following manner. If the previous day's End of Day Storage Depth, $D_{t-1}$, is greater than the current day's target depth, $T D_{t}$, then the current day's inflow, $I_{t}$, equals zero.

$$
\begin{gathered}
\text { If } \mathrm{TD}_{\mathrm{t}}>0 \text {, then } \\
\mathrm{E}_{\mathrm{t}}=(\% \mathrm{OW})\left(\mathrm{E}_{\mathrm{pan}, \mathrm{t}} \mathrm{K}_{\mathrm{p}, \mathrm{t}}\right) \\
\text { otherwise; } \\
\mathrm{E}_{\mathrm{t}}=0
\end{gathered}
$$

However, within the user interface, the user can request a "preflush" option (Figure 3.5) where the model simulates additional fresh water inputs to help flush out accumulated salt. In cases where the user selects a positive, non-zero value in the user interface, $I_{t}$ is set equal to the user-defined pre-flush value. The default is 0.4 inches for a period of 30 days - this can be changed to whatever is desired with the next release of the update.xls file.

\section{$B v-$ Evaporation, $E$}

Evaporation is a measured value. The evaporation data are measured by monitoring the drop in water elevation in an open pan. This method is called pan evaporation, $E_{\text {pan }}$. Evaporation data are obtained from the CIMIS website, www.cimis.water.ca.gov, operated by DWR, and must be compensated for local precipitation. These data are updated periodically and delivered to the user in the update.xls file. The evaporation data that is downloaded from CIMIS is manipulated for use in the model by multiplying it by the percentage of open water, $\% O W$, and by a pan coefficient, $K_{p}$. This coefficient is for use in translating corresponding evaporation pan data to the water body of concern.

$$
\begin{gathered}
\text { If } \mathrm{TD}_{\mathrm{t}}>0 \text {, then } \\
\mathrm{E}_{\mathrm{t}}=(\% \mathrm{OW})\left(\mathrm{E}_{\text {pan, } \mathrm{t}} \mathrm{K}_{\mathrm{p}, \mathrm{t}}\right) \\
\text { otherwise; } \\
\mathrm{E}_{\mathrm{t}}=0
\end{gathered}
$$




\section{Bvi-Evapotranspiration, ET}

Evapotranspiration (ET) data are calculated values. Evapotranspiration can be computed in several ways. These options include the Hargreaves method (Hargreaves and Samani, 1985) using temperature as an ET indicator, the Priestley-Taylor approach (Priestley and Taylor, 1972) which uses surface heat flux and large-scale parameters to calculate evaporation and evapotranspiration, and the Penman-Monteith equation (Monteith, 1965) which uses mostly atmospheric parameters. The Penman-Monteith equation is very robust and is the accepted method if multiple parameters such as vapor pressure, radiation, soil heat flux density, mean daily temperature, and wind speed, are available (Arnold et al., 1998).

CIMIS publishes daily ET data using a modified version of the Penman-Monteith equation for the various climate zones in California. The modification includes a wind function and was developed by the University of California, Davis (CIMIS, 2003). CIMIS publishes the data necessary to calculate reference evapotranspiration, but it also calculates and publishes reference evapotranspiration $\left(\mathrm{ET}_{\mathrm{o}}\right)$ using the modified version of the Penman-Monteith equation. This daily ET data can be found on the CIMIS website, www.cimis.water.ca.gov, operated by the DWR. For estimating $E T_{o}\left(E T_{r e f}\right)$, a modified version of the PenmanMonteith equation (Allen et al., 1999) with some fixed parameters was used (Walter et al., 2000 and Itenfisu et al., 2000.). The equation is written as follows:

$$
E T_{\text {ref }}=\frac{0.408 \Delta\left(R_{n}-G\right)+\gamma \frac{C_{n}}{T+273} u_{2}\left(e_{s}-e_{a}\right)}{\Delta+\gamma\left(1+C_{d} u_{2}\right)}
$$

where $\Delta$ is the slope of the saturation vapor pressure at mean air temperature curve $\left[\mathrm{kPa} /{ }^{\circ} \mathrm{C}\right]$; $R_{n}$ is the net radiation $\left[\mathrm{MJ} / \mathrm{m}^{2} \mathrm{~d}\right] ; G$ is the soil heat flux density $\left[\mathrm{MJ} / \mathrm{m}^{2} \mathrm{~d}\right] ; \gamma$ is the psychrometric constant $\left[\mathrm{kPa} /{ }^{\circ} \mathrm{C}\right] ; T$ is the daily mean temperature $\left[{ }^{\circ} \mathrm{C}\right], u_{2}$ is the mean wind speed $[\mathrm{m} / \mathrm{s}]$; and $e_{s}-e_{a}$ is the vapor pressure deficit $[\mathrm{kPa}] . C_{n}$ and $C_{d}$ are given specific values depending on the calculation time step and the reference crop, and are 900 and 0.34, respectively (Snyder et al., 2002). The modified Penman-Monteith equation is accepted widely and as such was chosen by DWR for its agricultural water use calculations, and these published daily values of $\mathrm{ET}_{\mathrm{o}}$ are used in the WETDWQM. The $\mathrm{ET}_{\mathrm{o}}$ data provided by 
CIMIS are manipulated for use in the model by multiplying by a wetland crop coefficient, $K_{c}$, the percentage of emergent vegetation, $\% E V$, and by an osmotic resistance factor, $R$ (Glenn et al, 1995).

$$
\begin{gathered}
\text { If } T D_{t}>0, \text { then, } \\
\mathrm{ET}_{\mathrm{t}}=(\% \mathrm{EV})\left(\mathrm{ET}_{\mathrm{o}, \mathrm{t}} \mathrm{K}_{\mathrm{c}, \mathrm{t}}\right) \mathrm{R}
\end{gathered}
$$

where $E T$ is the total evapotranspiration, $\% E V$ is the percentage of land covered by emergent vegetation, $E T_{o}$ is the reference ET published by CIMIS, $K c$ is the crop coefficient, and $\mathrm{R}$ is the osmotic resistance factor. The crop coefficient, $K c$, is used in translating reference evapotranspiration, $E T_{o}$, into actual evaporation for the vegetation of concern, in this case, emergent vegetation. Values for the $K c$ 's were taken from the several sources and compiled to create a crop coefficient curve (Snyder et al., 2002; USBR, 1993 - Figure 3.8). Although there was considerable discrepancy between the other sources regarding the magnitude of the seasonal change, there was a general agreement for the seasonal pattern and range (Hargreaves and Samani, 1985; USBR, 1993). This information has been adapted for the WETDWQM-GWD. The formula for the $K c$ as the season progresses is:

$$
K c=1.05+\frac{\left[\sin \left((x-135) \times \frac{\Pi}{180}\right)\right]}{5}
$$

where $x$ is the julian date. This formula was derived by fitting the sine curve to the interpolated $K c$ curve (Figure 3.8).

Another factor involved in the modeling of ET within the WETDWQM-GWD is salinity effects on plant uptake. Salinity has a marked effect on a plant's ability to take water in through their roots. This phenomenon is referred to as the Osmotic Resistance Factor, $R$. A recent study shows that emergent vegetation is not noticeably affected $(R=1)$ when salinity is below 1,460 EC (1,100 mg/L). However, when salinity is in the 4,600 EC range $(3,500$ $\mathrm{mg} / \mathrm{L})$ the growth rate of wetland vegetation decreases to about one-half the normal growth rate $(R=.5)$. When salinity reaches $8,000 \mathrm{EC}(6,000 \mathrm{mg} / \mathrm{L})$ and above, the growth of the 
vegetation stops altogether $(R=0)($ Glenn et al., 1995). This factor is incorporated into the model through a decision variable, so that if the salinity is below $1460 \mathrm{EC}$, then evapotranspiration is only a function of the modified Penman-Monteith equation (Equation 9), the $K c$ equation (Equation 11) and the percentage of emergent vegetation $(\% E V)$ present in the wetlands. The osmotic resistance factor, $R$, is considered when the salinity increases above $1,466 \mathrm{EC}$. When the salinity is below 1,466 EC, $R=1$, but as salinity increases above $1,466 \mathrm{EC}$, the decision variable includes the formula derived from the emergent vegetation study described above. The formula for calculating $R$ is as follows:

$$
\begin{gathered}
\text { If } E C D t>1,466, \text { then } \\
R=-0.0002(\mathrm{EC})+1.2263 \\
\text { otherwise } \\
R=1
\end{gathered}
$$

Bvii-Surface Water Outflow, O

Surface water outflow is calculated by the WETDWQM. While the wetlands are flooded, this value is calculated by adding the operational spill, $O S_{t}$, to the difference, if positive, between the modeled and target depths $\left(D_{t-1}\right.$ and $\left.T D_{t}\right)$. For instance if the current day's Target Depth is greater than the previous day's wetland storage depth, $D_{t}$, then no major wetland releases will occur, except for operational spill that is automatically released at a rate of $1 \mathrm{cfs}$ per every 235 wetland acres.

$$
\begin{gathered}
\text { If } T D_{t}>=D_{t-1}, \text { then, } \\
O S_{t}=1 \mathrm{cfs} / 235 \text { acres (or } 0.1 \text { inches/day) } \\
\text { Otherwise : } \\
\text { If } T D_{t}<D_{t-1}, \text { then } \\
O_{t}=O S_{t}+D_{t-1}+T D_{t}
\end{gathered}
$$$$
13 \quad O_{t}=O S_{t}
$$$$
14
$$ 


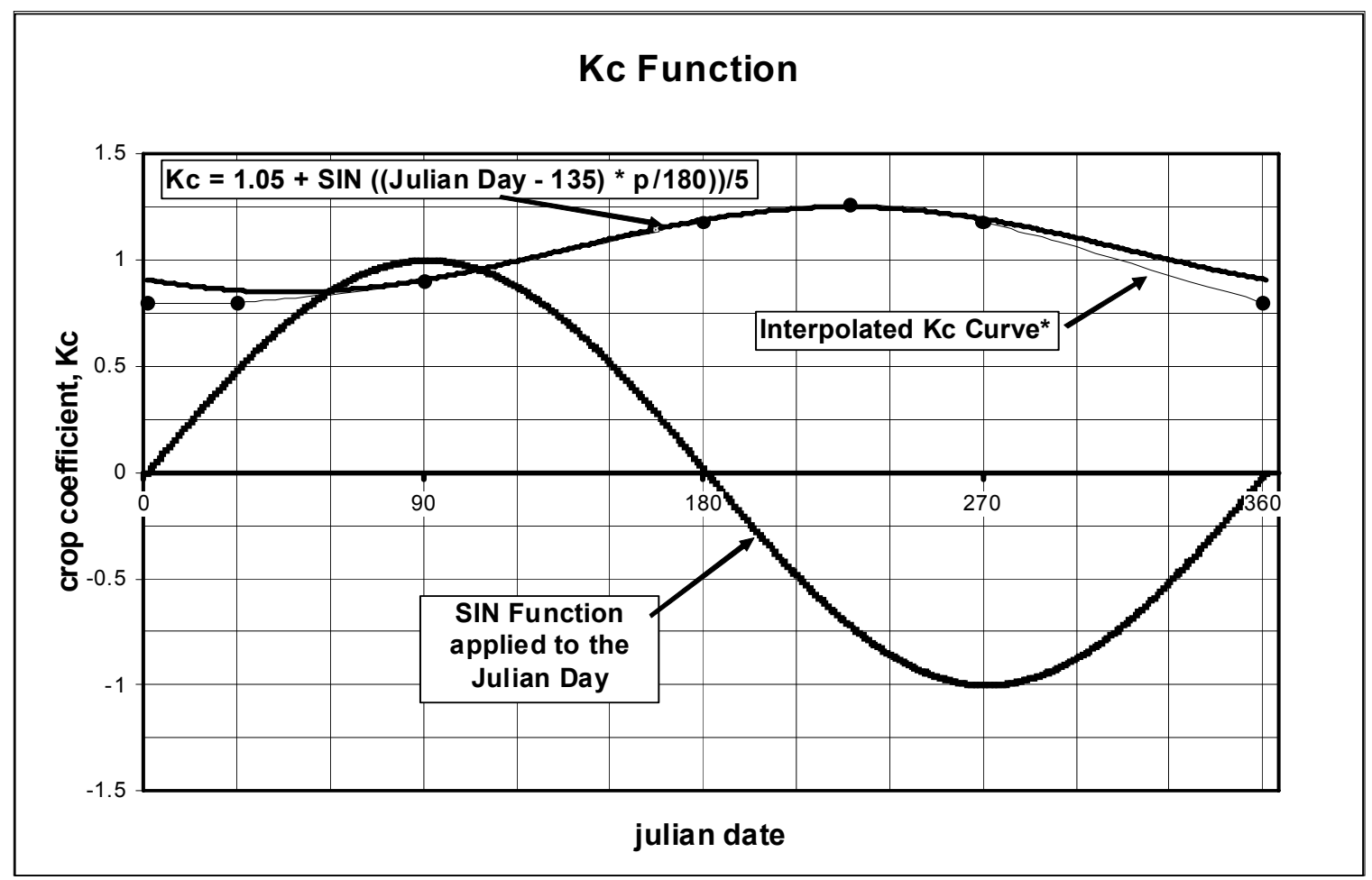

Figure 3.8. The Crop Coefficient, $K c$, for emergent wetland vegetation in the San Joaquin Valley

However, if there is a one-fourth inch discrepancy between $D_{t-1}$ and $T D_{t}$.

$$
\begin{gathered}
D_{t-1}-T D_{t},>0.25, \text { then } \\
O_{t}=0.33
\end{gathered}
$$

The upper limit of 0.33 for $O_{t}$ is set because there is a maximum outflow capacity of most wetland flow control structures of $3.3 \mathrm{cfs} / 235$ acres. There is also a depth cutoff of onefourth inch that functions as the threshold to wetland release prompting the model to stop releasing water from the wetlands.

\section{Bviii - Groundwater Outflow, GO}

Groundwater outflow and inflow are predicated on having quantitative regional flow data. 


\subsection{Wetland Salinity}

$C i-$ Wetland Storage Depth Salinity, $E C_{D}$

The wetland salinity for the end of day storage, $E C_{D t}$, is calculated on a daily basis by using the box model balancing equation detailed above. The box model uses proportional contributions of all inputs and outputs, together with the water and salts remaining from the previous day, and calculates the overall salinity in the ponded water volume, or end of day storage depth, $D_{t}$. The WETDWQM logical expression to calculate $E C_{D t}$, is:

$$
\begin{aligned}
& \text { If } D_{t}<=0 \text {; then } \\
& E C_{D t}=0 \\
& \text { otherwise, } \\
& \text { If } 0<D_{t-1}<1.2 ", \\
& \text { and if } D_{t}>0 ; \text { then } \\
& E C_{D t}=1.25 E C_{I t}
\end{aligned}
$$

17

18

An assumption was made that the end of each day the EC of the ponded water in each wetland is 1.25 times the EC of the inflow when the wetlands are filling and where the depth is between 0 and 1.2 inches. This comes from field observation of initial floodup in wetland units within the GWD. This is the minimal case. If, however, the wetlands are filling (above the 1.2 inch level) or are completely full, it follows that:

$$
\begin{gathered}
\text { If } D_{t-1}>1.2, \text { then } \\
E C_{D t} \text { is calculated by : } \\
E C_{D t}=E C_{I t}
\end{gathered}
$$

\subsection{San Joaquin River Assimilative Capacity}

The SJRMP publishes weekly assimilative capacity forecasts for salt in the SJR on the following website : http://www.dpla.water.ca.gov/sjd/sjrmp/index.html 
These forecasts can be downloaded and made available to users of the WETDWQM using the update.xls file. If and when San Joaquin River assimilative capacity for salt is adjudicated - the model can be used to compare and develop optimal drainage drawdown schedules for the San Luis National Wildlife Refuge and the adjacent state and private wetland areas.

\subsection{Wetland Management Incentive Programs}

State and Federal habitat management programs such as the California Department of Fish and Game's Pressley Program, reward land owners with a per acre fee for managing their wetlands in a habitat-friendly manner. Other habitat management scenarios can include agricultural activities such as grazing of cattle for weed control.

\section{Seasonal Wetland Management Drawdown Practice}

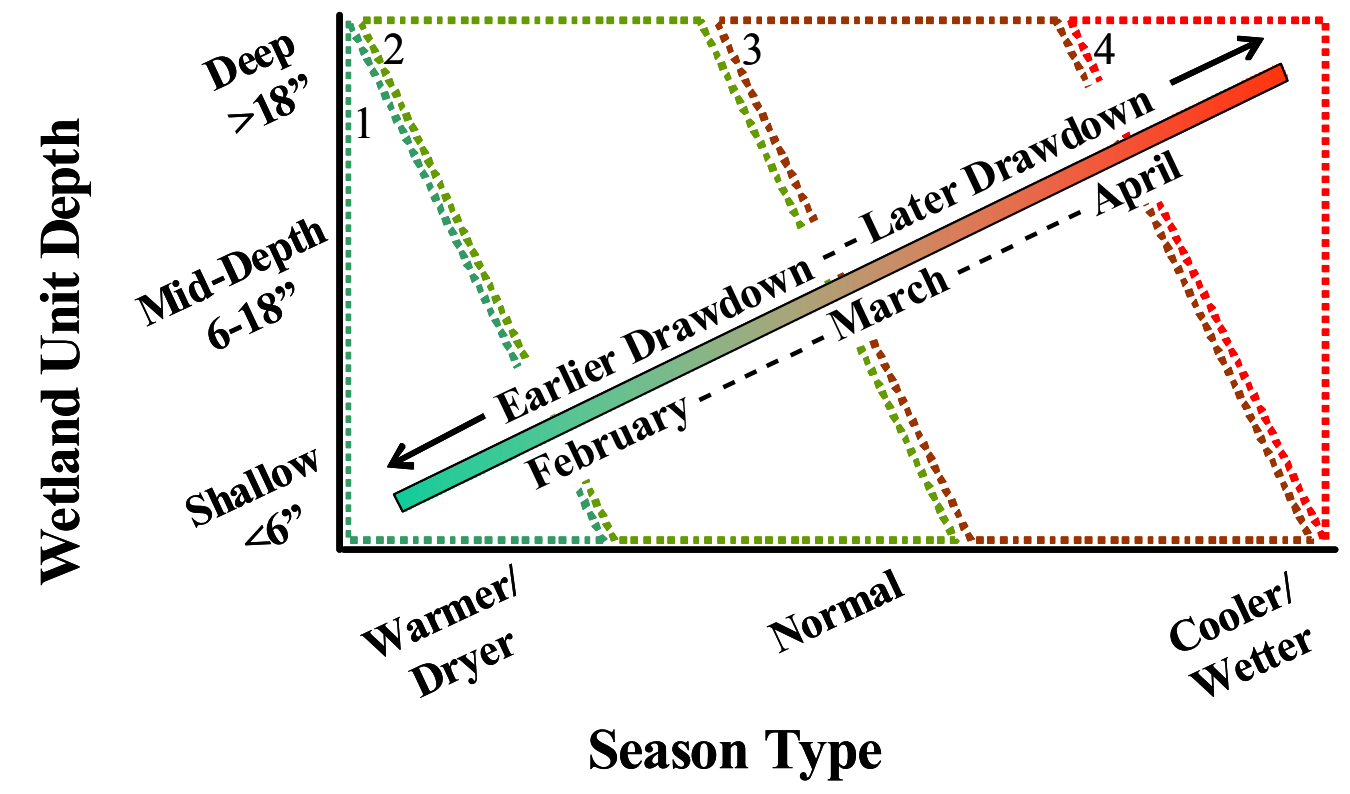

1 Earliest Drawdown, WWQM Type 13 Traditional Drawdown, WWQM Type 3 2 Earlier Drawdown, WWQM Type 24 Late Drawdown, WWQM Type 4

Figure 3.9 Seasonal wetland management drawdown practices. Although these were derived from information from the Salinas Duck Club the same principals can be applied to seasonal wetlands on the San Luis national Wildlife Refuge. 
For modeling purposes the Refuge is divided into smaller wetland units typically delineated according to their respective drainage basins. They are given a land use classification regarding their management practice type and assigned a percent open water value and a percent emergent vegetation value, based on satellite imagery vegetation classification. A surface water source ranking is also determined which depends on how much water re-use is occurring. In the San Luis National Wildlife Refuge most refuge water derives from a single source - the San Luis Canal Company "C" Canal - although some reuse of Salt Slough drainage also occurs during dry years. All of these data are managed in Microsoft Excel ${ }^{\mathrm{TM}}$ and Microsoft Access ${ }^{\mathrm{TM}}$ database tables so they are able to communicate directly with the WETDWQM as well as ArcGISTM.

Table 3.2 - Input data for the WETDWQM-GWD

\begin{tabular}{|c|c|c|c|}
\hline Data Element & Symbol & Units* & Source \\
\hline Time & $t(t-1, t+1)$ & day & na \\
\hline Target Depth & TD & inches & Smith et al, 1995 \\
\hline End of Day Storage Depth & D & inches & calculated \\
\hline Salinity of End of Day Storage Depth & ECD & $\mathrm{uS} / \mathrm{cm}$ & calculated \\
\hline Precipitation & $P$ & inches & CIMIS \\
\hline Inflow & 1 & inches & calculated \\
\hline Salinity of Inflow & $\mathrm{ECl}$ & $\mathrm{uS} / \mathrm{cm}$ & network \\
\hline Evaporation (from open water) & $E$ & inches & calculated \\
\hline Pan Evaporation & Ep & $\mathrm{mm}$ & CIMIS (USDA, Station 5) \\
\hline Pan Coefficient & Kp & na & USDA, 2000 \\
\hline Evapotranspiration & ET & inches & calculated \\
\hline Reference Evaporation & ETo & inches & CIMIS \\
\hline Crop Coefficient & $\mathrm{Kc}$ & na & calculated, USBR 1993 \\
\hline Operational Spill & OS & inches & estimated \\
\hline Outflow & 0 & inches & calculated \\
\hline Salinity of Outflow & ECO & $\mathrm{uS} / \mathrm{cm}$ & calculated \\
\hline Groundwater Inflow & $\mathrm{Gl}$ & inches & na \\
\hline Groundwater Outflow & GO & inches & na \\
\hline Desired Depth for Habitat Clubs & $H A B$ & inches & Smith et al, 1995 \\
\hline Desired Depth for Cattle Clubs & CAT & inches & estimated \\
\hline Percentage of open water wetlands & $\% \mathrm{OW}$ & $\%$ & GWD, 2000 \\
\hline Percentage of vegetated wetlands & $\% \mathrm{EV}$ & $\%$ & GWD, 2000 \\
\hline Percentage of wetlands managed as Cattle Clubs & $\% \mathrm{CC}$ & acres & GWD, 2000 \\
\hline Percentage of wetlands managed under the Habitat Programs & $\% \mathrm{HC}$ & acres & Cal. DFG, 2001 \\
\hline Osmotic Resistance Factor & $\mathrm{R}$ & na & Glenn et al., 1995 \\
\hline
\end{tabular}




\subsection{WETMANSIM}

\subsubsection{Background}

The WETMANSIM model (Wetland Management Simulator), is a monthly planning model that uses monthly inputs of water delivery and the salt content of these water deliveries to predict wetland drainage flow and drainage water quality. The model was first formulated in 1990 for the US Bureau of Reclamation to simulate potential impacts of Level IV water supplies to wetlands as mandated by the Central Valley Improvement Project Improvement Act (1989). The model was revised by CH2M-Hill for the final project report. The model was revived in 2003 to allow analysis of impacts of alternative water supply strategies being considered by the US Bureau of Reclamation to meet Level IV water supply requirements. The model was updated in 2004 by obtaining feedback and direct input from private wetland and refuge managers in the Grassland Water District, California Department of Fish and Game and US Fish and Wildlife Service, who manage the San Luis National Wildlife Refuge. The model represents an average hydrologic condition for a typical (normal year type). A more detailed model with time series input was not attempted owing to the lack of flow and water quality monitoring data required to develop such a model. Recent initiatives, primarily motivated by the inclusion of managed seasonal wetlands in the California Regional Water Quality Control Board Agricultural Waiver Program, have resulted in greater commitment to the monitoring of wetland return flows in the federal, state and private wetlands. Although the monitoring stations developed for this project in the San Luis Refuge pre-dated the Agricultural Waiver monitoring requirement - the stations have served as prototypes for future installations within the Refuge and in adjacent wetlands. For implementation of real-time water quality management a complete network of telemetered stations will be needed.

\subsubsection{Model design}

WETMANSIM was developed as an EXCEL spreadsheet and completes a monthly mass balance of flow and salt starting in the flood-up period each year, through the winter holding and spring drawdown sequence and summer moist soil plant irrigation. The model hydrology and salt mass balance cascades from month to month. Table 3.4 shows typical input values used in the model. 
Table 3.3 WETMANSIM assumptions and sample values

\begin{tabular}{|c|c|c|c|}
\hline PARAMETER & UNITS & AUG-MAR & ANNUAL \\
\hline $\begin{array}{ll}\text { 1. } & \text { flooded Surface Area } \\
\text { 2. } & \text { ETO loss inches per month } \\
\text { 3. } & \text { mean rainfall }\end{array}$ & $\begin{array}{l}\text { acres } \\
\text { inches } \\
\text { inches }\end{array}$ & $\begin{array}{r}2293 \\
6.9\end{array}$ & 9.4 \\
\hline $\begin{array}{ll}\text { 4. } & \text { porosity } \\
\text { 5. } & \text { target pond depth } \\
\text { 6. } & \text { fillable vadose zone depth } \\
\text { 7. } & \text { potential seepage loss }\end{array}$ & $\begin{array}{l}\text { percent } \\
\text { inches } \\
\text { inches } \\
\text { inches }\end{array}$ & $\begin{array}{l}0.2 \\
9.1 \\
6.9 \\
9.6\end{array}$ & $\begin{array}{c}0.2 \\
6.2 \\
8.6 \\
20.6\end{array}$ \\
\hline 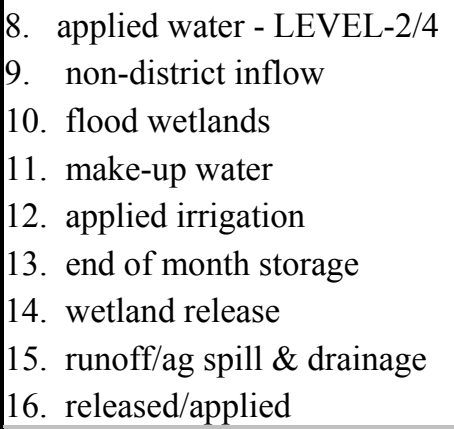 & $\begin{array}{l}\text { acre-feet } \\
\text { acre-feet } \\
\text { inches } \\
\text { inches } \\
\text { inches } \\
\text { inches } \\
\text { inches } \\
\text { inches } \\
\text { percent }\end{array}$ & $\begin{array}{c}19000 \\
0 \\
80.5 \\
42.7 \\
0.0 \\
\\
76.2\end{array}$ & $\begin{array}{c}19000 \\
0 \\
80.5 \\
42.7 \\
10.5 \\
\\
84.8\end{array}$ \\
\hline $\begin{array}{l}\text { 17. EC of supply water } \\
\text { 18. TDS supply water } \\
\text { 19. TDS wetland discharge } \\
\text { 20. TDS ag runoff } \\
\text { 21. total wetland discharge } \\
\text { 22. } \text { wetland discharge salt load }\end{array}$ & $\begin{array}{l}\mathrm{uS} / \mathrm{cm} \\
(\mathrm{mg} / \mathrm{L}) \\
(\mathrm{mg} / \mathrm{l}) \\
(\mathrm{mg} / \mathrm{l}) \\
\text { acre-feet } \\
\text { (tons) }\end{array}$ & $\begin{array}{c}603 \\
706 \\
10,387 \\
9,969\end{array}$ & $\begin{array}{r}645 \\
898 \\
11,540 \\
14,099\end{array}$ \\
\hline $\begin{array}{l}\text { 23. combined discharge to SJR } \\
\text { 24. combined discharge TDS }\end{array}$ & $\begin{array}{c}\text { acre-feet } \\
(\mathrm{mg} / \mathrm{l})\end{array}$ & $\begin{array}{c}10,387 \\
706\end{array}$ & $\begin{array}{c}11,540 \\
898\end{array}$ \\
\hline
\end{tabular}

\subsubsection{Model Detail}

The following is a line by line explanation of the parameters listed on the left column of Table 3.4.

1. The approximate flooded surface area was obtained from the wetland water managers for the State, Federal and private wetland areas. This represents the best guess for a normal water year of the acreage of ponded water during each month. Wetland units are defined as follows : Grassland WD is considered one wetland unit combining the North and South Grassland WD wetland areas; San Luis National Wildlife Refuge Complex is divided into San Luis, West Bear Creek, East Bear Creek, Freitas, Salt Slough and Kesterson wetland units; Los Banos WMA, Volta WMA and China island WMA are considered separate wetland units. Reducing the wetland footprint (flooded surface 
area) during any month reduces the volume of infiltrating water as a function of the water supplied to the wetland. This will result in a greater volume of wetland drainage.

2. ET0 is the potential monthly water loss from each flooded wetland. The average ET0 for the whole Grassland Ecological Area was obtained from the Grassland Water District.

3. Mean monthly rainfall. This estimate is based on rainfall records from CIMIS stations in Panoche Water District and with the former Kesterson Reservoir within the San Luis National Wildlife Refuge complex. NWR and are maintained by the Grassland Water District.

4. Porosity. This parameter is used to help estimate the amount of water that is required to displace the air-filled pores in the vadose zone of the regional aquifer. A higher porosity of 0.3-0.4, typical of sands, would require more water to fill and thus the wetland would exhibit greater water losses during flood-up. Monthly seepage would also be high and reach a steady-state once the initial flooding had filled all available pores. A value of 0.2 was used for most wetlands - which is indicative of a tighter soil with a high clay fraction.

5. Pond depth. The monthly average pond depth in seasonal wetlands will rise during flood-up to a level known as "shooting depth" (about 12 inches), which is a water depth that attracts diving ducks and other bottom-feeding waterfowl. This depth was assumed to be the average ponding depth once flood-up was completed.

6. Fillable vadose zone depth. This depth specifies the depth of the vadose zone and therefore help to define the pore volume that must be filled before water can pond on the wetland soil surface.

7. Potential seepage loss. This is calculated as : fillable vadose zone depth * soil porosity. It is the estimated depth of surface applied water that will move into the groundwater in any given month.

8. Applied water. The volume of water (acre-ft) diverted from surface channels and applied as groundwater to each wetland area. This quantity is greater for level IV water supply since it includes water allocated under CVPIA. Most incremental Level IV water is applied during the summer months and not uniformly distributed over the year. Monthly surface applied water for Level II and Level IV was developed in a series of open discussions with Grassland Water District, the California Department of Fish and Game and the Fish and Wildlife Service.

9. Non-district inflow. The volume of return flows from adjacent agricultural land. This mostly applies to return flows from CCID and San Luis Canal Company that have historically been conveyed through Grassland WD channels. These flows are occasionally used in Grassland Water District and supplement Reclamation water deliveries to the District. 
10. Flood wetlands. The depth of water applied to the average flooded area during each month during flood-up. For ease of accounting the spreadsheet begins in August. In most years flood-up occurs in September to minimize evaporative losses that would occur if flood-up occurred earlier. Shooting depth is achieved at different times in different parts of each wetland area. It is used as a calibration variable in the spreadsheet model.

11. Make-up water. The depth of water added after initial flood-up to bring water level to the desired average depth within each wetland management area.

12. Applied irrigation. The depth of water applied in the late spring and early summer months after initial drawdown to encourage the propogation of desirable moist soil plants. These quantities were supplied by water masters in the Grassland Water District, Los Banos Wildlife Management Area and San Luis National Wildlife Refuge.

13. End of month storage. A calculated water depth equivalent to the remaining depth of water after accounting for inflows and outflows to the wetland management area : EOMS $=$ flood wetlands + mean rainfall - potential evapotranspiration - seepage loss target pond depth.

14. Wetland release. The calculated depth of water is equivalent to the remainder when the monthly target pond depth is subtracted from the end of month storage depth. This is the equivalent depth of water returned to Mud or Salt Slough which discharge to the San Joaquin River. This can be converted to a volume by multiplying by the monthly average flooded surface area.

15. Runoff / ag spill. This water depth refers to any return flows generated during wetland irrigation. This volume is typically small owing to high evaporation during the late spring and early summer months.

16. Released/applied. The ratio of released water to water applied is expressed as a percentage. This is an index of wetland flushing - a higher percentage indicates a greater amount of wetland flushing.

17. Electrical conductivity (EC) of supply water. Most water applied to seasonal and permanent wetlands in the Grassland Ecological Area, other than groundwater pumping, derives from the Delta and is delivered via the Delta Mendota Canal. This supply water $\mathrm{EC}$ is the average salinity (measured in umhos/ $\mathrm{cm}$ ) in the turnout to the wetland entity. The monthly EC values were based on monitoring conducted by Berkeley National Laboratory for the Grassland Water District real-time water quality management project (Quinn et al., 2005).

18. Total Dissolved Solids (TDS) in the supply water. The ratio of EC to TDS varies depending on the salt composition of the water. For Delta water an average factor of 0.64 is used to convert EC to TDS. 
19. Salinity (TDS) of wetland discharge. Water ponded in seasonal and permanent wetlands is subject to direct evaporation losses and transpiration losses from emergent moist soil plants which remove pure water leaving saltier water behind. Dust and bird excreta also add to wetland salt loads. Evaporation increases in the summer months when temperatures are higher resulting in elevated wetland TDS concentrations.

20. Salinity (TDS) of agricultural runoff. In cases where summer irrigation results in surface drainage runoff - the salinity of this runoff is elevated owing to solution of surface salt crusts and other inorganic materials. Runoff is typically minimal and largely ignored in the model.

21. Total wetland discharge. This figure is obtained by multiplying the wetland drainage estimate (expressed as a depth of water) by the flooded surface area.

22. Wetland discharge salt load. This is obtained by multiplying the total wetland discharge (calculated in row 21) by the TDS of wetland discharge and adjusting the total using a conversion factor to convert the product (acre-ft * mg/l) to tons of salt.

23. Combined discharge to the SJR. This number should be the same as 19 except in the case of the Grassland Water District (GWD) where the return flow is a blend of the GWD wetland return flow and the surface return flows conveyed through GWD channels from the Central California Irrigation District (CCID) and the San Luis Canal Company (SLCC). The return flows from these Exchange Contractors typically improve the wetland drainage water quality providing some dilution effect to wetland drainage.

24. Combined discharge TDS. This item applies only to the Grassland Water District (GWD) and is the blended water quality when the wetland discharges and the agricultural surface return flows are combined.

\subsubsection{Calibration of WETMANSIM}

Calibration of WETMANSIM was attempted using the monitoring data collected in the San Luis National Wildlife Refuge during 2003 and 2004. The WETMANSIM spreadsheet for the San Luis Unit of the San Luis National Wildlife Refuge Complex is provided in Table 3.5. Table 3.6 shows a comparison between the WETMANSIM model estimated return flow salinity (TDS) and the salinity of the measured drainage return flows at Mallard Slough in the San Luis Unit of the San Luis National Wildlife Refuge Complex. The results show reasonable agreement for certain months between the modeled and measured salinity estimates. Given the large annual variation in return flow water quality, which is highly 
Table 3.4 WETMANSIM model output for San Luis Unit within the SLNWR Complex

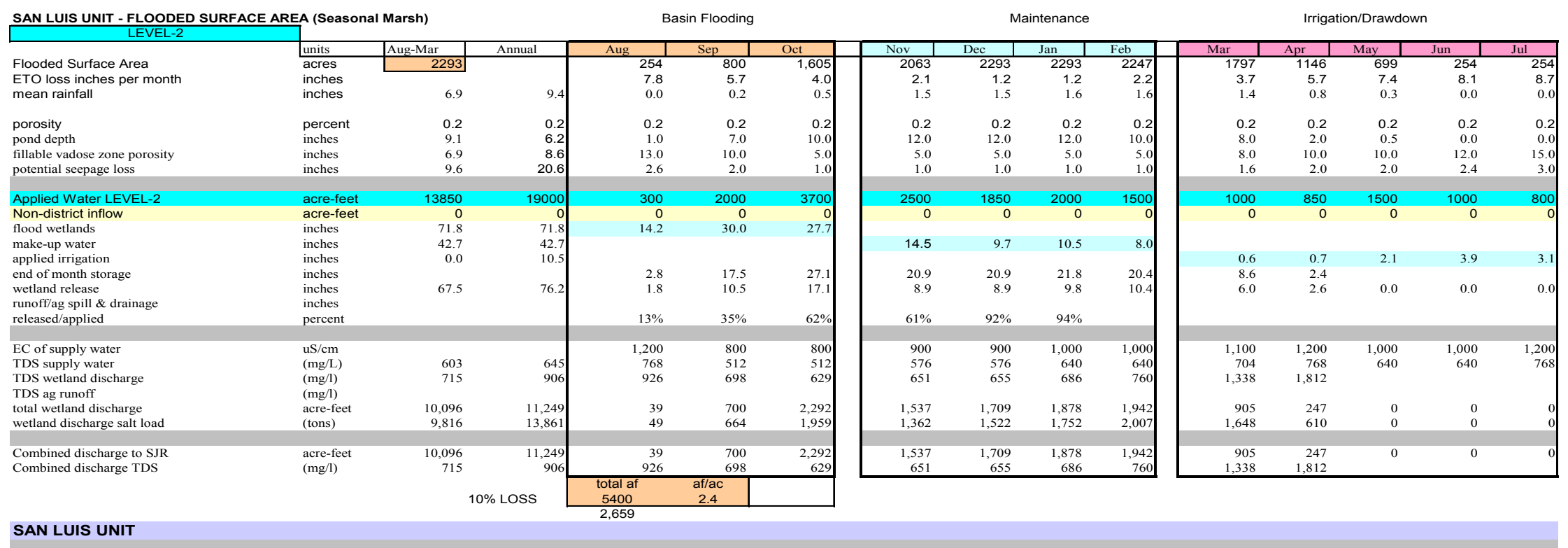

\section{SAN LUIS UNIT - FLOODED SURFACE AREA (Seasonal Marsh)}

\begin{tabular}{|c|c|c|c|c|c|c|}
\hline \multirow{3}{*}{$\begin{array}{l}\text { Flooded Surface Area } \\
\text { ETO loss inches per month } \\
\text { mean rainfall }\end{array}$} & & & & & & \\
\hline & $\begin{array}{l}\text { units } \\
\text { acres }\end{array}$ & \begin{tabular}{|c|} 
Aug-Mar \\
2293 \\
\end{tabular} & Annual & $\begin{array}{l}\text { Aug } \\
254\end{array}$ & $\frac{\text { Sep }}{800}$ & $\begin{array}{l}\text { Oct } \\
1,605\end{array}$ \\
\hline & $\begin{array}{l}\text { inches } \\
\text { inches }\end{array}$ & 6.9 & 9.4 & $\begin{array}{c}7.8 \\
0.0\end{array}$ & $\begin{array}{l}5.7 \\
0.2\end{array}$ & $\begin{array}{r}4.0 \\
0.5\end{array}$ \\
\hline porosity & percent & 0.2 & 0.2 & 0.2 & 0.2 & \\
\hline pond depth & inches & 9.1 & 6.2 & 1.0 & & \\
\hline fillable vadose zone porosity & inches & 6.9 & 8.6 & 13.0 & 10.0 & \\
\hline potential seepage loss & inches & 9.6 & 20.6 & 2.6 & 2.0 & 1.0 \\
\hline Applied Water LEVEL 2 + LEVEL-4 & acre-feet & 13850 & 19000 & 300 & 2000 & 3700 \\
\hline $\begin{array}{l}\text { Non-district inflow } \\
\text { flood wetlands }\end{array}$ & $\begin{array}{l}\text { acre-feet } \\
\text { inches }\end{array}$ & & & & 0 & \\
\hline $\begin{array}{l}\text { flood wetlands } \\
\text { make-up water }\end{array}$ & $\begin{array}{l}\text { inches } \\
\text { inches }\end{array}$ & $\begin{array}{l}71.8 \\
42.7\end{array}$ & $\begin{array}{l}71.8 \\
42.7\end{array}$ & 14.2 & & 27.7 \\
\hline $\begin{array}{l}\text { Make up waler } \\
\text { applied irrigation }\end{array}$ & inches & 0.0 & 10.5 & & & \\
\hline end of month storage & inches & & & 2.8 & 17.5 & 27.1 \\
\hline wetland release & inches & 67.5 & 76.2 & 1.8 & 10.5 & 17.1 \\
\hline $\begin{array}{l}\begin{array}{l}\text { runofffag spill \& } \\
\text { released/applied }\end{array}\end{array}$ & $\begin{array}{l}\text { inches } \\
\text { percent }\end{array}$ & & & $13 \%$ & $35 \%$ & $62 \%$ \\
\hline EC of supply water & $\mathrm{uS} / \mathrm{cm}$ & & & 1,200 & 800 & \\
\hline TDS su & $(\mathrm{m}$ & 603 & 645 & 768 & 512 & \\
\hline TDS wetland discharge & $(\mathrm{mg} / \mathrm{l})$ & 715 & 906 & 926 & 698 & 629 \\
\hline $\begin{array}{l}\text { TDS ag runoff } \\
\text { total wetland dis }\end{array}$ & $(\mathrm{mg} / \mathrm{l})$ & 10096 & 249 & 39 & & \\
\hline $\begin{array}{l}\text { Ther wetrand alscharge } \\
\text { wetland discharge salt load }\end{array}$ & $\begin{array}{l}\text { acre-ret } \\
\text { (tons) }\end{array}$ & $\begin{array}{r}90,890 \\
9,816\end{array}$ & $\begin{array}{l}11,249 \\
13,861\end{array}$ & 49 & 664 & 1,959 \\
\hline \multirow{3}{*}{$\begin{array}{l}\text { combined discharge to SJR } \\
\text { combined discharge TDS }\end{array}$} & acre-feet & 10,096 & 11,249 & 39 & 700 & 2,292 \\
\hline & $(\mathrm{mg} / \mathrm{l})$ & 715 & & 926 & 698 & 629 \\
\hline & & \multicolumn{2}{|c|}{$10 \%$ LOSS } & 5400 & affac & \\
\hline
\end{tabular}

\begin{tabular}{|c|c|c|c|}
\hline & \multicolumn{3}{|c|}{ Maintenance } \\
\hline \begin{tabular}{|c|} 
Nov \\
2063
\end{tabular} & \begin{tabular}{c|} 
Dec \\
2293
\end{tabular} & \begin{tabular}{|l|} 
Jan \\
2293
\end{tabular} & $\begin{array}{l}\text { Feb } \\
2247\end{array}$ \\
\hline 2.1 & 1.2 & $\begin{array}{r}1.2 \\
1.2\end{array}$ & $\begin{array}{r}2.2 \\
2.2\end{array}$ \\
\hline 1.5 & 1.5 & 1.6 & \\
\hline 0.2 & 0.2 & 0.2 & \\
\hline 12.0 & 12.0 & 12.0 & 10.0 \\
\hline 5.0 & 5.0 & 5.0 & \\
\hline & & & \\
\hline 0 & $\begin{array}{l}10000 \\
0\end{array}$ & 200 & \\
\hline 14.5 & 9.7 & 10.5 & 8.6 \\
\hline 20.9 & 20.9 & 21.8 & 20.4 \\
\hline 8.9 & 8.9 & 9.8 & 10.4 \\
\hline $61 \%$ & $92 \%$ & $94 \%$ & \\
\hline 900 & 900 & 1.000 & 1,000 \\
\hline 576 & 576 & 640 & 64 \\
\hline & & & \\
\hline $\begin{array}{l}1,537 \\
1,362\end{array}$ & $\begin{array}{l}1,709 \\
1,522 \\
-10\end{array}$ & $\begin{array}{l}1,878 \\
1,752\end{array}$ & $\begin{array}{l}1,942 \\
2,007\end{array}$ \\
\hline 1.537 & 1709 & 1878 & \\
\hline 651 & 655 & 686 & \\
\hline
\end{tabular}

Irrigation/Drawdown

\begin{tabular}{|rrrrr|r|}
\hline Mar & \multicolumn{1}{c|}{ Apr } & \multicolumn{1}{c|}{ May } & \multicolumn{1}{c|}{ Jun } & \multicolumn{1}{c|}{ Jul } \\
\hline 1797 & 1146 & 699 & 254 & 254 \\
3.7 & 5.7 & 7.4 & 8.1 & 8.7 \\
1.4 & 0.8 & 0.3 & 0.0 & 0.0 \\
0.2 & 0.2 & 0.2 & 0.2 & 0.2 \\
8.0 & 2.0 & 0.5 & 0.0 & 0.0 \\
8.0 & 10.0 & 10.0 & 12.0 & 15.0 \\
1.6 & 2.0 & 2.0 & 2.4 & 3.0 \\
1000 & 850 & 1500 & 1000 & 800 \\
0 & 0 & 0 & 0 & 0 \\
& & & & \\
0.6 & 0.7 & 2.1 & 3.9 & 3.1 \\
8.6 & 2.4 & 0.0 & 0.0 & 0.0 \\
6.0 & 2.6 & & & \\
& & & & \\
1,100 & 1,200 & 1,000 & 1,000 & 1,200 \\
704 & 768 & 640 & 640 & 768 \\
1,338 & 1,812 & & & \\
905 & 247 & 0 & 0 & 0 \\
1,648 & 610 & 0 & 0 & 0 \\
905 & 247 & 0 & 0 & 0 \\
1,338 & 1,812 & & & \\
& & & &
\end{tabular}


Table 3.5. Comparison of WETMANSIM model wetland drainage salinity and WY 2004 field data from Mallard Slough in the San Luis National Wildlife Refuge.

\begin{tabular}{|c|c|c|c|}
\hline & EC Mallard Slough & TDS Mallard Slough & $\begin{array}{c}\text { TDS WETMANSIM } \\
\text { (level 2 supply) }\end{array}$ \\
\hline Sept & 849 & 628 & 698 \\
Oct & 849 & 628 & 629 \\
Nov & 1158 & 857 & 651 \\
Dec & 1558 & 1153 & 655 \\
Jan & 1612 & 1193 & 686 \\
Feb & 1272 & 941 & 760 \\
Mar & 1771 & 1311 & 1338 \\
Apr & 1372 & 1015 & 1812 \\
May & 1124 & 832 & \\
Jun & 1472 & 1089 & \\
& & (TDS = EC * 0.74) & \\
\hline
\end{tabular}

correlated with water year type the results of this comparison are not unexpected given the potentially large interannual variation in basin hydrology. A wet spring can have a significant impact on return flow and improve water quality as a result of direct rainfall on ponded areas. Early snowmelt events in the Sierra Nevada can dilute wetland supply water from the Delta Mendota Canal and also help to dilute wetland return flow salinity. Time series of flow and salinity data for several years will be necessary to properly assess the merits of the model.

\subsection{Future model development}

Two different modeling approached have been presented in this chapter. The WETDWQM model is an operations model which requires daily hydrology, meteorology and water quality data to run. The model is meant as a screening and forecasting tool to assist water managers make scheduling decisions for wetland drainage in response to San Joaquin River assimilative capacity for salt loads. WETMANSIM is a planning tool which makes more generalized assumptions about wetland hydrology and uses monthly average data to calculate an average monthly wetland drainage salinity. Both models have utility until such time as all wetland drainage outlets are instrumented in the Grassland Ecological Area and data driven models such as WETDWQM can be calibrated with readily available data. 


\section{CHAPTER 4 HABITAT QUANTIFICATION AND ASSESSMENT USING REMOTE SENSING}

\subsection{Introduction}

The San Luis National Wildlife Refuge (SLNWR) is comprised of $113 \mathrm{~km}^{2}$ of seasonal wetlands in the San Joaquin Valley of California. These wetlands lie on the Pacific Flyway and are an important source of food and habitat for migrating and local bird populations. The wetlands, both publicly and privately owned, are also significant water users in the area. As water resources become increasingly scarce, the need to accurately estimate water needs and water quality impacts of these areas becomes an increasingly high-priority problem.

The water regime in these managed wetlands is largely artificial, with surface water inflows and outflows designed to replace a natural wetland hydrologic cycle. Water management practices include the timing of irrigations and draw-downs to maximize desirable food production plants and to minimize undesirable weeds. Outflow events, such as draw-downs, can influence water quality in the San Joaquin River, and so wetland managers are exploring ways of timing water management events in order to comply with water quality objectives. However, any change in water management practices that can impact the wetlands' ecological health or distribution of habitat requires a means of estimating these impacts accurately. Remote sensing has great potential to fulfill this assessment requirement. This study extends a basic methodology for using high resolution satellite imagery to map wetlands land cover.

There are increasing pressures in the San Joaquin Valley to quantify water usage and water needs. In addition to drains and measured outflows, water exits these wetland systems through evaporation and transpiration. Land managers' understanding of how local vegetation influences water usage is rudimentary. One way to improve water use estimates is to develop an understanding of the evapotranspiration characteristics of the existing plant communities. (Norman, et al 1993) With an understanding of the distribution of plant communities and their evapotranspiration characteristics, scientists could provide improved estimates of water needs and water usage for managed wetlands in the San Joaquin Valley. 
This study provides a basic methodology for estimating regional evapotranspiration values using literature values for evapotranspiration.

Remotely sensed digital imagery captures the spectral reflectance values of different land cover classes. By combining high resolution satellite images and image processing tools with industry standard environmental survey methods, we can accurately and efficiently estimate the abundance of different species of wetland vegetation over large regions. Analysis of satellite imagery to quantify land cover in managed wetlands has multiple benefits. Compared to traditional vegetation survey techniques, satellite imagery requires significantly less time and labor, while covering a larger area. Rather than the exhaustive ongoing field effort that would be required to survey a large area such as SLNWR, field work is limited to the time necessary to provide calibration for the image. While satellite imagery can be used effectively to map large or small areas, it becomes increasingly cost effective for larger study sites. Satellite imagery is also a flexible technology; depending on the variables of interest, image collection can be timed to capture different features throughout the growing season. Through tracking the changes in multi-temporal imagery and correlating changes with previous management decisions, impacts may be assigned to various land use activities (Holland, 1986, Fredrickson, 1991.)

Satellite imagery is also an unbiased and stable data source, reducing concerns of consistency between teams of surveyors, or drifts in field methodology and nomenclature throughout the field season. As an added benefit, the availability of satellite imagery as a standardized data source creates the potential for study sites to be viewed in a broader context, both regionally and worldwide. Finally, the imagery provides an archival data source, which after its initial use, continues to be available as a historical reference, and can be used in later studies, the requirements of which may not have been foreseen at the time.

\subsubsection{Background}

For SLNWR, management decisions such as scheduling drawdowns and irrigations are made routinely, and the timing of these events changes from year to year. Habitat assessment is needed to optimize the timing of these changes. Traditional means of habitat assessment 
such as random sampling or transects for large areas ( $>1000$ acres) are extremely labor intensive (Tatu et al., 1999.) It can also be difficult to acquire timely data at a high enough resolution. Moreover, although impact assessment using a fine scale sampling program at the individual pond level could be accomplished, the spatial variations found in larger areas may be missed completely (Link et al., 1994.) What is needed is a way to rapidly assess and quantify the various habitat communities at the regional scale, and readily track changes in those communities from year to year (Wiens and Parker, 1995, Shuford et al., 1998; Shuford et al., 1999.)

In this project, a methodology was developed for mapping seasonal wetlands in the San Joaquin Valley. In addition, for 2005, a methodology was developed for estimating the water lost from these wetlands through evapotranspiration. The project was performed in two study areas: the San Luis unit of SLNWR, and the northern zone of Grasslands Water District (NGWD.) Figure 4.1 shows the area in which land cover was mapped in 2004, and Figure 4.2 shows the area mapped in 2005. These two areas are in close association with similar climate, soils, and topography, and yet they differ significantly in their management goals, land history, and diversity of both flora and fauna. The two areas represent two end points achieved through differing management strategies, and provide the opportunity to evaluate the robustness of the mapping methodology. Mapping can perform two major functions for land managers of these areas; firstly to catalog the existing vegetation communities, both in composition and aerial extent; and secondly to assess changes in these communities over time. If a mapping methodology can perform these two functions conjunctively, it can provide valuable assistance to wetland managers in making effective management decisions. 


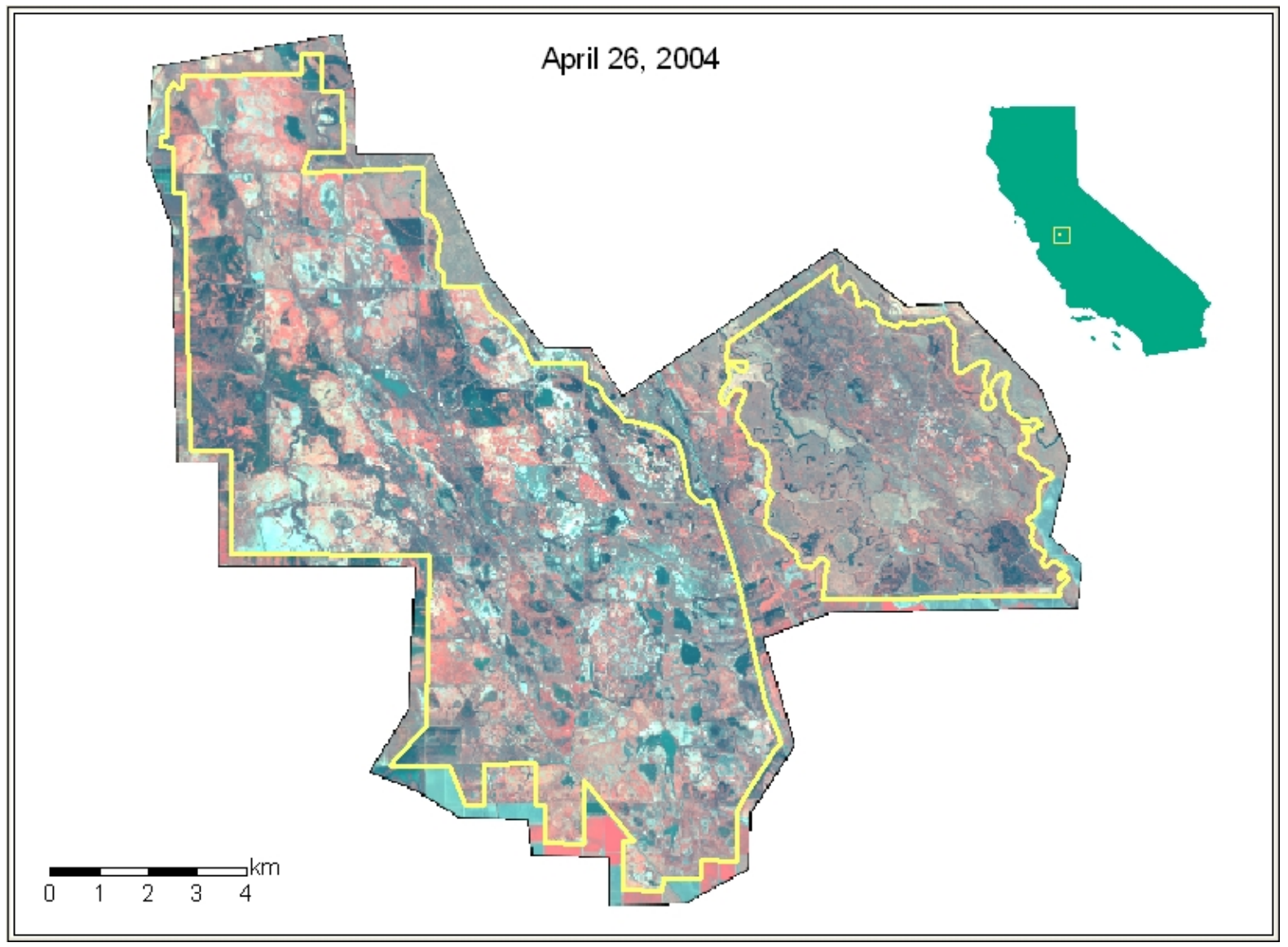

Figure 4.1 Project imagery from April 2004. NGWD is outlined on the western side, and SLNWR is shown to the east. The insert shows the location of the site within California. The image is displayed with a false color mapping and a contrast stretch to enhance viewability. Verdant vegetation displays as red in this mapping. Some differences between the two study areas are apparent via visual analysis. For example, the average size of wetland basins in SLNWR appears much smaller than in NGWD. 


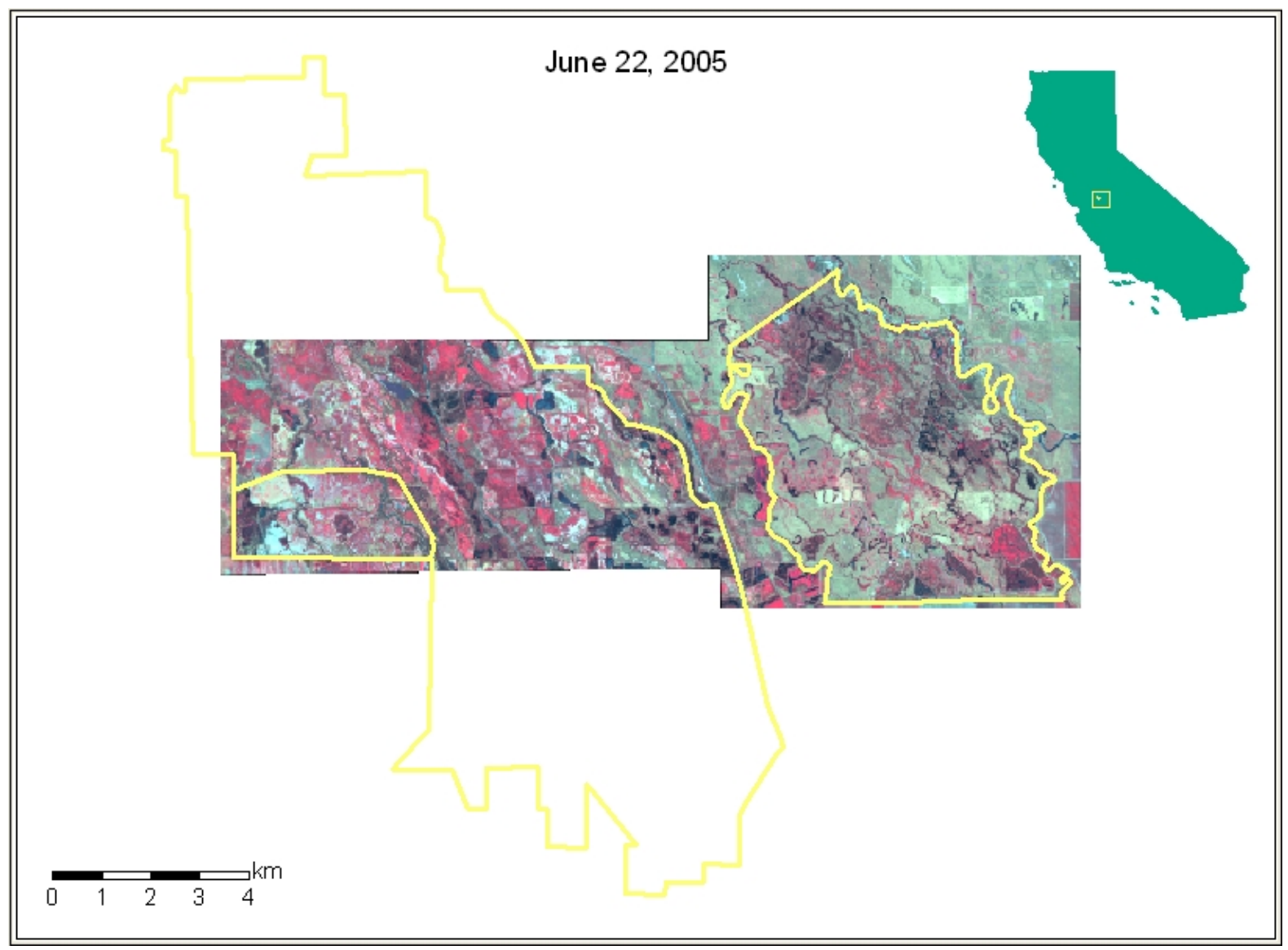

Figure 4.2 Project imagery from June 2005. NGWD is outlined on the western side, including an interior delineation of Salinas Land \& Cattle Club, and SLNWR is shown on the eastern side. The insert shows the location of the site within California. The image is displayed with a false color mapping and a contrast stretch to enhance viewability.

Additional imagery will be needed in order to estimate evapotranspiration in the wetlands year round. LANDSAT 7 ETM+ imagery can provide the necessary data. This imagery has a coarser spatial resolution but is available year round at low cost and is suitable for determining areas of open water and vegetation. More importantly, the ETM+ sensor provides a thermal infrared (TIR) band which is essential for the application of energy budget models to estimate evapotranspiration. The use of LANDSAT imagery is discussed in section 4.8 . 


\subsection{Methods}

\subsubsection{Data Acquisition - Imagery}

Various imagery could be used to map vegetation in California's San Joaquin Valley. This project used high-resolution, multi-spectral QuickBird imagery purchased from Digital Globe (Longmont, Colorado.) High-resolution satellite imagery refers to the recent generation of satellite sensors that have a spatial resolution of less than five meters. A high spatial resolution is necessary to capture the spatial variability of the small and irregularly shaped vegetation communities that are typical of the wetlands. The term "multispectral" denotes imagery with a small number of broad spectral bands (generally three to ten bands that each cover a significant section of the electromagnetic spectrum.) This land cover mapping project required imagery to provide bands in the blue, green, red and near-infrared (NIR) ranges of light. Multiple vendors provide an acceptable image product meeting these requirements. QuickBird and IKONOS data (Space Imaging - Thornton, Colorado) are both widely used to satisfy these requirements. Sensors flown on an aircraft platform can also produce high-resolution, multispectral data. A detail of the spectral and spatial characteristics of project image data is given in Table 4.1.

Table 4.1 Specifications of project imagery.

\begin{tabular}{|c|c|}
\hline Color/ Band & QuickBird \\
\hline Blue & $450-520 \mathrm{~nm}$ \\
\hline Green & $520-600 \mathrm{~nm}$ \\
\hline Red & $630-690 \mathrm{~nm}$ \\
\hline NIR & $760-900 \mathrm{~nm}$ \\
\hline Panchromatic & $450-900 \mathrm{~nm}$ \\
\hline Spatial resolution & $\begin{array}{c}2.4 \mathrm{~m} \text { multispectral } \\
60 \mathrm{~cm} \text { panchromatic }\end{array}$ \\
\hline
\end{tabular}

The imagery was geometrically corrected to improve spatial accuracy. The 2004 imagery was delivered in the form of orthorectified GeoTIFF files. Orthorectification is a process by which the imagery is tied to precisely located ground control points and corrected with 
respect to elevational distortion. The orthorectification was based on ground control points collected by project personnel and on a publicly available digital elevation model (DEM.) DigitalGlobe performed the orthorectification for the 2004 imagery, and the root mean square error (RMSE) for the imagery orthorectification process was 2.1 pixels. The 2005 imagery can be corrected for spatial distortion by co-registering it directly to the orthorectified 2004 imagery.

Imagery was collected for three dates in 2004 - April 26, May 14, and June 19. Image collection was timed to represent different stages of growth throughout the growing season. The late April image would capture seedlings and perennials in wetland basins, and verdant uplands vegetation. May imagery was timed to coincide with the maximum growth period for wetland basins, following the first summer irrigation, usually late May to early June (Lower, 2003; Poole, 2003.) The May imagery would therefore capture a mix of inflorescence and mature growth in the wetland basins, and a mix of inflorescence, verdant growth, and seeding in the uplands vegetation. June imagery was designed to capture inflorescence, mature growth, and seeding in the wetlands basin, and seeding and senescence in the uplands vegetation.

Figures 4.3, 4.4 and 4.5 show the project imagery for April, May and June 2004 in natural color. In this display, the red, green and blue bands are mapped to red, green, and blue respectively. A color stretch has been performed on the imagery to enhance contrast and ease of viewing. Since each band has been stretched to utilize the full range of digital values, the image appears vividly colored. Even without additional processing, differences in the spectral signal between images taken at the different times during the drawdown period can be detected. As the grasses mature and senesce their spectral signal shows less chlorophyll. 


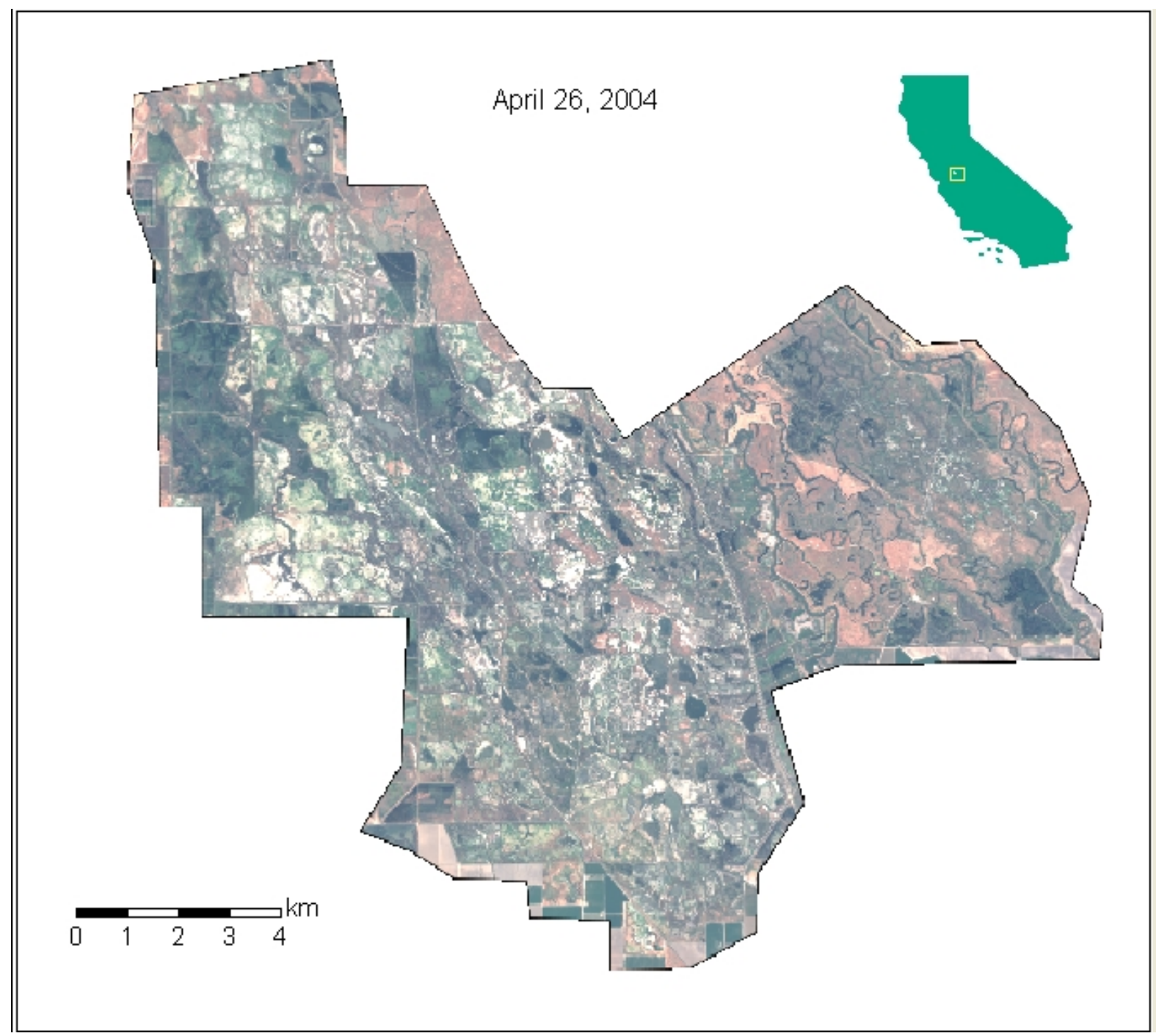

Figure 4.3 Project imagery from April 2004. The image is displayed using a contrast stretch to enhance ease of viewing. Wetland mosit soil plant diversity differences between the two study areas are visible even in this basic display. 


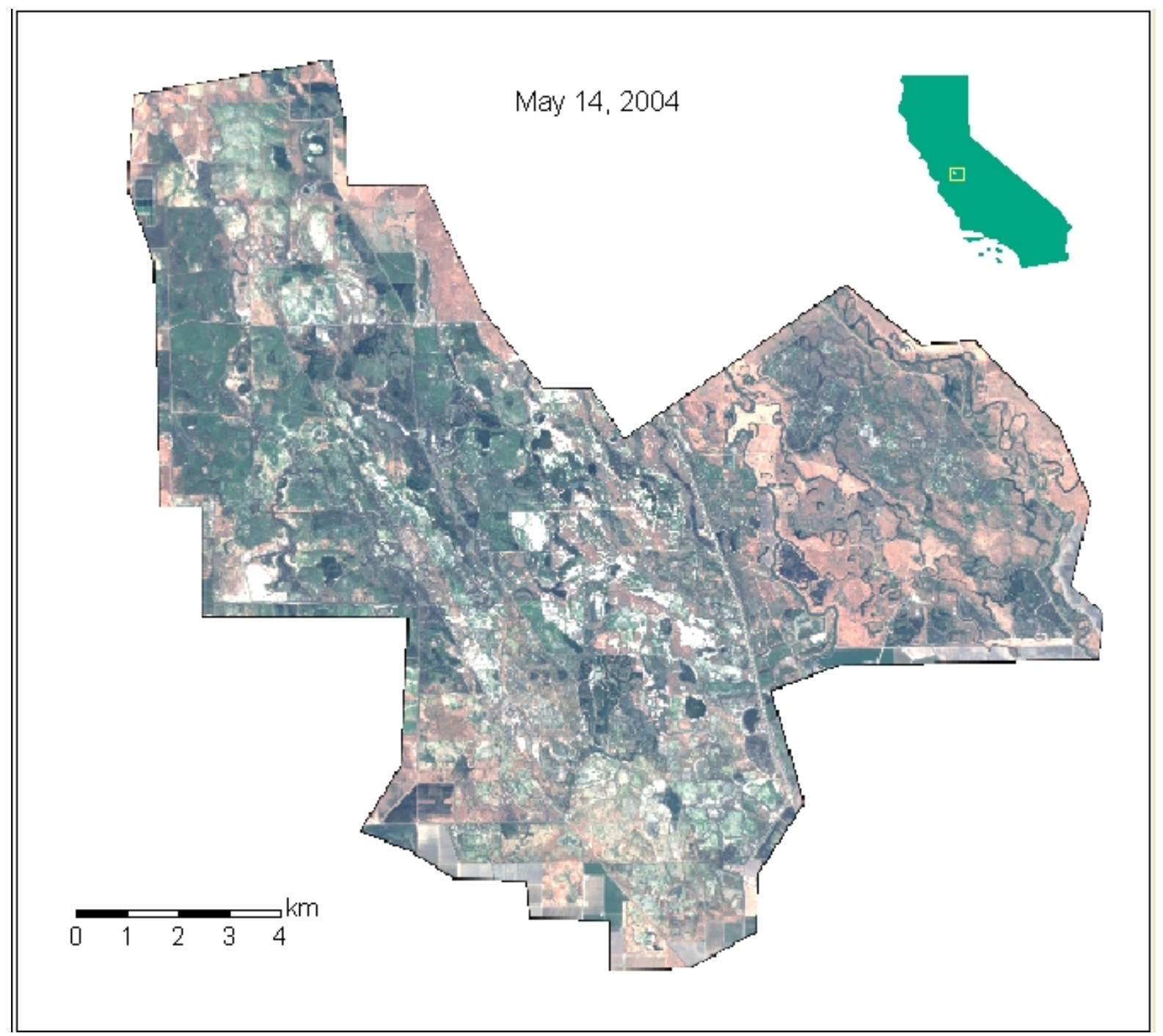

Figure 4.4 Project imagery from May 2004. The image is also displayed using a contrast stretch to enhance ease of viewing. This images shows some subtle changes in the spectral signal due to maturing of certain grasses as well as increased ground cover by growing wetland moist soil plants. 


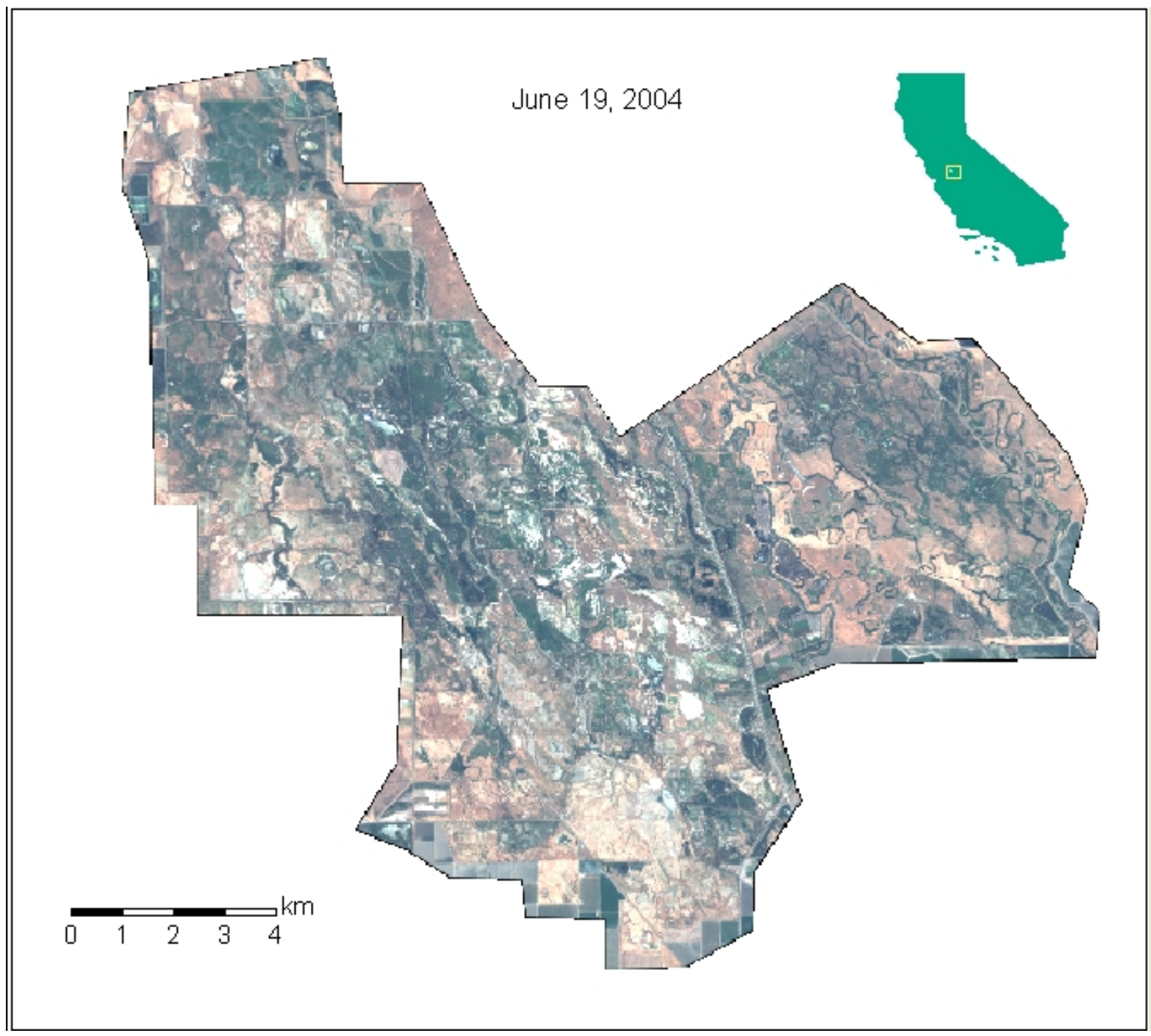

Figure 4.5 Project imagery from June 2004. The image is displayed using a contrast stretch. The June image appears less green than the May image - vegetative senescence already underway in June for certain moist soil plants.

\subsubsection{Data Acquisition - Field Data}

For field data collection, the project used a modification of the California Native Plant Society's Rapid Assessment Protocol (CNPS RAP), co-developed by the California Department of Fish and Game (CNPS, 2003.) The RAP is accepted widely for similar applications throughout California. The California Native Plant Society, the California Department of Fish and Game, California State Parks, National Parks, other state and federal agencies, and consulting firms all use this methodology to quickly and quantitatively inventory and map vegetation types for projects throughout California. For example, it has 
been used in conjunction with a Wildlife Habitat Relationships (WHR) Validation study at Point Reyes National Seashore. It is also being used to inventory and map vegetation for prioritization of conservation sites in the Los Angeles and San Gabriel River watersheds, the San Dieguito River drainage, Napa and Riverside Counties (CNPS, 2003.)

The CNPS RAP employs a community-based approach to surveying. In its original format, the CNPS RAP uses a one-page worksheet to rapidly assess large landscapes for a number of important parameters. These parameters include composition and abundance information on the communities' member plant species, and general site environmental factors. The RAP also provides guidance for identifying characteristics such level of community disturbance (CNPS, 2003.) The RAP is useful for collecting basic quantitative information sufficient for identification and verification of habitats. It can be used for rapid inventory of habitats in any management area, whether it is dominated by native or non-native plants. The RAP method provides land use managers with efficient tools for natural resource inventorying and planning (CNPS, 2003.)

Modifications were made to the CNPS protocol that reflected the needs and particular focus of this study. For example, in this project's field surveys, field protocols removed the CNPS's emphasis on native species and placed equal weight on cataloging important nonnative species. Because of the availability of detailed soils maps for the area, the timeconsuming soil classification technique used by the RAP was replaced by existing soil survey data. Other modifications included the addition of new data fields, such as noting the presence of visible salts, as it was perceived that this could have an effect on the spectral response of the landcover. In 2004, the traditional RAP vegetation worksheet was programmed into a hand-held GPS computer. A Trimble GeoExplorer 3 GPS was programmed with the data fields necessary to define a community according to the protocol, so that the collection of GPS positions would be automatically tied to attribute data for each data point. The land cover database was programmed with comprehensive, predefined pulldown menus wherever possible in order to standardize and streamline the entry of field data. The development of this computer-based data collection system made it possible to collect considerably more field data in comparison with previous projects. 


\subsubsection{Ground Truthing}

Ground truthing of remotely sensed imagery is the process of collecting in situ data that tie the spectral values in the imagery to land cover on the earth's surface. Ground truth data can be used both as input to the classification process and, once classification is complete, to check the accuracy of interpretation. Ground truth data was collected during the days shortly before, during, and after the satellite fly-overs to ensure maximum correlation between field data and the recorded image. Ground truth data was collected primarily on the San Luis unit of the SLNWR and at the Salinas Land and Cattle Club (Salinas Club), a privately owned area of approximately 1,600 acres, during the same time period.

Table 4.2 Distribution of ground truth points

\begin{tabular}{|c|c|c|c|c|}
\hline Location & April 26, 2004 & May 14, 2004 & June 19, 2004 & June 22, 2005 \\
\hline SLNWR & 97 & 127 & 183 & 207 \\
\hline Salinas Club & 79 & 79 & 93 & 58 \\
\hline Total & 176 & 206 & 276 & 265 \\
\hline
\end{tabular}

Table 4.2 shows the distribution of ground truth points for the four satellite images. In 2004, a total of 176, 206, and 276 ground truth points were collected for the April, May, and June images respectively. The increasing number of points collected throughout the growing season reflects both an increase in the efficiency of data collection and a decrease in the land surface that was flooded. In order to ensure coverage of important species, local refuge managers and wetland biologists assisted in the selection of ground truth locations. Also, to provide for coverage of the range of habitats within wetland basins, ground truth data was collected in all major accessible basins within the SLNWR and Salinas Club.

In 2005, the sampling design was changed to emphasize the diversity of habitats present at SLNWR. For the most common species, ground truth points were collected according to a random stratified sampling plan, based on the map of land cover produced for 2004. For species not so commonly present in the landscape, points were collected on an as-found, asneeded basis, similar to data collection for 2004 . 
Minor modifications were made to the field data collection protocol in 2005. In order to conform more closely to the original CNPS protocol, a few attribute fields were added to the data dictionary. These include the addition of a field which requires a field determination of wetland habitat versus upland habitat and the routine collection of one representative photo per data point. Percent coverage of bare soil or standing water was also explicitly defined for 2005, as it was recognized that this percentage could be ambiguous if implied from the coverage for vegetation and litter. Data was collected for only six plants per vegetation community (down from eight in 2004), as became clear during data processing that plants with only a minor presence in the community would not contribute significantly to the spectral signature for a pixel. Table 4.3 shows the extensive suite of data collected for one ground truth data point, along with abbreviated field names used in the database and an explanation of each field. 
Table 4.3 Sample field data from modified CNPS Rapid Assessment Protocol

\begin{tabular}{|c|c|c|}
\hline Attribute Name & Field Entered Data & Explanation \\
\hline Surveyor & Jos and Heather & personnel performing the survey \\
\hline waypt_type & cocklebur & type of vegetation expected at random point \\
\hline waypt_num & 2 & number to track which waypoint was located \\
\hline comm_type & wetland & community type - wetland, upland, riparian, or other \\
\hline Veg_cov & $35-50 \%$ & bird's eye view of ground cover of viable vegetation \\
\hline herb_hgt & $<12$ & height of herbaceous species - < or > 12" \\
\hline Litter_cov & $1-5 \%$ & bird's eye view of litter cover \\
\hline Litter_typ & herbaceous & type of litter, if present \\
\hline bare & $50-75 \%$ & bird's eye view of percent bare soil or standing water \\
\hline Soil_mois & dry & soil moisture \\
\hline cracking & & soil cracking, if present (low, medium, high) \\
\hline vis_salt & & visible salts, if present (low, medium, high) \\
\hline Soil_com & & soil comment \\
\hline Shape_1 & irregular & shape of vegetation community \\
\hline Shape_com & & shape comment \\
\hline Size & $300-600 \mathrm{sq} \mathrm{m}$ & size of vegetation community \\
\hline Topography & Flat & topography covered by community \\
\hline Disturb & & type of community disturbance, if present \\
\hline Dist_level & & disturbance level, if present \\
\hline Dist_com & & disturbance comment \\
\hline Com_com & & community comment \\
\hline plant1 & cocklebur & species ID of first plant \\
\hline Growth1 & pre-bloom & growth stage of first plant \\
\hline Health1 & good & health of first plant \\
\hline Per_cov1 & $35-50 \%$ & bird's eye view of ground coverage of first plant \\
\hline sp_conf1 & High & confidence in species ID \\
\hline sp_com1 & & species comment \\
\hline Oth_sp1 & & text field for field entry of unlisted species ID \\
\hline Hea_com1 & & health comment for first plant \\
\hline plant2 & swamp timothy & . \\
\hline Growth2 & pre-bloom & . \\
\hline Health2 & fair & . \\
\hline Per_cov2 & $1-5 \%$ & \\
\hline sp_conf2 & High & \\
\hline \multicolumn{3}{|l|}{ sp_com2 } \\
\hline \multicolumn{3}{|l|}{ Oth_sp2 } \\
\hline \multicolumn{3}{|l|}{ Hea_com2 } \\
\hline . & & . \\
\hline$\cdot$ & & . \\
\hline . & & . \\
\hline plant6 & & attributes for up to 6 species \\
\hline $\begin{array}{l}\text { patch1 } \\
\text { patch1_com } \\
\text { patch3_com }\end{array}$ & scirpus spp & $\begin{array}{l}\text { first patch within the community, if present } \\
\text { comment for first patch } \\
\ldots \text { attributes for up to } 3 \text { patches }\end{array}$ \\
\hline adjac1 & scirpus spp & dominant species of adjacent community, as needed \\
\hline adj1_com & & comment for first adjacent community \\
\hline adj3_com & & ... attributes for up to 3 adjacent communities \\
\hline
\end{tabular}


In 2004, ground truth data were post-processed for improved accuracy and utility. GPS feature positions were post-processed via differential correction to improve the accuracy of feature locations. 2005 data will be processed in this way also. Differential correction utilizes data from a regional base station with a known, fixed location to correct for GPS errors that may be introduced via satellite error, transmission error, or atmospheric effects. Differential correction was performed using Trimble Pathfinder Office software and using cotemporaneous base station data from the National Geodetic Survey Continuously Operating Reference Stations (NGS CORS.) Following differential correction, the data was exported to ESRI (Redlands, CA) shapefile format. The feature attribute data was then analyzed using ESRI's ArcGIS software to identify the two dominant species in each vegetation community. The field data could then be applied to classification of the images. Figures 4.6, 4.7, 4.8, and 4.9 depict the locations of ground truth data at SLNWR and Salinas Club for 2004 and 2005.

In a few cases, ground truth points were selected after the fact based on analyst interpretation of the images. Data points were selected this way for the land cover classes of trees, water, and buildings. Each of these land cover types is easily identifiable through visual analysis of the image, and difficult to obtain values for in the field. (For example, to obtain a ground truth point for open water, you either have to find a boat, or go stand in the middle of a pond.) Collecting points in this way involves a negligible risk of error on the part of the analyst and ensures adequate data to compile a robust spectral signature for these classes. The additional ground truth points were not included in the totals listed in Table 4.2. 


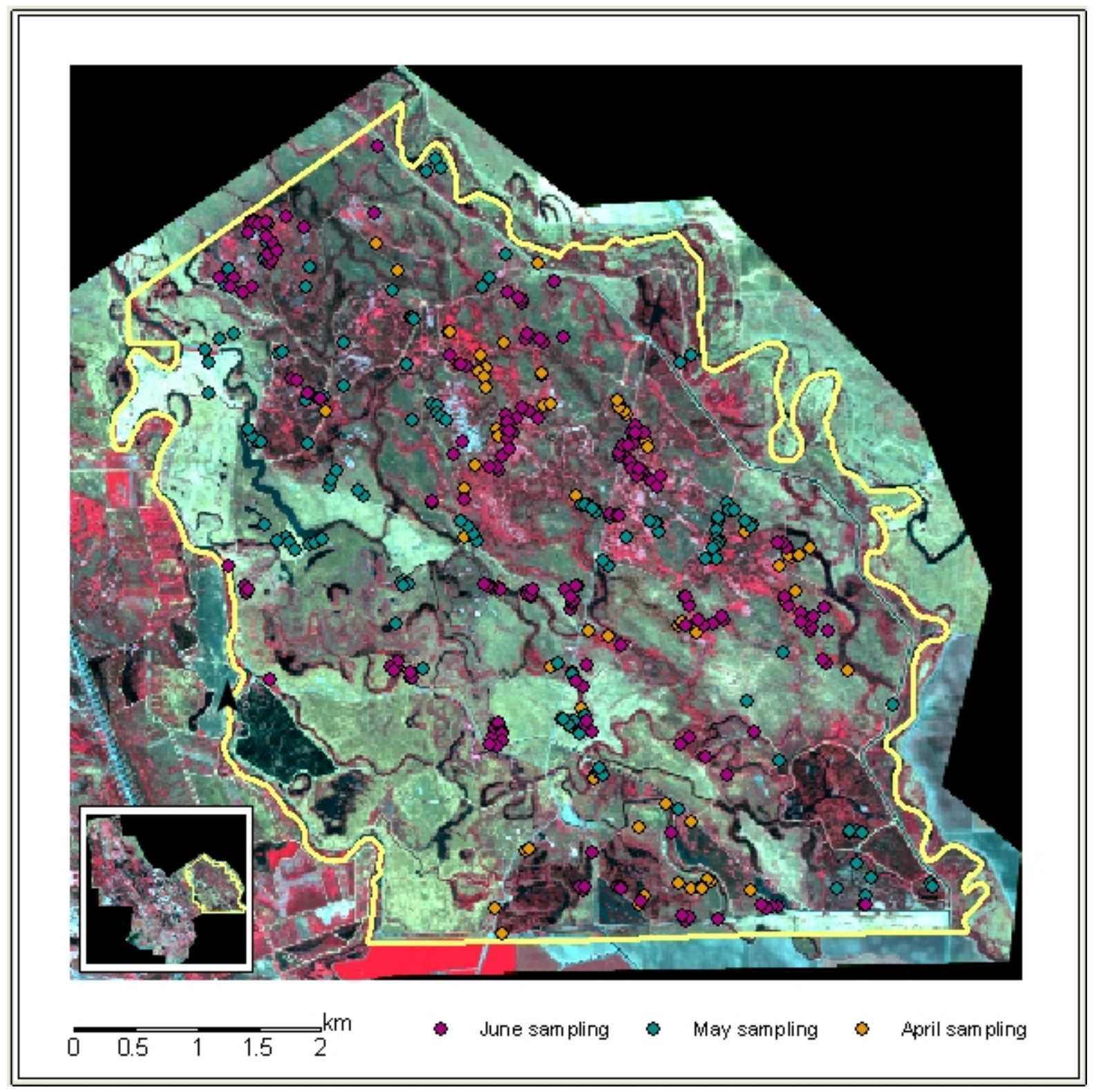

Figure 4.6 - Ground truth locations, 2004, San Luis unit, San Luis National Wildlife Refuge, Merced County, CA. NB: scale is different from display of Salinas Club in Figure 4.7. Field data locations have been overlain on a false color mapping of the NIR, red, and green bands of the May 14, 2004 satellite imagery. Regions of verdant vegetation appear red, water appears dark, and regions of dry uplands appear light green. 


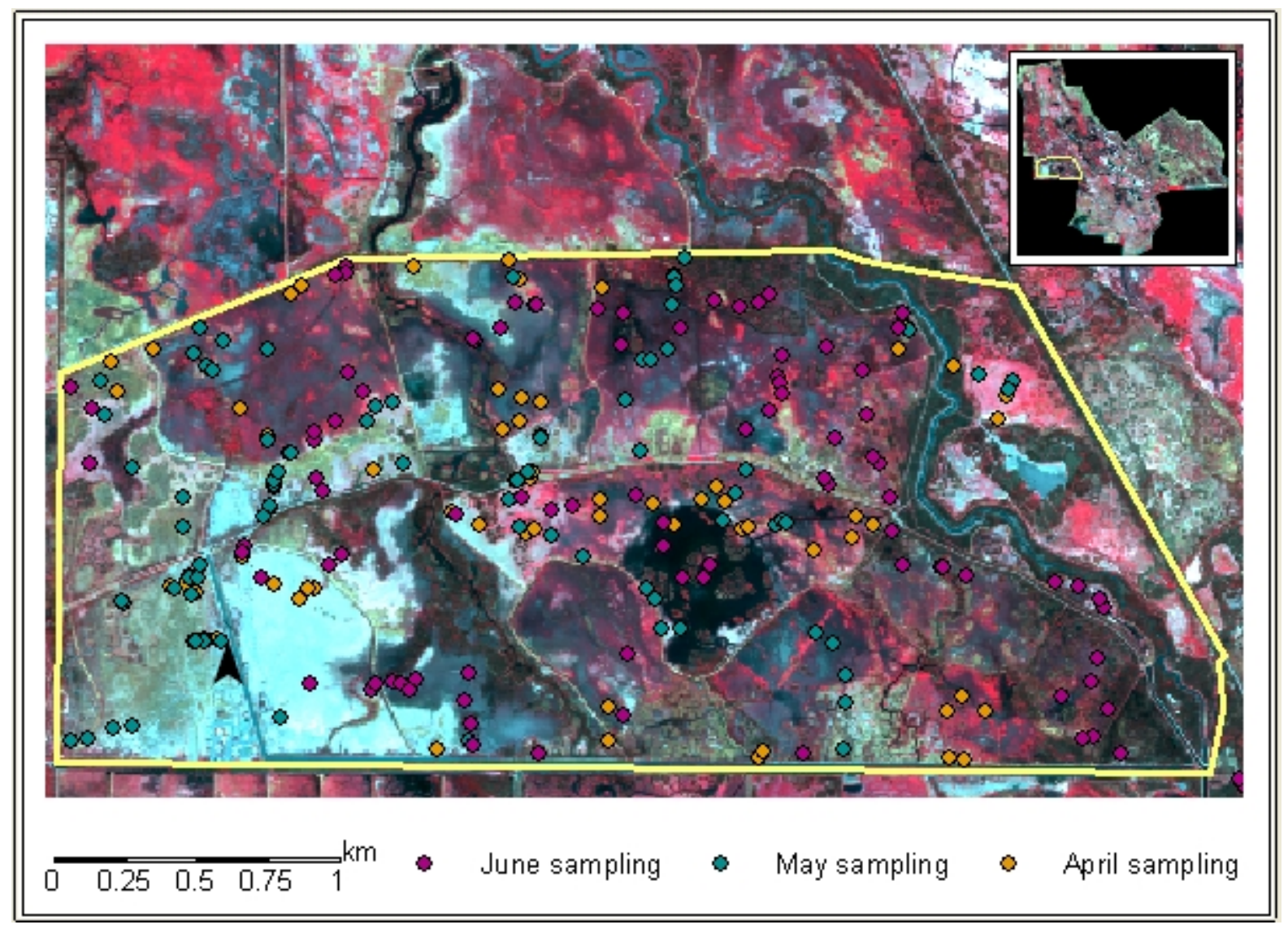

Figure 4.7 Ground truth locations, 2004, Salinas Club, Merced County, CA. NB: scale is different from display of SLNWR in Figure 4.6. Field data locations have been overlain on a false color mapping of the NIR, red, and green bands of the May 14, 2004 QuickBird imagery. Regions of verdant vegetation appear red, water appears dark, and regions of bare, dry soil appear bright. 


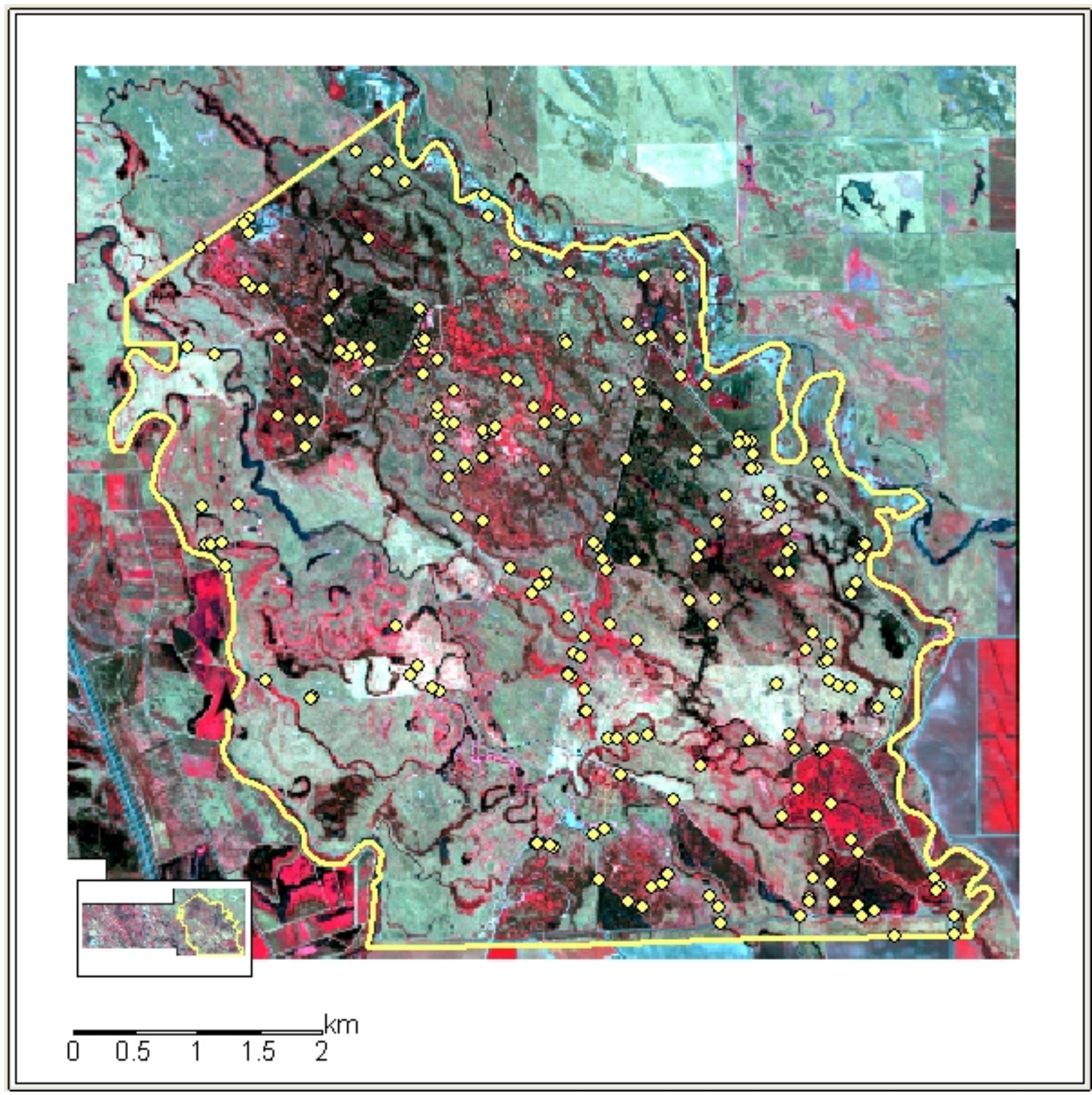

Figure 4.8 Ground truth locations, 2005, San Luis unit, San Luis National Wildlife Refuge, Merced County, CA. Field data locations have been overlain on a false color mapping of the NIR, red, and green bands of the June 22, 2005 satellite imagery. 


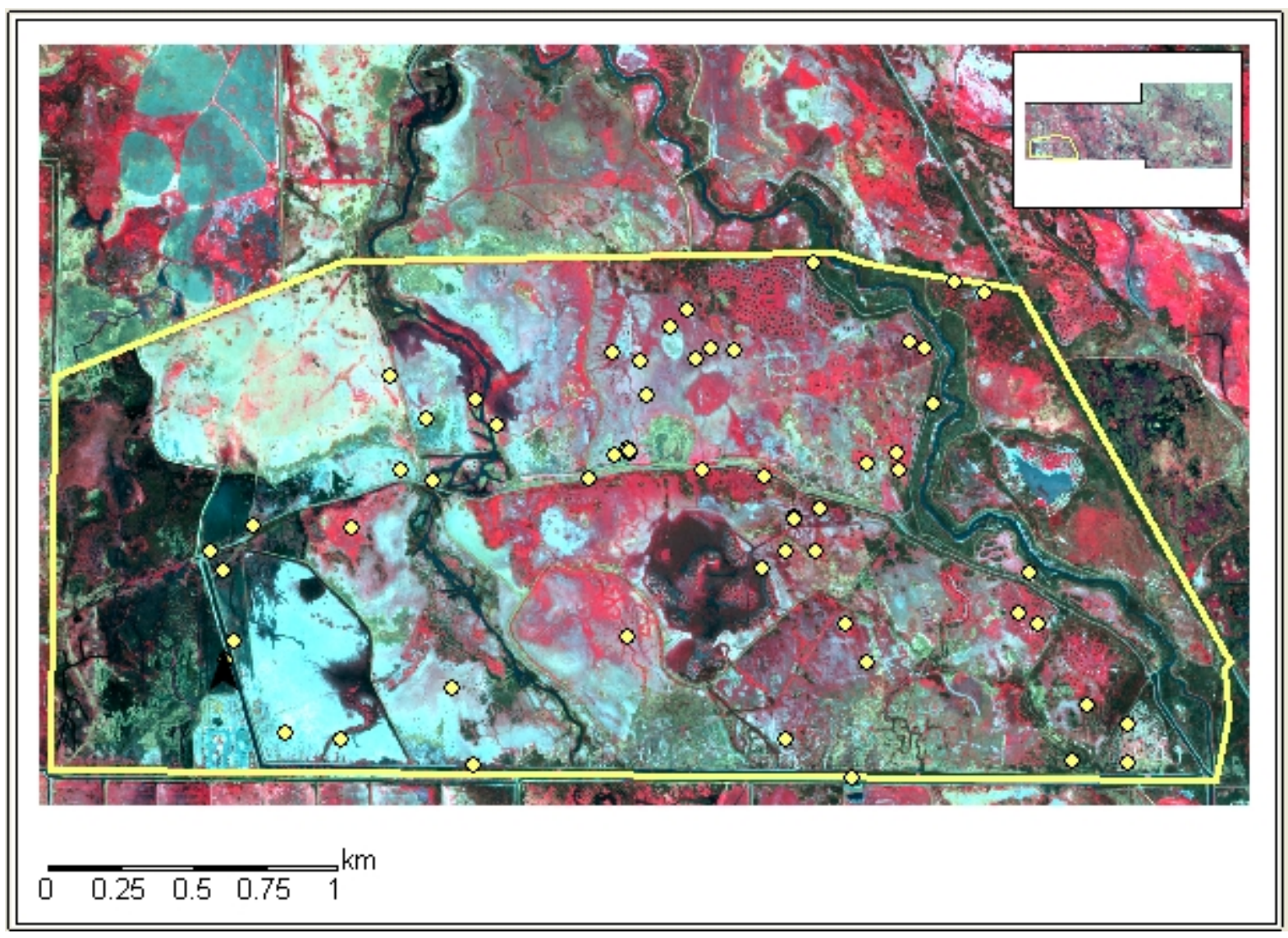

Figure 4.9 Ground truth locations, 2005, Salinas Club, Merced County, CA. Field data locations have been overlain on a false color mapping of the NIR, red, and green bands of the June 22, 2005 QuickBird imagery.

\subsubsection{Pixel-Based Image Processing}

Pixel-based image processing and data analysis was performed using software routines provided by ERDAS Imagine Professional. Other off-the-shelf commercial image processing packages are available that perform comparable analyses. A supervised classification technique - whereby data input by an analyst is used to determine seed values for classes - was selected for classification of the images. Maximum likelihood classification is a standard industry algorithm for projects wherein adequate ground truth data has been collected. This technique requires the input of "training" data, with which software algorithms define statistically-based spectral bounds for each class. Training data is derived from ground truth points; in this case, the analyst has defined an area around each ground truth point representative of that community of vegetation, and the image processing software compiles statistics that uniquely describe the spectral values for that community. 
Multiple ground truth points are combined into a robust spectral signature for a single land cover class, and this process is repeated until the analyst has created a signature for all known land cover classes. After all training data has been entered into the spectral signature file, the classification algorithm is implemented. The maximum likelihood algorithm uses the defined spectral signatures to extrapolate from the training pixels to all the pixels in the image. This is a very efficient process, resulting in the use of data from a few thousand pixels to classify an entire image comprised of tens of millions of pixels. In the end result, every pixel is assigned to a class - the class it is "most likely" to belong to, even if the pixel's spectral values fall outside the initial seed values for that class.

The start point for the classification process - a statistical representation of the raw imagery data - is shown in Figure 4.10. This figure shows four histograms, one for each spectral band in the imagery for May 14, 2004. The histogram shows the distribution of spectral values. For each band, the spectral values (or digital number, DN) are given on the $\mathrm{X}$-axis, and the number of pixels exhibiting that value is graphed on the Y-axis. Spectral values near the peak of the curve will be most common in the imagery. The histogram describes the statistical distribution of values within a band, but says nothing about the relationships between bands. Therefore, a pixel that is bright (high spectral value) in one band may be dark in another. 

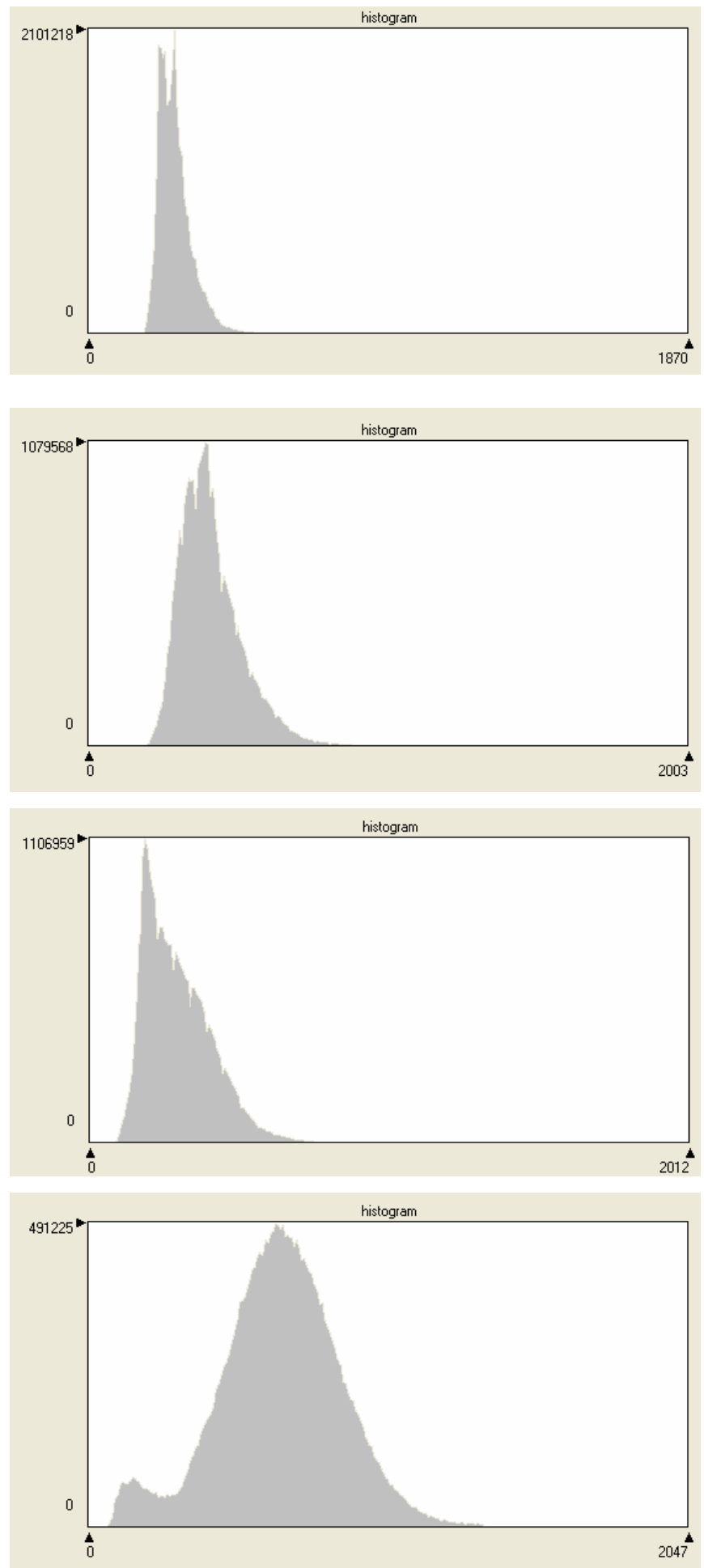

Figure 4.10 Histograms for the blue, green, red, and NIR bands (top to bottom) in the May 14, 2004 multispectral imagery. The $\mathrm{X}$-axis displays the spectral value, and the $\mathrm{Y}$-axis displays the number of pixels exhibiting the value in that band. The histograms show the range of spectral values present in the satellite imagery. 
An introduction to the relationship between bands is shown in Figure 4.11. Here, the mean values for the training signatures of three land cover classes - buildings, water, and scirpus spp - are shown for the four multispectral bands. Maximum likelihood classification also accounts for the range and co-variance of spectral signatures, however, it can be seen in this figure that these three classes may be separable based solely on their means in different bands. Scirpus and water have similar means in bands 1, 2, and 3. However, scirpus is significantly brighter in band 4 , due to the response of chlorophyll in this band. These three land cover classes were chosen for ease of illustration. As a general rule, land cover classes comprised of individual plant species will appear more similar and will be more challenging to separate.

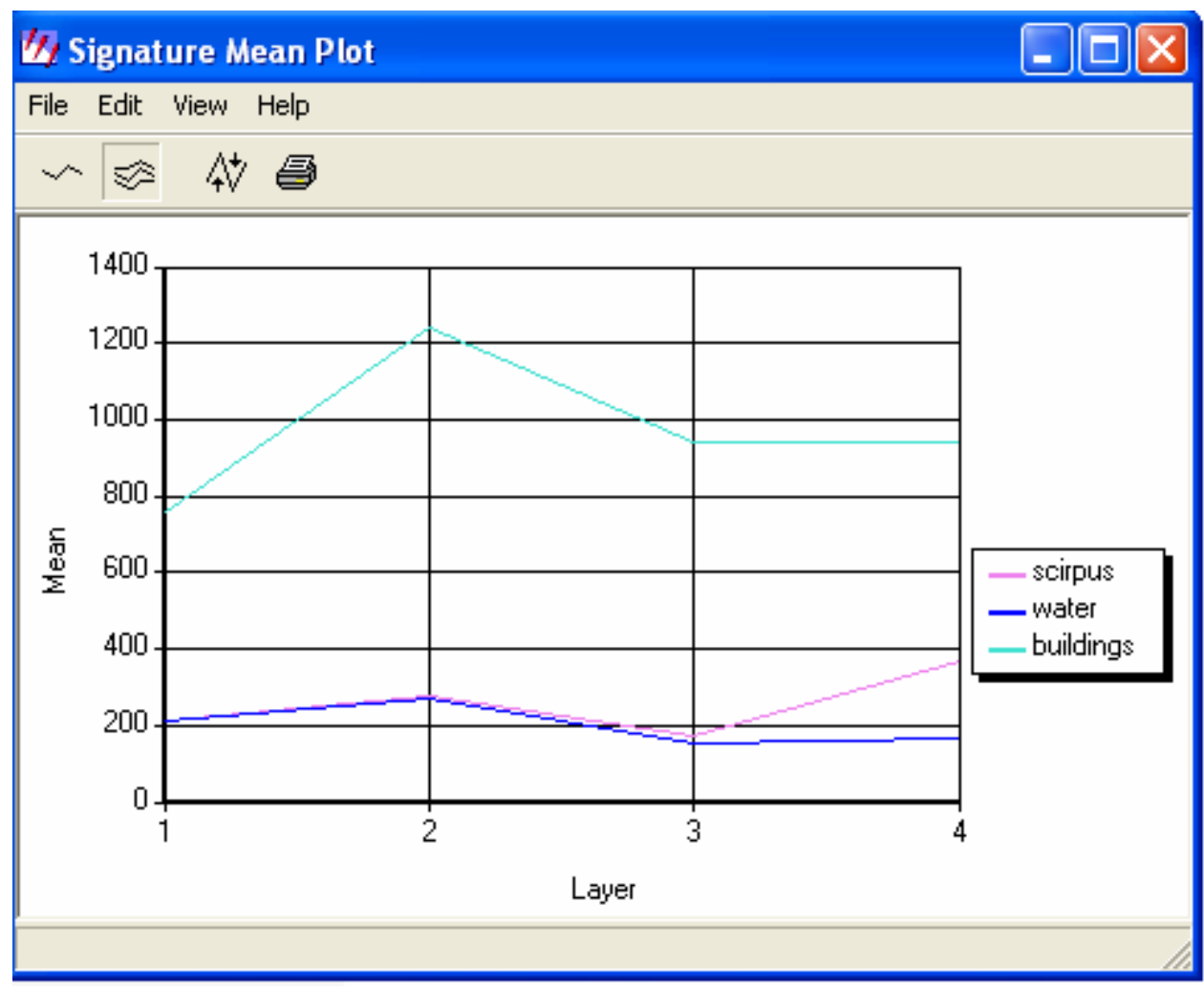

Figure 4.11 Mean values of the training signatures of three land cover classes in the May 14, 2004 imagery. Buildings are considerably brighter in all four bands. Water and scirpus spp take on similar mean values in bands 1, 2, and 3 (blue, green, and red), however scirpus spp is brighter in band 4 (near-infrared.) 
An example of creating a single training signature is shown in Figure 4.12. This view shows a zoomed-in area of an image, close enough that it is possible to discern the individual pixels. Several ground truth points appear in this area of the image. One ground truth point has been selected to create a training signature. A polygon has been drawn around the point and neighboring pixels known to belong to the same land cover class. The spectral characteristics of the selected pixels will be used to create the training signature.

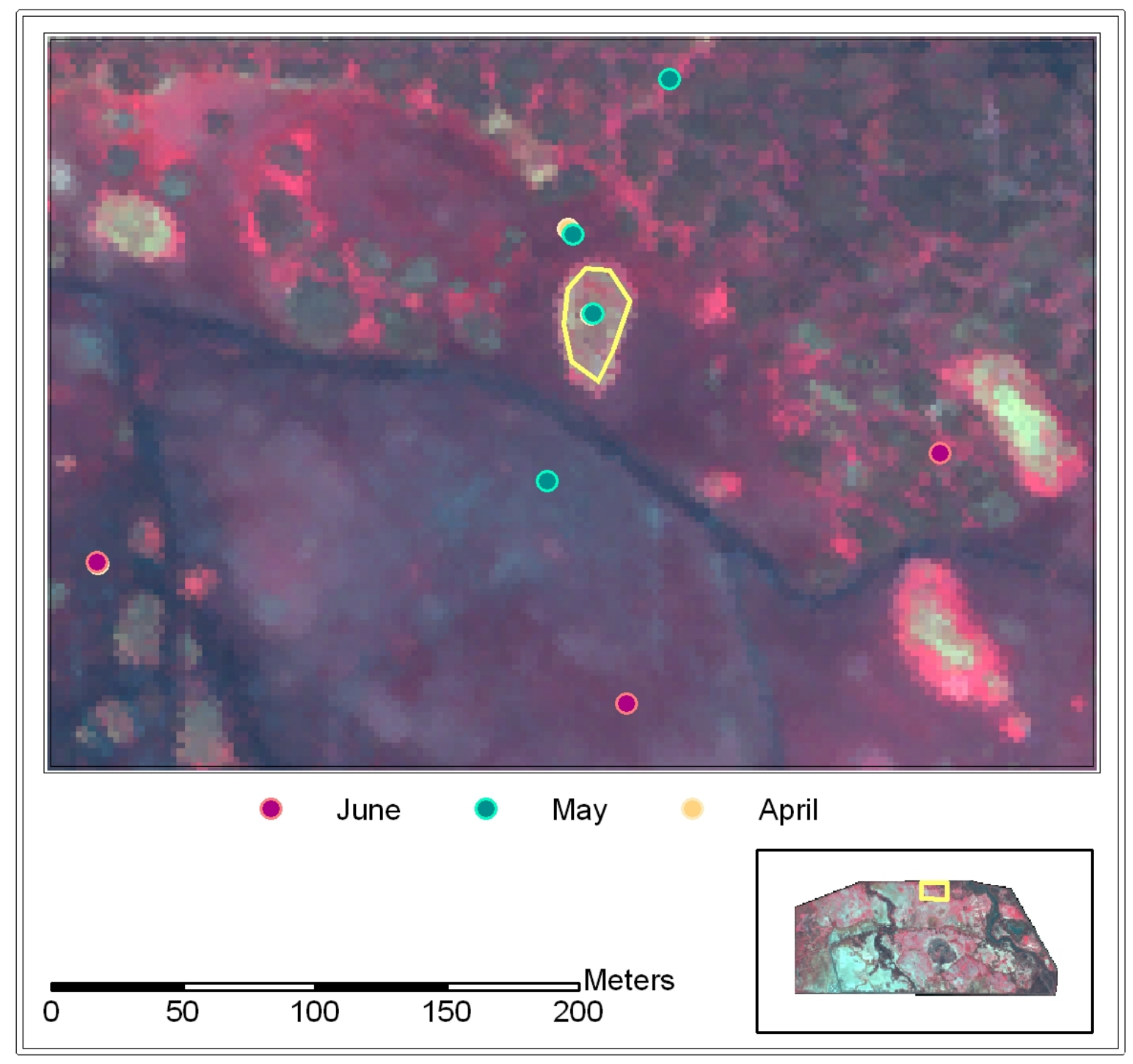

Figure 4.12 Example of training signature delineation, Salinas Club, Merced County, CA. Training signatures are collected in the areas surrounding ground truth points. While the ground truth point represents only a single pixel location, this can be extrapolated to the surrounding area using field collected attributes such as community size and shape. 


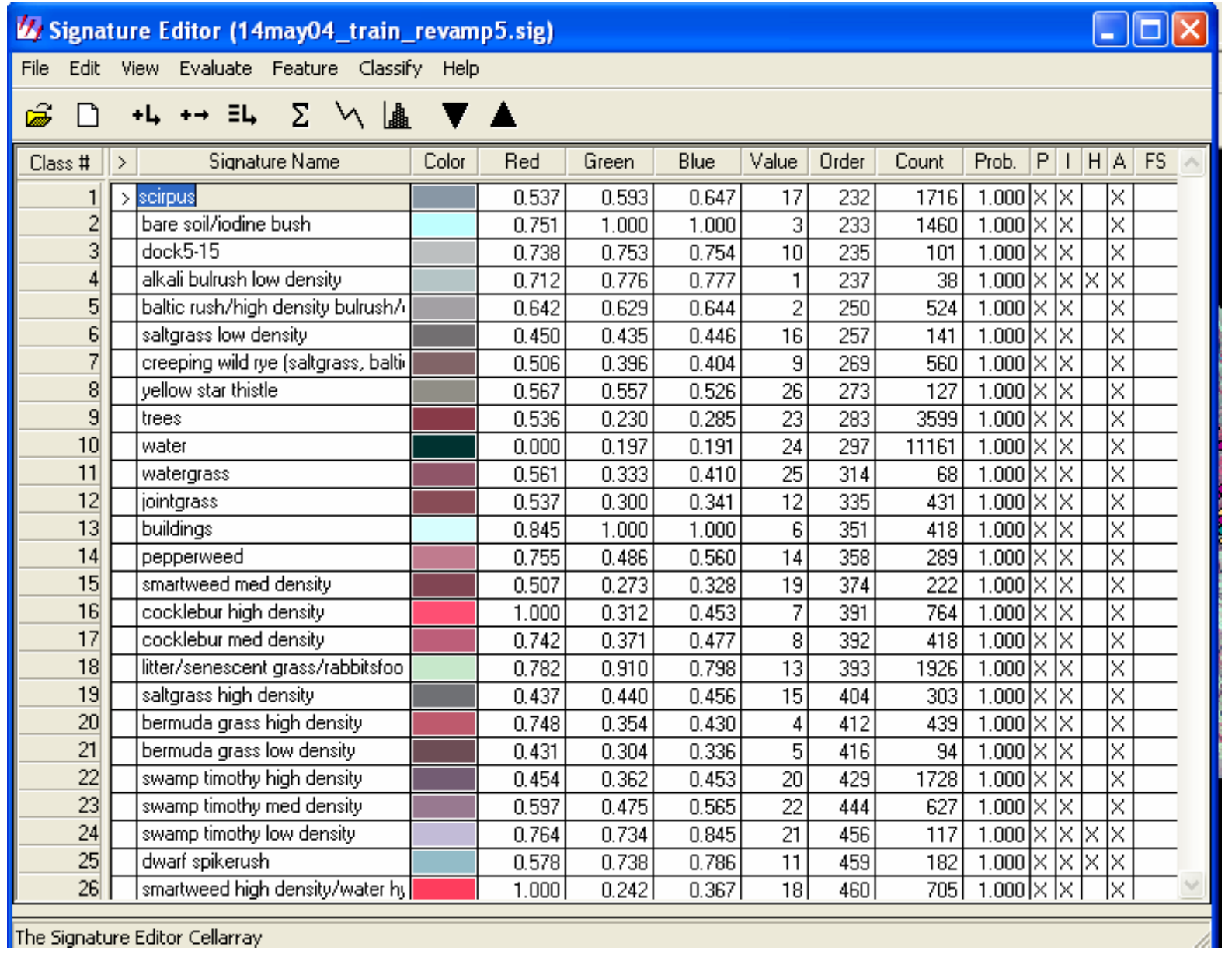

Figure 4.13 May 14, 2004 spectral signature file. Each class is the result of compositing training data for numerous ground truth points. The total number of pixels included in each class is displayed in the "Count" column. The color swatch, used for visualization only, is derived from the average values of all pixels comprising that class, based on the color mapping used in the display window. Since near-infrared response is mapped to red in the display window, vegetation tends to appear red.

The final spectral signature file used for the May 14, 2004 imagery is shown in Figure 4.13. Note that this figure shows only display values for the different land cover classes; the statistical description of each class is too complex to display in a single view. The color patches and RGB values shown in the signature file correspond to the average tone of that land cover type, as it is displayed in the working window. 
Through a complex process of signature refinement, individual training signatures (Figure 4.12) evolve into the final class signature file that is used to classify the image (Figure 4.13.) The class signatures are based on multiple single signatures added together in proportion to the number of pixels each represents. After signatures are compiled for each class, they may be evaluated for separability. There are several tools that may be used for this evaluation. Figure 4.14 shows a feature space image for bands 4 (NIR) and 2 (green) and the twodimensional separability of three classes (scirpus, buildings, and water) within this feature space. As an example of another tool, Figure 4.15 shows a matrix of separability values for ten land cover classes. Separability here is calculated in all four image bands, using a measure of the spectral distance between classes known as transformed divergence. Transformed divergence ranges in value from 0 to 2000, and values over 1500 are considered to be separable. If classes are insufficiently separable, the analyst may choose to combine classes, to add more training data, or to cull some training data before repeating the evaluation of signature separability. 


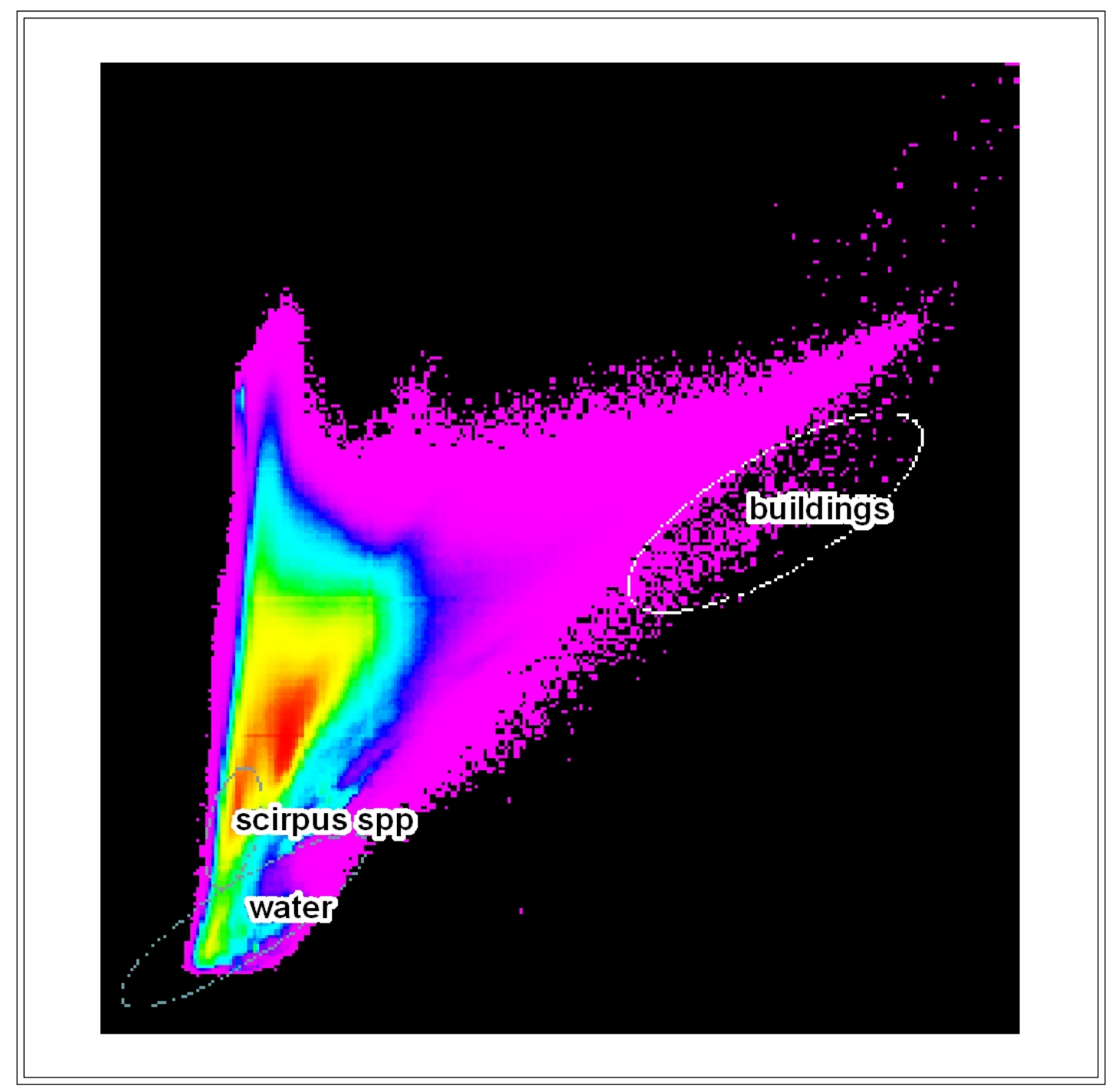

Figure 4.14 Feature space analysis of separability of three land cover classes in bands 2 and 4 of the May 14, 2004 imagery. Band 2 (green) is plotted on the X-axis, and band 4 (near-infrared) is plotted on the $\mathrm{Y}$-axis. The 2-dimensional location of a point on this plot is determined by its spectral value in the two bands. Colors represent the frequency of occurrence of that spectral value combination. Red depicts combinations that occur frequently in the dataset. Violet depicts the combinations that occur most rarely. The class bounds, as determined by training data, of buildings, scirpus spp, and water are plotted on this feature space. The three classes appear to be unambiguously separable in bands 2 and 4. Furthermore, buildings occupy a sector of feature space not represented in too many pixels. Scirpus spp, by contrast, is centered about a red sector. This could indicate either a predominance of scirpus in the image, or a predominance of land cover classes that reflect a signal similar to scirpus spp. 


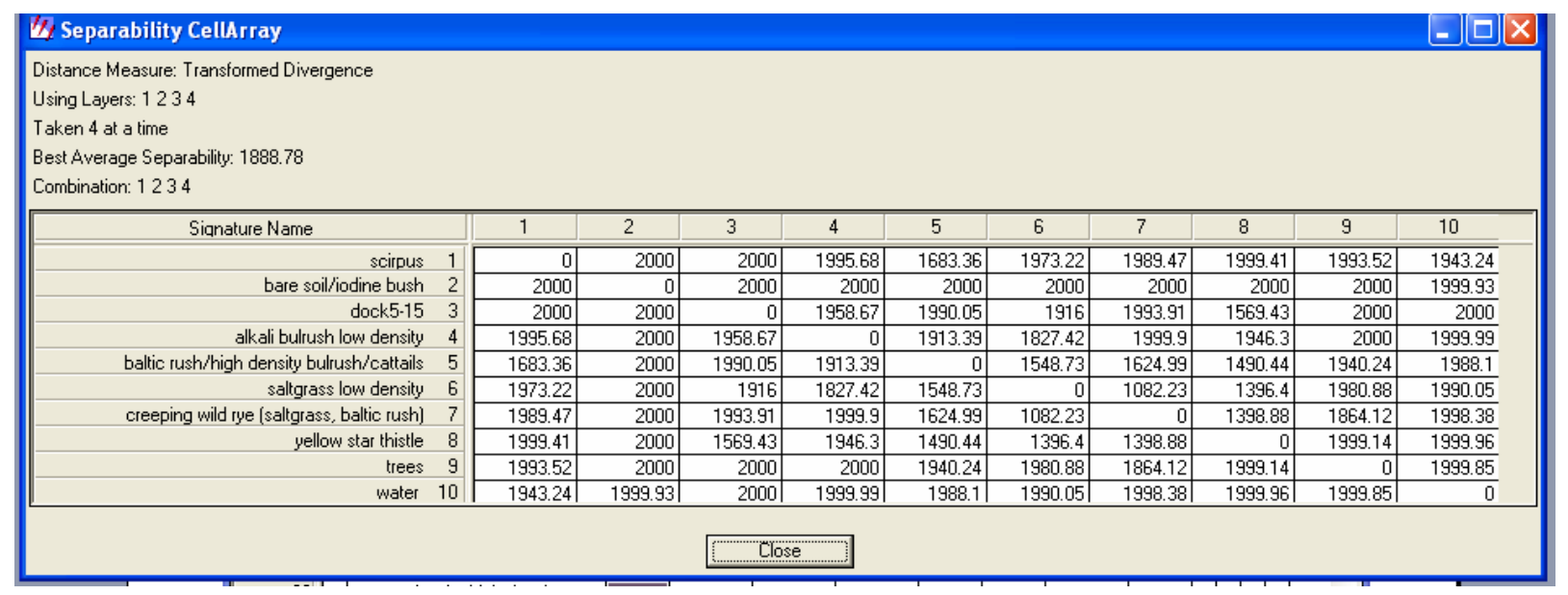

Figure 4.15 Separability matrix showing transformed divergence values for the first ten land cover classes from the spectral signature file. Values over 1900 are considered to indicate excellent separability; values greater than 1700 represent good separability; values greater than 1500 are considered adequately separable. The matrix shows the separability of pairs of classes. For example, the value in row 1 and column 2 would indicate an excellent separability between scirpus spp and bare soil/iodine bush. Classes that are not adequately separable can result in pixels misclassified as the other member of the pair.

\subsubsection{Object-Based Image Processing}

Definiens' eCognition software is an advanced, object-based image processing package providing specialized algorithms not currently available in traditional (pixel-based) image processing packages. For the purposes of this project, eCognition was used in conjunction with ERDAS Imagine Professional to apply a maximum likelihood classification to landscape objects in the form of polygons. ECognition uses spectral and shape characteristics of the raw imagery to separate pixels into self-similar landscape objects. This correlates well with viewing the landscape in terms of vegetation communities, or in terms of homogenous landcover classes such as roads and water. Polygon objects created using eCognition were used later in the study to compare a landscape-object based approach to a pixel-based approach in using the maximum likelihood classifier. A close up of the raw imagery divided into landscape object polygons is shown below in Figure 4.16. 


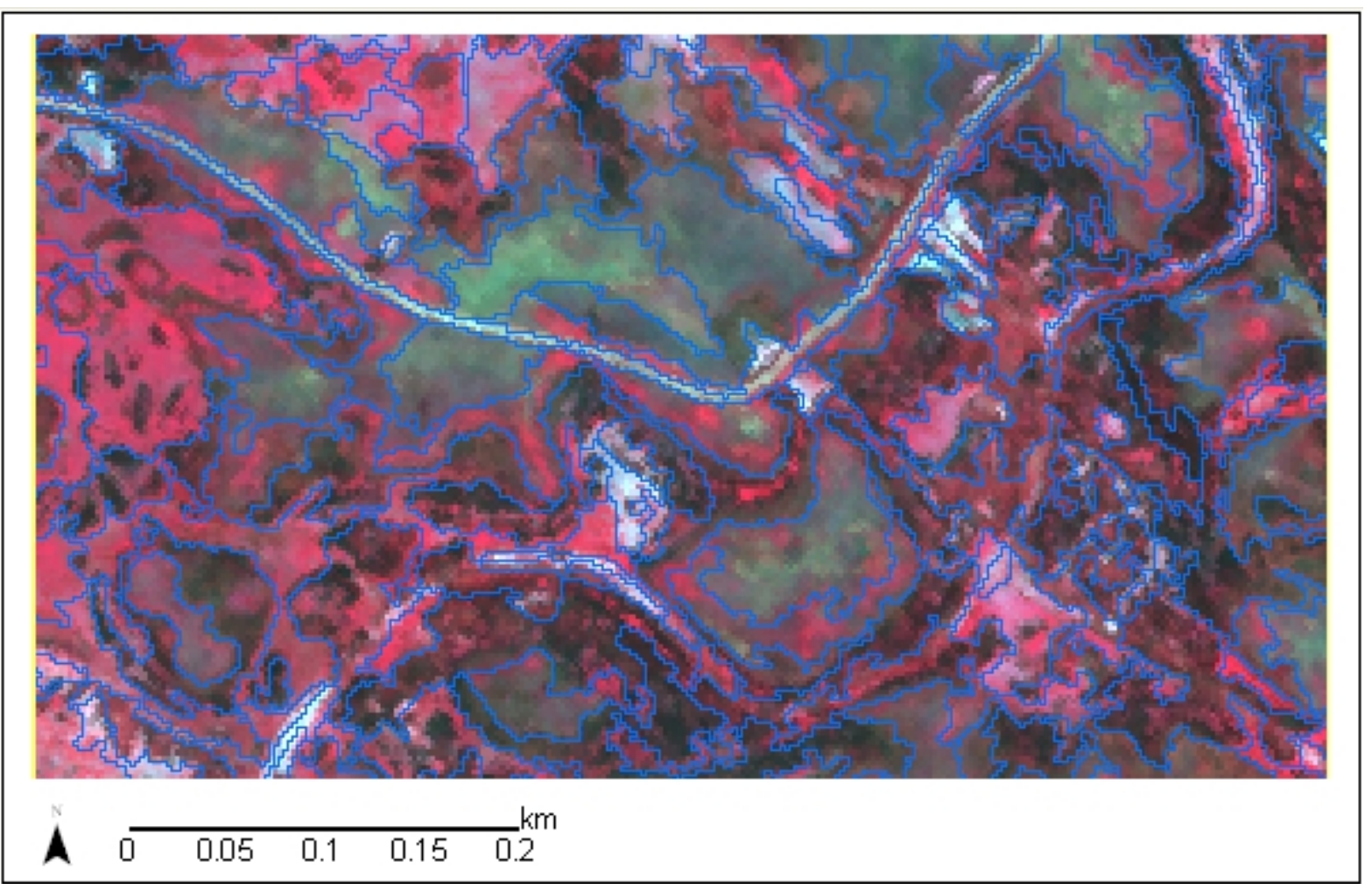

Figure 4.16 Close-up image showing eCognition's automated segmentation of the landscape into polygon objects. Polygons are limited to a maximum heterogeneity based on spectral characteristics, object compactness, and smoothness of their borders. Polygons were created using data from the April, May, and June images, reflecting that vegetation communities develop over the growing season. The May imagery is used as the backdrop for this figure.

In 2005, image processing of the satellite imagery will use some advanced eCognition functionality, including use of fuzzy classifiers and class hierarchy to perform land cover classification. ECognition provides a wide range of tools for data mining and assessing the spectral characteristics of ground truth data. This allows the analyst to take a top-down approach to image classification, where the landscape is first divided into broad landcover classes such as vegetation, water, and bare soil. Specialized tools allow the analyst to view which data parameters are most relevant for discriminating classes. In addition, compound parameters, such as NDVI, are readily created and examined with respect to the spectral data. Using additional data mining and spectral discrimination tools, these broad categories may be further subdivided down to the species level of classification. While the method is heretofore untested for diverse wetland habitats such as the project's study site, it is anticipated that this new paradigm in image classification will provide for accuracy 
improvements for some land cover classes. A preliminary top-down fuzzy classification of the 2004 imagery resulting in broad land cover categories is shown below in Figure 4.17.

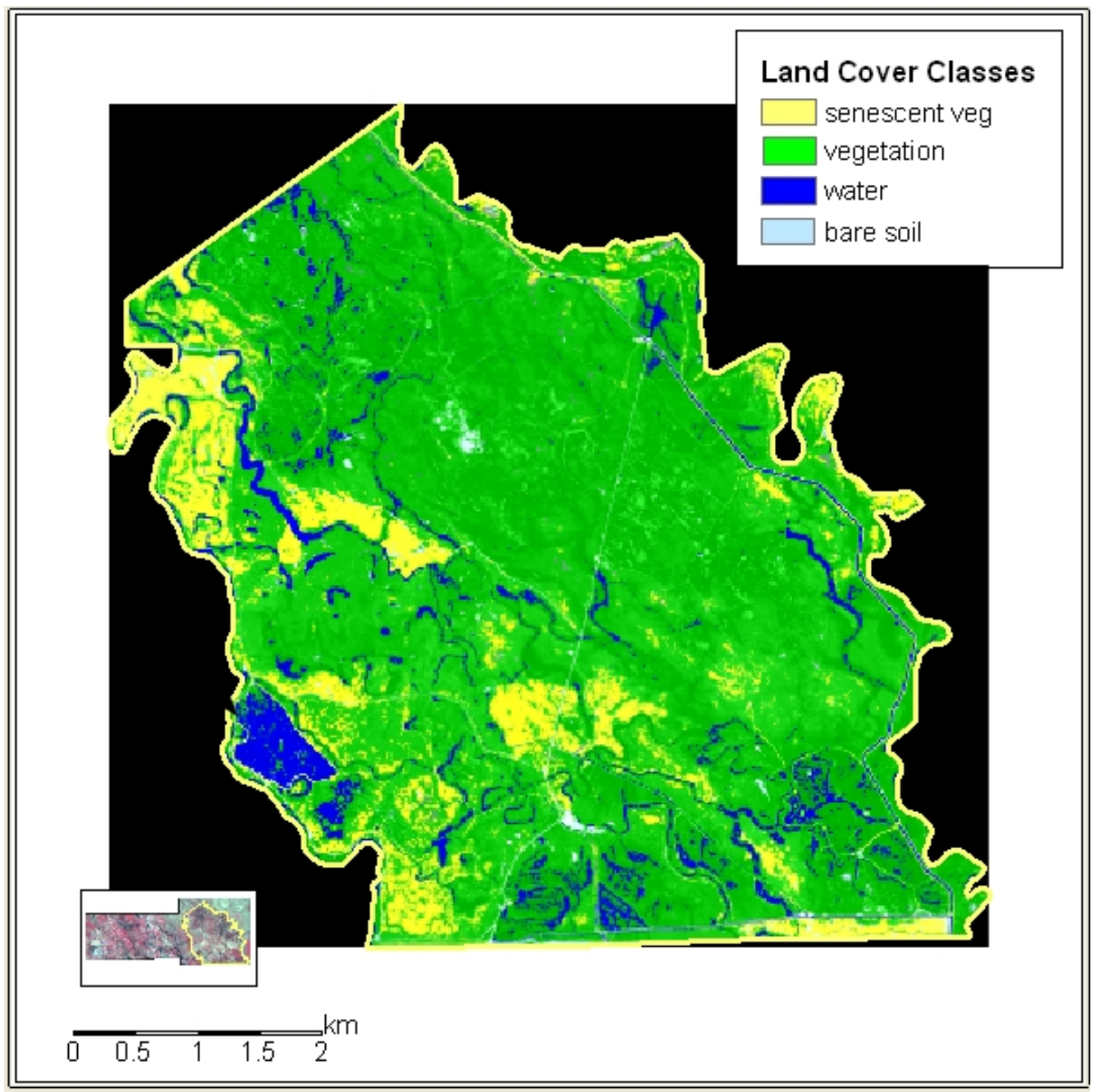

Figure 4.17 Preliminary fuzzy classification of May 2004 project imagery. Classification was based on landscape objects. Classification used data mining techniques to divide landscape into broad classes which can then be inherited by child classes representing specific members of those classes. 


\subsubsection{Image Processing Accuracy Assessment}

Accuracy assessment was performed through standard calculations using randomly selected ground truth points that had been set aside especially for this purpose. Check points, as this type of ground truth points are typically called, are not used during the process of creating training signatures. Therefore, they form a reliable, independent dataset for classification verification. The number of checkpoints was 79, 115 and 131 for the April, May and June 2004 imagery respectively.

Accuracy assessment was evaluated using two industry-standard metrics: producer's accuracy and user's accuracy. Producer's accuracy is the ratio of the number of correctly classified check points in a class to the total number of reference check points in that class. This metric indicates how accurately the check points in a certain class were classified. User's accuracy is the ratio of the number of correctly classified check points in a class to the total number of reference check points that were classified as the target class. This metric is a measure of commission error and represents how likely it is that an imagery pixel assigned to that class is actually a member of that class.

\subsubsection{ET Estimation via Landcover Categorization}

Using the established map of land cover classes, an estimate of evapotranspiration can be made for the study sites. Land cover classes were grouped into broad categories based on the management prescriptions for each habitat type. ET values were assumed to be comparable within categories for plants with similar management prescriptions (U.S. Fish and Wildlife Service, 2004.) ET values were compiled from a variety of tank studies of vegetation monocultures in western states (Russell et al., 1993.) ET values for each broad category were calculated through a variety of different methods. The grouping of land cover classes into broad categories is described below in Table 4.4. The categories and calculated ET values are shown in Table 4.5. 
Table 4.4 Categories of land cover classes

\begin{tabular}{|c|c|}
\hline Land Cover Class & ET Category \\
\hline alkali bulrush & deep \\
\hline alkali heath & shallow \\
\hline alkali sacaton & upland \\
\hline baltic rush & shallow \\
\hline bare soil & shallow \\
\hline bermuda grass high density & medium \\
\hline bermuda grass low density & medium \\
\hline buildings & buildings \\
\hline cattail & deep \\
\hline chufa & shallow \\
\hline clover & medium \\
\hline cocklebur high density & medium \\
\hline cocklebur med density & medium \\
\hline creeping wild rye & upland \\
\hline dock low density & upland \\
\hline dwarf spikerush & medium \\
\hline iodine bush & shallow \\
\hline jointgrass & medium \\
\hline litter/senescent grass/rabbitsfoot & upland \\
\hline pepperweed & upland \\
\hline saltgrass high density & shallow \\
\hline saltgrass low density & shallow \\
\hline hardstem bulrush & deep \\
\hline smartweed high density & medium \\
\hline smartweed med density & medium \\
\hline swamp timothy high density & medium \\
\hline swamp timothy low density & medium \\
\hline swamp timothy med density & medium \\
\hline trefoil & upland \\
\hline trees & riparian \\
\hline water & water \\
\hline watergrass & medium \\
\hline yellow star thistle & upland \\
\hline
\end{tabular}


Table 4.5 ET values of land cover categories

\begin{tabular}{|l|l|l|}
\hline Category & $\begin{array}{l}\text { ET } \\
\text { (inch/month) }\end{array}$ & Explanation \\
\hline shallow & 3.37 & subject to shallow or short-term seasonal flooding \\
\hline medium $^{2}$ & 4.93 & medium depth or longer seasonal flooding \\
\hline deep $^{3}$ & 11.08 & deep, permanent, or nearly year-round flooding \\
\hline upland & 1.69 & not seasonally flooded or irrigated \\
\hline riparian & 6.53 & trees or shrubs in riparian zones \\
\hline open water & 5.80 & open water \\
\hline buildings & 0 & buildings \\
\hline
\end{tabular}

shallow $^{1}-$ ET value derived from Norman et al, 1993

medium $^{2-}$ ET value derived from Snyder et al, 2001; UC Extension, 2000, and Olufayo et al, 2004

deep $^{3}$ - ET value derived from Norman et al, 1993

riparian $^{4}-\mathrm{ET}$ value derived from UC Extension, 2000

open water $^{5}$-ET value derived from Johnson et al, 1997

It was not possible to obtain literature ET values for most of the plant species growing at the study site. The broad groupings of plant types demonstrates the potential of this method, given the possibility of obtaining accurate ET values for different species or wetland types. ET values are given as an average for the entire year. For shallow and deep wetland species, ET values were averaged from many different studies of saltgrass (Norman et al, 2003.) For medium wetland species, ET values were averaged from crop coefficients for rice and bermuda grass (Snyder et al, 2001; UC Extension, 2000; Olufayo et al, 2004). The equation for this calculation is as below:

$$
\mathrm{ET}_{\mathrm{tr}}=\mathrm{k}_{\mathrm{crop}} * \mathrm{ET}_{\mathrm{pan}}
$$

where $\mathrm{k}_{\text {crop }}$ represents the crop coefficient for the particular species, and $\mathrm{ET}_{\text {pan }}$ represents the reference pan evaporation. $\mathrm{ET}_{\text {pan }}$ was calculated from reference ET data provided by CIMIS. For upland areas, it was assumed that ET was negligible for the summer months (May through October) and for the winter months (November through April), it was assumed ET values would correspond roughly to shallow basin systems. The ET value calculated is an 
average of these two numbers. For riparian zones, an ET value corresponding to orchard crops with cover crops was used (UC Extension, 2000). For open water evaporation, the effect of salinity on evaporation was modeled using the following equation:

$$
\mathrm{E}=\mathrm{Y}(\mathrm{ETo})
$$

where $\mathrm{Y}=1.3234-0.0066 \mathrm{EC}(\mathrm{dS} / \mathrm{m})$ for water with electrical conductivity (EC) up to 60 $\mathrm{dS} / \mathrm{m}$ and ETo represents reference evapotranspiration for the area (Johnson et al, 1997.) Reference evaporation rates were taken from local weather station data (CIMIS, 2004) - the CIMIS station \#92 at Kesterson.

While a method exists for applying these ET rates to the mapped area of the study site, it would be clearly beneficial to obtain ET values more applicable to species occupying California wetlands, and to extend our knowledge of how ET varies during the year.

\subsubsection{ET Estimation via Remote Sensing}

Recent developments in the application of an energy budget methodology to calculate ET have made remote sensing a viable and cost effective option for estimating ET over large areas. The cornerstone of the energy budget method is to look at the latent energy remaining when radiation absorbed by heating the soil and atmosphere have been accounted for. The latent energy remaining is assumed to be consumed by evaporation and transpiration processes. The following equation represents the relevant energy balance (Allen et al., 2005):

$$
L E=R_{n}-G-H
$$

where:

$\mathrm{LE}=$ the latent energy consumed by ET

$\mathrm{Rn}=$ net radiation (shortwave and longwave)

$\mathrm{G}=$ sensible heat flux conducted into the earth's surface

$\mathrm{H}=$ sensible heat flux convected into the atmosphere 
The advantage of using an energy balance model to calculate ET is that it represents actual evapotranspiration rather than potential evapotranspiration. This is particularly important in arid western states where water shortages may result in potential ET calculations overestimating the amount of water transmitted by dry soils or water stressed vegetation. Since there is no existing method to directly measure ET over large areas, validation of any method for calculating ET is an issue. However, the energy balance method has been tested against other measurement methods (Bastiaanssen et al., 1998), and has delivered comparable and apparently accurate results.

Several institutions have developed sophisticated models to calculate ET from radiation data available from satellite imagery. Two models of the energy balance concept have been most widely applied. The Surface Energy Balance Algorithm for Land (SEBAL) was developed by the company WaterWatch of the Netherlands (Bastiaanssen, et al., 1998.) Researchers at the University of Idaho and the Idaho Department of Water Resources (Allen et al., 2005) have developed the model Mapping Evapotranspiration at high Resolution and with Internalized Calibration (METRIC.) SEBAL and METRIC require similar inputs in order to calculate ET. These include:

- Visible radiation

- $\quad$ Near-infrared radiation

- $\quad$ Thermal radiation

- $\quad$ Wind speed

- $\quad$ Humidity

- Solar radiation

- $\quad$ Air temperature

The first three parameters are generally extracted from multispectral satellite imagery, while the latter four parameters are typically available from ground-based weather stations. In order to calculate ET for this project, a model closely derived from METRIC/SEBAL will be used. The model will be programmed into commercial image processing software such as ERDAS Imagine. Multiple imagery types may be combined to obtain the required radiation inputs into the model. The QuickBird multispectral satellite imagery used to map land cover 
for this study could contribute visible and near-infrared radiation inputs to the algorithms, but a thermal band is still required. This may be obtained from LANDSAT 7 ETM+ data. However, part of the LANDSAT sensor malfunctioned on July 14, 2003. Data collected after that date has suffered from regular strips of data dropout, as shown below in Figure 4.18. Fortunately, NGWD and SLNWR are near the center of the LANDSAT scene, so coverage of this area is minimally disrupted by the data dropout. Since LANDSAT covers the same scene once every 16 days, missing data can be filled in from the nearest temporally adjacent scene.

Application of an energy balance model will provide an accurate and comprehensive estimate of water loss through evapotranspiration at the study sites. An accurate estimate of ET is a prerequisite for a science-based assessment of water needs and water usage in San Joaquin Valley seasonal wetlands.

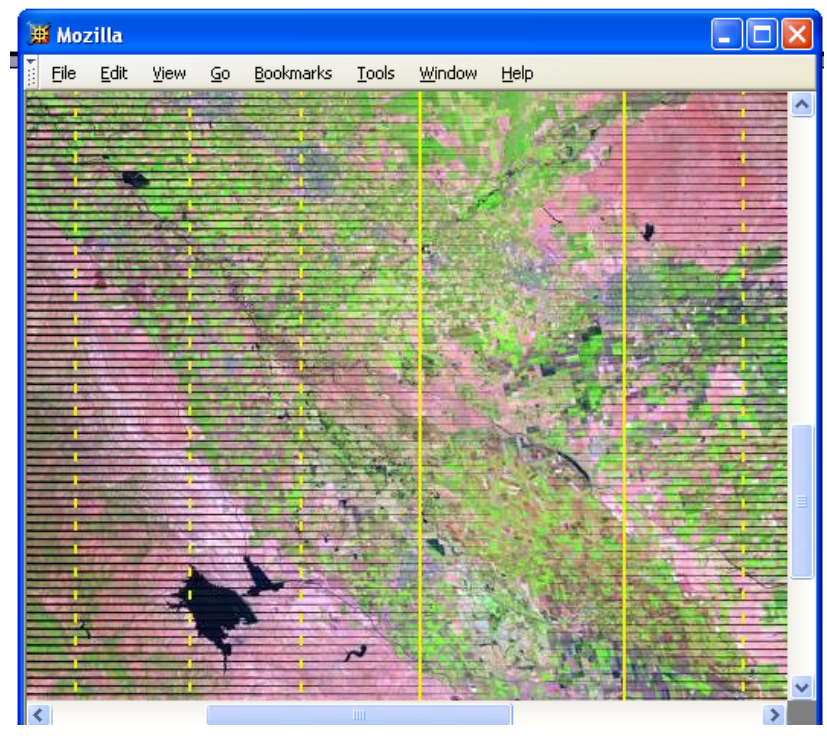

Figure 4.18 LANDSAT 7 ETM+ imagery from June 2005 showing black strips of missing data. This preview image covers a broad area of the San Joaquin Valley at a coarse resolution. San Luis Reservoir is visible in the lower left corner. The image is displayed with a false color mapping and a contrast stretch to enhance viewability. 


\subsection{Results}

\subsubsection{Vegetation Identification}

Over fifty species of wetlands and uplands vegetation were identified at SLNWR. Of these, only species with sufficient presence to dominate numerous communities were included in the classification schema. Species that were present only at a low density in observed communities, or were dominant only in small, rare pockets of the landscape, were not included in the classification. Table 4.6 provides a listing of dominant species, their scientific names, and the common names used in this report.

Table 4.6 Classified vegetation species

\begin{tabular}{|l|l|}
\hline Allenrolfea occidentalis & Iodinebush \\
\hline Bromus diandrus & Ripgut brome \\
\hline Bromus hordeaceus & Soft brome \\
\hline Centaurea solstitialis & Yellow starthistle \\
\hline Cressa truxillensis & Alkali weed \\
\hline Crypsis schoenoides & Swamp timothy \\
\hline Cynodon dactylon & Bermuda grass \\
\hline Cyperus esculentus & Chufa \\
\hline Distichlis spicata & Saltgrass \\
\hline Echinochloa crusgalli & Watergrass \\
\hline Eleocharis spp. & Spikerush \\
\hline Frankenia salina & Alkali heath \\
\hline Hordeum jubatum & Foxtail barley \\
\hline Hordeum murinum & Hare barley \\
\hline Juncus balticus & Baltic rush \\
\hline Leymus triticoides & Creeping wildrye \\
\hline Lotus corniculatus & Trefoil \\
\hline Paspalum distichum & Jointgrass \\
\hline Polygonum lapathifolium & Pale smartweed \\
\hline Polypogon monspeliensis & Rabbitsfoot grass \\
\hline Rumex spp. & Dock \\
\hline Scirpus maritimus & Alkali bulrush \\
\hline Scirpus spp. & Hardstem bulrush \\
\hline Sporobolus airoides & Alkali sacaton \\
\hline Typha spp. & Cattail \\
\hline Xanthium strumarium & Cocklebur \\
\hline & \\
\hline
\end{tabular}

\subsubsection{Pixel-Based Classification}

Separate training signatures were created for and applied to the May and June imagery. The April imagery was determined to have captured growth too early in the season to provide 
adequate differentiation of many species, especially moist soil plants, and so was not used to create a vegetation map. (It was, however, used in the process of creating landscape object polygons in eCognition.) The result of the pixel-based maximum likelihood classification for May and June is shown in Figures 4.19 and 4.20. Because the training signatures were developed entirely separately for these two images, they may show different biases.

Training signatures primarily were developed using ground truth data collected in close temporal association with each satellite fly-over. However, in some cases it was recognized that data from the adjoining months could be used to increase the amount of data used in signature development, and therefore to improve the robustness of the spectral signatures. In most cases, vegetation communities have some stability from month to month. When data from an adjoining time period was used, the point was individually inspected in both months to ensure that the vegetation community appeared stable. When a large degree of change was apparent, the point was not used for that month's analysis.

Land cover classes developed for May and June were similar but not identical. New land cover classes were added to June and old ones removed based on their observed presence or absence in the field data. Both time periods offer an opportunity to optimally observe certain vegetation communities. There is no one perfect time of year to collect data on all land cover classes. 


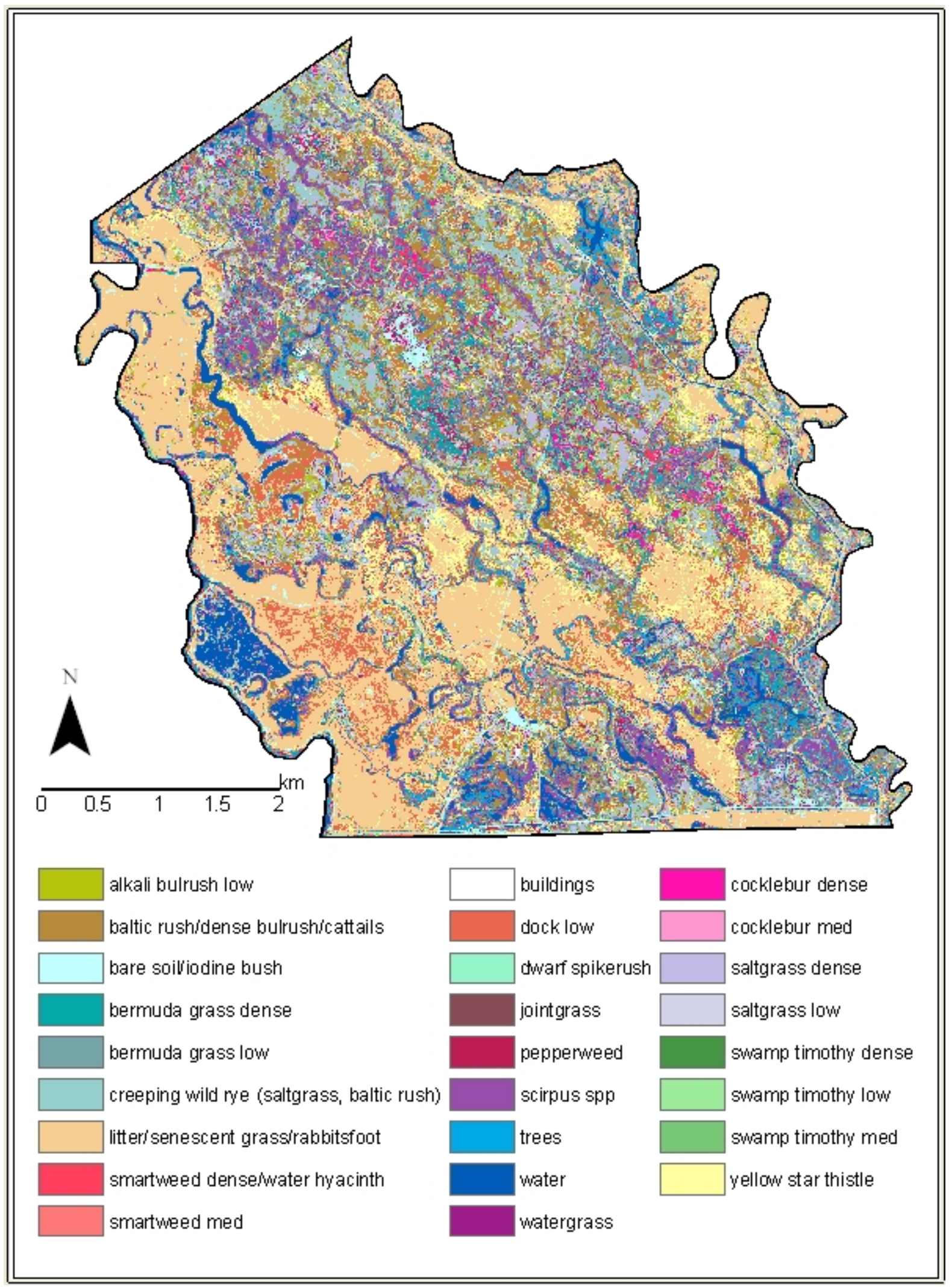

Figure 4.19 May 14, 2004 maximum likelihood pixel-based classification of SLNWR. 


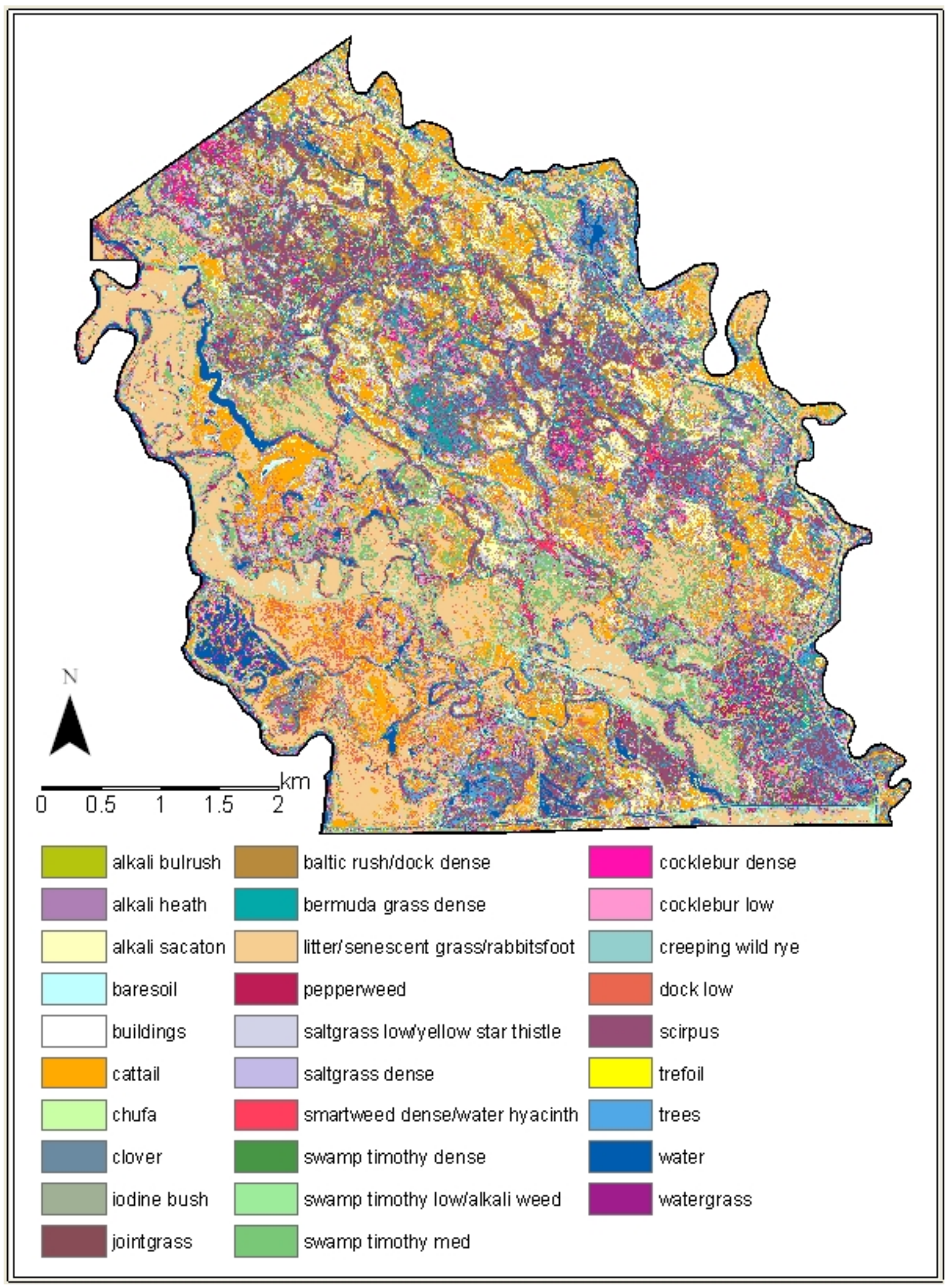

Figure 4.20 June 19, 2004 maximum likelihood pixel-based classification of SLNWR. 


\subsubsection{Object-Based Classification}

An object-based vegetation map was developed for the May 14, 2004 imagery. (As will be discussed in the section on accuracy assessment, the data suggest that the May imagery resulted in the most accurate vegetation map. Therefore, additional processing was concentrated on the May data.) An object-based map was created by using a zonal analysis method to synthesize the results of the pixel-based maximum likelihood classification with the landscape objects created via eCognition. Landscape objects incorporated spectral and shape information from the April, May, and June imagery, and used an eCognition scale factor of 50. Polygons were assigned a land cover class based on the plurality of pixels existing within each polygon. The result is a smooth, more easily interpretable vegetation map (Figure 4.21) which improves the classification accuracy for some classes. 


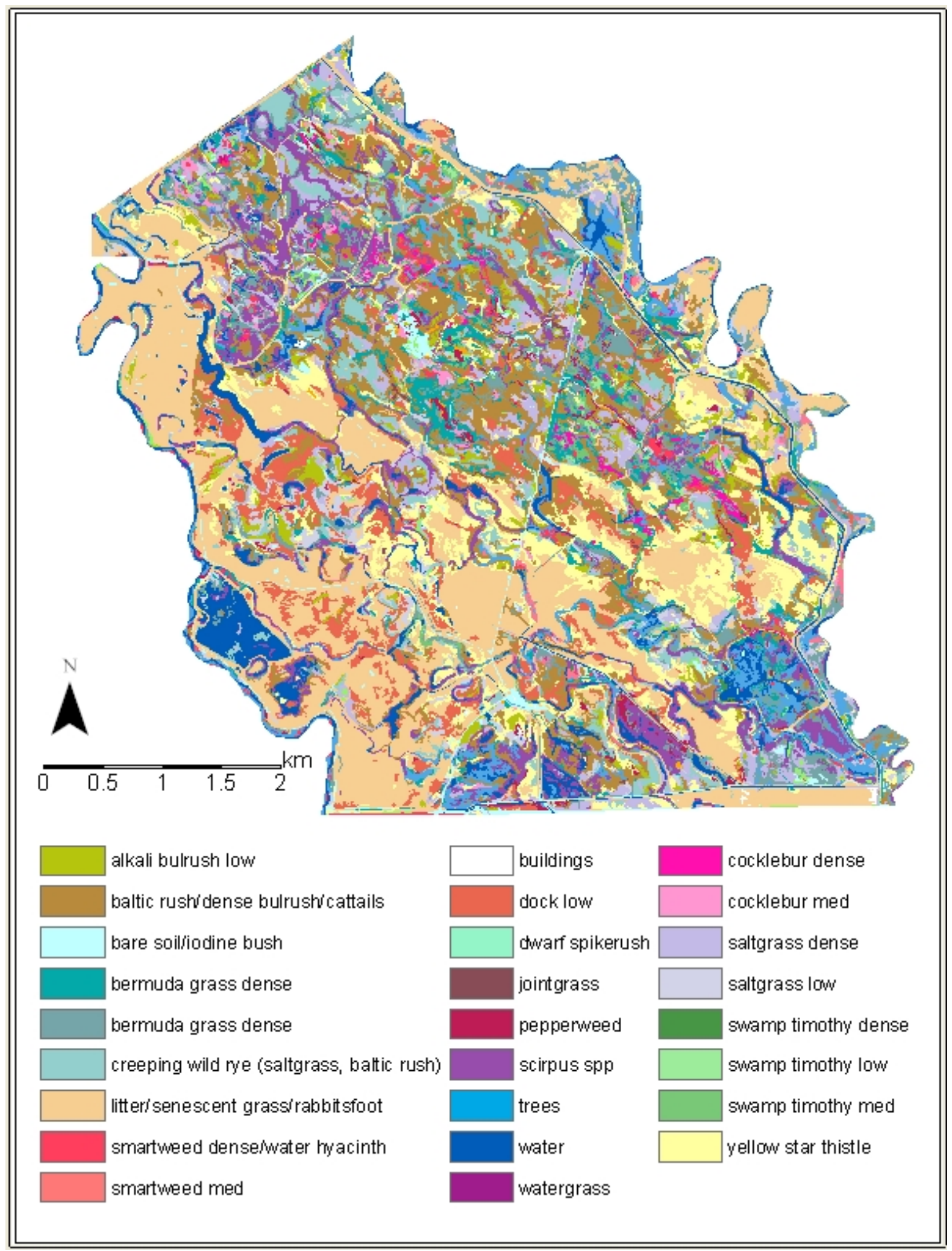

Figure 4.21 May 14, 2004 polygon-based maximum likelihood classification of SLNWR. Summarizing pixels into landscape polygons eases visual interpretability of the map and improves classification accuracy for some classes. 


\subsubsection{Accuracy Assessment}

A formal accuracy assessment of the May 14, 2004 classification is given in Table 4.7. The error matrix displays the results of analyzing independent reference data, or "check points." The number of check points correctly classified for each land cover class is displayed on the error matrix's diagonal. Check points in the same column as the target class were misclassified as some other class - an error of omission. Check points in the same row actually belonged to some other class and were incorrectly classified as the target class - an error of commission. Hence, the error matrix provides both accuracy assessment, and information about which classes are likely to be confused.

Producer's accuracies, listed along the bottom row, are calculated as the ratio of correctly classified reference points to the total number of reference points in the class. User's accuracies, listed in the far right column, are calculated as the ratio of correctly classified reference points to the total number of reference points assigned to that class. On the vegetation map, user's accuracies are expected to correlate with the probability that a pixel assigned to that class is actually a member of that class in the real world.

Accuracy assessment for the pixel-based June 19, 2004 maximum likelihood classification, and the polygon-based May 14, 2004 maximum likelihood classification are given in Tables 4.8 and 4.9 . 


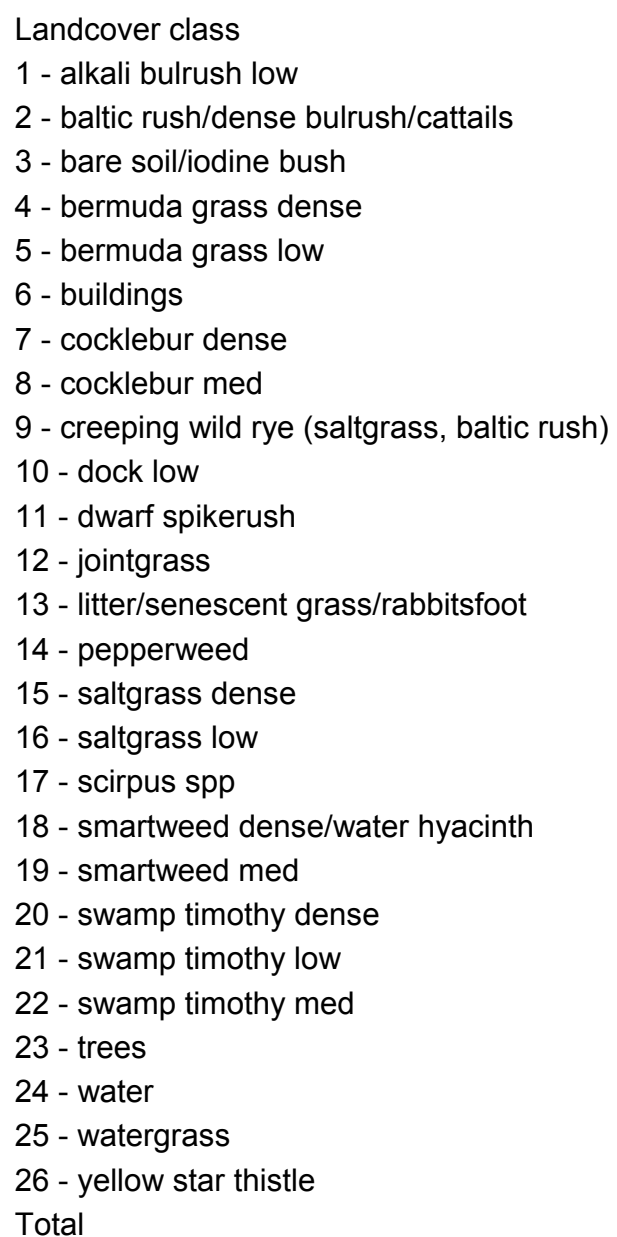

Producer's accuracy \%

\begin{tabular}{|c|c|c|c|c|c|c|c|c|c|c|c|c|c|}
\hline 1 & 2 & 3 & 4 & 5 & 6 & 7 & 8 & 9 & 10 & 11 & 12 & 13 & 14 \\
\hline 3 & - & - & - & - & - & - & - & - & - & - & - & 1 & - \\
\hline- & 8 & - & - & - & - & - & - & - & 1 & - & - & - & - \\
\hline- & - & 6 & - & - & - & - & - & - & - & 1 & - & - & - \\
\hline- & - & - & 4 & - & - & - & - & 1 & - & - & 3 & - & - \\
\hline- & - & - & - & 0 & - & 1 & - & - & - & - & - & - & - \\
\hline- & - & - & - & - & 7 & - & - & - & - & - & - & - & - \\
\hline- & - & - & - & - & - & 4 & - & - & - & - & - & - & - \\
\hline- & - & - & - & - & - & - & 6 & - & - & - & - & 1 & - \\
\hline- & - & - & - & - & - & - & - & 1 & - & - & - & - & - \\
\hline- & - & - & - & - & - & - & - & 1 & 1 & - & - & - & - \\
\hline- & - & - & - & - & - & - & - & - & - & 0 & - & - & - \\
\hline 1 & - & - & - & 1 & - & - & - & - & - & - & 0 & - & - \\
\hline- & 1 & - & - & - & - & - & - & - & - & - & - & 12 & 1 \\
\hline- & - & - & - & - & - & - & - & - & - & - & - & - & 0 \\
\hline- & - & - & - & - & - & - & - & - & - & - & 1 & 3 & - \\
\hline- & - & - & - & - & - & - & - & - & - & - & - & - & 1 \\
\hline- & - & - & - & - & - & - & - & - & - & - & - & - & - \\
\hline- & - & - & 1 & - & - & - & - & - & - & - & 1 & - & - \\
\hline- & - & - & 1 & 1 & - & - & 2 & - & - & - & - & - & - \\
\hline- & - & - & - & - & - & - & - & - & - & - & - & - & - \\
\hline- & - & - & - & - & - & - & - & - & - & - & - & - & - \\
\hline 2 & - & - & - & - & - & - & - & - & - & - & - & - & - \\
\hline 2 & - & - & - & - & - & - & - & - & - & - & 1 & - & - \\
\hline- & - & - & - & - & - & - & - & - & - & - & - & - & - \\
\hline 1 & - & - & - & - & - & - & 1 & - & - & - & - & 1 & 1 \\
\hline- & - & - & - & - & - & - & - & 1 & - & - & - & - & - \\
\hline 9 & 9 & 6 & 6 & 2 & 7 & 5 & 9 & 4 & 2 & 1 & 6 & 18 & 3 \\
\hline 33.3 & 88.9 & 100 & 66.7 & 0.0 & 100 & 80.0 & 66.7 & 25.0 & 50.0 & 0.0 & 0.0 & 66.7 & 0.0 \\
\hline
\end{tabular}

Table 4.7 Error matrix for pixel-based maximum likelihood classification of May 14, 2004 imagery. 


\begin{tabular}{|c|c|c|c|c|c|c|c|c|c|c|c|c|c|c|}
\hline 15 & 16 & 17 & 18 & 19 & 20 & 21 & 22 & 23 & 24 & 25 & 26 & Total & User's Acc. & Landcover Class \\
\hline- & - & - & - & - & - & - & - & - & - & - & - & 4 & $75.0 \%$ & 1 - alkali bulrush low \\
\hline 1 & - & - & - & - & - & - & - & - & - & - & 1 & 11 & $72.7 \%$ & 2 - baltic rush/dense bulrush/cattails \\
\hline- & - & - & - & - & - & 4 & - & - & - & - & - & 11 & $54.5 \%$ & 3 - bare soil/iodine bush \\
\hline- & - & - & 1 & 1 & 1 & - & - & - & - & - & - & 11 & $36.4 \%$ & 4 - bermuda grass dense \\
\hline- & - & 1 & - & 1 & 1 & 1 & - & - & 1 & - & - & 6 & $0.0 \%$ & 5 - bermuda grass low \\
\hline- & - & - & - & - & - & - & - & - & 1 & - & - & 8 & $87.5 \%$ & 6 - buildings \\
\hline- & - & - & - & - & - & - & - & - & - & - & - & 4 & $100.0 \%$ & 7 - cocklebur dense \\
\hline- & - & - & 2 & 1 & - & 1 & - & - & - & 1 & - & 12 & $50.0 \%$ & 8 - cocklebur med \\
\hline 1 & - & - & - & - & - & - & - & - & - & - & - & 2 & $50.0 \%$ & 9 - creeping wild rye (saltgrass, baltic rush) \\
\hline- & - & - & - & - & - & 1 & - & - & - & - & - & 3 & $33.3 \%$ & 10 - dock low \\
\hline- & - & - & - & - & 1 & 1 & - & - & - & - & - & 2 & $0.0 \%$ & 11 - dwarf spikerush \\
\hline- & - & - & - & - & - & - & 1 & - & - & - & - & 3 & $0.0 \%$ & 12 - jointgrass \\
\hline- & - & - & - & - & - & 2 & - & - & - & - & - & 16 & $75.0 \%$ & 13 - litter/senescent grass/rabbitsfoot \\
\hline- & - & - & - & - & - & - & - & - & - & - & - & 0 & $\mathrm{~N} / \mathrm{A}$ & 14 - pepperweed \\
\hline 1 & - & - & - & - & - & 3 & - & - & - & - & - & 8 & $12.5 \%$ & 15 - saltgrass dense \\
\hline- & 3 & - & - & - & - & 2 & - & - & - & - & - & 6 & $50.0 \%$ & 16 - saltgrass low \\
\hline- & - & 2 & - & - & - & - & - & - & 1 & - & - & 3 & $66.7 \%$ & 17 - scirpus spp \\
\hline- & - & - & 1 & - & - & - & - & - & - & - & - & 3 & $33.3 \%$ & 18 - smartweed dense/water hyacinth \\
\hline- & - & - & - & 0 & 2 & - & 2 & - & - & - & - & 8 & $0.0 \%$ & 19 - smartweed med \\
\hline- & - & - & - & 1 & 11 & - & - & - & - & - & - & 12 & $91.7 \%$ & 20 - swamp timothy dense \\
\hline- & - & - & - & - & - & 5 & - & - & - & - & - & 5 & $100.0 \%$ & 21 - swamp timothy low \\
\hline- & - & - & - & - & - & - & 4 & - & - & - & - & 6 & $66.7 \%$ & 22 - swamp timothy med \\
\hline- & - & - & - & - & 1 & - & - & 8 & - & - & - & 12 & $66.7 \%$ & 23 - trees \\
\hline- & - & - & - & - & - & - & - & - & 10 & - & - & 10 & $100.0 \%$ & 24 - water \\
\hline- & - & - & - & - & 1 & - & - & - & - & 2 & - & 7 & $28.6 \%$ & 25 - watergrass \\
\hline- & - & - & - & - & - & 1 & - & - & - & - & 1 & 3 & $33.3 \%$ & 26 - yellow star thistle \\
\hline 3 & 3 & 3 & 4 & 4 & 18 & 21 & 7 & 8 & 13 & 3 & 2 & 176 & & Column Total \\
\hline 33.3 & 100 & 66.7 & 25.0 & 0.0 & 61.1 & 23.8 & 57.1 & 100 & 76.9 & 66.7 & 50.0 & & & \\
\hline
\end{tabular}

Table 4.7 cont'd Error matrix for pixel-based maximum likelihood classification of May 14, 2004 imagery. 


\begin{tabular}{|c|c|c|c|c|c|c|c|c|c|c|}
\hline Landcover classes & 1 & 2 & 3 & 4 & 5 & 6 & 7 & 8 & 9 & 10 \\
\hline 1 - alkali bulrush & 3 & - & - & - & - & - & - & - & - & - \\
\hline 2 - alkali heath & - & 0 & - & 1 & - & - & - & - & 1 & - \\
\hline 3 - alkali sacaton & - & - & 2 & - & - & - & - & - & - & - \\
\hline 4 - baltic rush/dock dense & - & - & - & 6 & - & - & - & 1 & - & - \\
\hline 5 - bare soil & - & 1 & - & - & 2 & - & - & - & - & - \\
\hline 6 - bermuda grass dense & 3 & - & - & - & - & 2 & - & - & - & - \\
\hline 7 - buildings & - & - & - & - & - & - & 7 & - & - & - \\
\hline 8 - cattail & 1 & - & - & - & - & - & - & 0 & - & - \\
\hline 9 - chufa & 1 & - & - & - & - & - & - & - & 1 & 1 \\
\hline 10 - clover & - & - & - & - & - & - & - & - & - & 1 \\
\hline 11 - cocklebur dense & - & - & - & - & - & - & - & - & - & - \\
\hline 12 - cocklebur low & 1 & - & - & - & - & - & - & - & - & - \\
\hline 13 - creeping wild rye & - & - & - & - & - & 1 & - & - & - & - \\
\hline 14 - dock low & - & - & - & - & - & - & - & - & - & - \\
\hline 15 - iodine bush & 1 & - & - & - & - & - & - & - & - & - \\
\hline 16 - jointgrass & - & - & - & - & 1 & - & - & - & - & - \\
\hline 17 - litter/senescent grass/rabbitsfoot & - & - & - & - & 1 & - & - & - & - & - \\
\hline 18 - pepperweed & - & - & - & - & - & 1 & - & - & - & - \\
\hline 19 - saltgrass low/yellow star thistle & - & - & - & - & - & - & - & - & - & - \\
\hline 20 - saltgrass dense & - & - & - & - & - & - & - & - & - & - \\
\hline 21 - scirpus & 1 & - & - & - & - & - & - & - & - & - \\
\hline 22 - smartweed dense/water hyacinth & - & - & - & - & - & - & - & - & - & - \\
\hline 23 - swamp timothy dense & - & - & - & - & - & - & - & - & - & - \\
\hline 24 - swamp timothy low/alkali weed & - & 3 & - & - & - & - & - & - & - & - \\
\hline 25 - swamp timothy med & 1 & 2 & 1 & 1 & - & - & - & - & - & - \\
\hline 26 - trefoil & - & - & - & - & - & - & - & - & - & - \\
\hline 27 - trees & 1 & - & - & - & - & 2 & - & - & - & - \\
\hline 28 - water & - & - & - & - & - & - & - & - & - & - \\
\hline 29 - watergrass & - & - & - & - & - & 1 & - & - & - & - \\
\hline Column Total & 13 & 6 & 3 & 8 & 4 & 7 & 7 & 1 & 2 & 2 \\
\hline Producer's Accuracy & $23.1 \%$ & $0.0 \%$ & $66.7 \%$ & $75.0 \%$ & $50.0 \%$ & $28.6 \%$ & $100.0 \%$ & $0.0 \%$ & $50.0 \%$ & $50.0 \%$ \\
\hline
\end{tabular}

Table 4.8 Error matrix for pixel-based maximum likelihood classification of June 19, 2004 imagery. 


\begin{tabular}{|c|c|c|c|c|c|c|c|c|c|c|c|}
\hline Landcover classes & 11 & 12 & 13 & 14 & 15 & 16 & 17 & 18 & 19 & 20 & 21 \\
\hline 1 - alkali bulrush & - & 1 & - & - & - & - & - & - & - & - & - \\
\hline 2 - alkali heath & - & 1 & 1 & - & - & - & 1 & - & - & - & - \\
\hline 3 - alkali sacaton & - & - & 1 & - & - & - & - & - & 2 & 2 & - \\
\hline 4 - baltic rush/dock dense & - & - & - & - & - & - & 1 & - & - & - & - \\
\hline 5 - bare soil & - & - & - & - & - & - & - & - & - & - & - \\
\hline 6 - bermuda grass dense & - & - & - & - & - & 1 & 1 & 1 & - & - & 1 \\
\hline 7 - buildings & - & - & - & - & - & - & - & - & - & - & - \\
\hline 8 - cattail & - & - & - & - & - & - & 1 & - & - & - & - \\
\hline 9 - chufa & 1 & - & - & - & - & 1 & - & - & - & - & - \\
\hline 10 - clover & 1 & 1 & - & - & - & - & - & - & - & - & - \\
\hline 11 - cocklebur dense & 2 & - & - & - & - & 2 & - & - & - & - & - \\
\hline 12 - cocklebur low & - & 4 & - & - & - & - & - & - & - & - & - \\
\hline 13 - creeping wild rye & 1 & - & 1 & - & - & 1 & - & - & - & - & - \\
\hline 14 - dock low & - & - & - & 2 & - & - & 1 & - & 1 & - & - \\
\hline 15 - iodine bush & - & - & - & - & 4 & - & 1 & - & - & - & - \\
\hline 16 - jointgrass & - & - & - & - & - & 2 & - & - & - & - & - \\
\hline 17 - litter/senescent grass/rabbitsfoot & - & - & - & - & - & - & 6 & 1 & - & - & - \\
\hline 18 - pepperweed & - & - & - & - & - & - & - & 0 & - & - & - \\
\hline 19 - saltgrass low/yellow star thistle & - & - & 2 & - & - & - & 1 & - & 2 & - & - \\
\hline 20 - saltgrass dense & - & 3 & - & - & - & - & - & 1 & - & 1 & - \\
\hline 21 - scirpus & - & - & - & - & - & - & - & - & - & - & 2 \\
\hline 22 - smartweed dense/water hyacinth & - & - & - & - & - & - & - & - & - & - & - \\
\hline 23 - swamp timothy dense & - & - & - & - & - & - & - & - & - & - & - \\
\hline 24 - swamp timothy low/alkali weed & - & - & - & - & - & - & 2 & - & - & - & - \\
\hline 25 - swamp timothy med & - & - & 2 & - & - & - & 1 & - & 1 & - & - \\
\hline 26 - trefoil & - & - & - & - & - & - & - & - & - & - & - \\
\hline 27 - trees & - & - & - & - & - & - & - & - & - & - & - \\
\hline 28 - water & - & - & - & - & - & - & - & - & - & - & - \\
\hline 29 - watergrass & - & - & - & - & - & - & - & 1 & - & - & - \\
\hline Column Total & 5 & 10 & 7 & 2 & 4 & 7 & 16 & 4 & 6 & 3 & 3 \\
\hline Producer's Accuracy & $40.0 \%$ & $40.0 \%$ & $14.3 \%$ & $100.0 \%$ & $100.0 \%$ & $28.6 \%$ & $37.5 \%$ & $0.0 \%$ & $33.3 \%$ & $33.3 \%$ & $66.7 \%$ \\
\hline
\end{tabular}




\begin{tabular}{|c|c|c|c|c|c|c|c|c|c|c|}
\hline Landcover classes & 22 & 23 & 24 & 25 & 26 & 27 & 28 & 29 & Total & User's Acc. \\
\hline 1 - alkali bulrush & - & - & 1 & - & - & - & - & - & 5 & $60.0 \%$ \\
\hline 2 - alkali heath & - & - & - & - & - & - & - & - & 5 & $0.0 \%$ \\
\hline 3 - alkali sacaton & - & - & - & 1 & - & - & - & - & 8 & $25.0 \%$ \\
\hline 4 - baltic rush/dock dense & - & - & - & 1 & - & - & - & - & 9 & $66.7 \%$ \\
\hline 5 - bare soil & - & - & - & 2 & - & - & - & - & 5 & $40.0 \%$ \\
\hline 6 - bermuda grass dense & - & - & - & - & - & - & - & 1 & 10 & $20.0 \%$ \\
\hline 7 - buildings & - & - & - & - & - & - & - & - & 7 & $100.0 \%$ \\
\hline 8 - cattail & - & 1 & - & 1 & - & - & - & - & 4 & $0.0 \%$ \\
\hline 9 - chufa & 4 & - & - & - & - & - & - & - & 9 & $11.1 \%$ \\
\hline 10 - clover & 2 & 1 & - & - & - & - & - & - & 6 & $16.7 \%$ \\
\hline 11 - cocklebur dense & - & - & - & 1 & - & - & - & - & 5 & $40.0 \%$ \\
\hline 12 - cocklebur low & 1 & - & - & 1 & - & - & - & - & 7 & $57.1 \%$ \\
\hline 13 - creeping wild rye & - & - & - & - & - & - & - & - & 4 & $25.0 \%$ \\
\hline 14 - dock low & - & - & - & - & - & - & - & - & 4 & $50.0 \%$ \\
\hline 15 - iodine bush & - & - & - & - & - & - & - & - & 6 & $66.7 \%$ \\
\hline 16 - jointgrass & - & 1 & - & - & - & - & - & - & 4 & $50.0 \%$ \\
\hline 17 - litter/senescent grass/rabbitsfoot & - & - & - & 2 & - & - & - & - & 10 & $60.0 \%$ \\
\hline 18 - pepperweed & - & - & - & 1 & - & - & - & - & 2 & $0.0 \%$ \\
\hline 19 - saltgrass low/yellow star thistle & - & 1 & - & 1 & - & - & - & - & 7 & $28.6 \%$ \\
\hline 20 - saltgrass dense & - & - & 1 & 1 & - & - & - & - & 7 & $14.3 \%$ \\
\hline 21 - scirpus & - & - & - & - & - & 1 & - & - & 4 & $50.0 \%$ \\
\hline 22 - smartweed dense/water hyacinth & 4 & - & - & - & 1 & - & - & 3 & 8 & $50.0 \%$ \\
\hline 23 - swamp timothy dense & - & 2 & - & - & - & - & - & - & 2 & $100.0 \%$ \\
\hline 24 - swamp timothy low/alkali weed & - & - & 26 & 3 & - & - & - & - & 34 & $76.5 \%$ \\
\hline 25 - swamp timothy med & - & - & - & 9 & - & - & - & - & 18 & $50.0 \%$ \\
\hline 26 - trefoil & - & - & - & - & 1 & - & - & - & 1 & $100.0 \%$ \\
\hline 27 - trees & - & - & - & - & - & 7 & - & 1 & 11 & $63.6 \%$ \\
\hline 28 - water & - & - & - & - & - & - & 9 & - & 9 & $100.0 \%$ \\
\hline 29 - watergrass & 1 & - & 1 & - & - & - & - & 0 & 4 & $0.0 \%$ \\
\hline Column Total & 12 & 6 & 29 & 24 & 2 & 8 & 9 & 5 & 215 & \\
\hline Producer's Accuracy & $33.3 \%$ & $33.3 \%$ & $89.7 \%$ & $37.5 \%$ & $50.0 \%$ & $87.5 \%$ & $100.0 \%$ & $0.0 \%$ & & \\
\hline
\end{tabular}




\section{Classified Data}

1 - alkali bulrush low

2 - baltic rush/dense bulrush/cattails

3 - bare soil/iodine bush

4 - bermuda grass dense

5 - bermuda grass low

6 - buildings

7 - cocklebur dense

8 - cocklebur med

9 - creeping wild rye (saltgrass, baltic rush)

10 - dock low

11 - dwarf spikerush

12 - jointgrass

13 - litter/senescent grass/rabbitsfoot

14 - pepperweed

15 - saltgrass dense

16 - saltgrass low

17 - scirpus spp

18 - smartweed dense/water hyacinth

19 - smartweed med

20 - swamp timothy dense

21 - swamp timothy low

22 - swamp timothy med

23 - trees

24 - water

25 - watergrass

26 - yellow star thistle

Column Total

Producer's accuracy \%

$$
\begin{array}{ccccccccccccc}
1 & 2 & 3 & 4 & 5 & 6 & 7 & 8 & 9 & 10 & 11 & 12 & 13 \\
1 & - & - & - & - & - & - & - & - & - & - & - & - \\
- & 6 & - & - & - & - & - & 2 & - & 1 & - & 1 & - \\
- & - & 6 & - & - & - & - & - & - & - & - & - & 1 \\
- & - & - & 3 & - & - & 2 & - & - & - & - & 1 & - \\
2 & - & - & - & 1 & - & - & - & - & - & - & - & 1 \\
- & - & - & - & - & 7 & - & - & - & - & - & - & - \\
- & - & - & - & - & - & 3 & - & - & - & - & - & - \\
1 & - & - & - & - & - & - & 5 & - & - & - & - & - \\
- & - & - & - & - & - & - & 1 & 2 & - & - & - & - \\
- & - & - & - & - & - & - & - & 1 & 1 & - & - & - \\
- & - & - & - & - & - & - & - & - & - & 0 & - & 2 \\
- & - & - & - & - & - & - & - & - & - & - & 0 & - \\
- & 2 & - & - & - & - & - & - & - & - & - & - & 8 \\
- & - & - & - & - & - & - & - & - & - & - & - & - \\
2 & - & - & - & - & - & - & - & - & - & - & 2 & 3 \\
- & 1 & - & 1 & - & - & - & - & - & - & - & - & - \\
- & - & - & - & - & - & - & - & - & - & - & - & - \\
- & - & - & 1 & - & - & - & - & - & - & - & 1 & - \\
- & - & - & - & - & - & - & - & - & - & - & - & - \\
- & - & - & - & - & - & - & - & - & - & - & - & - \\
- & - & - & - & - & - & - & - & - & - & - & - & - \\
1 & - & - & - & - & - & - & - & - & - & 1 & - & - \\
1 & - & - & - & 1 & - & - & - & - & - & - & 1 & - \\
- & - & - & - & - & - & - & - & - & - & - & - & - \\
1 & - & - & 1 & - & - & - & 1 & - & - & - & - & - \\
- & - & - & - & - & - & - & - & 1 & - & - & - & 2 \\
9 & 9 & 6 & 6 & 2 & 7 & 5 & 9 & 4 & 2 & 1 & 6 & 17 \\
11.1 & 66.7 & 100 & 50.0 & 50.0 & 100 & 60.0 & 55.6 & 50.0 & 50.0 & 0.0 & 0.0 & 47.1
\end{array}
$$

Table 4.9 Error matrix for polygon-based maximum likelihood classification of May 14, 2004 imagery. 


\begin{tabular}{|c|c|c|c|c|c|c|c|c|c|c|c|c|c|c|c|}
\hline 14 & 15 & 16 & 17 & 18 & 19 & 20 & 21 & 22 & 23 & 24 & 25 & 26 & Total & UsersAcc. & Classified Data \\
\hline- & - & 1 & - & - & - & - & - & - & - & - & - & - & 2 & $50.0 \%$ & 1 - alkali bulrush low \\
\hline- & - & - & - & 1 & 1 & - & 1 & - & - & - & - & 1 & 14 & $42.9 \%$ & 2 - baltic rush/dense bulrush/cattails \\
\hline- & - & 1 & - & - & - & - & 5 & 1 & - & - & - & - & 14 & $42.9 \%$ & 3 - bare soil/iodine bush \\
\hline- & - & - & - & - & 1 & - & - & - & 1 & - & - & - & 8 & $37.5 \%$ & 4 - bermuda grass dense \\
\hline 1 & - & - & 1 & - & - & 4 & 2 & 1 & 1 & - & 1 & - & 15 & $6.7 \%$ & 5 - bermuda grass low \\
\hline- & - & - & - & - & - & - & - & - & - & 1 & - & - & 8 & $87.5 \%$ & 6 - buildings \\
\hline 1 & - & - & - & - & - & - & - & - & - & - & - & - & 4 & $75.0 \%$ & 7 - cocklebur dense \\
\hline- & - & - & - & 1 & - & - & 1 & - & - & - & 1 & - & 9 & $55.6 \%$ & 8 - cocklebur med \\
\hline- & - & - & - & - & - & 1 & - & - & - & - & - & - & 4 & $50.0 \%$ & 9 - creeping wild rye (saltgrass, baltic rush) \\
\hline- & - & - & - & - & - & - & - & - & - & - & - & - & 2 & $50.0 \%$ & 10 - dock low \\
\hline- & - & - & - & - & - & 1 & 1 & - & - & - & - & - & 4 & $0.0 \%$ & 11 - dwarf spikerush \\
\hline- & - & - & - & - & - & 1 & - & - & - & - & - & - & 1 & $0.0 \%$ & 12 - jointgrass \\
\hline 1 & - & - & - & - & - & 1 & 3 & - & - & - & - & - & 15 & $53.3 \%$ & 13 - litter/senescent grass/rabbitsfoot \\
\hline 0 & - & - & - & - & - & 1 & - & - & - & - & - & - & 1 & $N / A$ & 14 - pepperweed \\
\hline- & 3 & - & - & - & - & - & 1 & - & - & - & - & - & 11 & $27.3 \%$ & 15 - saltgrass dense \\
\hline- & - & 2 & - & - & - & - & - & - & - & - & - & - & 4 & $50.0 \%$ & 16 - saltgrass low \\
\hline- & - & - & 2 & 1 & - & - & - & - & - & 1 & - & - & 4 & $50.0 \%$ & 17 - scirpus spp \\
\hline- & - & - & - & 1 & - & - & - & - & - & - & - & - & 3 & $33.3 \%$ & 18 - smartweed dense/water hyacinth \\
\hline- & - & - & - & - & 2 & 1 & - & - & - & - & - & - & 3 & $66.7 \%$ & 19 - smartweed med \\
\hline- & - & - & - & - & - & 8 & - & - & - & - & - & - & 8 & $100.0 \%$ & 20 - swamp timothy dense \\
\hline- & - & - & - & - & - & - & 5 & - & - & - & - & - & 5 & $100.0 \%$ & 21 - swamp timothy low \\
\hline- & - & - & - & - & - & - & - & 3 & - & - & 1 & - & 4 & $50.0 \%$ & 22 - swamp timothy med \\
\hline- & - & - & - & - & - & - & - & - & 6 & - & - & - & 9 & $66.7 \%$ & 23 - trees \\
\hline- & - & - & - & - & - & - & 1 & - & - & 11 & - & - & 12 & $91.7 \%$ & 24 - water \\
\hline- & - & - & - & - & - & - & - & 2 & - & - & 0 & - & 5 & $0.0 \%$ & 25 - watergrass \\
\hline- & - & - & - & - & - & - & 1 & - & - & - & - & 1 & 5 & $20.0 \%$ & 26 - yellow star thistle \\
\hline 3 & 3 & 4 & 3 & 4 & 4 & 18 & 21 & 7 & 8 & 13 & 3 & 2 & 176 & & Column Total \\
\hline 0.0 & 100 & 50.0 & 66.7 & 25.0 & 50.0 & 44.4 & 23.8 & 42.9 & 75.0 & 84.6 & 0.0 & 50.0 & & & Producer's accuracy \% \\
\hline
\end{tabular}




\subsubsection{ET Estimation via Land Cover Categorization}

A monthly ET estimate was preparing by multiplying the ET value for each category by the total land area occupying that category. A table showing the total land area, estimated ET from that category in inches, and total estimated ET for the SLNWR is shown below in Table 4.10. Estimates of land area are derived from the object-based classification of SLNWR.

Table 4.10 ET values of land cover categories

\begin{tabular}{|l|l|l|l|}
\hline Category & $\begin{array}{l}\text { Estimated Acreage } \\
\text { (sq-km) }\end{array}$ & $\begin{array}{l}\text { ET } \\
\text { (inches/month) }\end{array}$ & $\begin{array}{l}\text { Estimated annual ET } \\
\left(\mathbf{m}^{3} / \mathbf{y e a r}\right)\end{array}$ \\
\hline shallow & 38.3 & 3.37 & $39,378,721$ \\
\hline medium & 46.1 & 4.93 & $69,283,257$ \\
\hline deep & 12.6 & 11.08 & $42,422,186$ \\
\hline uplands & 48.6 & 1.69 & $25,053,148$ \\
\hline riparian & 6.5 & 6.53 & $12,964,816$ \\
\hline open water & 10.9 & 5.80 & $19,313,526$ \\
\hline buildings & 2.0 & 0 & 0 \\
\hline
\end{tabular}

\subsection{Discussion and Further Investigation}

It can be seen from the error matrices that the May 14, 2004 imagery provides the most accurate assessment of land cover classes. The difference is not large, however, and both May and June provide considerable improvement over the preliminary results for analysis of imagery collected earlier in the year in April. An optimal date will also depend on yearly weather patterns, and on the timing of irrigations. (Ideally, imagery should be collected at a time when minimal land is flooded.) Mid-May through early June is recommended for future image data collections.

The error matrices show that the compilation of individual pixels into landscape objects improved the accuracy for some classes and decreased it for others. The overall effect, for the parameters chosen, was a small decrease in accuracy. The size of the landscape objects is determined by an abstract parameter which sets the maximum allowable heterogeneity for a polygon, in terms of both spectral and shape characteristics. The scale parameter used in this study was 50. After visual review of the landscape objects created using this scale 
parameter, and completion of the formal accuracy assessment, it is hypothesized that a smaller scale parameter - and therefore smaller landscape objects - would yield improved results.

In considering the error matrix for the pixel-based May 14, 2004 classification result, it is apparent that the classification performed well for a number of important species, among them alkali bulrush, cocklebur, scirpus, and swamp timothy. However, other important species were less accurately mapped, including bermuda grass, jointgrass, smartweed, and watergrass. Future work should emphasize ground data collection for these species, so that a robust spectral signature can be developed, and so that any mapping limitations are well understood. It should also be noted that open water was classified with a high degree of accuracy in all three maps. Accurately mapped water bodies could be used to improve calculations of open water evaporation for these wetland areas, thereby contributing to a quantitative understanding of water needs and water usage for wetland regions.

In this methodology, an industry standard maximum likelihood classification methodology was used, combining multiple spectral signatures into a single spectral signature per landcover class, which is then used in the classification algorithm. Combining signatures in this way ensures that the full range of values exhibited by a species is included in the final signature. However, an alternative method is to run the classification algorithm using one spectral signature per ground truth point, and to manually recode the classification after the algorithm has run (Milliken, 2005.) This method reduces overlap between classes that have similar locations in feature space, as most vegetation does, and may result in a more accurately classified final product.

One of the image processing packages used in this study, eCognition, provides a large number of advanced, object-based, scale-dependent feature extraction methods. Examples of these include neighborhood attributes (such as nearness to open water), ratios (dividing one spectral band by another), and texture characteristics (such as spectral heterogeneity.) Some of the more intractable land cover classes may have characteristics that would make them 
readily distinguishable. ECognition contains a suite of data-mining tools that makes possible the exploration and utilization of complex object-based land cover characteristics.

This methodology for using remotely sensed imagery to map land cover can have an immediate impact on resource management programs in the Central Valley of California. Salinity TMDL's and other actions to control salt and nutrient loading from managed wetlands may influence the wetlands' hydroperiod, as basin drawdown is adjusted to match the San Joaquin River's assimilative capacity. This broadly-applicable mapping technique provides a tool to assess the long-term impact of these adaptive management strategies on the wetland resource. Results from this methodology can also help provide a scientific basis for estimation of water needs of the moist-soil vegetation in managed seasonal wetlands. This research promotes better use of existing water resources to maximize wetland benefit with the possibility of long-term water savings. 


\section{CHAPTER 5 WETLAND SOIL SALINITY IMPACT ASSESSMENT}

\subsection{Background}

Soil salinity is an important conservation and environmental problem in wetlands of the San Joaquin Basin. Salinity affects plant germination and development, and can lead to significant increases in salt tolerant species' populations, thereby creating imbalances in the wetland ecosystem. Consequently, it can also influence fauna diversity, such as invertebrate, fish, and bird. Thus, it is important to evaluate the extent and variability of soil salinity on those wetlands in order to develop sound planning and management practices for improving long-term habitat health and restoring wetlands.

Measurement methods such as the four-electrode probes and soil sampling are generally applied to determine soil salinity; however, these methods require extensive data collection and laboratory analyses that are very slow, labor-intensive, and expensive. Recently, remote sensing technologies have become easier to use for surveying salt-affected lands. Among those techniques, the electromagnetic induction (EM) method has been very efficient in

rapidly collecting salinity information in soil systems (Ceuppens et al., 1997; Hendrickx et al.). Furthermore, the EM technology generally provides better and faster estimates of soil salinity than direct methods (Sudduth et al., 1999). The principle of the EM technique is based on the fact that electrical conductance increases with salinity. The instrument generates a primary electromagnetic field in the soil, which in turn creates a secondary field. The ratio of both fields correlates with the depth-weighted electrical conductivity (EC) in the volume of soil below the EM sensor (Slavish, 1990). Since solid soil particles and rock material have very low EC (McNeill, 1980), the instrument response is primarily influenced by the electrolyte concentration of the soil water, i.e., salinity.

\subsection{Objective of the Study}

The objective of the study was to assess and map soil salinity in wetlands of the San Luis National Wildlife Refuge (NWR), located in the San Joaquin River Basin, using the EM technique. 


\subsection{Methodology}

Soil salinity surveys were conducted in April 2004 on selected lands of the San Luis National Wildlife Refuge (SLNWR). Maps showing the locations of the surveys are presented in Figure 5.1. Two sites were surveyed at each wetland. Selection of the sites was based on representative soil conditions and vegetation population, as well as locations of previous ground plant identification.

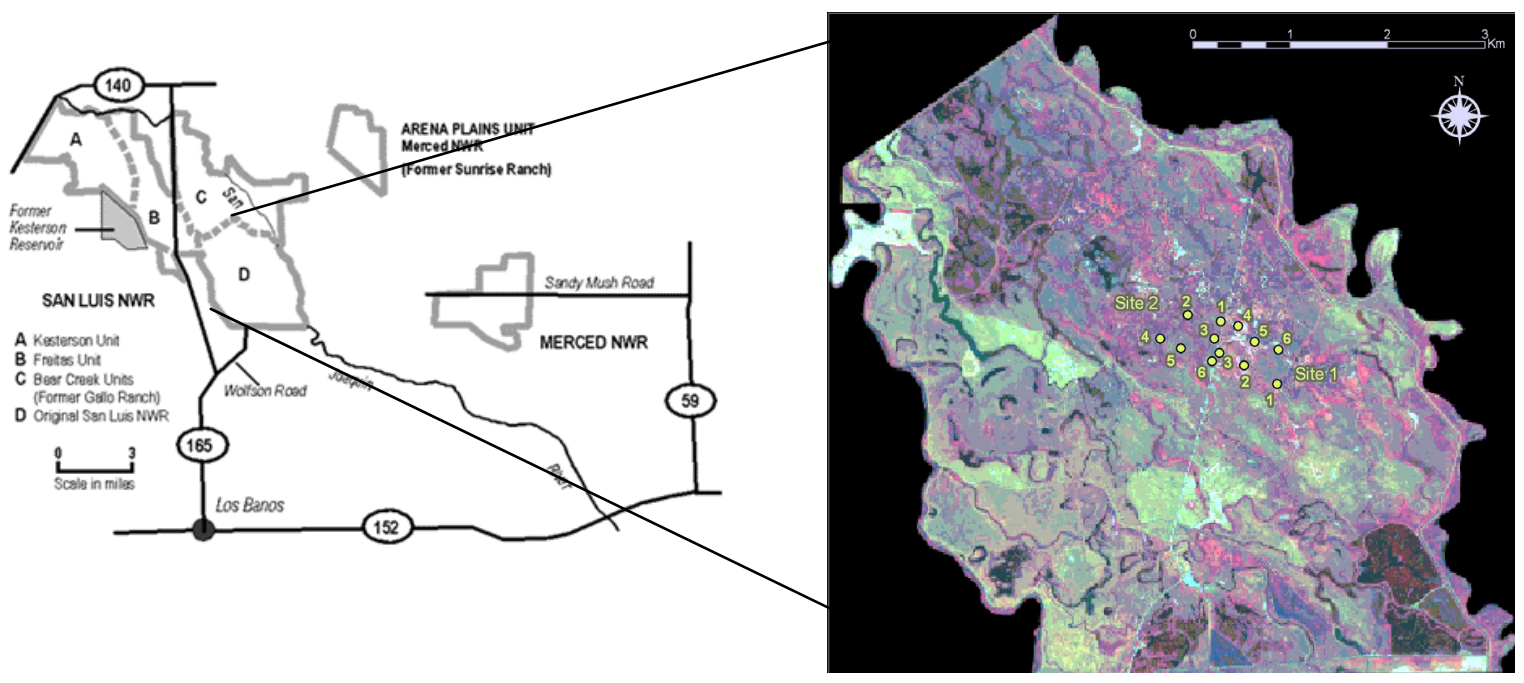

Figure 5.1. Location of sites surveyed at the SLNWR San Luis Unit

The salinity surveys were conducted using a mobilized system available at the California State University, Fresno. This system comprised a geographical positioning system (GPS) and a dual EM-38 meter (Geonics Ltd) placed in a carrier-sled that was attached at the rear of an ATV and operated in both horizontal and vertical modes, providing bulk salinity estimates of both shallow (top 6 inches) and deep (top 6 feet) soils. Such system allowed for rapid salinity measurements (about 2 hours per survey), after initial setup, at both wetlands. The EM and GPS data were collected along transects spaced 150 to $300 \mathrm{ft}$ apart, depending on the extent of vegetation cover, and recorded simultaneously to a laptop computer. After the surveys, the data were analyzed using ESAP (Lesch and Rhoades, 1999) and a soil sampling plan was developed to calibrate the EM data. 


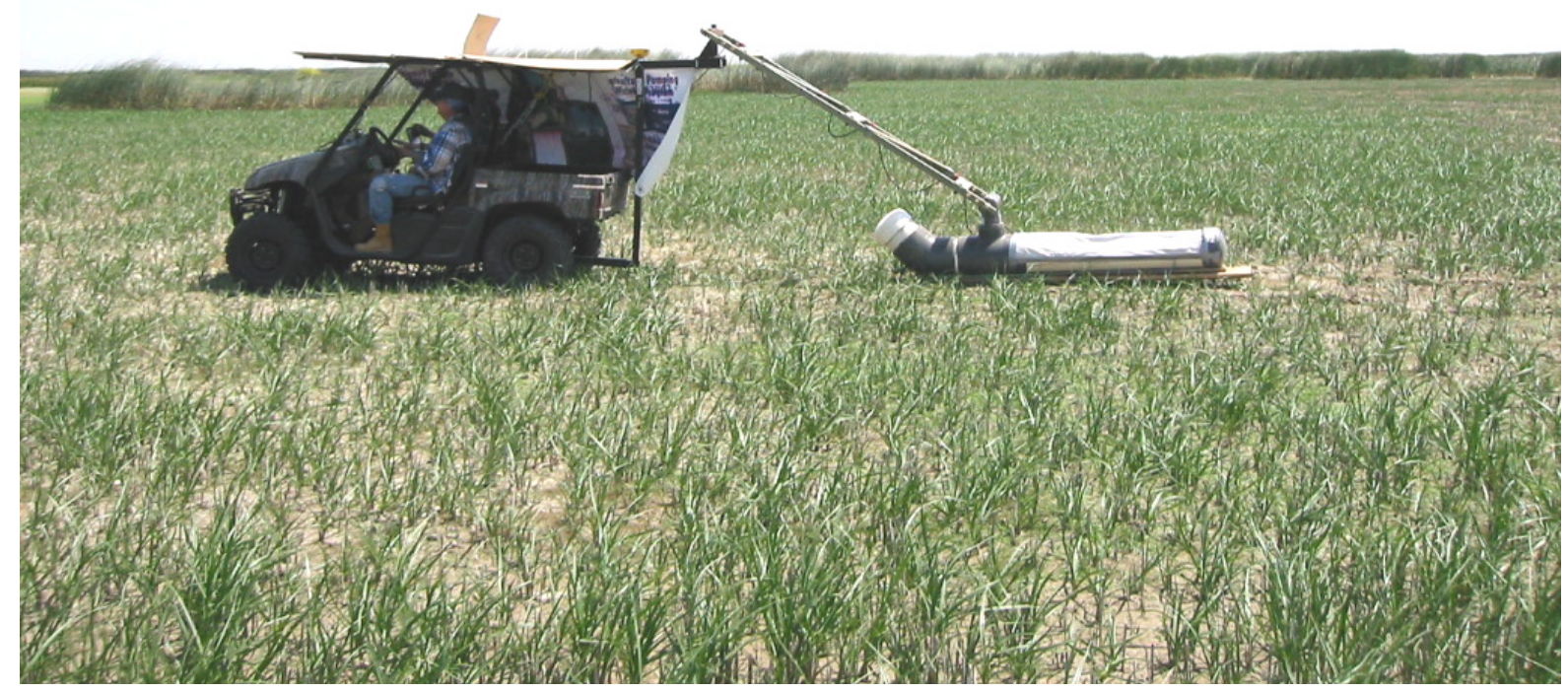

Figure 5.2 EM-38 dual mode meter (Geonics Ltd) placed in a carrier-sled that was attached at the rear of an ATV. Horizontal and vertical aligned coupled meters provide sensing of near-surface bulk salinity (top 6 inches) and deeper bulk salinity (up to 6 feet).

For each survey, the sampling plan comprised 6 locations that were spatially representative of the entire survey area. Ground truthing soil sampling was then conducted at each site. Soil samples were collected at 0-6" and 6-12" depths (associated with horizontal and vertical EM38 alignments of the dual instrument) and then analyzed for EC, moisture, texture, and total dissolved solids (TDS) following standard analytical methods (Rhoades, 1996). Based on the EM data and laboratory analyses, maps of soil salinity were generated for each site surveyed using GIS (Environmental System Research Institute, 1996).

\subsection{Results}

Table 5.1 presents the EC levels of soils sampled at the San Luis Refuge and Salinas Club. Sampling locations at each site are shown in Figure 5.1. Soil EC at the San Luis Refuge ranged from 0.4 to $19.8 \mathrm{dS} / \mathrm{m}$, indicating a high degree of variability across the surveyed 
areas. The EC levels were relatively lower at site 1 as compared to site 2. Typically, higher EC values were observed in the first six inches of the soil profile in site 1, which could suggest lower drainage of water.

Table 5.1. Soil electrical conductivity $(\mathrm{dS} / \mathrm{m})$ for samples collected on all surveyed sites.

\begin{tabular}{|c|c|c|c|}
\hline \multirow{2}{*}{$\begin{array}{c}\text { Sampling } \\
\text { location }\end{array}$} & \multirow[t]{2}{*}{ Depth } & \multicolumn{2}{|c|}{ San Luis Refuge } \\
\hline & & Site 1 & Site 2 \\
\hline 1 & $0-6 "$ & 12.2 & 3.34 \\
\hline & $6-12 ”$ & 8.69 & 3.57 \\
\hline 2 & $\begin{array}{l}0-6 " \\
6-12 "\end{array}$ & $\begin{array}{l}3.80 \\
4.31\end{array}$ & $\begin{array}{l}1.86 \\
2.64\end{array}$ \\
\hline 3 & $\begin{array}{l}0-6 " \\
6-12 "\end{array}$ & $\begin{array}{l}2.02 \\
0.42\end{array}$ & $\begin{array}{l}4.21 \\
1.57\end{array}$ \\
\hline 4 & $\begin{array}{l}0-6 " \\
6-12 "\end{array}$ & $\begin{array}{l}2.28 \\
1.31\end{array}$ & $\begin{array}{l}7.54 \\
9.52\end{array}$ \\
\hline 5 & $\begin{array}{l}0-6 " \\
6-12 "\end{array}$ & $\begin{array}{l}1.67 \\
0.94\end{array}$ & $\begin{array}{l}19.8 \\
21.1\end{array}$ \\
\hline 6 & $\begin{array}{l}0-6 " \\
6-12 "\end{array}$ & $\begin{array}{l}1.44 \\
0.65\end{array}$ & $\begin{array}{l}6.63 \\
2.21\end{array}$ \\
\hline
\end{tabular}

The texture data indicated that the soils were loamy to clayey. The average EC values of the six samples collected at 0-6" and 6-12" depths at site 2 of the San Luis Refuge were compared (Table 5.2). Site 1 at the San Luis Refuge exhibited the lowest average EC levels for both depths; all EC data were below $9 \mathrm{dS} / \mathrm{m}$. A high variability in the EC data was observed for all sites and depths, as indicated by the large standard deviations.

Table 5.2. Statistics for EC analyzed on all soil samples collected in 2004.

\begin{tabular}{|l|c|c|c|c|c|}
\hline Site & Depth & Mean & Std. dev. & Minimum & Maximum \\
\hline SLR, site 1 & $0-6 "$ & 3.90 & 4.14 & 1.44 & 12.2 \\
\hline & $6-12 "$ & 2.72 & 3.25 & 0.42 & 8.69 \\
\hline SLR, site 2 & $0-6 "$ & 7.23 & 6.51 & 1.86 & 19.8 \\
\hline & $6-12 "$ & 6.76 & 7.58 & 1.57 & 21.1 \\
\hline & $6-12 "$ & 5.61 & 6.33 & 1.34 & 18.2 \\
\hline
\end{tabular}

SLR $=$ San Luis Refuge

Table 5.3 shows the TDS results obtained from the soil analyses conducted on all samples. The TDS values followed the same trend observed with EC. 
Table 5.3. Statistics for TDS analyzed on all soil samples collected in 2004.

\begin{tabular}{|l|c|c|c|c|c|}
\hline Site & Depth & Mean & Std. dev. & Minimum & Maximum \\
\hline SLR, site 1 & $0-6 ”$ & 3138 & 2984 & 1300 & 9017 \\
\hline & $6-12 ”$ & 2186 & 2436 & 467 & 6200 \\
\hline SLR, site 2 & $0-6 ”$ & 5967 & 5726 & 1480 & 16860 \\
\hline & $6-12 ”$ & 6106 & 8096 & 350 & 21425 \\
\hline
\end{tabular}

$\mathrm{SLR}=$ San Luis Refuge.

These soil laboratory data were used to calibrate the EM measurements and estimate soil salinity over the surveyed areas. For each site, the correlations between measured TDS and calculated conductivity data were above 0.8 , suggesting a high degree of survey reliability and accuracy for salinity estimation. The soil salinity levels estimated at 0-6" and 6-12" depths for the surveyed areas in 2004 at the San Luis Refuge are presented in Figures 5.3 and 5.4. The contour maps indicate that the soil salinity levels were generally higher in site 2 . Greater salinity was also observed at 0-6" depth as compared to the lower depths for both sites, suggesting that drainage could be poor on those sites. At site 1, the soil salinity was greatest in the western part of the surveyed area, and decreased gradually in a north-west direction. At site 2 , salinity was variable across the surveyed area.

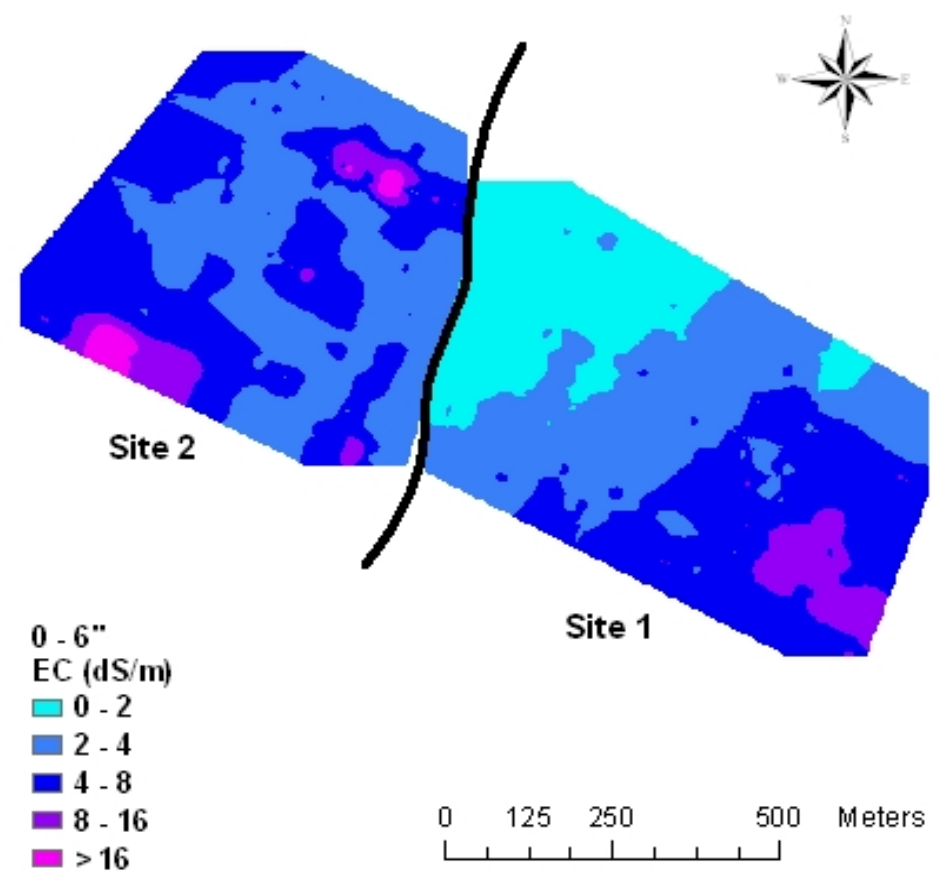

Figure 5.3. Soil salinity estimated at $0-6$ " depth on two sites surveyed at the San Luis Refuge in 2004 
Although the salinity levels were not as variable as those observed at the San Luis Refuge, the salinity distribution was quite different between the 0-6" and 6-12" depths. On both sites, the salinity was higher at the soil surface (0-6”). At site 2, the soil salinity levels remained mostly between 4 to $8 \mathrm{dS} / \mathrm{m}$ on surface, indicating low spatial variability in the surveyed area. However, at 6-12" depth, the site exhibited greater spatial variability with salinity values ranging from 0.3 to $15.7 \mathrm{dS} / \mathrm{m}$.

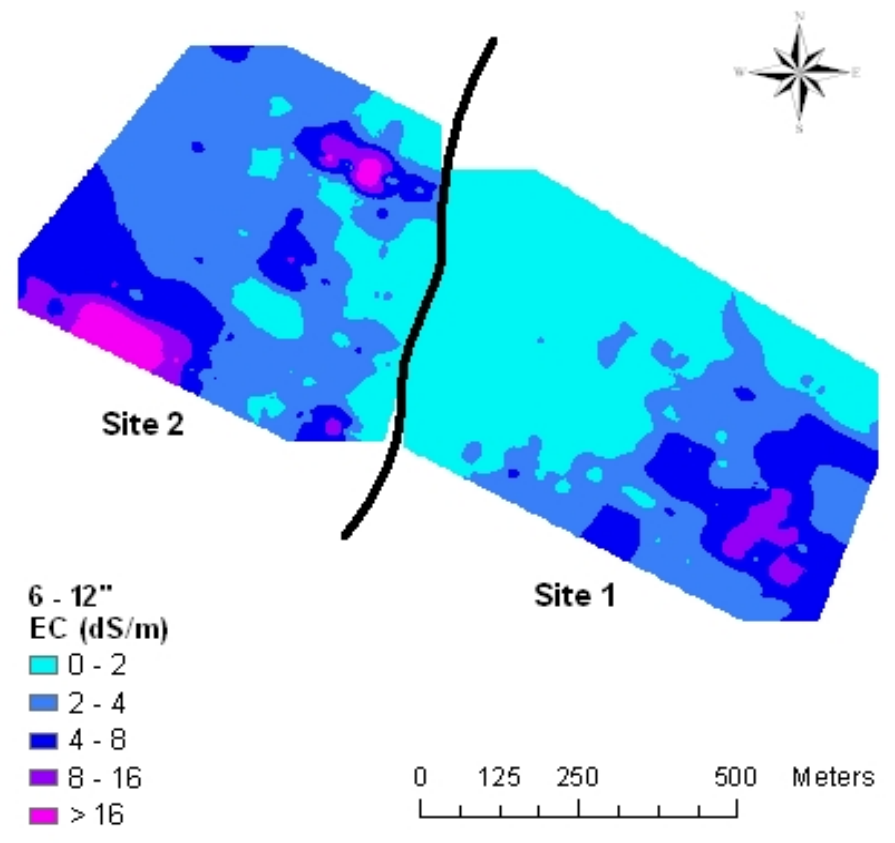

Figure 5.4 Soil salinity estimated at 6-12" depth on two sites surveyed at the San Luis Refuge in 2004

Data analyses indicated a high degree of survey reliability and accuracy for predicting salinity levels on both sites. The soil salinity maps generated at each site are presented in Figures 5.7 and 5.8. The mobile system was not used for conducting the 2003 salinity surveys at the Salinas Club; thus, the surveys were performed on smaller areas. Site 1 showed a very uniform salinity pattern, with values ranging from 8 to $16 \mathrm{dS} / \mathrm{m}$. At site 2 , a higher salinity variability was observed across the survey area. However, the salinity levels were lower than $8 \mathrm{dS} / \mathrm{m}$ in most areas. 


\subsection{Conclusions}

The results of the study indicated that the EM technique was very effective to accurately assess soil salinity distribution across the surveyed areas of the San Luis Refuge wetlands. The soil profile shapes (regular or inverted), indicative of drainage management practices, could be suggested from the salinity surveys and soil sampling at various depths. The EM surveys indicated that the soil salinity levels were relatively high on both wetlands, and particularly at the San Luis Refuge at site 2 .

The soil salinity survey technique described in this section, when combined with the remote sensing methodology described in Chapter 4 should form the basis of a physically-based (as opposed to biologically based) assessment of baseline conditions in advance of a wetlandwide strategy of real-time management of seasonal drainage. These techniques will allow wetland managers to document any long-term changes in wetland soil salinity conditions and take appropriate management actions to avoid the type of damage to the wetland resource that occurred in the Southern Division of the Grassland Water District. Changes in the health of the wetland resource occurs slowly and insidiously requiring a quantitative approach to assessment. The techniques described in Chapters 4 and 5 can be further refined to improve their accuracy and reduce their cost. 


\section{CHAPTER 6 CONCLUSIONS}

\subsection{Summary}

The goal of the Real-Time Adaptive Wetland Water Quality Management research project in the San Luis Unit of the SLNWR Complex was to develop a telemetered flow and water quality monitoring system and associated tools to improve management of seasonal wetland drainage to the San Joaquin River to meet State salinity objectives. Decision support tools were developed to complement the real-time monitoring system to improve understanding of seasonal wetland salt mass balance and to assess potential impacts on habitat quality of actions to improve water quality in the San Joaquin River. The project deliverables include:

1. A real-time flow and salinity data acquisition network for use in seasonal wetlands

2. A remote habitat assessment methodology for measuring the impacts of alternative wetland drawdown schedules on moist-soil plant production

3. Soil salinity maps based on electromagnetic surveys of project wetlands within the San Luis Unit.

4. A wetland water quality model that can be adapted to simulate expected salt exports from the San Luis Unit of the SLNWR Complex to the San Joaquin River;

5. A WETMANSIM spreadsheet model for the San Luis Unit - calibrated with data collected during 2003/2004. .

These decision support tools provide a resource to wetland managers to adaptively respond to San Joaquin River salt discharge opportunities while maximizing long-term wetland function and habitat value. Adaptive management can be defined as "changing or altering management decisions based on past or current conditions, either physical or political" (Chess et al., 2000). The Decision Support System (DSS) assists in the computation of Refuge wetland water requirements including an estimation of wetland salinity loads in seasonal wetlands. The DSS was designed to interact with the existing SJR water quality forecasting model, SJRIODAY, to allow the partition of assimilative capacity among the wetland releases (Quinn and Hanna, 2003).

Decision Support Systems are becoming more important to ecosystem managers. As the habitat value of the wetlands within the Grassland Ecological Area increases so do the 
impacts of the decisions of wetland managers. As concerns over water quality conditions in the San Joaquin River multiply both in degree and complexity - tools that combine information from several disciplines are essential to allow general practitioners to make better informed decisions (Chess et al., 2000; Young et al., 2000).

\subsection{Project Geographic Information System}

The Decision Support System design allows data to be automatically loaded into a Microsoft Access database for use with Geographic Information System (GIS) software. The GIS can assist wetland managers develop salinity forecasts salinities on individual allowing drainage from each to be scheduled. Included in the GIS, for each wetland unit, are useful information to the water master. This information includes:

1. the name of the wetland unit

2. the wetland unit's owner's name (State, Federal, or private) and phone number

3. the location of the wetland unit and its upstream and downstream neighbors

4. the water supply and drainage canals, including the drainage basin

5. the total area, total wetland area, and total upland area

6. the total volume of water and estimated mass of salt remaining on the property

7. management goals, shallow, mid-depth or deep (permanent) wetlands

8. satellite, mapped, and schematic images of the wetland unit

9. contact phone numbers where the wetland manager can be reached.

This meta-information allows staff in the SLNWR to quickly ascertain wetlands where salinity is accumulating fastest, whether they will be draining earlier or later (swamp timothy demands earlier drawdown than habitat managed for watergrass), what drainage basin this may impact, and who to contact when decisions are made.

\subsection{Discussion}

The research performed for this project has provided several useful results that can be immediately applied to wetland "best management practices" (BMP). Results from the 
research have shown that real-time data acquisition is feasible in seasonal wetlands and can meet regulatory requirements under EPA mandated TMDL's. The same data can also be used to develop and run a wetland water quality model, providing the capability to forecast wetland salinity levels during the drawdown period. These forecasts, when compared to the San Joaquin River assimilative capacity forecasts for salts, can help decision makers adaptively manage salt export. Use of remote sensing techniques to monitor moist soil plant impacts and mobile salinity sensors to map longer term soil salinity impacts - a methodology has been created to aid the development of sustainable best management practices.

Information obtained through this project will be transferable and of significant value to all wetlands in the Grassland Ecological Area including State and privately managed wetlands. The successful implementation of this combined monitoring, experimentation and evaluation program can provide the basis for adaptive management of wetland drainage throughout the entire 70,000 hectare Grassland Ecological Area. The project will involve local landowners, duck club operators, and managers of State and Federal refuges in the Grassland Basin. Although this pilot project has concentrated on the San Luis unit of the SLNWR, the goal of the project is to disseminate the findings of the project more widely. The SLNWR Complex , the State Los Banos Wildlife Management Area and the private Grassland Water District have a successful history of local involvement through high school and college-level educational outreach programs; and "Wild on Wetland" days which educate the public about the benefits and techniques of wetland management.

The project has demonstrated the ability to coordinate wetland drainage activities contributing to water quality impairments the San Joaquin River. If a basin-wide effort, combining the activities of environmental, agricultural, municipal and industrial interests is implemented, water quality compliance with environmental objectives in the San Joaquin River is possible. 


\section{CHAPTER 7 REFERENCES}

Allen, R.G., L.S. Pereira, D. Raes, and M. Smith. 1999. Crop evapotranspiration: Guidelines for computing crop water requirements. FAO Irrigation and Drainage Paper 56, FAO, Rome.

Allen, R.G., A. Morse, M. Tasumi. 2003. Application of SEBAL for western US water rights regulation and planning. ICID Workshop on Remote Sensing of Crop Evapotranspiration for Large Regions, September 2003, Monpellier, France

Aragues, R., Tanji, K.K., Quilez, D., Alberto, F., Faci, J., Machin, J., Arrue, J.L. 1985. Calibration and verification of an irrigation return hydrosalinity model. Irrigation Science, Vol. 6.

Arnold, J.G., Srinivasan, R., Muttiah, R.S., and Williams, J.R. 1998. Large Area Hydrologic Modeling and Assessment, Part I: Model Development. Journal of the American Water Resources Association, Vol. 34, No. 1

Bay-Valley Consultants. 1971. Recommended water quality management plan. Sacramento River Basin, San Joaquin River Basin, Sacramento-San Joaquin Delta. Report to the California State Water Resources Control Board.

Bastiaanssen, W.G.M., M. Menenti, R.A. Feddes, A.A.M. Holstag. 1998. A remote sensing surface energy balance algorithm for land (SEBAL) 1. Formulation. Journal of Hydrology, Vol. 212-213.

Bastiaanssen, W.G.M., H. Pelgrum, J. Wang, Y. Ma, J.F. Moreno, G.J. Roerink, T. van der Wal. 1998. A remote sensing surface energy balance algorithm for land (SEBAL) 2. Validation. Journal of Hydrology, Vol. 212-213.

Bundy, R.M. 1997. Hydrology influences on vegetation response in a managed moist-soil impoundment. Master's Thesis, University of Missouri-Columbia.

California Department of Water Resources. 1969. Lower San Joaquin River water quality investigation. Bulletin No. 143-5. Dept. of Water Resources, Sacramento.

California Department of Water Resources, Office of Water Use Efficiency. 2004. California Irrigation Management Information System (CIMIS)

California Environmental Protection Agency, 2002. Total Maximum Daily Load for Salinity and Boron in the Lower San Joaquin River. Staff report by the Regional Water Quality Control Board, Central Valley Region.

CNPS, 2003. California Native Plant Society, Vegetation Sampling Program, Sampling Protocols and Projects. http://www.cnps.org, Sacramento, CA 
Campbell, M.B. 1988. Ownership and recreational use of wetlands in the Grassland Water District and refuges of the Central San Joaquin Valley. Federal-State San Joaquin Valley Drainage Program, U.S. Bureau of Reclamation.

Chess, Caron; Billie Jo Hance, Ginger Gibson, 2000 Adaptive Participation In Watershed Management. Journal of Soil and Water Conservation vol 55, no 3.

Clemmens, A.J., T.L. Wahl, M.G. Bos, and J.A. Replogle. 2001. Water Measurement With Flumes And Weirs, ILRI Publication 58 (2001).

CRWQCB, 2000. Review of selenium concentrations in wetland water supply channels in the Grassland watershed. California Regional Water Quality Control Board, Jeanne Chilcott, CRWQCB, Sacramento, CA 95827

Cogswell, H.L. 1977. Water Birds of California. California Natural History Guides:40. University of California Press. 399 pages.

Comiso, J. 1995. Unsupervised classification of arctic sea ice using neural network. International Geoscience and Remote Sensing Symposium, Firenze, Italy. Ppg. 414-418

Cooper, A.B., Bottcher, A.B. 1993. Basin-scale modeling as a tool for water-resource planning. Journal of Water Resources Planning and Management, Vol. 119, No. 3.

Ceuppens, J., M.C.S. Wopereis, and K.M. Miézan. 1997. Soil salinization processes in rice irrigation schemes in the Senegal River Delta. Soil Sci. Soc. Am. J. 61:1122-1130.

Eadie, J., 2003. Conversation regarding remote sensing of Central Valley Wetlands and the possible use with the CVJHV. Davis, CA, April 29, 2003

Environmental System Research Institute. 1996. ArcView GIS. Environmental System Research Institute, Inc. Cambridge, England.

Fredrickson, L. 1991. Strategies for Water Level Manipulations in Moist-Soil Systems. United States Fish and Wildlife Leaflet 13.4.6, of the Waterfowl Management Handbook

Fredrickson, L.H., Taylor T.S. 1982. Management of seasonally flooded impoundments for wildlife. Resource Publication 148. U.S. Dept. of the Interior, Fish and Wildlife Service, Washington, D.C.

Glenn, E., Thompson, T.L., Frye, R., Riley, J., Baumgartner, D. 1995. Effects of salinity on growth and evapotranspiration of Typha domingensis Pers. Aquatic Botany, Vol. 52, ppg. $75-91$

Grassland Water District, 2001. Land Use and Economics Study, Grassland Ecological Area, Merced County, California. Report prepared by Thomas Reid Associates, Palo Alto, CA, and Strong Associates, Oakland, CA. July, 2001. 
Grassland Water District. 1986. Ecological and Water Management Characterization of Grassland Water District. California State Water Resources Control Board and Central Valley Water Quality Control Board. Prepared by the Grassland Water District and the Grassland Water Task Force with assistance from Jones \& Stokes Associates, Inc., Summers Engineering, Inc., Stoddard \& Associates. 61 pp.

Grober, L.F., Karkoski J., Poole T. 1995. Water quality impact of wetlands on San Joaquin River, California, paper no. 00149 In T.G. Cleveland [ed.], Advances in the development and use of models in water resources: Proceedings of the American Water Resources Association held in Houston, Texas, November 5-10, 1995. Department of Civil and Environmental Engineering, University of Houston, Houston, Texas.

Hendrickx, J.M.H., B. Baerends, Z.I. Raza, M. Sadig, and M.A. Chaudhry. 1992. Soil salinity assessment by electromagnetic induction of irrigated lands. Soil Sci. Soc. Am. J. 56:1933-1941.

Isola, C.R. 1998. Habitat use by foraging waterbirds in the Grasslands of California's Northern San Joaquin Valley. Master's Thesis, California State University, Humboldt.

Itenfisu, D., R.L. Elliot, R.G. Allen and I.A. Walter. 2000. Comparison of Reference Evapotranspiration Calculations across a Range of Climates. Proc. of the National Irrigation Symposium, November 2000, Phoenix, AZ, American Society of Civil Engineers, Environmental and Water Resources Institute, New York, NY

Johnson, W.R., K.K. Tanji, R.T. Burns. 1997. Management of Agricultural Drainage Water Quality, Chapter 6: Drainage Water Disposal, Food and Agriculture Organization of the United Nations.

Karaka, M., Wirth, A., Ghil, M. 1999. A box model for the paleoceanography of the Black Sea. Geophysical Research Letters, Vol. 26, No. 4.

Knisel, W.G. 1980. CREAMS, A field scale model for Chemicals, Runoff, and Erosion from Agricultural Management Systems. USDA Conservation Research Report No. 26, U.S. Dept. of Agriculture, Washington, D.C.

Lesch, S.M., and J.D. Rhoades. 1999. ESAP-95 Software Package Version 2.01R. USDAARS, George E. Brown Jr. Salinity Laboratory, Riverside, CA.

Letey, J. 2001. Salinity, drainage, toxics continue to plague agricultural activities. Currents: A Newsletter of the UC Center for Water Resources, Vol 2, No. 1.

Link, W.A., Barker, R.J., Sauer, J.R., Droege, S. 1994. Within-site variability in surveys of wildlife populations. Ecology, Vol. 74, No. 5.

Lower, T., 2001. Conversation regarding wetland flow through and make-up water for the seasonal wetlands in the Grassland Water District. Los Banos, California. September 2001 
Lower, S., 2003. Conversation regarding wetland drawdowns, irrigations, and peak vegetative periods in the wetlands of the Grassland Water District. Los Banos, CA, April 23,2003

Mason, H.L. 1969. A Flora of the Marshes of California. University of California Press. 879 pages.

McNeill, J.D. 1980. Electrical conductivity of soils and rocks. Tech. Note TN-5. Geonics Ltd., Mississauga, ON, Canada.

Milliken, Jeff. 2005. US Bureau of Reclamation, personal communication

Mushet, D.M., Euliss, Jr., N.H., Harris, S.W. 1992. Effects of irrigation on seed production and vegetative characteristics of four moist-soil plants on impounded wetlands in California. Wetlands, Vol. 12, No. 3.

Naylor, L. 2002. Evaluating Moist-Soil Seed Production and Management in Central Valley Wetlands to Determine Habitat Needs for Waterfowl. M.S. Thesis, University of California, Davis. 85 ppg.

Norman, R., L. Finger, D. Titus, R. Gearheart. 1993. Review of Wetland Evapotranspiration Literature. United States Bureau of Reclamation report.

Novotny, V., Capodaglio, A., Jones, H. 1992. Real-time control of wastewater treatment operations. Water Science and Technology, Vol. 256, No. 4-5

Olufayo A. and A.E. Ajayi. 2004. Consumptive water use of bahama grass (Cynodon dactylon) using drainage and hydraulic weighing micro lysimeters, $4^{\text {th }}$ International Crop Science Congress, September 2004, Brisbane, Australia

Orlob, G.T., Ghorbanzadeh, A. 1981. Impact of water resource development on salinization of semi-arid lands. Agricultural Water Management, Vol. 4.

Oster, J.D., Rhoades, J.D. 1975. Calculated drainage water compositions and salt burdens resulting from irrigation with river waters in the Western United States. Journal of Environmental Quality, Vol. 4, No. 1.

Owen, C.R. 1995. Water budget and flow patterns in an urban wetland. Journal of Hydrology, Vol. 169, ppg. 171-187

Ozesmi, S., Bauer, M., 2002. Satellite remote sensing of wetlands. Wetlands Ecology and Management. Vol. 10, ppg. 381-402

Poole, T., 2003. Conversation regarding wetland drawdowns, irrigations, and peak vegetative periods in the wetlands of the Grassland Water District. Los Banos, CA, April 23, 2003 
Quinn, N.W.T., Chen, C.W., Grober, L.F., Kipps, J., Cummings, E. 1997. Computer model improves real-time management of water quality. California Agriculture, Vol. 51, No. 5.

Quinn, N. W. T., and W. M. Hanna, 2003. A decision support system for adaptive real-time management of seasonal wetlands in California. Environmental Modelling and Software, Volume 18, Issue 6, ppg. 503-511

Quinn, N.W.T., Karkoski, J. 1998. Real-time management of water quality in the San Joaquin River Basin, California. American Water Resources Association, Vol. 34, No. 6.

Quinn, N.W.T., 1999. A Decision Support System for Real-Time Management of Water Quality in the San Joaquin River. California Environmental Software Systems. Environmental Information and Decision Support $3^{\text {rd }}$ International Symposium on Environmental Software Systems (ISESS'99). Edited by Ralf Denzer, David A. Swayne, Martin Purvis, and Gerald Schimak. Publisher: Kluwer Academic Publishers, Massachusetts.

Rhoades, J.D. 1996. Salinity: Electrical conductivity and total dissolved salts. In D.L. Sparks (Ed.) Methods of Soil Analysis, Part 3 Chemical Methods. American Society of Agronomy, Madison, WI.

Rosenberg, K. V., Sillett, T. S. 1991 Shorebird use of agricultural fields and mini-refuges in Louisiana's rice country. Final Report, Louisiana State University, Museum of Natural Science.

Rundel, P.W., Vankat, J.L., 1989. Chaparral communities and ecosystems. In: Keeley, S. (Ed.) The California Chaparral, Paradigms Reexamined. Los Angeles County Museum of Natural History, Los Angeles, pp. 127-139.

Shuford, W.D., Humphrey, J.M., Nur, N. 1999. Surveys of nesting terns and cormorants in California's Central Valley in 1998. Final report of Point Reyes Bird Observatory. Contribution No. 722 of PRBO.

Shuford, W.D., Page, G.W., Kjelmyr, J.E. 1998. Patterns and dynamics of shorebird use of California's Central Valley. The Condor, Vol. 100.

Sibley, D.A. 2000. National Audubon Society: The Sibley Guide to Birds. Alfred A. Knopf, Inc. Publishers, New York, New York. 544 pages.

Small, A. 1974. The Birds of California. Collier Books (Macmillan Publishing), New York, New York. 310 Pages.

Smith, W.D., Rollins, G.L., Shinn, R.L. 1995. A Guide to Wetland Habitat Management in the Central Valley. California Dept. of Fish and Game, California Waterfowl Ass., Sacramento, CA. 34 pp. 
Snyder, R.L., Orang, M., Matyac, S., and Eching, S., 2002. Reference Crop Evapotranspiration. Published by the California Irrigation Management Information System (CIMIS) at http://www.cimis.water.ca.gov/ Copyright - Regents of the University of California.

Stoddard \& Associates, 1998. Water management plan for Grassland Water District. Report for the Grassland Water District, Los Banos, CA. 72 pp.

Sudduth, K.A., N.R. Kitchen, and S.T. Drummond. June 1999. Soil conductivity sensing on clay pans: comparison of electromagnetic induction and direct methods. In Geonics Limited (Ed) Applications of electromagnetic methods: Agriculture. Geonics Ltd., Mississauga, ON, Canada.

Swanson, G.A. 1988. Aquatic Habitats of Breeding Waterfowl. In: Hook et al. (Eds.) Ecology and Management of Wetlands, Vol. 1: Ecology of Wetlands. Timber Press, Portland, Oregon. 592 pp.

Tanji, K.K. 1977. A conceptual hydrosalinity model for predicting salt load in irrigation return flows. In: Dregne, H.E. (Ed.), Managing saline water for irrigation, Texas Tech. University, Lubbock, Texas. pp. 49-65.

Tatu, K., Kimothi, M.M., Parihar, J.S. 1999. Remote sensing based habitat availability model (HAM) - A tool for quick-look assessment of wetlands as waterbird habitats. Indian Forrester, October, 1999. Pages $1004-1017$.

Tanji, K. K. 1977. A conceptual hydrosalinity model for predicting salt load in irrigation return flows. pages 49-70. In: Proceedings of the International Salinity Conference, Texas Tech University, Lubbock, TX

Tedeschi, A., Beltran, Aragues. 2001. Irrigation management and hydrosalinity balance in a semi-arid area of the middle Ebro river basin (Spain). Agricultural Water Management, Vol. 49, pp. 31-50

University of California Cooperative Extension (UC Extension) and Department of Water Resources (UC Extension). 2000. A Guide to Estimating Irrigation Water Needs of Landscape Plantings in California.

USBR, 1993. "Review of Wetland Evapotranspiration Literature." Prepared for the Bureau of Reclamation, Lower Colorado Region by Gearheart, R., R., Norman, L. Finger, and D. Titus. Humboldt State University. Arcata California.

USFWS - United States Fish and Wildlife Service, 2000. Handout for Information on the Pacific Flyway.

U.S. Fish and Wildlife Service. 2004. San Luis National Wildlife Refuge Habitat Management Plan 2004. 
USFWS, 1999. Wetlands of California's Great Central Valley. Poster prepared by Division of Habitat Conservation, Branch of Habitat Assessment. Interior - Geological Survey, Reston, Virginia

U.S. Bureau of Reclamation. 1977. Prediction of mineral quality of irrigation return flow, Vo. 111, simulation model of conjunctive use and water quality for a river system or basin. User's manual, EPA-600/2-77-179c. U.S. Environmental Protection Agency. 285 pp.

Waldemark, J. 1996. An automated procedure for cluster analysis of multivariate satellite data. International Conference EANN "Solving engineering problems with neural networks: Proceedings of the International Conference EANN, London, England. Vol. 1, ppg 237-240

Walter, I.A., R.G. Allen, R. Elliott, M.E. Jensen, D. Itenfisu, B. Mecham, T.A. Howell, R. Snyder, P. Brown, S. Echings, T. Spofford, M. Hattendorf, R.H. Cuenca, J.L. Wright, D. Martin. 2000. ASCE's Standardized Reference Evapotranspiration Equation. Proc. of the Watershed Management 2000 Conference, June 2000, Ft. Collins, CO, American Society of Civil Engineers, St. Joseph, MI.

Walters, C., Korman, J., Stevens, L., and Gold, B. 1999. Ecosystem Modeling for Evaluation of Adaptive Management Policies in the Grand Canyon. Conservation Ecology. Vol. 4, No. 2

Water Resources Engineers, Inc. 1969. An investigation of salt balance in the Upper Santa Ana River Basin. Final Report to the California Dept. of Water Resources. 198 pp.

Wiens, J.A., Parker, K.R. 1995. Analyzing the effects of accidental environmental im pacts: approaches and assumptions. Ecological Applications, Vol. 5, No. 4.

Woods, P.C. 1967. Management of hydrologic systems for water quality control. Water Resources Center Contribution No. 121, University of California. 121 pp.

Woods, P.C., Orlab, G.T. 1963. The Lost River System: A water quality management investigation. Water Resources Center Contribution No. 68, University of California. 54 $\mathrm{pp}$

Young, W.J., Lam, D.C.L., Ressel, V., and Wong, I.W. 2000. Development of an environmental flows decision support system. Environmental Modelling \& Software. Vol. 15, ppg. 257-265 


\section{CHAPTER 8 APPENDICES}

Appendix 1 : Quinn, N. W. T., and W. M. Hanna, 2003. A decision support system for adaptive real-time management of seasonal wetlands in California. Environmental Modeling and Software (18) 2003, 503-511.

Appendix 2 : Quinn N.W.T. Sensor Quality Assurance Workshop. San Luis National Wildlife Refuge Complex Office, Los Banos, CA. April 8, 2005.

Appendix 3 : Cassels F. Soil Salinity Assessment and MappingWorkshop. San Luis National Wildlife Refuge Complex Office, Los Banos, CA. April 22, 2005.

Appendix 4 : Cassels F. Soil Salinity Assessment : Theory and Practice. Presentation for : Soil Salinity Assessment and Mapping Workshop. San Luis National Wildlife Refuge Complex Office, Los Banos, CA. April 22, 2005.

Appendix 5 : Cassels F. Soil Salinity Assessment Manual: Handout presented at: Soil Salinity Assessment and Mapping Workshop. San Luis National Wildlife Refuge Complex Office, Los Banos, CA. April 22, 2005. 
Appendix 1 - Quinn, N. W. T., and W. M. Hanna, 2003

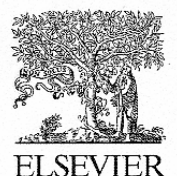

Available online at www.sciencedirect.com

SCIENCE

Environmental

\title{
A decision support system for adaptive real-time management of seasonal wetlands in California
}

\author{
N.W.T. Quinn ${ }^{\mathrm{a}, *}$, W.M. Hanna ${ }^{\mathrm{b}}$ \\ a Berkeley National Laboratory, 1 Cyclotron Road, Building 70A-3317H, Berkeley, CA 94720, USA \\ ${ }^{\mathrm{b}}$ Department of Civil and Environmental Engineering, University of California, Los Angeles, CA 90095, USA
}

Received 15 October 2001; accepted 15 July 2002

\begin{abstract}
This paper describes the development of a comprehensive flow and salinity monitoring system and application of a decision support system (DSS) to improve management of seasonal wetlands in the San Joaquin Valley of California. The Environmental Protection Agency regulates salinity discharges from non-point sources to the San Joaquin River using a procedure known as the total maximum daily load (TMDL) to allocate the assimilative capacity of the river for salt among watershed sources. Management of wetland sources of salt load will require the development of monitoring systems, more integrative management strategies and coordination with other entities. To obtain local cooperation, the Grassland Water District (GWD), whose primary function is to supply surface water to private duck clubs and manage wetlands, needs to communicate to local landowners the likely impacts of salinity regulation on the long-term health and function of wildfowl habitat. The project described in this paper will also provide this information. The models that form the backbone of the DSS, develop salinity balances at both a regional and local scale. The regional scale concentrates on deliveries to and exports from the GWD while the local scale focuses on an individual wetland unit where more intensive monitoring is being conducted. The design of the DSS is constrained to meet the needs of busy wetland managers and is being designed from the bottom up utilizing tools and procedures familiar to these individuals.
\end{abstract}

(c) 2003 Elsevier Science Ltd. All rights reserved.

Keywords: Wetlands; Salinity; Real-time monitoring; Assimilative capacity

\section{Introduction}

The Grassland Water District (GWD) together with the adjacent State and Federal refuges constitute the largest contiguous wetland in the State of California (Fig. 1). The GWD comprises two interconnected units - the northern and southern GWD units-which together provides water to more than 20,000 ha of privately owned wetlands, mostly used as over-wintering habitat for wildfowl on the Pacific Flyway. The Northern GWD (NGWD) is larger in area than the Southern GWD and contains discrete drainage outlets, which provide drainage to distinct subbasins within the NGWD (Fig. 2). For this reason, the NGWD was chosen as the subject of the study described in this paper.

Seasonal wetlands in the GWD are flooded in the fall

* Corresponding author. Tel.: +1-510-486-7056; fax: +1-510-4867152 .

E-mail address: nwquinn@lbl.gov (N.W.T. Quinn). and drawn-down in the spring to provide habitat for migratory waterfowl, shorebirds, and other wetlanddependent species. Due to alterations in natural hydrology, these wetlands are flooded with Central Valley Project water supplies delivered through GWD canals. In the spring, during the months of March-April, seasonal wetlands are drawn-down to mimic the natural dry cycle of a seasonal wetland. Wetland drawdowns are timed to make seed and invertebrate resources available during peak waterfowl and shorebird migrations and to correspond with optimal germination conditions (primarily soil temperature) to grow naturally occurring moist-soil plants. The seeds of moist-soil plants are recognized as a critical waterfowl food source, providing essential nutrients and energy for wintering and migrating birds (Fredrickson and Taylor, 1982). Optimal timing of wetland flood-up and release has been determined by trial and error for different species of moist-soil plants and for different environmental conditions, although guidelines for these practices are poorly documented. 


\section{San Joaquin River Basin}

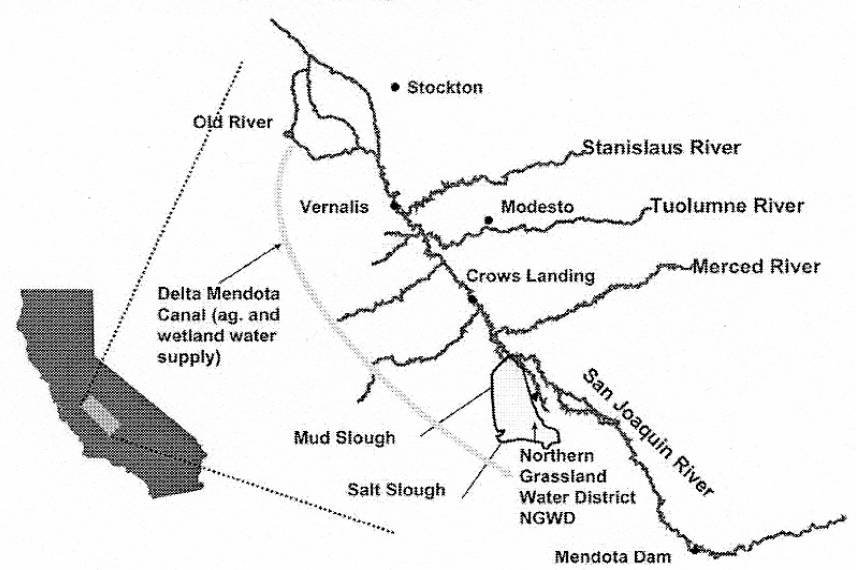

Fig. 1. SJR Basin showing NGWD and the major west-side wetland drainage conveyances Mud and Salt Sloughs. Water supply to agriculture and wetlands in the Grassland subbasin is provided through pumping from the Sacramento-San Joaquin Delta via the Delta Mendota Canal.

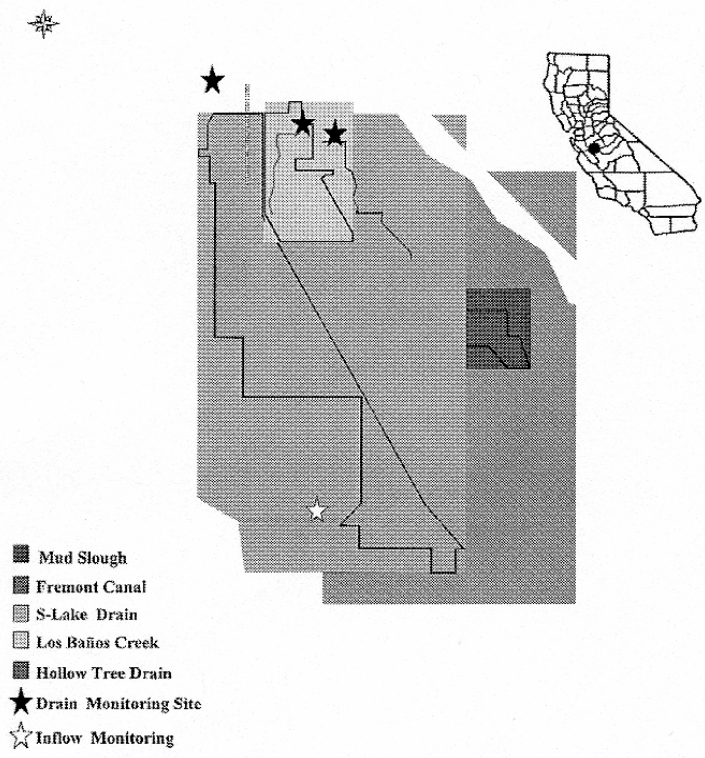

Fig. 2. NGWD showing drainage subbasins and both inflow and drainage monitoring.

\section{Wetland management}

The seasonal wetlands of the GWD are managed to meet habitat requirements by flooding in the fall and releasing their waters in the spring. Spring releases are discharged into tributaries of the Lower San Joaquin River (SJR). These releases, in combination with agricultural drainage that flows through the GWD, contain varying amounts of total dissolved solids (TDS), boron, and selenium. These constituents have been identified as stressors that lead to frequent exceedance of water quality objectives established for the SJR by state and federal agencies.

Research conducted by Grober et al. (1995) suggests that wetland drainage from the GWD could be scheduled to coincide with peak assimilative capacity in the SJR to help improve downstream water quality (Fig. 3). Assimilative capacity in the SJR occurs during periods when the average electrical conductivity (EC) at Vernalis is below the seasonal running average concentration. Fig. 3 shows that the irrigation season EC objective of $700 \mathrm{uS} / \mathrm{cm}$ between April 15 and August 15 each year is frequently violated. Between 1985 and 1998 the $\mathrm{EC}$ objective at Vernalis was violated more than $70 \%$ of the time.

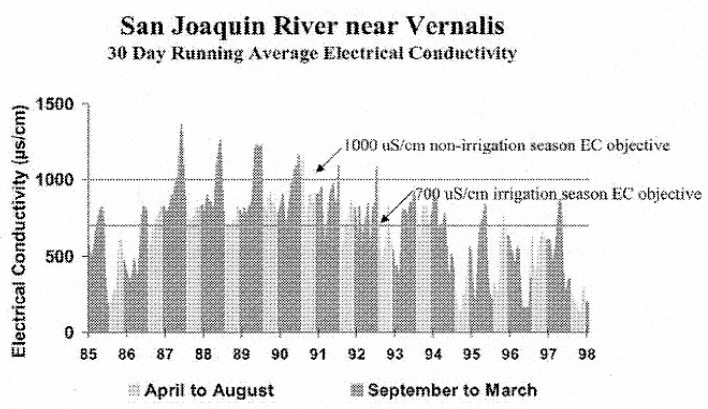

Fig. 3. SJR 30-day running average EC showing periods of assimilative capacity (graph below seasonal objective) and violation (graph above seasonal objective). Over the past 13 years, salinity (EC) objectives have been violated approximately $70 \%$ of the time. 
Increased water supply allocations ie Central Valley Project Improvement Act (CVPIA) - environmental legislation that resulted in a large transfer of water between irrigated agriculture and the environment-have created opportunities to coordinate the release of seasonal wetland drainage with the assimilative capacity of the SJR. Coordinated releases will help to achieve salt and boron water quality objectives and improve fish habitat in the main-stem of the SJR and Sacramento-San Joaquin Delta. Improved scheduling of west-side discharges can assist in avoiding critical time periods for fish rearing and remove an important stressor leading to improvements in the San Joaquin salmon fishery. To date, however, no systematic data collection program has been undertaken to evaluate the short- and long-term consequences of real-time wetland drainage management. Drainage monitoring (Fig. 4), undertaken as part of the project described in this paper, has been undertaken to address this deficiency.

Management of wetland drainage, through scheduling of releases to coincide with periods of SJR assimilative capacity, can help to improve SJR water quality. However, these actions may need to be considered relative to potential biological impacts of changes to traditional wetland management practices. Figs. 5 and 6 show how water management for optimal productivity differs between smartweed and water. Peak assimilative capacity typically occurs between the months of January and April. This time period is often earlier than the traditional wetland drawdown period (March-April). Hence, the response of moist-soil plants and of migratory waterfowl and shorebirds to an altered drawdown regime needs to be assessed. This assessment will

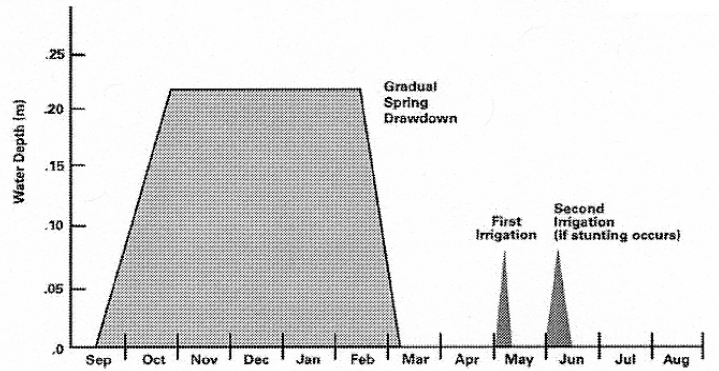

Fig. 5. Wetland flood-up and return flow schedule for smartweed in the Grassland Basin.

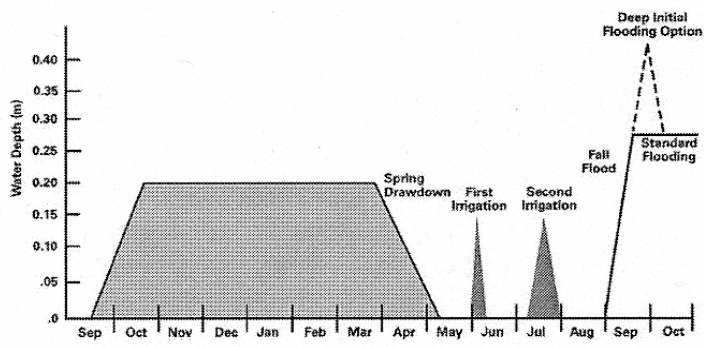

Fig. 6. Wetland flood-up and return flow schedule for watergrass in the Grassland Basin.

identify potential impacts to seed germination rates, waterbird foraging rates, habitat availability, and species diversity and abundance. It is possible that early experimental drawdown may make food sources available to wildlife without negatively affecting wetland vegetation

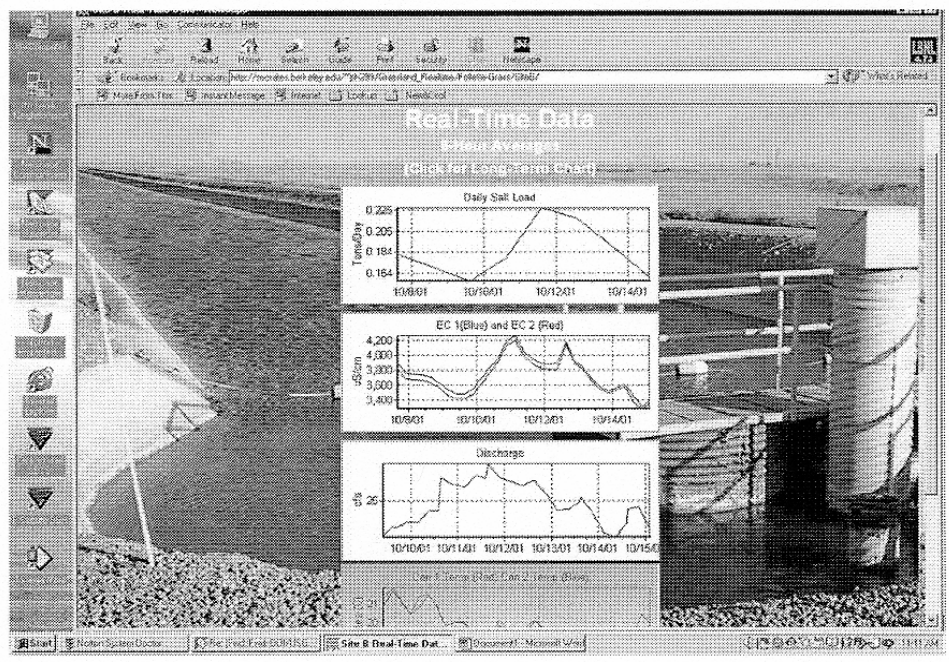

Fig. 4. Example of the real-time data acquisition and reporting system installed at wetland sites and the San Luis Drain. Wetland drainage combines with agricultural drainage in the San Luis Drain (shown above) and the combined flow is discharged to the SJR via Mud Slough. 
community and plant species diversity-hence benefiting both wildlife and the health of the SJR. This ongoing research phase of this project will have considerable technology transfer value to other agencies that operate seasonal wetlands and also discharge constituents of concern to the River.

\section{Water quality management}

As a result of recent landmark environmental legislation that drastically changed water allocations among agricultural, municipal and environmental consumers, increases in water supply have helped to improve the quality of wetland habitat in the Grassland Basin. Additional water allocations, while increasing the flexibility of operation of seasonal wetlands and improving the quality of their return flows, increase the total salt load discharged to the SJR. Exploitation of opportunities to improve coordination of seasonal wetland drainage with the assimilative capacity of the SJR can improve compliance with river water quality objectives (Fig. 3). These objectives were established originally to encourage improvements in the management of agricultural and wetland return flows. These objectives were set to protect downstream riparian irrigators who use the SJR as their sole water supply and to protect the salmon fishery. Wetland releases that contain high salt loads during the months of April coincide with agricultural pre-season irrigation to propagate plant seedlings. Saline water can inhibit germination and reduce crop yields. Salmon can become confused during their annual migration when higher flows emanate from sloughs carrying drainage water than along the main-stem of the SJR.

Better coordination of agricultural and wetland releases with reservoir releases of good quality snowmelt water on the east-side of the San Joaquin Basin has been suggested as a means of improving SJR water quality for all beneficial uses (Karkoski et al., 1995a,b; Quinn and Karkoski, 1998; Quinn et al., 1997). Quinn (1999) described the results of a demonstration project of real-time monitoring and management of agricultural drainage and east-side reservoir releases that forecasts the assimilative capacity for salinity on the SJR (Fig. 7). These forecasts are made weekly based on an analysis of current data at all monitoring stations on a Monday morning in combination with information directly obtained from east-side reservoir operators on the main tributaries, riparian diverters along the main-stem of the SJR and those agricultural drainage districts that continuously monitor their drainage return flows. Wetland real-time water quality management project complements this existing program to coordinate seasonal wetland drainage with the assimilative capacity of the SJR. Since there exists little coordinated monitoring of salt loading leaving the GWD, this project has required the installation of wetland monitoring stations at major drainage outlets from the district (Fig. 2). To allow salt balance modeling, a similar station has been installed at the main GWD inlet at the Volta Wasteway channel. The DSS, described below, was developed to help organize field monitoring data and to allow wetland managers make timely decisions regarding return flows to the SJR. These decisions are aided by the fact that the elements of the DSS will eventually be common for the SJR and wetland salt management projects.

\section{Real-time flow and water quality monitoring}

Flow transducers and EC sensors have been installed at control structures within the GWD (Figs. 2 and 4). These instruments take measurements every $15 \mathrm{~min}$ to provide an accurate measurement of salt loading in to and out of the GWD boundary. Flow and EC data at each site is collected on a battery-powered datalogger that is attached to a phone telemetry system, allowing these data to be accessed $24 \mathrm{~h}$ a day.

Flow measurements at the inlet and most of the outlet sites are being made using a state-of-the-art acoustic velocity transducers. These transducers utilize the Doppler principle whereby during operation, each transducer produces short pulses of sound at a known frequency along two different axes. Sound from the outgoing pulses is reflected ('scattered') in all directions by particulate matter in the water. These return signals have a frequency shift proportional to the velocity of the scattering material. By combining data from both beams, and knowing the relative orientation of those beams, the device measures $2 \mathrm{D}$ velocity in the plane defined by its two acoustic beams. Each transducer is equipped with two stage measurement sensors, a vertical beam and a pressure sensor which, with information on the stream cross-sectional profile and the velocity, is used in the flow computation.

Temperature-compensated EC sensors are being used to obtain real-time salinity and temperature data at each site. EC is a measure of the TDS, or the presence of ions, in the water. When compensation is made for the water temperature, EC readings provide an accurate count for the salinity in the water. Maps have been prepared locating water delivery and drainage turnouts in the GWD drainage system. These maps will document drainage hydrology within individual wetland basins. The location of the monitoring stations has been determined by Global Positioning System (GPS) survey and located on the set of Geographic Information System (GIS) maps of the study area. These monitoring sites are strategically placed within wetland channels so as to allow computation of salt loads in real-time from different sectors of the GWD.

Real-time flow, EC and temperature data from the 
N.W.T. Quinn, W.M. Hanna / Environmental Modelling \& Software 18 (2003) 503-511

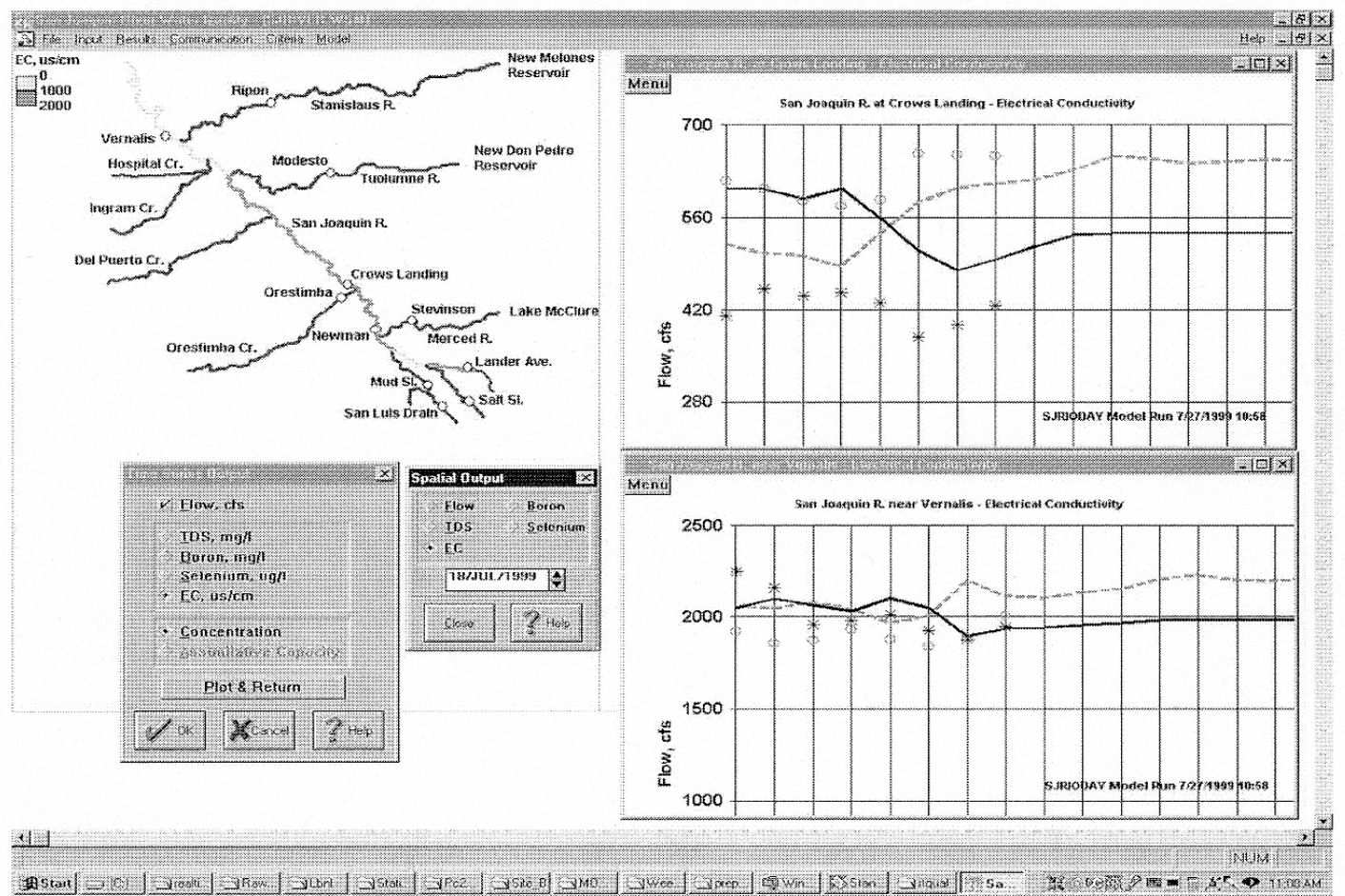

Fig. 7. Graphical user interface for the SJR salinity forecasting model. Wetland drainage enters the SJR through Mud and Salt Sloughs and, when combined with agricultural flows, account for $37 \%$ of the salt load in the SJR at Vernalis.

GWD is provided by e-mail and through a website http://socrates.berkeley.edu/ nwquinn/GrasslandRealtime/Quinn-Grass/ as input to the real-time water quality model of the SJR operated by the SJRMP Water Quality Subcommittee (Fig. 7) http://wwwdpla.water.ca. gov/sjd/waterquality/realtime/index.html. The SJRMP Water Quality Subcommittee has been funded to enhance the existing network of real-time monitoring stations along the main-stem of the SJR and to improve the coordination of agricultural return flows and scheduled east-side fish flows (Quinn et al., 1997). Installation of flow and water quality monitoring equipment and cellular telemetry equipment at key locations in the GWD helps to provide wetland and refuge managers the data necessary to make scheduling decisions. Mean daily salinity loading from the GWD is calculated from the monitoring data and is compared with the daily assimilative capacity determinations on the SJR. Wetland discharge opportunities during the spring months, when the majority of saline discharges from seasonal wetlands occur, is evaluated weekly by the project team, cooperatively with the watermaster and district biologist from the GWD.

\section{Habitat evaluation}

The biological and ecological monitoring and data objectives of the project are to document the effects of changing traditional flood-up and wetland drainage discharge patterns on wetland habitat and bird species (Williams, 1996). Achievement of these objectives will assist in developing adaptive management approaches to optimize wetland habitat conditions while minimizing the negative effects of wetland drainage on the water quality in the SJR.

A program of wetland habitat assessment is proceeding concurrently with the real-time monitoring and water quality management program. Changing the scheduling of wetland drainage to the SJR affects the timing and rate of drawdown of wetland ponds and hence the forage value of the wetlands for migrating and wintering shorebirds and waterfowl. Wetland salinity management measures can also affect the productivity and diversity of vegetation that can be grown in the watershed. The research underway is documenting the impacts of altering traditional wetland management practices and developing guidelines for multi-objective wetland oper- 
ations including forage production, nesting cover establishment and salinity management. The concurrent program of habitat evaluation and salinity management could lead to optimization of wildlife and environmental benefits to the Grassland Basin and SJR.

Wetland habitat monitoring sites have been randomly chosen from available seasonal wetlands within the GWD. These wetlands correspondingly drain into locations where flow and EC monitoring sites are situated. At all wetland study plots, a paired study design is being used to directly assess differences in traditionally drained wetlands vs. non-traditionally drained wetlands. Biological monitoring is being conducted on adjacent traditionally and non-traditionally drained wetlands. The monitoring includes both a waterbird (waterfowl and shorebirds) usage component and a moist-soil plant production component. The waterbird component measures abundance and diversity and determine time-activity budgets of waterbirds through scan sampling and direct observation to assess foraging potential. The moist-soil plant production component determines the impacts, if any, to the vegetation by assessing changes in total plant biomass, percent coverage, and species composition through grid sampling and aerial photography.

\section{DSS design}

The rationale for developing a DSS was to provide a set of analytical tools that assist in computation of GWD wetland water requirements, estimation of wetland salinity load in seasonal wetlands and in the selection of best management practices. A requirement of the DSS was that it be simple in design and intuitive, similar to data management tools typically used by the GWD. GWD staffs spend much of their time in the field and do not have large blocks of time that they can devote to learning new software. The DSS was designed to interact with existing SJR water quality forecasting models and software to allow the partition of river assimilative capacity among the wetland releases.

\section{Water quality model}

The wetland water and salinity model simulates seasonal and permanent wetland management in the GWD and mimics the wet/dry seasonal cycle that these wetlands experience as well as the quantity and water quality of wetland releases. The main objective of the wetland water quality model is to predict the effects of salt loading to the SJR during spring drawdown (JanuaryApril). The model incorporates the weekly water use requirements of the major wetland habitat types in the GWD and the adjacent State and Federal refuges. Mapping of the wetland habitat has been limited to date to discriminating open water areas within the wetland complex. Evapotranspiration from moist-soil plants within the GWD is presently estimated and not specifically modeled owing to lack of field data for model calibration. There are no reliable techniques available using remote sensing technology to quantify the areal extent of the major moist-soil plants and other wetland habitat within the GWD. In spite of these limitations the model tracks salinity changes in each of the wetlands over the winter season and incorporates user-defined schedules for wetland drawdown in the spring months. By running scenarios of different weekly wetland fill and release schedules and annual changes in vegetation type and waterbird usage, managers are able to plan operations to minimize water quality impacts on the SJR while maximizing wildlife benefits.

The current model has been developed as a Microsoft Excel spreadsheet on account of the widespread familiarity with this product among wetland managers in the Grassland Basin. The model has been designed to perform historic hydrology simulations as well as seasonal alternatives (along with sensitivity analyses). Seasonal alternatives include different wetland drawdown protocols such as: (a) early drawdown (critically dry to dry year), (b) traditional drawdown (dry to wet year), (c) late drawdown (wet year), and (d) preflushing. The wetland water quality model has been designed to allow easy linkages to popular software packages such as RAISON and ARCVIEW. In addition, the Excel spreadsheet model has been designed to predict salt loading from the NGWD watershed as well to read salt assimilative capacity output directly from the Department of Water Resources' Delta Simulation Model II (DSM-2). First the wetland water quality model provides wetland outflow quantities and salt loads to DSM-2 at Mud and Salt Sloughs for use in its river forecasts and second, the wetland water quality model uses SJR assimilative capacity forecasts provided by DSM-2 as input.

\subsection{Input data}

Input data for the wetland water quality model fall into four categories; static, annually constant, annually varying, and real-time. Static data, which do not vary with time, include soil properties, land classifications, acreages, drainage basin allocations, and precipitation and ET qualities. Annually constant data, which are static year to year but vary within the year, include crop coefficients (for ET subroutines), best management practices, and water table depth. Annually varying data include precipitation, water year classification, air, water, and soil temperatures, irrigation schedule, and wetland flood-up schedule. Real-time data includes supply water quantity and quality, drainage water quantity and quality, evapotranspiration, precipitation, and SJR assimilative capacity. Much of the static and annually 
constant data are assumptions, since intensive monitoring in these wetlands only commenced in water year 2000. A typical user will not need modify these data, once measured, except for system changes, calibration, or sensitivity analyses.

\subsection{Model runs}

The model was applied to historical northern GWD drainage data collected during the 1998-1999 water year. The NGWD contains the major drainage outlets to the SJR and, since it is geographically separated from the southern GWD by the city of Los Banos, it can be considered as a hydrologically separate system. During the spring of 1999 , NGWD wetland drawdown contributed over $6 \%$ of the total salt load in the SJR at the Crows Landing monitoring station, located downstream of the Mud and Salt Slough discharge points, on the SJR. The Mud Slough discharge to the SJR combines flow and salt loads from Mud Slough (north), Fremont Canal, Los Baños Creek, Hollow Tree Drain, and S-Lake Drain. Fremont Canal alone contributes flows and salt loads of approximately $2 \%$ of the total wetland acreage in the NGWD (GWD, 2001).

Model simulations have been made, comparing SJR flow and water quality at Crows Landing under several different wetland management plans for the drawdown season between January 1999 and April 1999 (Figs. 8 and 9). The different wetland management plans were simulated using calculated wetland water quality. The salt loads generated from this analysis were compared to river assimilative capacity, estimated by the DSM-2 river hydrodynamic model for the same period. The first step of the model run required developing high and low baseline flow and salt load values for the SJR. The high SJR baseline selected was the actual modeled (DSM-2) salt load at Crows Landing. The low SJR baseline was the salt load at Crows Landing assuming zero contribution of flow and salt load from the NGWD.

Once baseline values were established, the wetland water quality model simulated early and late drawdown release scenarios from the NGWD. For these historical model runs, early and late wetland drawdown scenarios were generated by skewing the actual drainage data by $+/-1$ standard deviation. To view the impacts of the alternative wetland management plans, the modeled results were added to the low SJR baseline values. Although the actual NGWD salinity contribution to the SJR was roughly $6 \%$ during the 1999 wetland drawdown season, effects from altered drawdown schedules are apparent.

7.2.1. Scenario 1: baseline values: DSM-2 model values (actual) vs. DSM-2 w/o NGWD contribution

This comparison shows the difference between the actual modeled (DSM-2) SJR qualities and quantities (high baseline) and the SJR had there been no contribution from the NGWD (low baseline).

7.2.1.1. Water quantity Completely removing the NGWD contribution considerably reduced the flow in the SJR at Crows Landing. The reduction in flow ranged from one to almost $11 \%$, with the maximum observed deficit occurring in late March and early April (Fig. 8).

7.2.1.2. Water quality Completely removing the contributions from the NGWD to the SJR had a marked effect by reducing the EC at Crows Landing by more than $4 \%$ during peak wetland withdrawals in February and March (Fig. 9). It is interesting to note that during the week ending March 25th, removing the NGWD contribution actually increased the EC of the SJR at Crows

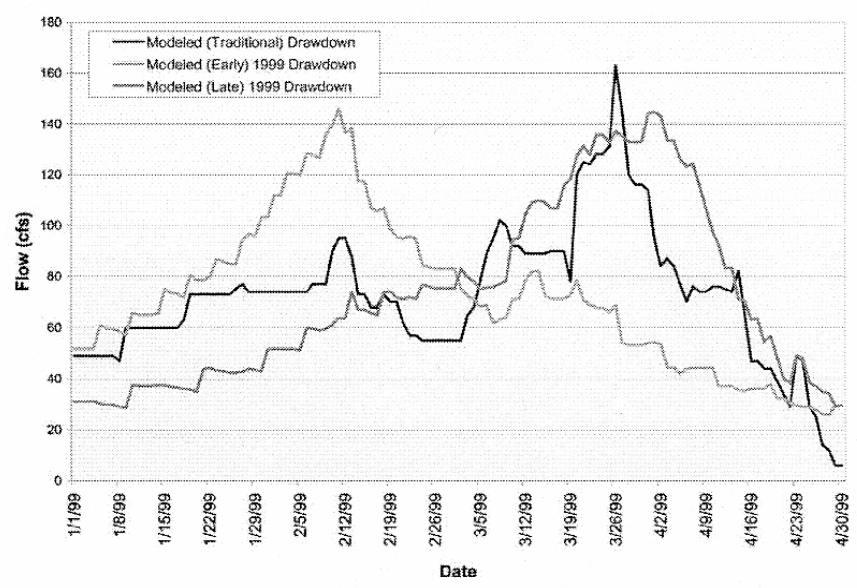

Fig. 8. Comparison of drainage flow for traditional, early and late drawdown scenarios for NGWD. 
N.W.T. Quinn, W.M. Hanna / Environmental Modelling \& Software 18 (2003) 503-511

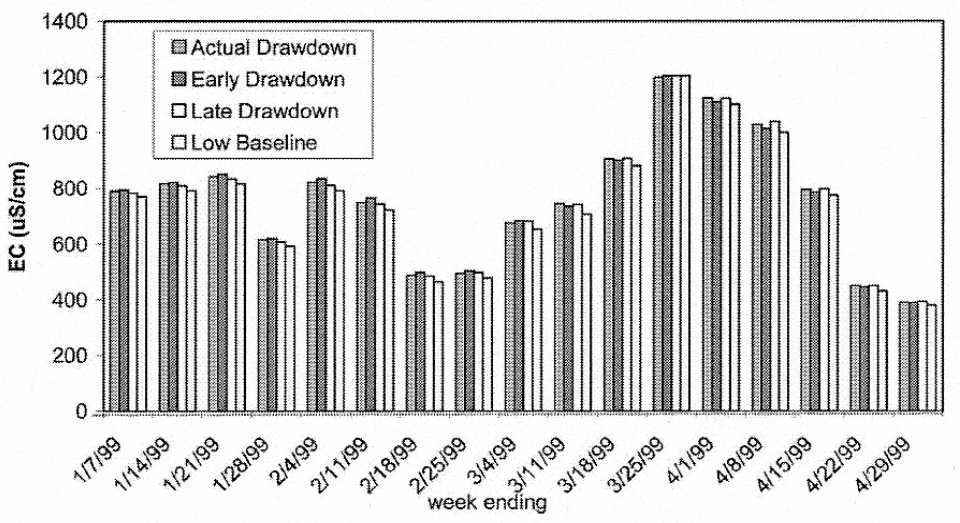

Fig. 9. Average weekly EC at Crows Landing for WY 1999 spring drawdown.

Landing. Further review of the data confirms this, showing that indeed the EC of the SJR was higher during that time than the wetland releases. However, other than that 1 week, removal of the NGWD component decreased the EC, and hence increased the assimilative capacity, of the SJR at Crows Landing.

\subsubsection{Scenario 2: wetland water quality model run 1-early wetland drawdown}

This comparison is designed to show the difference between the actual modeled (DSM-2) SJR qualities and quantities (high baseline) and the SJR, had there been an early wetland drawdown from the NGWD.

7.2.2.1. Water quantity An early wetland drawdown management plan from the NGWD to the SJR increased the flow in the SJR at Crows Landing during the early months and reduced it in the later months (Fig. 8).

7.2.2.2. Water quality Applying an early wetland drawdown management plan from the NGWD to the SJR had a marked effect by increasing the EC by an average of $1.5 \%$ during the early months (January and February) and by reducing the EC by an average of $2.5 \%$ in the later drawdown months (March and April)-(Fig. 9).

\subsubsection{Scenario 3: wetland water quality model run} 2-late wetland drawdown

This comparison shows the difference between the actual modeled (DSM-2) SJR qualities and quantities (high baseline) and the SJR, had there been a late wetland drawdown from the NGWD.

7.2.3.1. Water quantity A late wetland drawdown management plan from the NGWD to the SJR did not have as great an impact on the SJR as did the early drawdown management plan. The late drawdown did decrease the flow in the SJR at Crows Landing during the early months and increased it in the later months, however, on average, it did not change the flows by more than $+1-1 \%$ (Fig. 8 ).

7.2.3.2. Water quality Because traditional drawdown management plans tend to be later in the season, applying a late wetland drawdown management plan from the NGWD to the SJR did not have as marked an effect on the water quality of the SJR. The late drawdown decreased the EC by an average of $0.5 \%$ during the early months (January and February) and increased the EC by an average of $0.25 \%$ in the later drawdown months (March and April)-(Fig. 9).

\subsection{Analysis}

It was apparent that even though an early withdrawal management plan has the greatest effect on altering the quality of the SJR, this is mainly because wetland managers in the NGWD schedule traditional drawdown later in the season. These simulations will need to be performed on subsequent years to verify the findings from the one drawdown season of 1999 .

\subsection{Discussion - adaptive management of wetland releases}

The overall goal of the project is to provide basic monitoring information and to develop decision support tools to allow wetland managers in the GWD to respond to the long-term challenge of improving water quality while maximizing wetland functions and habitat values. The project considers two levels of monitoring and analysis - the first, at the water district scale, will develop inflow and outflow monitoring and a salinity loading mass balance for the entire North-Grasslands region. The second, conducted at the scale of a single duck club, in this case the most progressive and scien- 
tifically managed in the water district, which has designated functional wetland units to attract different bird species and which offers a great diversity of hunting experience. The project is fortunate in having enlisted the cooperation of one of the most innovative wetland managers in the GWD, who has for years been experimenting with different regimes of wetland filling and release-primarily with the objective of optimizing wildfowl habitat under various regimes of water availability and supply water quality. The duck club will benefit by the more intensive level of water flow and quality monitoring while providing the wetland manager a test-bed to observe and evaluate alternative management regimes. More intensive monitoring of a suite of water quality factors is underway at the duck club with including flow, EC, $\mathrm{pH}$, turbidity, dissolved and particulate organic carbon concentrations and biochemical oxygen demand, which provide a comprehensive comparison of management-related impacts.

The synergy between the monitoring and research objectives of our project and the practical aspects of improving wetland function in a climate of increased environmental regulation and control of non-point source discharges provides a unique opportunity for advancement of the art and the science of wildfowl wetland management. By taking this 'pre-emptive' actionthe GWD is seen to be proactive in the eyes of the EPA and the Regional Water Quality Control Board (enforcement division for the EPA), which are presently laying the groundwork for salt load allocation and salinity water quality objectives on the SJR.

\section{Summary}

Information obtained through this project will likely be transferable and of significant value to all wetlands in the grassland ecological arca including those wetlands managed by State and Federal wildlife agencies. The successful implementation of this combined monitoring, experimentation and evaluation program will provide the basis for adaptive management of wetland drainage throughout the entire 70,000 ha grassland ecological area. The project will involve local landowners, duck club operators, and managers of State and Federal refuges in the Grassland Basin. Although this pilot project has concentrated on the 20,000 ha that comprise the GWD, the goal of the project is to disseminate the findings of the project more widely. The GWD has a successful history of local involvement through the district newsletter, published monthly; high school and collegelevel educational outreach programs; and through 'Wild on Wetland' days, which help to educate the public about the benefits and techniques of wetland management.

\section{Acknowledgements}

The authors gratefully acknowledge project funding from the US Bureau of Reclamation and the CALFED Bay-Delta Program and project support from Don Marciochi and Scott Lower of the Grassland Water District.

\section{References}

Fredrickson, L.H., Taylor, T.S., 1982. Management of Seasonally Flooded Impoundments for Wildlife. US Department of the Interior, Fish and Wildlife Service, Washington, DC (Resource publication 148).

Grober, L.F., Karkoski, J., Poole, T., 1995. Water quality impact of wetlands on San Joaquin River, California, paper no. 00149. In: Cleveland, T.G. (Ed.), Texas, November 5-10, Advances in the Development and Use of Models in Water Resources: Proceedings of the American Water Resources Association held in Houston. Department of Civil and Environmental Engineering, University of Houston, Houston, TX.

Karkoski, J., Quinn, N.W.T., Grober, L.F., 1995a. The potential for real-time water quality management in the San Joaquin River Basin of California. In: AWRA Annual Conference and Symposium Proceedings, Houston, Texas, July, Advances in Model Use and Development for Water Resources.

Karkoski, J., Quinn, N.W.T., Grober, L.F., Chilcott, J.E., Vargas, A., 1995b. Selenium transport in the grasslands watershed. In: Veterinary Medical Extension Conference, June 1, 2, Sacramento, Selenium in the Environment: Essential Nutrient, Potential Toxicant. Cooperative Extension and U.C. (Poster session).

Quinn, N.W.T., 1999. A decision support system for real-time management of water quality in the San Joaquin River, California Environmental Software Systems. Environmental information and decision support. IFIP TC5 WG5. In: Denzer, R., Swayne, D.A., Purvis, M., Schimak, G. (Eds.), 30 August-2 September, Dunedin, New Zealand, Third International Symposium on Environmental Software Systems (ISESS'99). Kluwer Academic Publishers, Massachusetts.

Quinn, N.W.T., Karkoski, J., 1998. Potential for real time management of water quality in the San Joaquin Basin, California. American Water Resources Association 34 (6).

Quinn, N.W.T., Chen, C.W., Grober, L.F., Kipps, J., Cummings, E. 1997. Computer model improves real-time management of water quality. California Agriculture 51 (5).

Williams, O.E., 1996. Waterbird responses to late winter and early spring drawdowns of moist-soil managed wetlands in California's San Joaquin Valley. MS thesis, Humboldt State University, California, USA. $136 \mathrm{pp}$. 


\section{APPENDIX 2 : Quinn N.W.T. Sensor Quality Assurance Workshop.}

San Luis National Wildlife Refuge Complex Office, Los Banos, CA. April 8, 2005.. 


\section{SENSOR QUALITY ASSURANCE WORKSHOP}

San Luis National Wildlife Refuge Office, Los Banos, CA

April 8, 2005

\section{In attendance :}

US Fish and Wildlife Service

Department of Water Resources

US Bureau of Reclamation

Grassland Water District

Berkeley National Laboratory

University of the Pacific

The workshop purpose was to familiarize wetland water managers with the flow and water quality sensors and associated instrumentation currently being used at the five refuge monitoring sites serving the San Luis National Wildlife refuge. Each of the monitoring systems for flow and electrical conductivity was described in detail and the procedures for installing the monitoring equipment were reviewed. Since many of the sensors are hidden from view it is important for those maintaining the stations to understand how the sensors are deployed in the culverts and channels and the means of access. The reasoning behind the redundancy of measurement was explained together with the way to use one instrument to check the performance of another. This led into a discussion of quality assurance, the filling out of data quality assurance sheets and how to make adjustments to the instruments to ensure calibration.

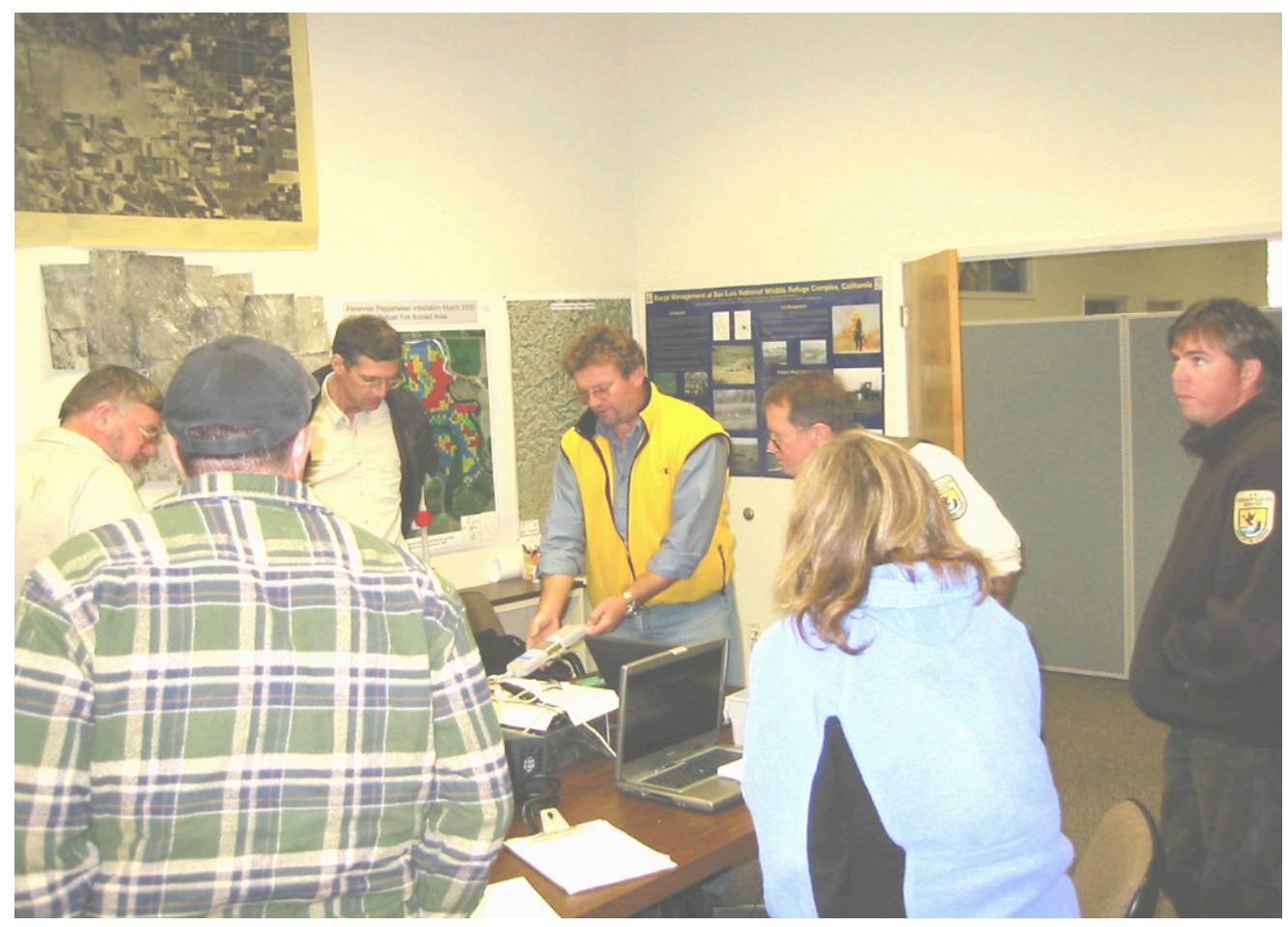

Figure 1. Explaining the theory and function of the STARFLOW acoustic Doppler sensor and the important factors to be considered during deployment. 


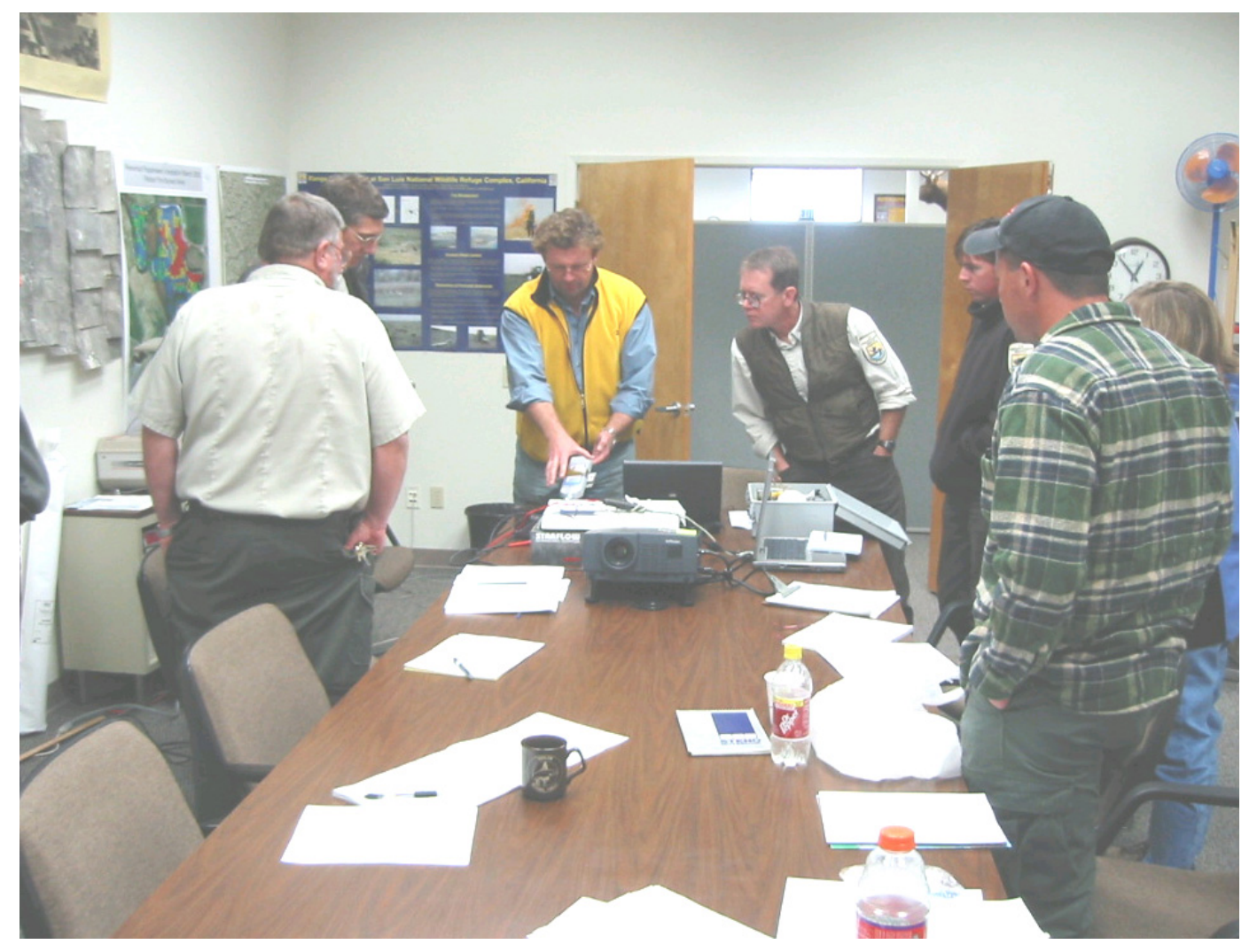

Figure 2. Demonstration of datalogger programming software and how sensors such as the STARFLOW acoustic Doppler meter, Design Analysis Smart Gas bubbler system and Campbell Scientific electrical conductivity probes are interfaced with the datalogger. Participants were shown various ways of downloading data from the datalogger. 
APPENDIX 3 : Cassels F. Soil Salinity Assessment: Theory and Practice. Soil Salinity Assessment and Mapping Workshop. San Luis National Wildlife Refuge Complex Office, Los Banos, CA. April 22, 2005. 


\section{SOIL SALINITY ASSESSMENT AND MAPPING WORKSHOP}

San Luis National Wildlife Refuge Office, Los Banos, CA

April 22, 2005

\section{In attendance :}

US Fish and Wildlife Service

US Bureau of Reclamation

Grassland Water District

Berkeley National Laboratory

The workshop was organized by Dr Florence Cassel of the California Water Institute, California State University, Fresno. Dr Cassel is a leading expert in the application of ElectroMagnetic induction meters for the measurement and mapping of soil salinity in agriculture and was responsible for the salinity mapping in the first CALFED real-time wetland water quality management project. The methodology developed at CSU. Fresno for agricultural crops was easily adapted for application to the emergent moist soil plants and grasses during the spring months, post-drawdown.

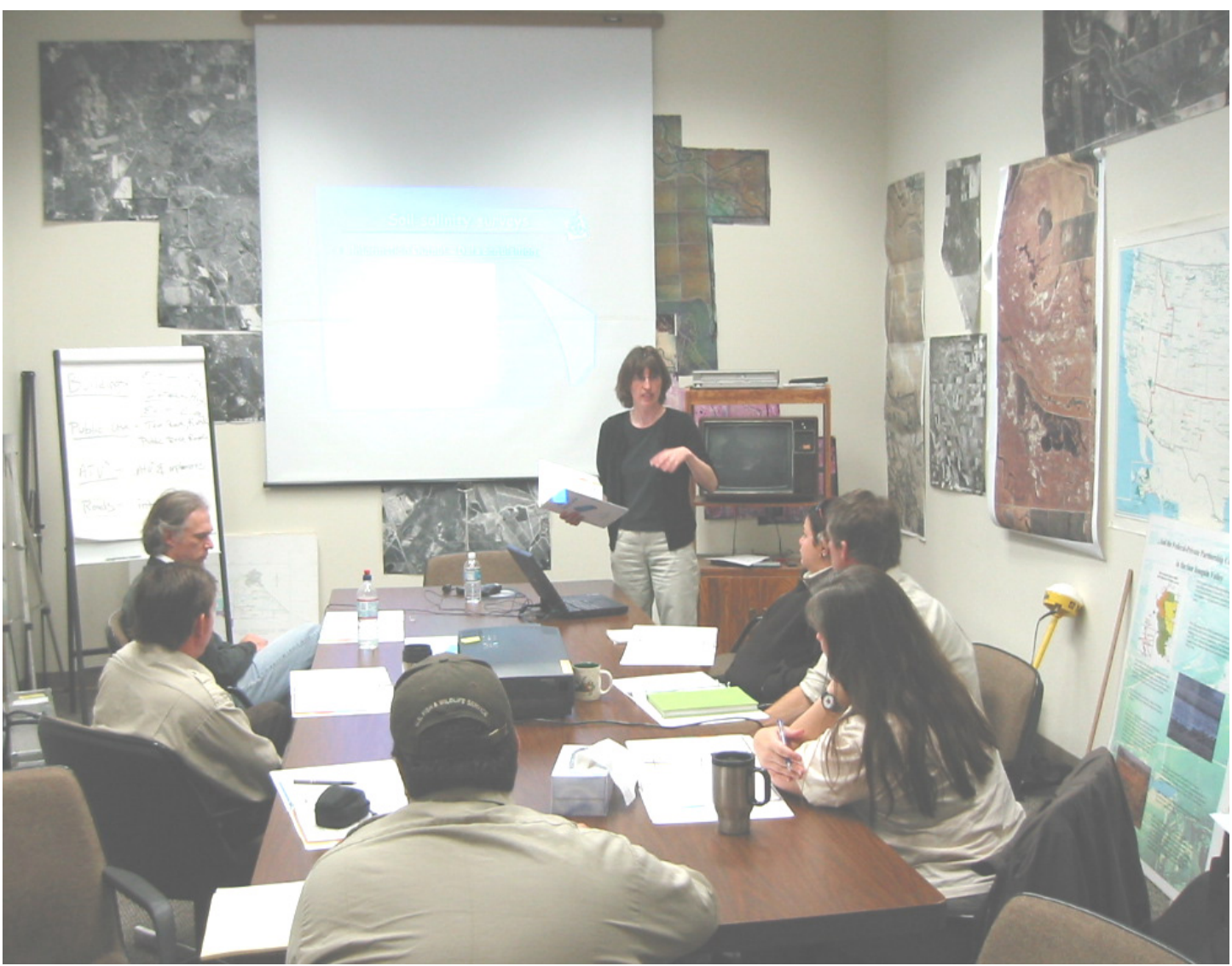

Figure 3. Classroom overview of the theoretical aspects of EM surveying and mapping and hand-on demonstration of the ESAP and soil salinity mapping software.

In the workshop, Dr Cassel presented an overview of the theory of performing soil salinity surveys with the Geonics ElectroMagnetic (EM) induction meter, the design of 
the instrument, its limitations and calibration. She then reviewed the steps to conducting a soil salinity survey beginning with reconnaissance of the wetland tract, setting up flags in a sampling grid and setting up the instruments and mobile platform to acquire the data (Appendix B). Once the data has been logged on to a datalogger or portable laptop a statistical software package known as ESAP is used to determine the mean and variance of the data and to design a statistically valid soil sampling program to calibrate the EM meter readings with reference soil salinity derived from saturated soil extracts. The ESAP program and associated analysis and mapping procedures were demonstrated in a hands-on computer training session. At the conclusion of the workshop all participants were able to process the demonstration data set, derive a sampling grid and produce a soil salinity map using the built-in software.

In the afternoon the workshop moved to one of the wetland areas that were surveyed during 2003 and 2004 and the techniques of setting out a grid and taking measurements with the Geonics EM38 meter demonstrated. Calibration of the instrument was explained and participants were able to observe the configuration of a second EM38 meter hooked up to GPS and a portable datalogger, deployed for single-user surveying.

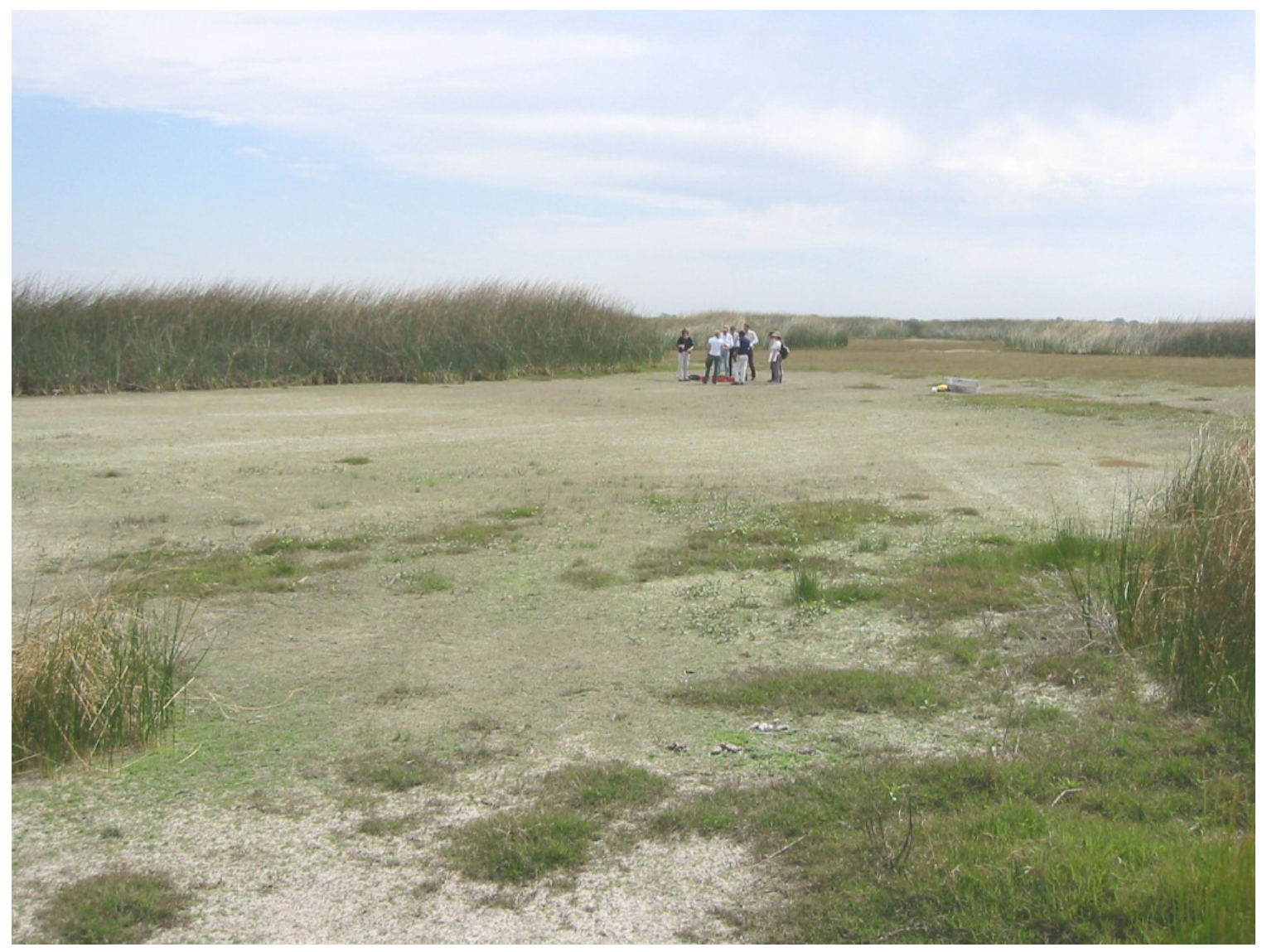

Figure 4. Field demonstration soil salinity survey protocol and use of the Geonics EM38 ElectroMagnetic induction meter in a seasonal wetland after drawdown in the San Luis National Wildlife Refuge 

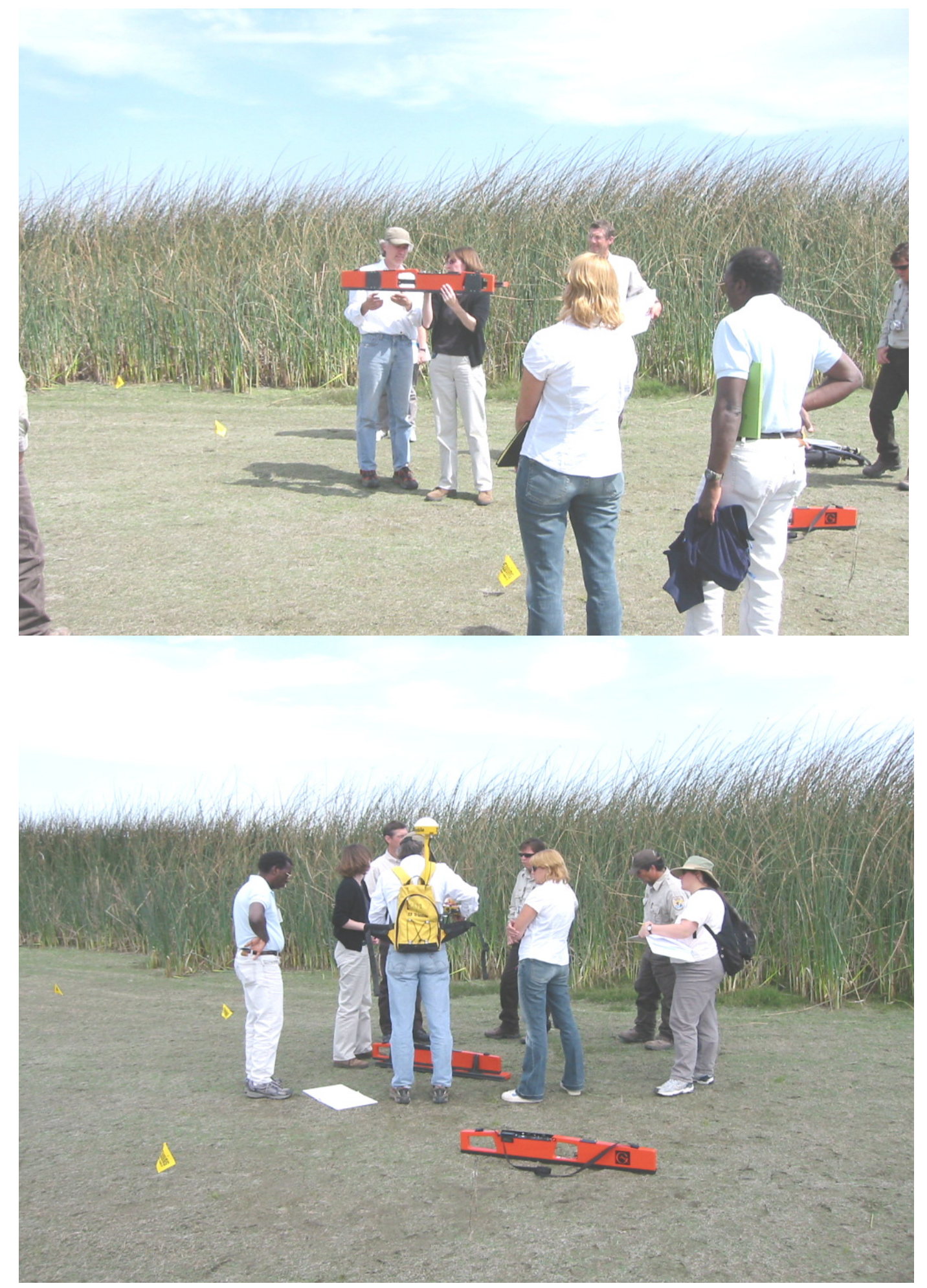

Figure 5. Field calibration of the Geonics EM38 ElectroMagnetic induction meter in a seasonal wetland after drawdown in the San Luis National Wildlife Refuge (above). Use of a single pole Geonics EM38 with GPS backpack and handheld datalogger for solo surveying. 
APPENDIX 4: Cassels F. Soil Salinity Assessment: Theory and Practice.

Presentation for : Soil Salinity Assessment and Mapping Workshop.

San Luis National Wildlife Refuge Complex Office

Los Banos, CA.

April 22, 2005 


\section{Soil Salinity Assessment}

Theory and Practice

F. Cassel S.

Californita Water Institute

California State University, Fresno

Workshop

San Luis National Wildllife Refuge

Los Banos, CA

April 22, 2005 


\section{Worksfrop out line}

1. Soil salinity surveys - Theory

* Instruments

* Survey steps

2. On-site salinity measurements - Practice

* Survey layout

* Data acquisition

3. Salinity data analyses

* ESAP software

* RSSD program

* Calibrate program

* Saltmapper program

4. General information 


\section{Irtroduction}

- Importance

* Soil salinity: important conservation \& environmental problem

* Affects crop growth, wetland ecosystem

* Soil salinity assessment: important for developing sound management practices 


\section{Introduction}

- Soil salinity

* Difficult to quantify over space and time

* Traditional methods: four-electrode probes, soil sampling

* New technology: electromagnetic induction (EM)

* Rapid, non-invasive method, accurate measurements 


\section{Introduction}

- Remote sensing

EM

GPS

* GIS, mapping

* Rapid assessment over space and time, improve decision-making 


\section{Soil salinity surveys}

- Description of techniques

$E M=$ Electromagnetic induction

* Salinity in soils

* No ground contact - non-invasive, rapid

* Principle: Transmitter induces EM field in ground $\rightarrow 2^{\text {nd }}$ field measured by receiver, proportional to depth-weighted EC

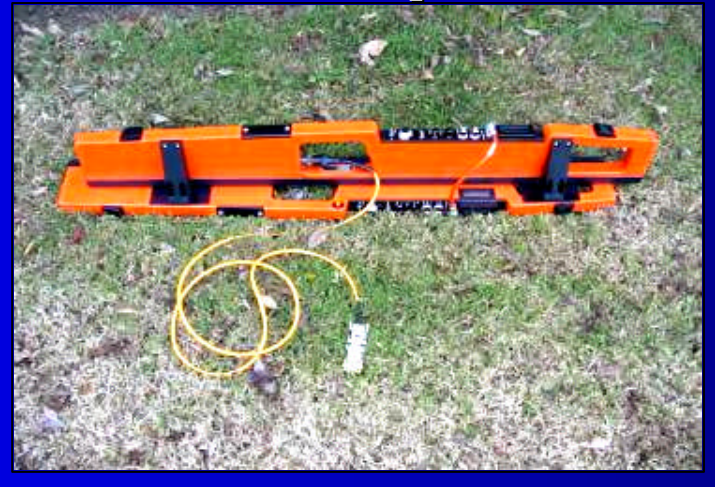

EM-38 dual dipole 


\section{Soil salinity sur oeys}

- EM = Electromagnetic Induction

* Principle: Transmitter induces EM field in ground $\rightarrow 2^{\text {nd }}$ field measured by receiver, proportional to depthweighted EC

* Schematic of EM principle : $\mathrm{ECa}=\left(4 / \mathrm{FPS}^{2}\right) \mathrm{x}(\mathrm{Tx} / \mathrm{Rx})$

$\mathrm{ECa}=$ apparent conductivity $(\mathrm{mS} / \mathrm{m})$ $\mathrm{F}=$ frequency

$\mathrm{P}=$ permeability of free space

$\mathrm{S}=$ coil spacing

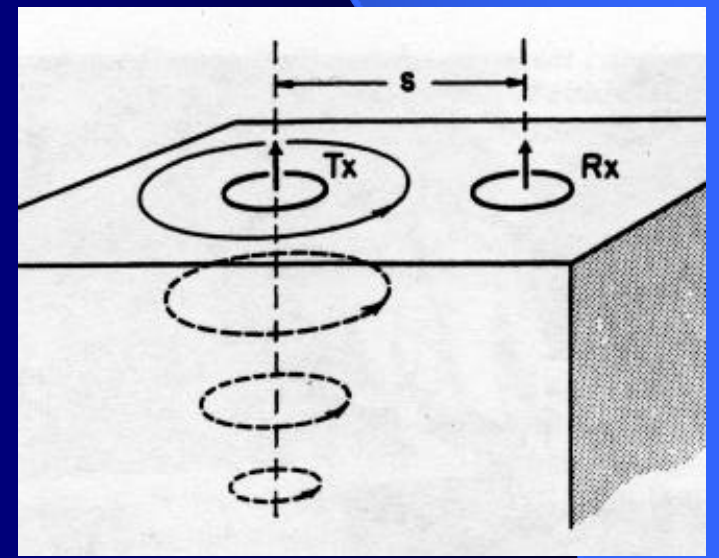

$\mathrm{Tx}, \mathrm{Rx}=$ primary, secondary magnetic fields 


\section{TEM- 38 tise ter cfuaracteristics}

- Length (intercoil spacing) $=\mathbf{3 . 3 \mathrm { ft }}$

- Weight $=6.6 \mathrm{lb}$

- Operating frequency $=14.6 \mathbf{~ k H z}$

- Depth of measurement:

\&orizontal $=\mathbf{3} \mathrm{ft}$

\& Vertical $=6 \mathrm{ft}$

- Measurement accuracy: $\pm 5 \%$ at $30 \mathrm{~ms} / \mathrm{m}$ 


\section{Soil salinity surdeys}

- Description of techniques

\section{GPS}

- Antenna - magnet or backpack

* Differentially corrected
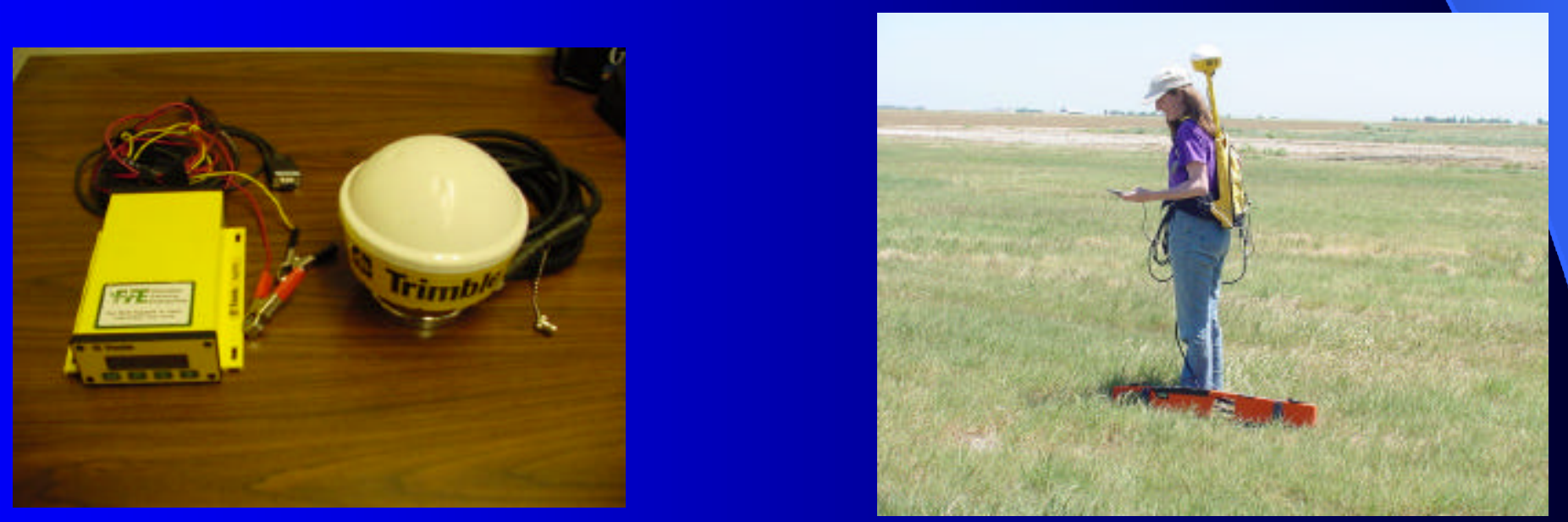


\section{Soil salinity surveys}

- Salinity and GPS measurements

EM38- Backpack GPS

* Carry EM meter \& backpack GPS

* Record data: scoutingmanual or hand-held computer in table format 


\section{Soil salinity surteys}

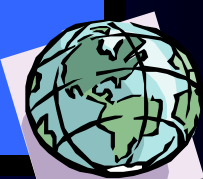

- Information Output - Data acquisition

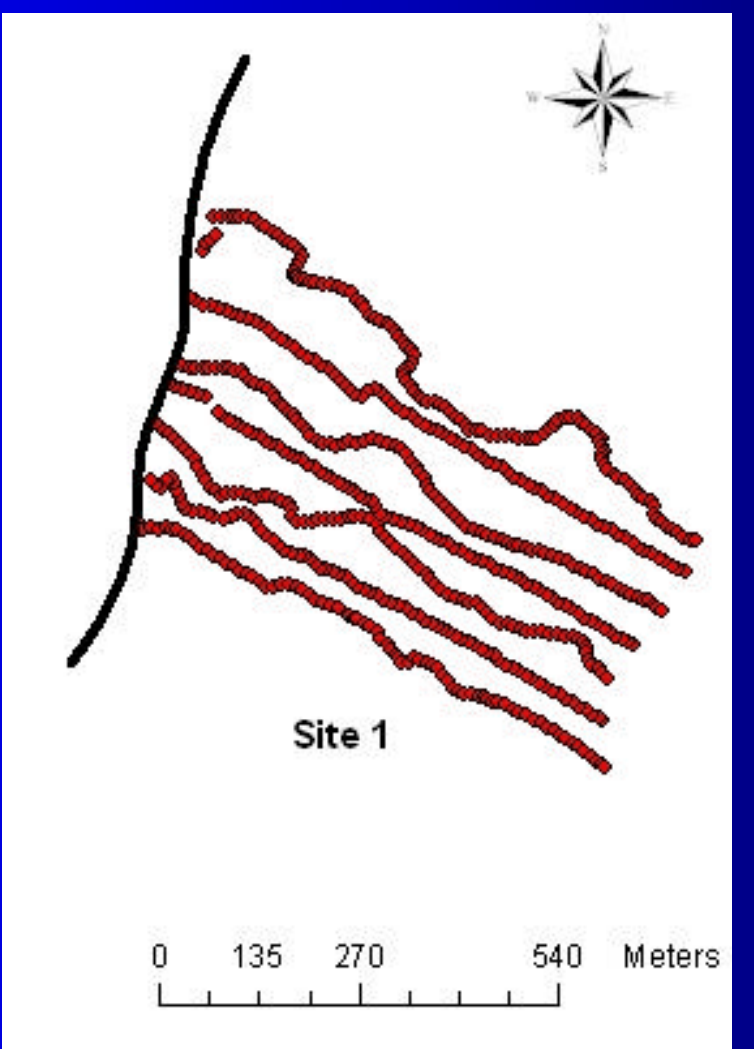




\section{Soil salinity surveys}

- Soil sampling

* ESAP software, generate sampling design

* Ground-truthing

- Soil analyses

* EC, SP, moisture

- Data calibration

* ESAP software, calibrate EM data 


\section{Remote sensing tectriques}

- Advantages

\section{EM/GPS}

* Rapid method (mobile)

* Non-invasive

- Very precise

- Disadvantages

* Expensive

* Relative measurements

- Problems

* Need certain soil conditions

* GPS signal acquisition 


\section{APPENDIX 5 : Cassels F. Soil Salinity Assessment Manual:}

Handout presented at: Soil Salinity Assessment and Mapping

Workshop. San Luis National Wildlife Refuge Complex Office Los Banos, CA.

April 22, 2005. 


\section{SOILSALINITY}

\section{ASSESSMENT MANUAL}

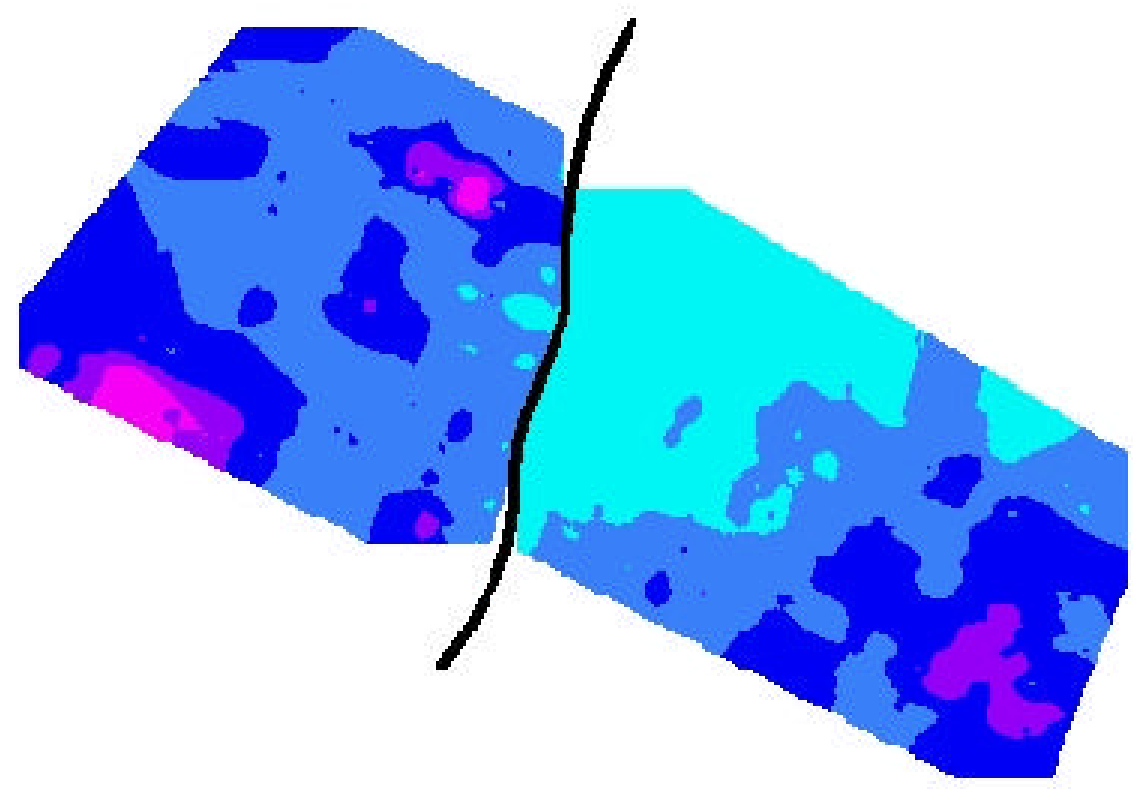

by

Florence Cassel S., Ph.D.

California Water Institute

California State University, Fresno

Fresno, CA 


\section{SOIL SALINITY}

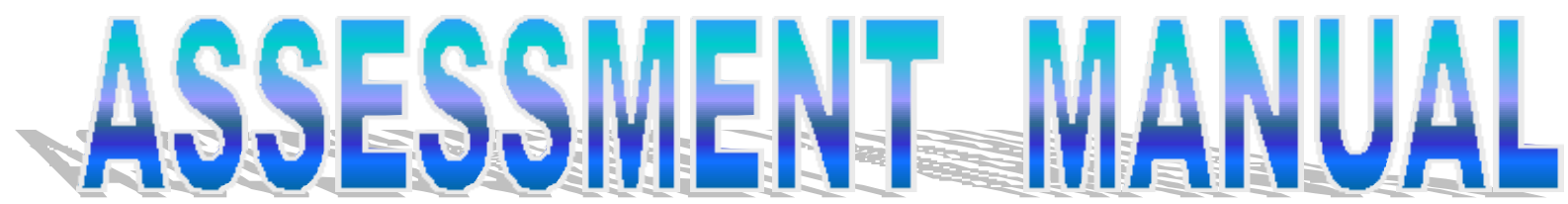

A guide for conducting soil salinity surveys, analyzing data, and generating maps

$$
\text { by }
$$

Florence Cassel S. Ph.D.

California Water Institute California State University, Fresno Fresno, CA

\section{Project funded by}

Association of Bay Area Governments

CALFED Drinking Water Program Contract Number: 4600001642 


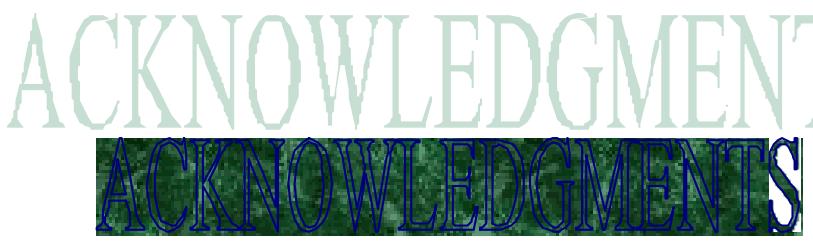

I would like to thank Dr. Nigel Quinn from the Lawrence Berkeley National Laboratory for his support in this project.

Funding for developing this manual has been provided by the Association of Bay Area Governments - CALFED Drinking Water Program, under contract number 4600001642. 


\section{nencense}

INTRODUCTION

page

CHAPTER 1. SOIL SALINITY SURVEYS - Theory

1.1. Instruments

1.1.1. Electromagnetic Induction (EM)

1.1.2. Global Positioning System (GPS)

1.2. Survey steps

1.2.1. Salinity and GPS measurements

1.2.2. Soil sampling design

1.2.3. Soil analyses

1.2.4. Data calibration

CHAPTER 2. ON-SITE SALINITY MEASUREMENTS - Practice

2.1. Survey layout

2.1.1. Grid sampling

2.1.2. Input file

2.2. Data acquisition

2.2.1. EM

2.2.2. GPS

CHAPTER 3. SALINITY DATA ANALYSES

3.1. ESAP software

3.1.1. Overview

3.1.2. Getting the software

3.2. RSSD program

3.2.1. Input data

3.2.2. View/graph input data

3.2.3. Data analyses

3.2.4. Generate sampling design

3.2.5. View/print output data

3.3. CALIBRATE PROGRAM

3.3.1. Import data files

3.3.2. Calibrate EM data

3.3.3. Other data analyses

3.4. SALTMAPPER PROGRAM

3.4.1. Import input files

3.4.2. Mapping

CHAPTER 4. GENERAL INFORMATION

4.1. Crop tolerance to salt

16

4.2. References

18

4.3. Unit conversions

18

4.4. Contact information 


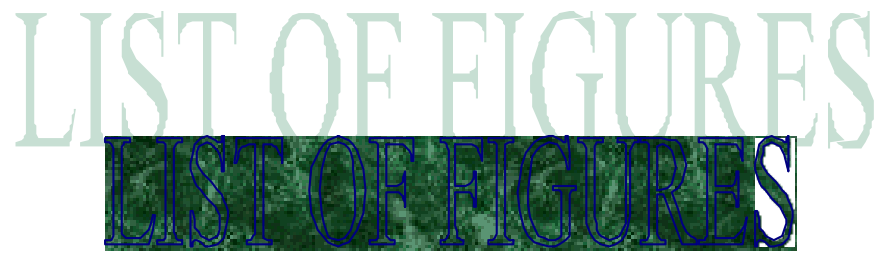

1. Geonics EM-38 meter: Dual Dipole

2. Schematic of EM principle

3. Measurement locations from an EM survey conducted in April 2004 at SLNWR

4. Back Panel of AgGPS Receiver

5a. GPS Home Screen Hierarchy

5b. GPS Operations Screen Hierarchy

5c. GPS Status Screen Hierarchy

5d. GPS Configuration Screen Hierarchy 


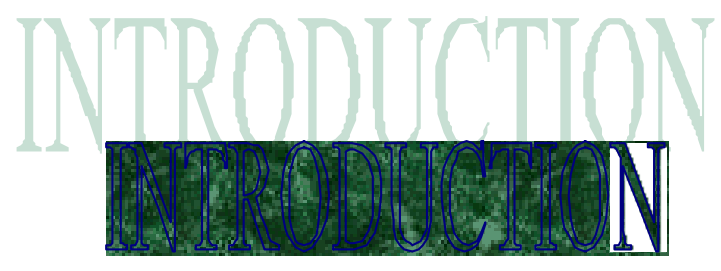

\section{SOIL SALINITY}

Soil salinity is an important conservation and environmental problem in wetlands of the San Joaquin Basin. Salinity affects plant germination and development, and can lead to significant increases in salt tolerant species' populations, thereby creating imbalances in the wetland ecosystem. Consequently, it can also influence fauna diversity, such as invertebrate, fish, and bird. Thus, it is important to evaluate the extent and variability of soil salinity on those wetlands in order to develop sound planning and management practices for improving long-term habitat health and restoring wetlands.

Soil salinity is difficult to quantify because of rapid changes over space and time. Measurement methods such as the four-electrode probes and soil sampling are generally applied to determine soil salinity; however, these methods require extensive data collection and laboratory analyses that are very slow, labor-intensive, and expensive. Recently, remote sensing technologies have become easier to use for surveying salt-affected lands. Among those techniques, the electromagnetic induction (EM) method has been very efficient in rapidly collecting salinity information in soil systems (Ceuppens et al., 1997; Hendrickx et al., 1992). Furthermore, the EM technology generally provides better and faster estimates of soil salinity than direct methods (Sudduth et al., 1999). In this manual, we will focus on the use of this technique for assessment of soil salinity in wetlands.

The EM technique is based on the electromagnetic induction principle where the ratio of the received to transmitted magnetic fields is proportional to the electrical conductivity of the soil.

Use of the EM technology in combination with global positioning systems (GPS) and geographical information systems (GIS) can provide rapid assessment of soil salinity variability in the wetlands over space and time. Such information may improve decisions concerning appropriate practices for improving and/or restoring wetland ecosystems.

It is important to regularly conduct soil salinity surveys to detect trends and changes occurring across wetlands over time, in order to predict emerging problems and evaluate the effectiveness of newly implemented management practices. 


\section{MANUAL OVERVIEW}

This manual provides theoretical and practical information for soil salinity assessment in wetlands. It describes the different steps for conducting soil salinity surveys using the EM technique and developing maps based on the salinity data.

The manual is divided into four major chapters: 1) Soil salinity surveys - Theory, 2) On-site salinity measurements - Practice, 3) Salinity data analyses, and 4) General Information. The first chapter presents the equipment used to carry out the soil salinity surveys and gives a theoretical knowledge of the soil salinity assessment procedure. The second chapter illustrates the different steps to collect soil salinity measurements on site. The third chapter provides step-by-step instructions to analyze the EM survey data using the ESAP software. Finally, the last chapter gives additional information that can be useful for soil salinity assessment and management decisions.

\section{DISCLAIMER}

The mention of any trade names and/or commercial products in this manual does not constitute any endorsement or recommendation for use by the California State University Fresno or its employees. 


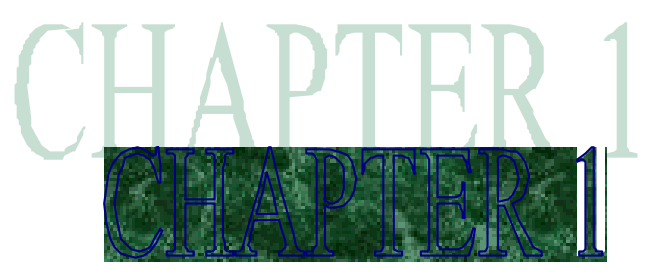

\section{SOIL SALINITY SURVEYS Theory}

This chapter provides a description of the materials and methods used to cond uct soil salinity surveys in wetland environments. It also explains the theory behind the electromagnetic induction technique.

\subsection{INSTRUMENTS}

\subsubsection{Electromagnetic Induction (EM)}

The instrument used to conduct soil salinity surveys in wetlands and agricultural fields is the Geonics EM-38 meter. This sensor was designed specifically for agricultural applications at relatively shallow depths to provide measurements within the plant root zone. The instrument is particularly useful in detecting spatial variations of soil salinity over large areas without ground contact (non-invasive method).

The EM-38 sensor is very lightweight, small, highly durable, and gives excellent lateral resolution. The instrument measures the apparent electrical conductivity in millisiemens per meter $(\mathrm{mS} / \mathrm{m})$ and operates at a frequency of $14.6 \mathrm{kHz}$. The EM-38 can be placed in two different positions, horizontal and vertical, thereby providing measurements of ground conductivity at two depths of exploration: 0.75 meter ( 2.5 feet) and 1.5 meter ( 5 feet) in the horizontal and vertical dipole modes, respectively. Measurements are made by placing the instrument on the ground and recording the reading. Readings can be logged manually or digitally using a data logger. Geonics provides a data logger that can be used to collect data either discreetly or continuously at a time interval selected by the operator. Measurements can be done manually or by using a mobilized system where the instrument is towed by a vehicle. Building a mobilized systemis expensive and costs at least $\$ 50,000$.

Two EM-38 instruments are offered by Geonics: 1) the standard EM-38 comprising one sensor, and 2) the dual dipole EM-38 including two integrated units oriented in the horizontal and vertical positions. Figure 1 shows the dual dipole EM-38. Horizontal and 
vertical measurements can be obtained simultaneously with the dual dipole sensor; whereas, separate measurements have to be conducted with the standard instrument.

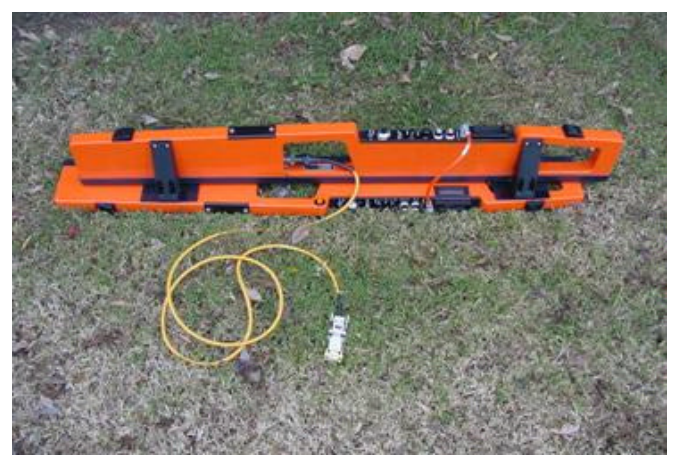

\section{Figure 1. Geonics EM-38 meter: Dual Dipole}

The specifications of the Geonics EM-38 sensor are presented below:

$\begin{array}{ll}\text { Measurements } & \text { Apparent conductivity (mS/m) } \\ \text { Primary field source/sensor } & \text { Self container dipole transmitter/receiver } \\ \text { Intercoil spacing } & 1 \text { meter } \\ \text { Measurement depths } & 0.75 \mathrm{~m} \text { (horizontal mode) and } 1.5 \mathrm{~m} \text { (vertical mode) } \\ \text { Operating frequency } & 14.6 \mathrm{kHz} \\ \text { Measurement range } & 100-1000 \mathrm{mS} / \mathrm{m} \\ \text { Measurement resolution } & \pm 0.1 \% \text { of full scale } \\ \text { Measurement accuracy } & \pm 5 \% \text { at } 30 \mathrm{mS} / \mathrm{m} \\ \text { Noise level } & 0.5 \mathrm{mS} / \mathrm{m} \\ \text { Power supply } & 9 \mathrm{~V} \mathrm{battery} \\ \text { Battery life } & 30 \mathrm{hours} \\ \text { Instrument dimensions } & 106 \times 15 \times 3.6 \mathrm{~cm}(3.5 \times 0.5 \times 0.12 \mathrm{ft}) \\ \text { Weights } & 3 \mathrm{~kg}(6.6 \mathrm{lb}) \text { for standard EM-38 } \\ & 6 \mathrm{~kg}(13.2 \mathrm{lb}) \text { for dual dipole EM-38 } \\ \text { Cost } & \sim \$ 10,000 \text { for standard EM-38 } \\ & \sim \$ 20,000 \text { for dual dipole EM-38 }\end{array}$

The principle of measurement was patented by Geonics and can be described as follows: the EM instrument's transmitter coil induces an electromagnetic field in the ground, which in turn create a secondary magnetic field that is measured by the receiver coil (McNeill, 1980). The ratio of both fields represents the depth-weighted apparent electrical conductivity $\left(\mathrm{EC}_{\mathrm{a}}\right)$ in a volume of soil below both coils (Rhoades and Corwin, 1990). Since 
solid soil particles and rock material have very low EC (McNeill, 1980), the instrument response is primarily influenced by the electrolyte concentration of the soil water, i.e., salinity (Figure 2).

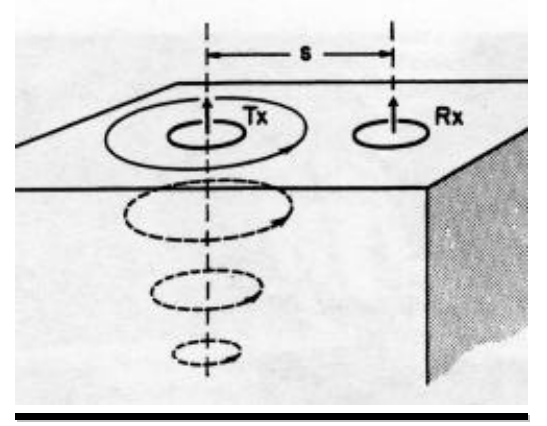

Figure 2. Schematic of EM principle

The electromagnetic induction method can be summarized by the following equation:

$$
\mathrm{ECa}=\left(4 / \mathrm{FPS}^{2}\right) \times(\mathrm{T} x / \mathrm{Rx})
$$

where:

$\mathrm{ECa}=$ apparent conductivity $(\mathrm{mS} / \mathrm{m})$

$\mathrm{F}=$ frequency

$\mathrm{P}=$ permeability of free space

$\mathrm{S}=$ coil spacing

$\mathrm{Tx}, \mathrm{Rx}=$ primary and secondary magnetic fields

\subsubsection{Global Positioning System (GPS)}

A GPS system is usually used in conjunction with the EM sensor to provide the geographical coordinates of each measurement point and link the survey location to a larger spatial area, such as a wetland, field, or region. The survey data can then easily be transferred into a geographic information system (GIS) for data analyses and mapping. In the absence of a GPS system, $\mathrm{X}$ and Y coordinates of the survey area can be recorded manually using a grid format, however the survey data will not be related to any type of coordinate system.

Prices of typical GPS systems range from a few hundred to several thousand dollars, depending on the system accuracy. For soil salinity surveys, GPS systems providing differential correction is required to provide location accuracy of 1-2 meters. Such systems usually cost above $\$ 2000$. 


\subsection{SURVEY STEPS}

\subsubsection{Salinity and GPS measurements}

The EM and GPS data can be collected in any type of grid pattern or along transects. Measurement location layout will depend on the size and shape of the survey area, any obstacle encountered across the survey area, the objective of the study, and the equipment available. A map showing the locations of the EM and GPS measurements taken at the San Luis Wildlife refuge last year is presented in Figure 3.
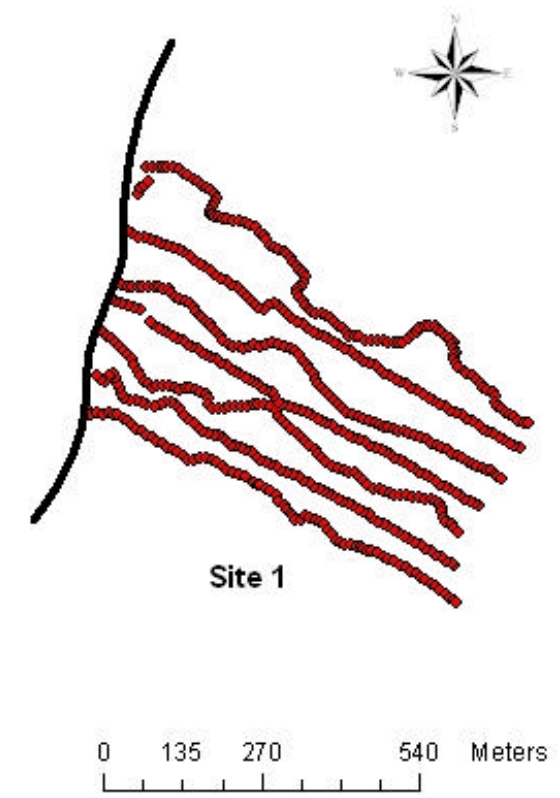

Figure 3. Measurement locations from an EM survey conducted in April 2004 at SLNWR.

\subsubsection{Soil sampling design}

After an EM survey has been completed, the ESAP software (Lesch and Rhoades, 1999 ) is used to generate an optimal soil sampling plan that is spatially representative of the survey area. The sampling plan encompasses six or twelve locations depending on the size of the survey area. Ground truthing sampling is then conducted at each of those sites using a GPS for geographical positioning. Soil samples are collected at different depths depending on the objective of the study. In the EM survey conducted last year at SLNWR, samples were collected at 0-6" and 6-12" depths at six locations.

\subsubsection{Soil analyses}

Once collected, the soil samples are sent to the laboratory for analyses of moisture, saturation percentage (SP) and electrical conductivity on a saturated paste extract (ECe). 
Both SP and ECe analyses are conducted after drying and grinding the soil. SP is the ratio of the weight of water added to the dry soil (to make a saturated paste) to the weight of the dry soil, and gives an estimate of soil texture. The condition of saturation is obtained when all the pores in the soil are filled with water and the soil paste glistens from light reflection. The solution of the saturated paste is then extracted using a vacuum extraction procedure and EC is measured on the extracted solution. This measurement is generally called the EC of the saturation extract and is referred to as ECe. The EC measurement conducted on a saturated paste extract can be used to assess the effects of soil salinity on plant growth, based on

published guidelines listing crop tolerance to salt. Some of the guidelines for grasses and forage crops can be found in Chapter 4 of this manual.

\subsubsection{Data calibration}

The next step consists in calibrating and converting the apparent soil conductivity data (ECa) into soil salinity data (ECe) for the entire survey area. This is accomplished using the ESAP program with the EM survey data and the laboratory data of the soil sample analyses. Salinity estimate values are obtained for all depths sampled during ground truthing. Then, surface contour maps of the salinity distribution on the wetland can be generated using ESAP, GIS, or any mapping software. 


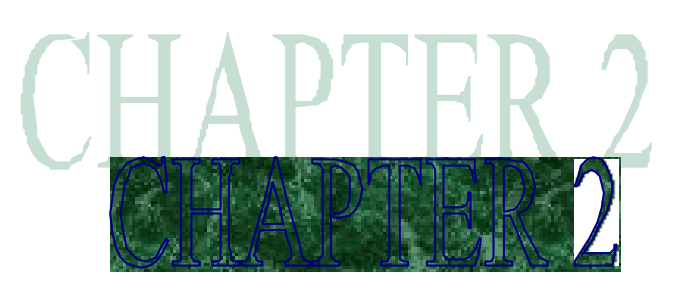

\section{ON-SITE SALINITY MEASUREMENTS}

\section{Practice}

During this session, we will go to the SLNWR where you will learn how to conduct manual soil salinity surveys in-situ. You will learn how to design the survey layout and how to acquire EM and GPS measurements.

\subsection{SURVEY LAYOUT}

\subsubsection{Grid sampling}

Before starting a survey, it is important to define the layout of your measurements based on the parameters defined in Chapter 2. For this training, our layout will consist of measurements taken in a regular grid pattern of $10 \mathrm{ft} \times 10 \mathrm{ft}$ across a $50 \mathrm{ft}^{2}$ area. Put flags every $10 \mathrm{ft}$ along the boundaries of the survey area to delineate the grid layout.

\subsubsection{Input file}

Please use the table provided at the end of this Chapter to record the EM and GPS data at each measurement location.

This table will then need to be imported in the same format as an ASCII text file (comma or space delimited) into the ESAP program for selection of ground truthing sites.

\subsection{DATA ACQUISITION}

\subsubsection{EM}

\section{INITIAL CHECK-UP}

The battery of the EM-38 sensor should be checked before each survey by switching the ON/OFF/BATT switch to BATT. The value in the display unit should read between 1500 to -720 for a good battery. If the reading is below or close to 720 , the battery needs to be changed. The life of a 9-volt alkaline battery is about 25-30 hours of continuous 
operation. To remove the battery, undo the two screws holding the battery compartment in the top center of the instrument.

Other checkings, such as zeroing of the instrument and synchronization of the two dipole units (for dual dipole sensor only) are also performed.

\section{$\underline{\text { MEASUREMENTS }}$}

To conduct a survey, turn on the EM-38 sensor and simply lay the instrument on the ground to take a reading. Readings can be taken either in the horizontal or in the vertical dipole mode, depending on the depth of exploration required. Any metallic object too close to the instrument can affect the readings.

\subsubsection{GPS}

\section{INITIAL SETUP PROCEDURES (see Fig.4)}

a. Connect black spiral cable from "ANT" port of GPS receiver to GPS antenna.

b. Connect black cable from "Port B" of GPS receiver to a battery or power supply.

c. Wait 1-2 minutes to obtain the satellite signals.

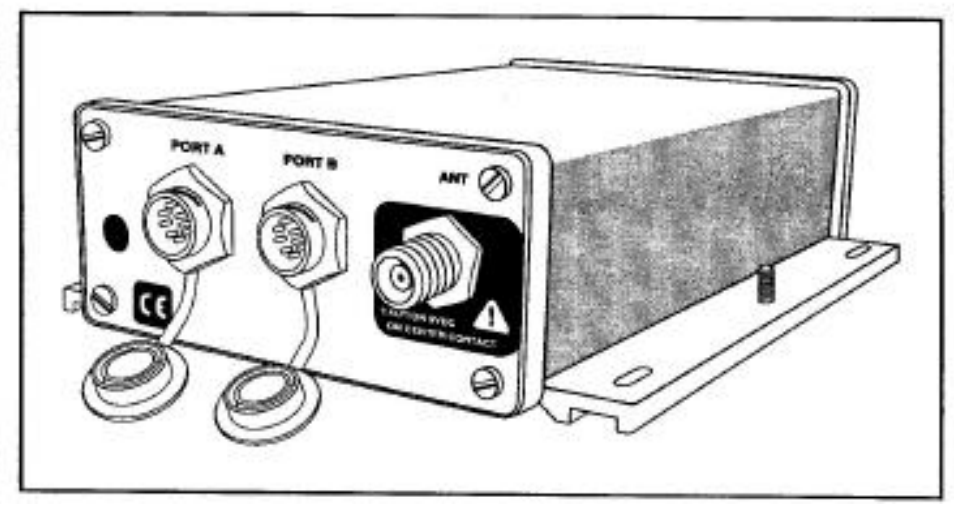

Fig. 4. Back Panel of AgGPS Receiver

Figures $5 \mathrm{a}, \mathrm{b}, \mathrm{c}$, and d show the different screen displays to view and configure the operating parameters available with the GPS used in this session.
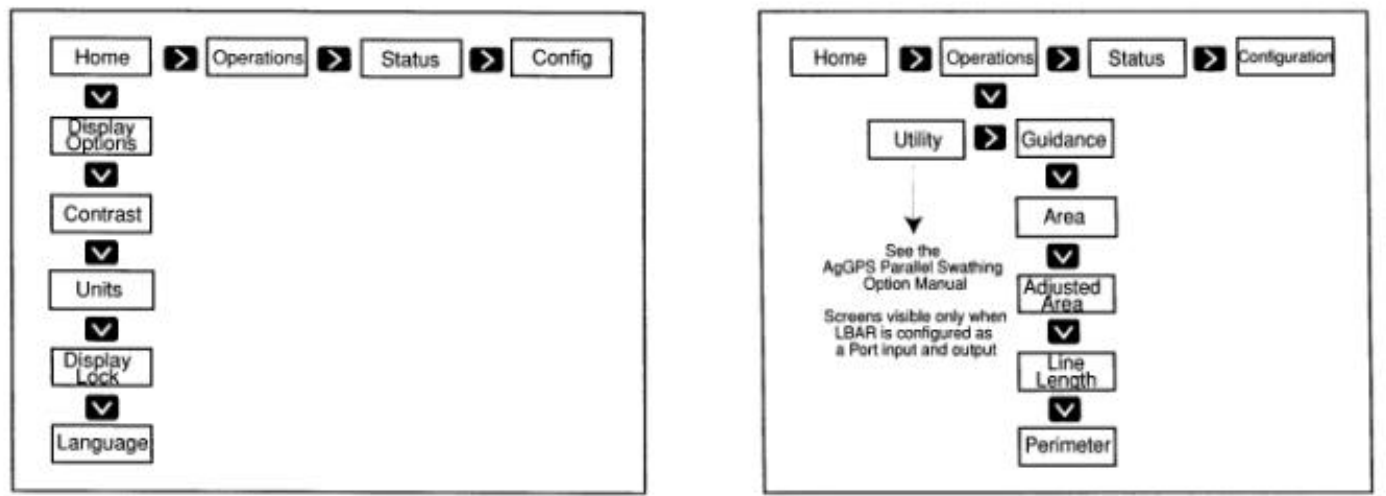

Fig. 5a. GPS "Home" Screen Hierarchy. Fig. 5b. GPS "Operations" Screen Hierarchy 


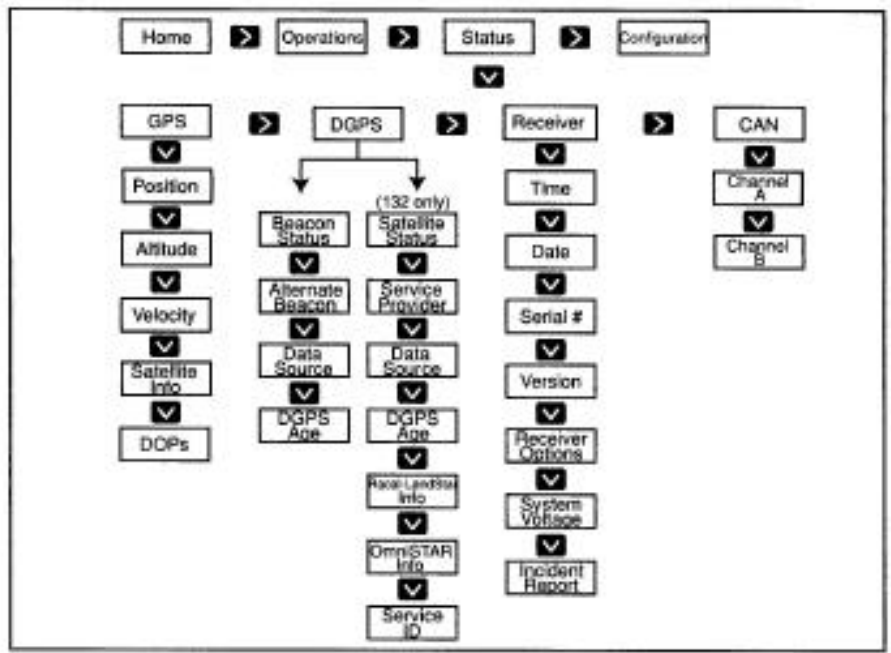

Fig. 5c. GPS "Status" Screen Hierarchy

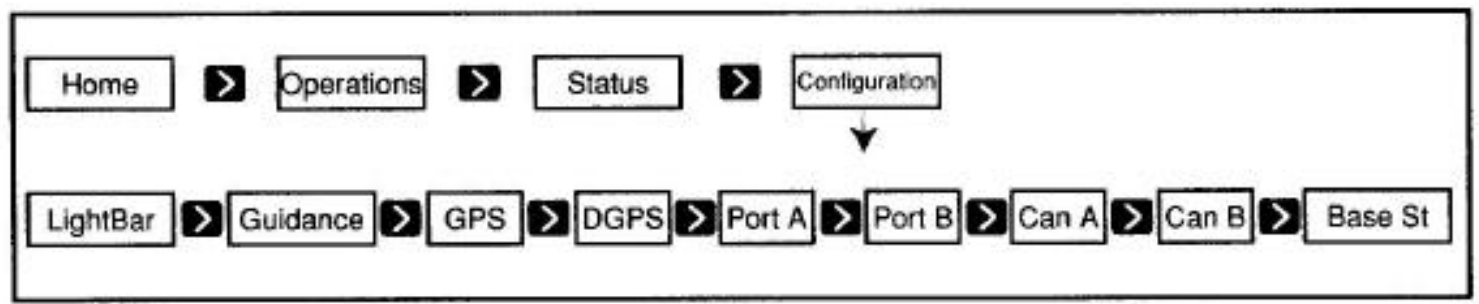

Fig. 5d. GPS "Configuration" Screen Hierarchy

\section{MEASUREMENTS}

Before starting the survey, set the GPS unit to view the latitude and longitude coordinates in the display unit. Select Status - GPS - position. Readings can be given in decimal numbers or as degree/minute/second depending on the configuration of the GPS. At each measurement location, enter both the EM and GPS readings in the log table. 


\section{EM READINGS AND GIS COORDINATES LOG FILE}

Date:

Operator:

Wetland/Location:

Observations:

\begin{tabular}{|c|c|c|c|c|c|}
\hline \multirow{2}{*}{$\begin{array}{l}\text { Site } \\
\text { ID }\end{array}$} & \multirow{2}{*}{$\begin{array}{l}\text { Lane } \\
\#\end{array}$} & \multicolumn{2}{|c|}{ Geographic coordinates } & \multicolumn{2}{|c|}{$\mathrm{EM}(\mathrm{mS} / \mathrm{m})$} \\
\hline & & Latitude (Y) & Longitude $(\mathrm{X})$ & Vertical & Horizontal \\
\hline 1 & & & & & \\
\hline 2 & & & & & \\
\hline 3 & & & & & \\
\hline 4 & & & & & \\
\hline 5 & & & & & \\
\hline 6 & & & & & \\
\hline 7 & & & & & \\
\hline 8 & & & & & \\
\hline 9 & & & & & \\
\hline 10 & & & & & \\
\hline 11 & & & & & \\
\hline 12 & & & & & \\
\hline 13 & & & & & \\
\hline 14 & & & & & \\
\hline 15 & & & & & \\
\hline 16 & & & & & \\
\hline 17 & & & & & \\
\hline 18 & & & & & \\
\hline 19 & & & & & \\
\hline 20 & & & & & \\
\hline 21 & & & & & \\
\hline 22 & & & & & \\
\hline 23 & & & & & \\
\hline 24 & & & & & \\
\hline 25 & & & & & \\
\hline
\end{tabular}




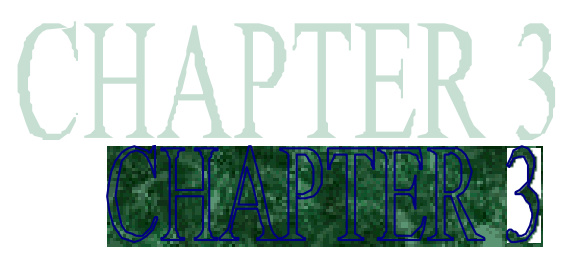

\section{SALINITY DATA ANALYSES}

This chapter describes the ESAP statistical software used to analyze the EM survey data. It provides a detailed description of the different programs available in the software and the analysis steps to generate soil sampling designs, calibrate the soil salinity data, and produce salinity maps.

\subsection{ESAP SOFTWARE}

\subsubsection{Overview}

The ESAP software contains three main programs to use for survey data analyses and mapping: ESAP-RSSD, ESAP-Calibrate, and ESAP-SaltMapper.

The ESAP-RSSD program is used to generate soil sampling designs from EM survey data. The ESAP-Calibrate program is designed to calibrate the EM data and provide output salinity data of the entire survey area. The ESAP-SaltMapper can be used to produce 1-D and 2-D maps of the survey and calibrated salinity data.

\subsubsection{Getting the software}

The ESAP software is public domain and can be obtained from the following website: www.ussl.ars.usda.gov/models/esap.htm. To install the software, double click on the setup.exe programs to initiate the installation procedure, then follow the instructions. Make sure you don't have any other program running before installing the software.

\subsection{RSSD PROGRAM}

\subsubsection{Input data}

a. Open ESAP Software and select the ESAP-RSSD program

b. Define Directory and Field ID Code.

c. Import the input data file as a grid or transect file. The input file should be in an ASCII text format, either comma or space delimited. The file also needs to be 
structured as follow: $x$-coordinate, y-coordinate, $1^{\text {st }}$ EM signal, $2^{\text {nd }}$ EM signal (if available), row number.

\subsubsection{View/graph input data}

a. Initializing Graphic options (required) by clicking on Graph > Open Graphics Window > Options > Initialize Graphic Component and select the appropriate boxes based on the type of plots you wish to display.

b. View/Graph data.

c. Save and print graphs.

\subsubsection{Data analyses}

a. Basic Statistics. Perform these analyses if you need to log-transformed your EM data and change the data unit from $\mathrm{mS} / \mathrm{m}$ to $\mathrm{dS} / \mathrm{m}$.

b. Signal Decorrelation.

c. Signal Validation.

These last two steps are used to mask or eliminate any outliers in your survey data.

\subsubsection{Generate sampling design}

Choose one of the following two options: (a) SRS sample design, or (b) manual sample site selection. The first option is generally used for most EM surveys. The second option is used when you want to select your own sample design; it usually applied to already surveyed field and collected soil samples.

The SRS sample design is obtained by clicking on Design > Calculate SRS Sample Design and invoking the SRSS algorithm. In this procedure, you can select three different sample sizes; your selection will be based on the size of the survey area, the cost of soil sampling and laboratory analyses. Do not forget to save the sample design generated and click on Finished. You must EXIT the program using the File > Exit menu option, otherwise all output files may not be created.

\subsubsection{View/print output data}

You can view and print the locations of your sampling design by clicking on the Graphics menu and selecting Sampling site map and Print Current Graph.

The program will generate four files containing information on the general data processing and sample design. These files are xxxinfo.txt, xxxrsd.txt, xxxgps.txt, and xxxsvy.txt. This last file is important and will be used for calibration of the EM data.

\subsection{CALIBRATE PROGRAM}

The methodology of this program focuses on the use of spatial regression models for calibrating and predicting soil salinity from EM survey data. 


\subsubsection{Import data files}

Two files need to be imported into the Calibrate program: the *.svy file and the laboratory data file. First, import the *.svy file using the File > Import data file menu and selecting the survey data file option. To import this file, you must set the project directory and specify the file name. Then, import your laboratory data file using the File > Import data file menu and selecting the profile data file option. To successfully import this file, the laboratory data need to have previously been stored in a comma or space delimited ASCII text file. For most salinity surveys, the laboratory data will be imported as a DPPC file and have the following structure: site_ID, sample depth, salinity, SP, moisture (5 columns). The file also needs to be sorted by site_ID numbers and sampling depths.

After importing a new profile data file, you will need to validate this laboratory data. This procedure performs checks on the data and is invoked by clicking on the File > Edit or Validate profile data menu option. Editing and conversion of the laboratory data values and column labels can also be performed by checking the appropriate boxes in the DPPC profile data options frame. Then invoke the data validation routine by clicking on the Compute summary statistics command button. Once the validation tests have been performed, save the data as a permanent *.pro file.

\subsubsection{Calibrate EM data}

The ESAP-Calibrate program allows to perform calibration of the EM data using either deterministic or stochastic modeling techniques. The deterministic approach is used when no ground truthing samples are collected. Such technique processes one single depth and directly converts conductivity data into salinity data using linear regression techniques and estimates of soil temperature and texture. When soil samples are collected, it is preferable to conduct stochastic analyses for calibrating the EM data. Such procedure is invoked by clicking on the spatial MLR analysis from the Calibrate > Stochastic methods menu.

a. Response variable specification. Choose the variable you wish to predict (ECe), set the project directory and merge the survey and profile data files. Invoke the site deletion window if you want to remove data from your laboratory file. Accept the results if there is no error.

b. Specify the model parameters. For calibrating the EM data, a stochastic model must be selected and the parameters of the model equation identified. The model parameters can be selected by the ESAP program or specify by the user. The calibration model parameters typically consist of two components: signal and trend surface parameters. It is advisable to let ESAP choose the model, particularly if you are not very familiar with regression modeling techniques.

c. Estimate the calibration equation. Invoke the MLR model estimation window to display the model and summary statistics. The model fitted $\mathrm{R}^{2}$ values and the coefficient of variation are shown for each profile depth. 
d. Advanced options (optional). Summary statistics of the model chosen and residual error diagnostics can be viewed using the sub-menu items.

e. View prediction plots.

f. Field statistics. Invoke this option to generate the summary statistics of your survey area.

g. Save output predictions as a permanent *.prd data file.

\subsubsection{Other data analyses}

a. Profile shape/Magnitude analyses. This analysis provides a graphical representation of the profile data. Plots can be generated for each soil variable and display the magnitude of the selected variable against the sampling depth.

b. Standard correlation. This option can be used to produce correlation plots and statistics between any two soil variables.

c. DPPC correlation analyses. This option can be invoked to perform a standard DPPC analysis on your data and provides estimates of calculated conductivity data.

\subsection{SALTMAPPER PROGRAM}

This program can be used to generate, display and plot 1-D and 2-D maps of your conductivity data and predicted soil salinity data. The Saltmapper program is designed to read output data files produced by the other ESAP programs.

\subsubsection{Import output files}

a. Specify Project/Input file. Import your output file by selecting the first sub-option in the File menu.

b. Column manipulation option can be used to change/rename any column labels or create new columns.

c. Create output data file. Save any changes made under b.

\subsubsection{Mapping}

a. 1-D transect plot. This option is designed to create and output different types of 1Dplots of your survey or calibrated data. Before creating a plot, you need to use the controls within the Initialize window to initialize the plot. You can print and save the displayed plot as a bitmap file.

b. 2-D raster image map to generate contour maps of your prediction data in a two-step process: data interpolation and map creation. To interpolate your data, you must initialize the raster window and set the kernel size. You can then plot, print, and save your map. 


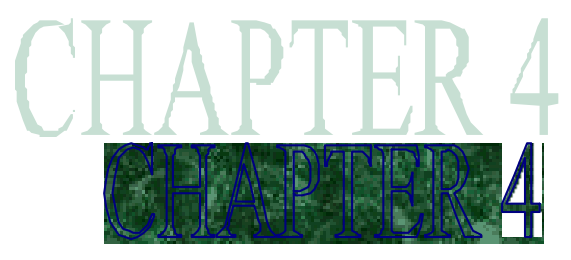

\section{GENERAL INFORMATION}

\subsection{CROP TOLERANCE TO SALT}

\begin{tabular}{|c|c|c|c|}
\hline Crop & Threshold Salinity (A) & Slope (B) & \\
\hline Alfalfa & 2.0 & 7.3 & MS \\
\hline Alkali grass, nuttall & & & $\mathrm{T}$ \\
\hline Alkali sacaton & & & MT \\
\hline Barley (forage) & 6.0 & 7.1 & MT \\
\hline Bentgrass & & & MS \\
\hline Bermuda grass & 6.9 & 6.4 & $\mathrm{~T}$ \\
\hline Bluestem, Angleton & & & MS \\
\hline Brome, mountain & & & MT \\
\hline Brome, smooth & & & MS \\
\hline Buffelgrass & & & MS \\
\hline Burnet & & & MS \\
\hline Canary grass, reed & & & MT \\
\hline Clover alsike & 1.5 & 12.0 & MS \\
\hline Clover, Berseem & 1.5 & 5.7 & MS \\
\hline Clover, Hubam & & & MT \\
\hline Clover, ladino & 1.5 & 12.0 & MS \\
\hline Clover, red & 1.5 & 12.0 & MS \\
\hline Clover, strawberry & 1.5 & 12.0 & MS \\
\hline Clover, sweet & & & MT \\
\hline Clover, white Dutch & & & MS \\
\hline Corn, forage & 1.8 & 7.4 & MS \\
\hline Cowpea (forage) & 2.5 & 11.0 & MS \\
\hline
\end{tabular}

- $S=$ sensitive; $M S=$ moderately sensitive; $M T=$ moderately tolerant, $T=$ tolerant

**Currently being re-examined 
Dallis grass

Fescue, tall

Fescue, meadow

Foxtail, meadow

Grama, blue

Harding grass

Kallar grass

Love grass

Milkvetch, cicer

Oat grass, tall

Oats (forage)

Orchard grass

Panic grass, blue

Rape

Rescue grass

Rhodes grass

Rye (forage)

Ryegrass, Italian

Ryegrass, perennial

Salt grass, desert

Sesbania

Sirato

Sphaerophysa

Sundan grass

Timothy

Trefoil, big

Trefoil, narrowleaf bird's foot

Trefoil, broadleaf bird's foot

Vetch, common

Wheat (forage)

Wheat, durum (forage)

Wheat grass, standard crested

Wheat grass, fairway crested

Wheat grass, intermediate

Wheat grass, slender

Wheat grass, tall

Wheat grass, western

Wild rye, Altai

Wild rye, beardless

Wild rye, Canadian

Wild rye, Russian
3.9

1.5

4.6

2.0

1.5

6.2

5.3

9.6

7.6

8.4

MS

MS

MS

MS

MS

MT

MT

MT

MT

MS

MT

5.6

2.3

7.6

MT

$\mathrm{T}$

MS

MS

MS

2.2

2.8

2.3

5.0

3.0

4.5

2.1

3.5

7.5

7.5

2.7
7.0

7.0

4.3

19.0

10.0

11.0

2.6

2.5

4.0

6.9

4.2

6.0
MT

MS

MS

MT

MT

MS

MT

MT

MT

T

MT

MT

$\mathrm{T}$

MT

T

MT

MT

$\mathrm{T}$

- $S$ = sensitive; $M S$ = moderately sensitive; $M T$ = moderately tolerant; $T=$ tolerant 


\subsection{REFERENCES}

Ceuppens, J., M.C.S. Wopereis, and K.M. Miézan. 1997. Soil salinization processes in rice irrigation schemes in the Senegal River Delta. Soil Sci. Soc. Am. J. 61:1122-1130.

Geonics. 2001. EM38 Operating Manual. Geonics Limited. Mississauga, ON, Canada. 35 pp.

Hendrickx, J.M.H., B. Baerends, Z.I. Raza, M. Sadig, and M.A. Chaudhry. 1992. Soil salinity assessment by electromagnetic induction of irrigated lands. Soil Sci. Soc. Am. J. 56:1933-1941.

Lesch, S.M., and J.D. Rhoades. 1999. ESAP-95 Software Package Version 2.01R. USDAARS, George E. Brown Jr. Salinity Laboratory, Riverside, CA.

McNeill, J.D. 1980. Electrical conductivity of soils and rocks. Tech. Note TN-5. Geonics Ltd., Mississauga, ON, Canada.

Rhoades, J.D., and D.L. Corwin. 1990. Soil electrical conductivity: Effects of soil properties and application to soil salinity appraisal. Commun. Soil Sci. Plant Anal. 21:837-860.

Sudduth, K.A., N.R. Kitchen, and S.T. Drummond. June 1999. Soil conductivity sensing on clay pans: comparison of electromagnetic induction and direct methods. In Geonics Limited (Ed) Applications of electromagnetic methods: Agriculture. Geonics Ltd., Mississauga, ON, Canada.

\subsection{UNIT CONVERSIONS}

$\begin{array}{ll}\frac{\text { Length }}{1 \mathrm{~cm}=0.3937 \mathrm{in}=0.03281 \mathrm{ft}} & 1 \mathrm{in}=2.54 \mathrm{~cm} ; 1 \mathrm{ft}=30.48 \mathrm{~cm} \\ 1 \mathrm{~m}=3.281 \mathrm{ft} & 1 \mathrm{ft}=0.3048 \mathrm{~m} \\ 1 \mathrm{~km}=0.6214 \text { mile } & 1 \mathrm{mile}=1.609 \mathrm{~km} \\ 1 \mathrm{~m}=100 \mathrm{~cm} & 1 \mathrm{ft}=12 \mathrm{in} \\ 1 \mathrm{~km}=1000 \mathrm{~m} & 1 \mathrm{mile}=5280 \mathrm{ft} \\ \text { Area } & \\ 1 \mathrm{~m}^{2}=10.76 \mathrm{ft}^{2} & 1 \mathrm{ft}^{2}=9.29 \times 10^{-2} \mathrm{~m}^{2} \\ 1 \mathrm{~km}^{2}=1.076 \times 10^{7} \mathrm{ft}^{2} & 1 \mathrm{ft}^{2}=9.29 \times 10^{-8} \mathrm{~km}^{2} \\ 1 \mathrm{~m}^{2}=2.471 \times 10^{-4} \mathrm{ac} & 1 \mathrm{ac}=4046.856 \mathrm{~m}^{2} \\ 1 \mathrm{ha}=2.471 \mathrm{ac} & 1 \mathrm{ac}=0.4047 \mathrm{ha} \\ & \\ \text { Salinity } & \\ 1 \mathrm{dS} / \mathrm{m}=1 \mathrm{mS} / \mathrm{cm} & \\ 1 \mathrm{dS} / \mathrm{m}=100 \mathrm{mS} / \mathrm{m} & \\ 1 \mathrm{dS} / \mathrm{m}=1 \mathrm{mmho} / \mathrm{cm} & \end{array}$




\subsection{CONTACT INFORMATION}

Dr. Florence Cassel S.

California Water Institute

California State University, Fresno

5370 N. Chestnut Ave., M/S OF18

Fresno, CA 93740

Tel: (559) 278-7955

Fax: (559) 278-6033

Email: fcasselss@csufresno.edu 
NOTES

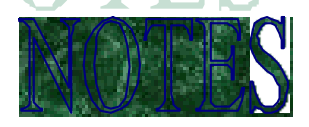


NOTES

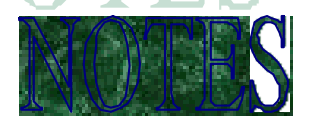


NOTES 